\title{
Manual de estilo del Servicio Geológico Colombiano
}

Julián Escallón Silva / Carolina Hernández
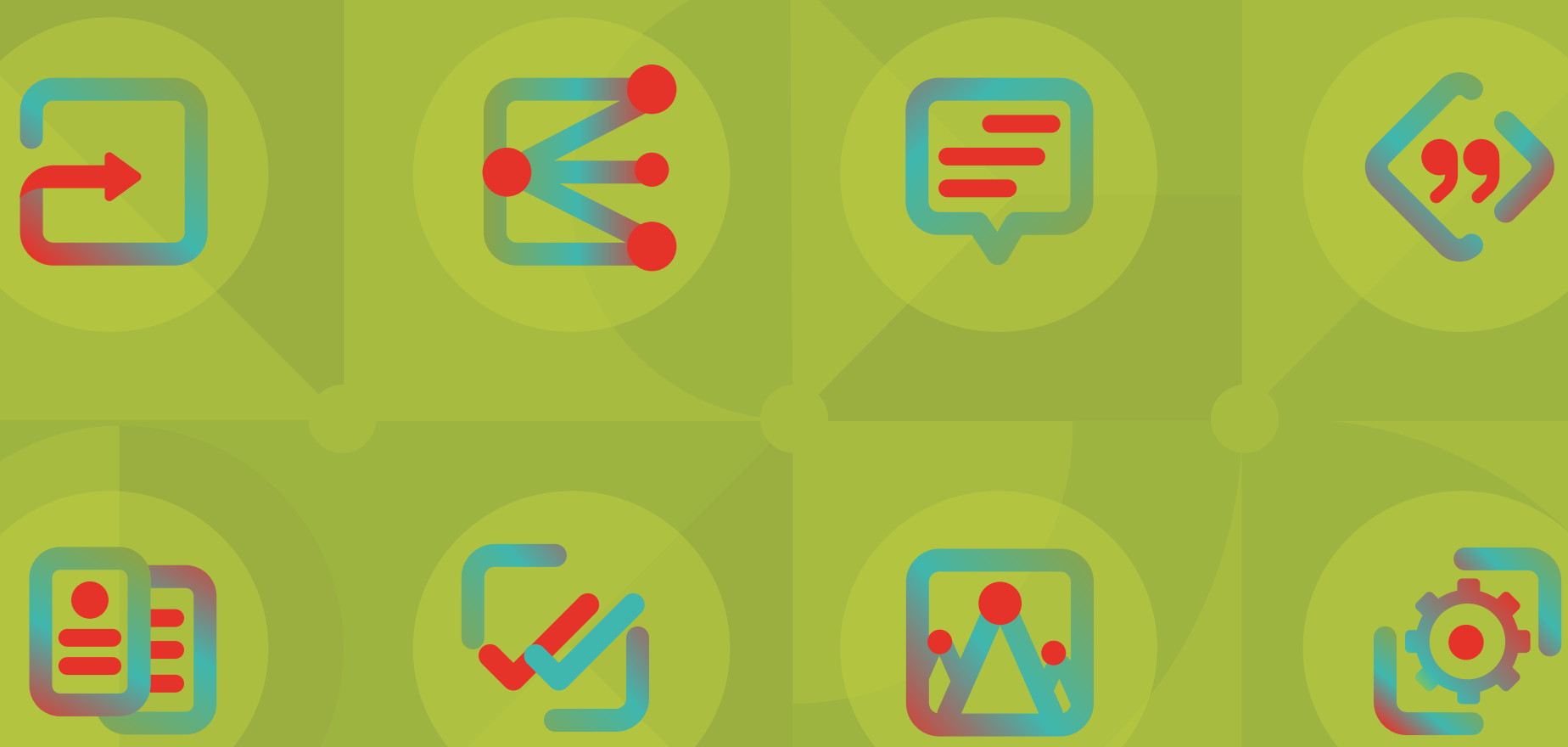

CC
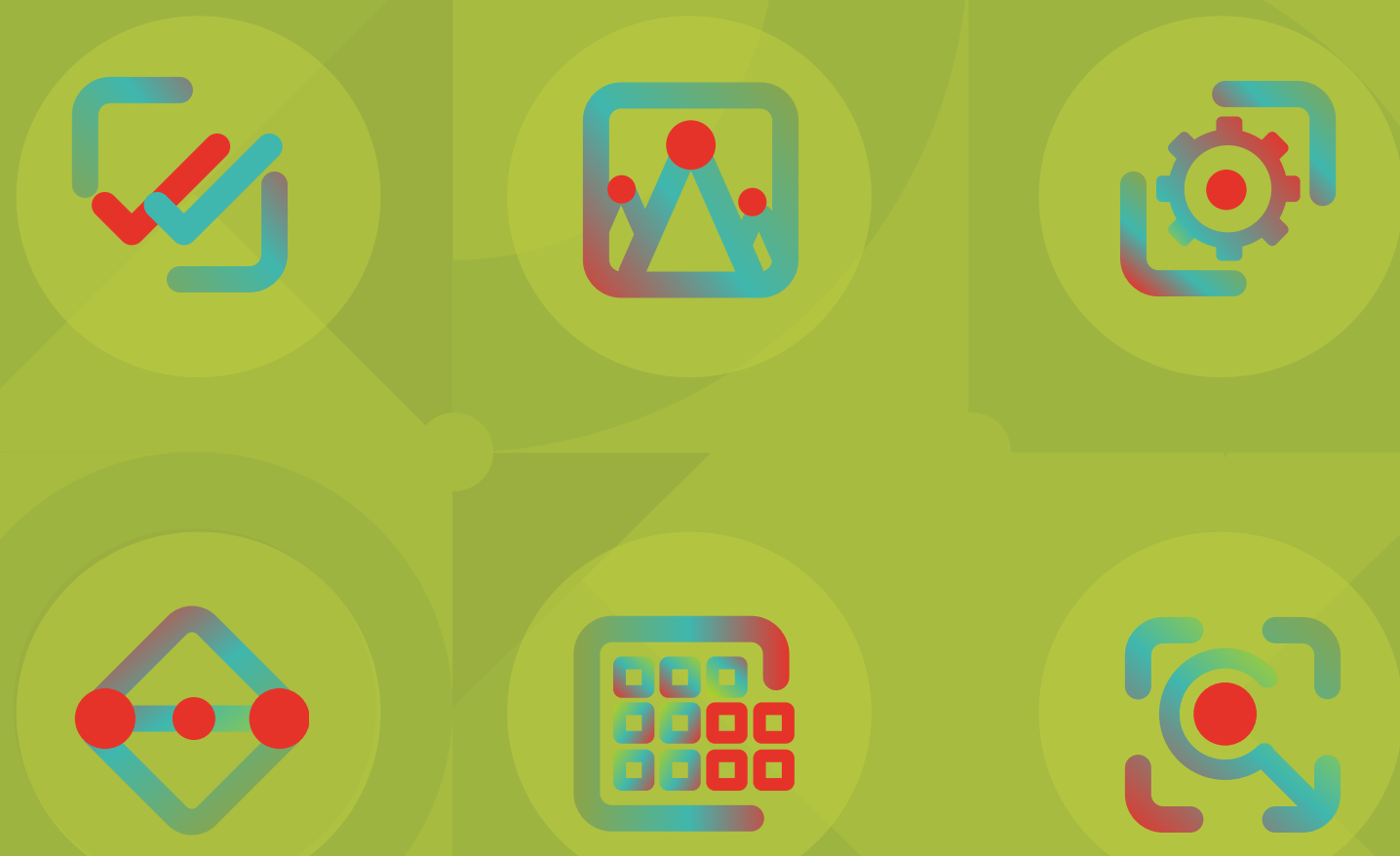


\title{
Manual de estilo del Servicio Geológico Colombiano
}

\author{
Julián Escallón Silva / Carolina Hernández
}

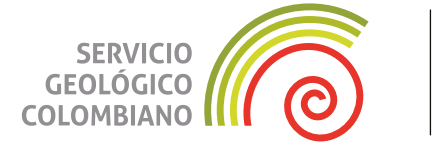


Servicio Geológico Colombiano

Oscar Paredes Zapata

Director general

ISBN digital: 978-958-53131-3-2

DOI: https://doi.org/10.32685/9789585313132

\section{(c) (i)}

(C) Servicio Geológico Colombiano. (2021). Esta obra es distribuida bajo licencia internacional Creative Commons Atribución/Reconocimiento 4.0

\section{Autores}

Julián Escallón Silva

Carolina Hernández

Comité Editorial

Presidente

Juan Guillermo Ramírez

Integrantes

Mario Andrés Cuéllar

Gloria Prieto Rincón

Marta Calvache Velasco

Diana Paola Abadía Z.

Hernán Olaya Dávila

Diseño de cubierta y diagramación

Humberto Andrés Fuenzalida

Hernando Camargo

Victoria Díaz Acosta

Virgilio Amaris Ibáñez

Viviana Dionicio

Teresa Duque

Julián Escallón Silva

Armando Espinosa

Constanza Martínez

Comité Editorial SGC

Diagonal 53 n. ${ }^{\circ} 34-53$

Bogotá D. C., Colombia

Teléfono: 220 0200, ext.: 3048

ceditorial@sgc.gov.co

Corrección de estilo

Édgar Ordóñez

Fernando Carretero

Carolina Hernández

Editora

Bogotá, D. C., Colombia

Agosto, 2021

Citación: Escallón, J. y Hernández, C. (2021). Manual de estilo del Servicio Geológico Colombiano. Servicio Geológico Colombiano. https://doi. org/10.32685/9789585313132 


\section{Agradecimientos}

Este Manual fue producto del apoyo, interés, soporte y retroalimentación por parte de todos los miembros del Comité Editorial del Servicio Geológico Colombiano.

Manifestamos nuestra gratitud a Mario Maya, editor del Boletín Geológico, y a Esperanza Castellanos, editora de la Revista Investigaciones y Aplicaciones Nucleares, por sus aportes y discusiones en distintos temas relacionados con la preparación de artículos científicos.

Asimismo, expresamos nuestro agradecimiento a María Eugenia Chamorro y a Luis Eduardo Salas, por las extensas discusiones y su retroalimentación en la elaboración de informes del SGC, en el diseño de la plantilla documental y en numerosos temas del manual.

A Jorge Gómez y Daniela Mateus por sus revisiones y aportes en diferentes aspectos del manual.

A Édgar Ordóñez por la elaboración de la versión inicial de la plantilla documental.

A Cristian Orlando Hernández, por su invaluable ayuda en el diseño y construcción de mapas, y ejemplos ilustrativos de cartografía.

A Elizabeth Cortés Castillo, por sus aportes de ejemplos de fotografías panorámicas y fotografías de petrografía.

A los funcionarios y colaboradores de los distintos grupos de trabajo que revisaron las propuestas en distintas secciones del manual o que realizaron la prueba de la nueva plantilla documental.

Finalmente, manifestamos nuestra gratitud a Diana Paola Abadía, por el diseño editorial, la elaboración de figuras y el desarrollo de formas innovadoras para comunicar las ideas con claridad y eficiencia. 
"Dar el ejemplo no es la principal manera de influir sobre los demás; es la única manera". Albert Schweitzer 


\section{Contenido}

$\begin{array}{ll}\text { Prólogo } & 10\end{array}$

$\begin{array}{ll}\text { Prefacio } & 12\end{array}$

$\begin{array}{ll}\text { 1. Introducción } & 13\end{array}$

2. Estructura de los documentos científicos y divulgativos 17

2.1. Tipos de contenidos en el Sistema de Publicaciones del SGC 18

2.2. Organización de secciones del texto según el tipo de publicación 19

2.3. Descripción de los elementos fundamentales de las publicaciones, recomendaciones y prácticas que deben evitarse $\quad 22$

2.3.1. Título $\quad 22$

2.3.2. Resumen 22

2.3.3. Palabras clave 24

2.3.4. Introducción $\quad 25$

2.3.5. Método/metodología 26

2.3.6. Especificaciones de los datos $\quad 27$

2.3.7. Resultados 28

2.3.8. Discusión 29

2.3.9. Conclusiones 30

2.3.10. Referencias $\quad 31$

\section{Recomendaciones desde el punto de vista lingüístico} para la composición de textos científicos y divulgativos 32

3.1. Planear la escritura (prerredacción) 33

3.2. Escoger adecuadamente entre figuras, tablas o textos 33

3.3. Considerar algunas recomendaciones estilísticas básicas 34

3.3.1. Evitar el abuso de formas verbales 34

3.3.2. Evitar las cacofonías $\quad 35$

3.3.3. Evitar el mal uso del gerundio $\quad 36$

3.3.4. Privilegiar el uso del punto seguido 38

3.3.5. Redactar oraciones cortas $\quad 39$

3.3.6. Evitar párrafos de más de siete líneas $\quad 39$

$\begin{array}{ll}\text { 3.3.7. Preferir la voz activa } & 39\end{array}$

3.3.8. Evitar el abuso de adjetivos calificativos 40

3.4. Escribir con claridad 40

3.5. Ser precisos en la escritura 41

3.6. Ser concisos 41 
3.7. Escribir en forma impersonal 43

3.8. Usar metáforas $\quad 44$

3.9. Ser coherente $\quad 45$

3.10. Demostrar cohesión 46

3.11. Demostrar la intencionalidad $\quad 47$

3.12. Lograr la aceptación $\quad 47$

3.13. Asegurar la informatividad en el texto 48

$\begin{array}{ll}\text { 3.14. Implementar la intertextualidad } & 48\end{array}$

4. Normas editoriales de presentación general $\quad 49$

4.1. Normas de presentación tipográficas y estructurales 50

4.1.1. Formato de títulos y textos para las publicaciones 51

4.1.2. Jerarquía de títulos en los informes del SGC 54

4.2. Uso de algunos elementos clave en la escritura 56

4.2.1. Tildes diacríticas 56

4.2.2. Uso de comillas 56

4.2.3. Uso de los corchetes $\quad 57$

4.2.4. Uso de los paréntesis $\quad 57$

4.2.5. Uso de cursivas $\quad 57$

4.2.6. Uso de negritas $\quad 58$

4.2.7. Uso de mayúsculas y minúsculas $\quad 58$

4.2.8. Uso de signos de puntuación en las enumeraciones $\quad 61$

4.2.9. Particularidades sobre algunos signos y símbolos 62

5. Estándares para la construcción de los elementos de las publicaciones $\quad 67$

5.1. Cubierta 68

5.2. Portadilla 68

5.3. Portada 68

5.4. Página legal, citación sugerida y DOI 75

5.5. Dedicatoria 83

5.6. Epígrafe 83

5.7. Contenido 83

5.8. Prólogo $\quad 84$

5.9. Prefacio $\quad 84$

5.10. Agradecimientos $\quad 84$

5.11. Cronología o línea de tiempo 85

5.12. Lista de abreviaturas y lista de siglas 85

5.13. Nota técnica o transliteraciones 89

5.14. Tablas 90

5.15. Figuras $\quad 95$

5.16. Ecuaciones 105 
5.16.1. Ecuaciones en la línea del texto 105

5.16.2. Ecuaciones desplegadas del texto 106

5.17. Unidades de medida del Sistema Internacional 106

$\begin{array}{lr}\text { 5.18. Sobre la escritura de números } & 107\end{array}$

$\begin{array}{ll}\text { 5.18.1. Reglas generales } & 107\end{array}$

5.18.2. Sobre la escritura de números generados estadísticamente 109

5.18.3. Formatos para los valores de una cantidad 110

5.18.4. Formato de números, separador de millares y marcador decimal 111

5.19. El nombre de algunos números 113

$\begin{array}{ll}\text { 5.20. Prefijos } & 114\end{array}$

$\begin{array}{ll}\text { 5.21. Citas bibliográficas } & 116\end{array}$

$\begin{array}{ll}\text { 5.21.1. Citas indirectas o paráfrasis } & 117\end{array}$

5.21.2. Citas textuales 118

5.22. Referencias 119

5.22.1. Libros 119

5.22.2. Capítulos de libros $\quad 121$

5.22.3. Reseñas de libro 123

5.22.4. Artículos de revista 125

$\begin{array}{ll}\text { 5.22.5. Informes y literatura gris } & 127\end{array}$

5.22.6. Congresos, seminarios y otros 129

5.22.7. Páginas web 131

5.22.8. Mapas 134

5.23. Epílogo 134

$\begin{array}{ll}\text { 5.24. Glosario } & 135\end{array}$

5.25. Anexos 135

5.26. Referencias cruzadas 136

$\begin{array}{ll}\text { 5.27. Índice de figuras } & 137\end{array}$

5.28. Índice de tablas $\quad 138$

5.29. Índice de mapas 138

5.30. Índice de anexos 139

5.31. Colofón 139

6. Recomendaciones para la elaboración de figuras 140

6.1. Recomendaciones básicas de diseño 141

6.1.1. Uso de técnicas de jerarquía visual 141

$\begin{array}{ll}\text { 6.1.2. Manejo de color } & 144\end{array}$

6.1.3. Consideraciones sobre el tamaño de las figuras 144

6.1.4. Consideraciones sobre la tipografía para las figuras 145

$\begin{array}{ll}\text { 6.2. Uso de herramientas y formatos } & 147\end{array}$

$\begin{array}{ll}\text { 6.2.1. Software recomendado } & 147\end{array}$

6.2.2. Uso de formatos apropiados para cada caso 147

6.3. Recomendaciones específicas para la construcción de mapas 151 
6.3.1. Jerarquía visual en los mapas 151

6.3.2. Disposición de elementos de un mapa 151

6.3.3. Manejo de coordenadas y escalas 155

6.3.4. Mapas de ubicación 155

6.3.5. Perfiles en los mapas 157

6.3.6. Nomenclatura de figuras con diferentes partes 158

6.3.7. Textos de descripción de las figuras cuando no hay espacio en la misma página $\quad 159$

6.3.8. Textos y convenciones de las figuras cuando no hay espacio en la misma página

6.3.9. Consideraciones sobre la posición de los textos descriptivos en los mapas 162

6.3.10. Aplicación de estas recomendaciones en un mapa geológico 162

6.4. Tratamiento de fotografías de campo 164

6.5. Tratamiento de imágenes de petrografía 167

6.5.1. Imágenes macroscópicas 167

6.5.2. Imágenes microscópicas 168

$\begin{array}{ll}\text { 6.6. Construcción de figuras mixtas } & 169\end{array}$

$\begin{array}{ll}\text { 6.7. Infografías en temas de geociencias } & 171\end{array}$

$\begin{array}{ll}\text { 7. Lista de chequeo de revisión final de los textos } & \mathbf{1 7 3}\end{array}$

7.1. Numeración de páginas y pie de página 174

$\begin{array}{ll}\text { 7.2. El título del trabajo } & 174\end{array}$

7.3. Use espaciado sencillo en todo el texto 175

$\begin{array}{ll}\text { 7.4. Formato de párrafo } & 176\end{array}$

$\begin{array}{ll}\text { 7.5. Márgenes } & 177\end{array}$

7.6. Puntuación después de las citas 177

$\begin{array}{ll}\text { 7.7. Títulos de sección } & 177\end{array}$

$\begin{array}{ll}\text { 7.8. Referencias } & 178\end{array}$

7.9. Verificación del uso de cursivas en la expresión "et al." 178

$\begin{array}{ll}\text { 7.10. Numeración de figuras y tablas } & 178\end{array}$

$\begin{array}{ll}\text { 7.11. Consistencia y actualidad de las URL } & 178\end{array}$

8. Gestores de referencias 180

8.1. Uso de plantillas para el gestor de referencias 181

8.2. Gestor de referencias Mendeley 181

8.3. Gestor de referencias Zotero 185

9. Licencias de uso de las publicaciones 188

9.1. Características de la licencia de uso de las publicaciones

e informes técnicos y científicos del Servicio Geológico Colombiano 
9.2. Forma de incluir los elementos de la licencia de uso en las publicaciones e informes técnicos y científicos

10. Pautas de ética para autores y evaluadores

10.1. Consideraciones sobre la autoría de contenidos

10.2. Comportamientos no éticos relacionados con publicaciones

10.2.1. Fabricación y falsificación de datos

10.2.2. Plagio

10.2.3. Múltiples presentaciones

10.2.4. Publicaciones redundantes (o publicaciones salami)

10.2.5. Contribución o atribución incorrecta del autor

\section{Plantilla del SGC para soportar los estilos del manual}

11.2. Características principales y comandos para la plantilla

11.2.1. Comandos de la plantilla relacionados con estilos de títulos

11.2.2. Comandos de la plantilla relacionados con el texto normal y estilos para listas

11.2.3. Comandos para obtener signos matemáticos y letras griegas

11.2.4. Comandos para obtener distintos tipos de espacios

11.2.5. Comandos de formato y diversas acciones en macros

11.2.6. Otros comandos y acciones útiles de la plantilla por defecto de Word

11.3. Diccionario de términos especializados en geociencias usados en los últimos años 


\section{Prólogo}

El Servicio Geológico Colombiano (SGC) contribuye al desarrollo económico y social del país mediante la investigación en geociencias básicas y aplicadas del subsuelo, el potencial de sus recursos, la evaluación y el monitoreo de amenazas de origen geológico, la gestión integral del conocimiento geocientífico, y la investigación y el control nuclear y radiactivo. Esta investigación genera un volumen de conocimiento que debe ser gestionado integralmente, incluyendo su eficiente divulgación para la toma de decisiones en el marco del desarrollo del país. Más aun, el SGC, como entidad vinculada al Sistema Nacional de Ciencia, Tecnología e Innovación (SNCTI), debe divulgar los resultados de sus investigaciones y desarrollos tecnológicos y de innovación sin perjuicio de los derechos de propiedad intelectual y de la información que, por su naturaleza, tiene carácter de reserva.

La escritura de textos geocientíficos es un enorme reto para los funcionarios y colaboradores del SGC, y para autores externos que optan por contribuir a las publicaciones de la institución, no solo por las dificultades que esta labor encarna, sino, especialmente, por la importancia de la transmisión del conocimiento a la sociedad.

Para facilitar la publicación de los escritos generados, el SGC estableció el Sistema Institucional de Publicaciones, que acoge una completa gama de colecciones de libros, revistas, boletines, mapas e informes, y para las que existe un flujo permanente de contribuciones que deben estar sujetas a revisiones y correcciones previas a su publicación. En este proceso editorial participan tanto los autores como los pares evaluadores, los correctores de estilo, los diseñadores y los editores, quienes requieren parámetros comunes y estándares de trabajo para la eficiente coordinación y preparación de los manuscritos.

Como aporte a la calidad de las publicaciones del SGC, el Comité Editorial dio su aval a la elaboración del Manual de estilo del Servicio Geológico Colombiano, escrito por el geofísico Julián Escallón Silva y la editora general Carolina Hernández. Este incluye las mejores prácticas de estilo y organización para publicaciones científicas, adaptadas a las temáticas misionales del SGC. Asimismo, en él se han adoptado algunos elementos y prácticas de iniciativas editoriales recientes que enriquecen y facilitan la preparación de textos y figuras. 
El Manual de estilo del Servicio Geológico Colombiano es una guía invaluable e imprescindible para autores y editores en la producción de documentos científicos y publicaciones de la institución. De manera didáctica y mediante ejemplos, aborda asuntos clave relacionados con la preparación de textos científicos y divulgativos del SGC, incluyendo artículos, libros e informes. En doce capítulos expone estándares actualizados para los principales elementos de textos geocientíficos y nucleares, que han sido orientados para garantizar su aplicación de forma ágil y efectiva.

Invito a todos los interesados en la generación de contenidos para el Sistema de Publicaciones del SGC a explorar e implementar este manual con el fin de asegurar la calidad de los contenidos en beneficio de la sociedad, y con la mejor optimización de esfuerzos en su proceso editorial. 


\section{Prefacio}

Este manual es la referencia fundamental para autores y editores de los contenidos científicos del Servicio Geológico Colombiano (SGC), desde donde se difunden y se publican revistas científicas, libros científicos y divulgativos, informes técnicos y textos asociados a mapas, entre otros.

Este Manual es el resultado de una amplia consulta de las mejores prácticas en la generación de documentos científicos y divulgativos, tanto en el SGC, como en el ámbito nacional e internacional, junto con la exploración de las necesidades de los usuarios internos y externos a la institución. Para su elaboración y consolidación, fue sometido a diferentes consultas y tuvo en cuenta las sugerencias y observaciones de quienes participaron.

Aquí se tratan de manera esquemática y visual elementos fundamentales de los escritos, sus funciones lingüísticas y recomendaciones específicas, identificando además prácticas que se deben evitar. Asimismo, se plantean recomendaciones generales para la redacción de textos científicos y divulgativos del SGC, en aspectos como su planificación y ejecución, para su mejor claridad, precisión, concisión, objetividad, coherencia, cohesión e intertextualidad.

Con el fin de facilitar su uso, se exponen los estándares para los principales elementos y se ilustran, mediante sesenta ejemplos, aspectos que incluyen citación de fuentes consultadas, manejo de referencias, tablas, figuras, ecuaciones y tipografías, criterios para la escritura de números y unidades de medida, y disposición de índices, glosarios y anexos. En especial, y dada la gran cantidad de contenidos gráficos en las publicaciones del SGC, se propone una serie de recomendaciones para la elaboración de figuras, acogiendo las prácticas de los recientes proyectos editoriales exitosos de la institución.

Finalmente, el manual aporta valiosas recomendaciones para el uso de gestores de referencia, así como las instrucciones y recomendaciones para el uso de una plantilla en el programa Word que facilita y acelera el cumplimiento de los estándares promovidos. 
1. Introducción
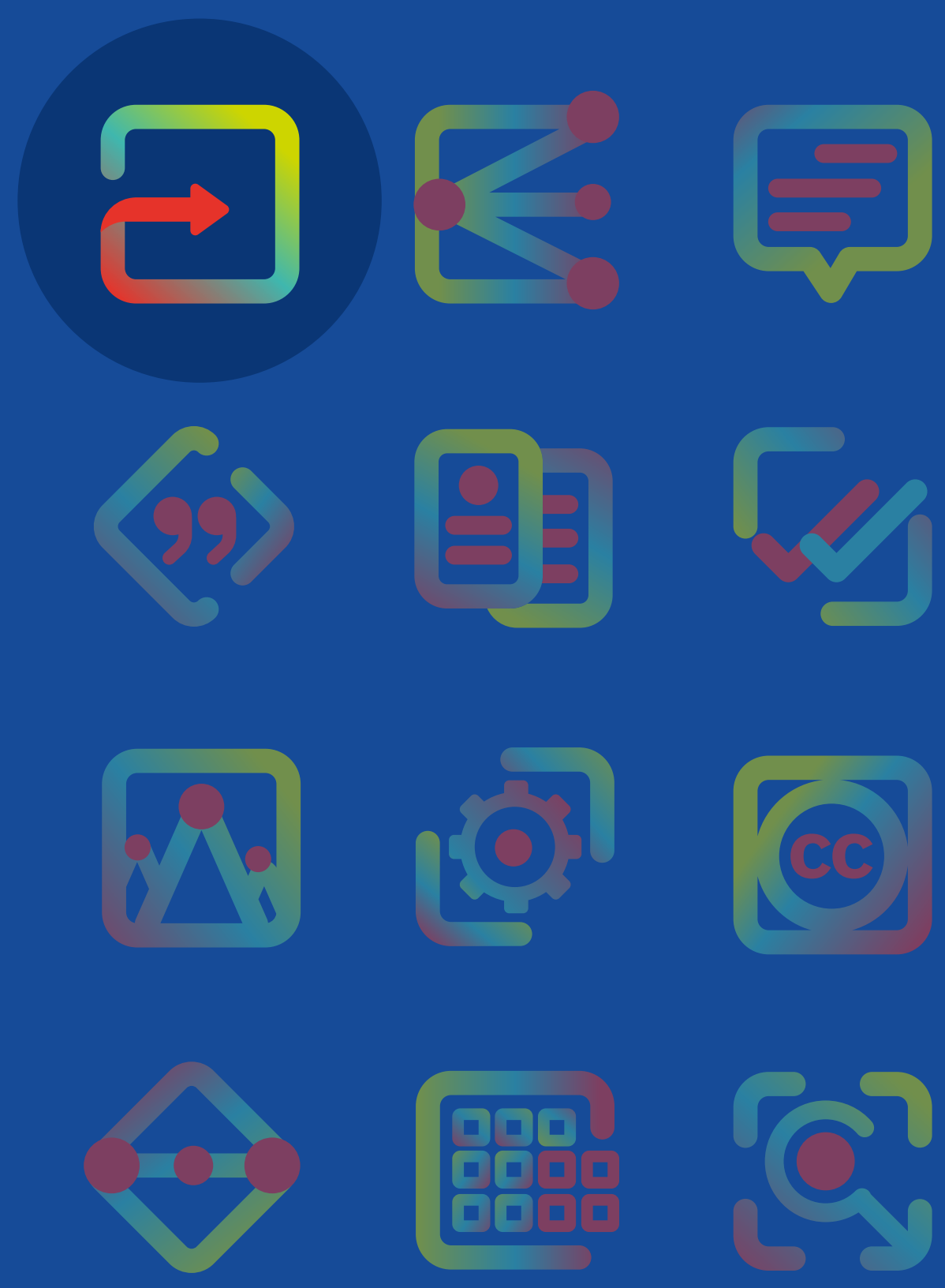
I Servicio Geológico Colombiano (SGC) cuenta con un sistema de publicaciones mediante el cual se han emprendido diversas acciones de mejora, entre las que se destacan el impulso a la publicación de contenidos en canales digitales y un mayor control de la calidad editorial y de estilo. En estos procesos se han observado prácticas de escritura y estructura de contenidos con base en manuales anteriores, los cuales son susceptibles de mejora y hacen pertinente la actualización, construcción e implementación de otros manuales y guías.

En diferentes reuniones con los grupos de trabajo del SGC para socializar la Política de Gestión Editorial, se recibieron numerosas inquietudes relacionadas con la necesidad de estandarizar la presentación de los productos del SGC, de tal manera que tengan en cuenta los aportes de los profesionales, dado su conocimiento y experiencia en la escritura de documentos técnicos y científicos de publicaciones nacionales e internacionales.

Las acciones de mejora emprendidas por el Comité Editorial del SGC desde su creación, en 2015, incluyen la formulación y aprobación de la Política Institucional de Gestión Editorial, en noviembre de 2019, y la preparación del presente manual, en 2020 y 2021.

Dado el imperativo de comunicar efectivamente las disposiciones de la Política de Gestión Editorial del SGC, tanto en su forma como en su contenido, este manual ofrece un lineamiento claro sobre cómo elaborar escritos para revistas científicas, libros científicos y divulgativos, informes técnicos y textos asociados a mapas, con el propósito de que estos expongan correctamente las ideas y los datos relacionados, a partir de unas pautas prácticas y de uniformidad, y con sujeción a las mejores y más actualizadas prácticas a nivel internacional.

Para la preparación, elaboración y revisión de documentos científicos se ha consultado, adaptado y desarrollado una serie de recomendaciones, dirigidas a mejorar la calidad e impacto de los contenidos. El SGC tiene una larga trayectoria científica e investigativa, en la que se observa diversidad de estilos y se presentan prácticas que pueden ser mejoradas con la implementación de este manual, que es producto del consenso de todos los actores interesados y con el fin de que se adopten de forma homogénea las mejores prácticas contemporáneas.

El Comité Editorial del SGC aporta en este documento las recomendaciones dirigidas a quienes deseen publicar contenidos en las distintas colecciones previstas en la Resolución 471 de 2019 del Servicio Geológico Colombiano. Estas sugerencias, en conjunto con estándares conocidos, son aplicables a las publicaciones y a los informes de carácter técnico-científico que elabora la institución en los proyectos de investigación y de recolección de datos.

El Manual tiene como objetivo guiar la preparación de textos, e incluye recomendaciones sobre criterios lingüísticos y de estructura de contenidos -tipos de publicaciones-, específicos del formato -ortotipográficos-; estándares de preparación de tablas, figuras; citación y referenciación bibliográfica; manejo de números y unidades, y buenas prácticas de verificación previas al sometimiento de los textos, artículos o documentos al proceso de edición. Este manual no aborda la presentación específica y detallada de mapas de gran formato, los cuales son elaborados según los estándares cartográficos en uso en el SGC. 
También, el Manual aborda los aspectos estructurales de los documentos que produce el SGC. Adicionalmente, se tratan aspectos conceptuales relacionados con una buena escritura, las funciones comunicativas de las distintas secciones y su uso según los tipos de documento. En los capítulos finales se exponen orientaciones sobre la preparación de los textos, los estándares para referir adecuada y consistentemente los contenidos que han sido consultados en otras fuentes y, finalmente, una lista de verificación de los problemas más recurrentes, para su depuración antes de someterlos al proceso de publicación.

Como elementos complementarios, se introduce a los autores en el uso de los gestores bibliográficos, herramientas que son fundamentales para garantizar una adecuada citación y referenciación de fuentes, y se abordan las nociones sobre el tipo de licencia que se otorga a los usuarios en las distintas publicaciones.

Con el propósito de ilustrar las distintas normas y sugerencias, en los capítulos de este manual se proponen ejemplos que se numeran de manera consecutiva, con un título en la parte superior. Para diferenciarlos del resto del texto del manual, los ejemplos que incluyan figuras siempre se referirán a la figura 99 con un título; aquellos que involucran tablas siempre harán alusión a la tabla 88 , con un título y unas notas de la tabla, y los ejemplos que muestren contenidos en textos o en figuras tendrán un símbolo en la parte superior izquierda de una mano apuntando a la derecha y una línea vertical de color verde en la parte izquierda del ejemplo respectivo.

La figura 1 ilustra los tipos de ejemplos que se encuentran en este manual y la notación utilizada para su identificación y diferenciación.

Ejemplo xx: figura de un diagrama de barras comparativo con medidas de dispersión de mediciones

0,5

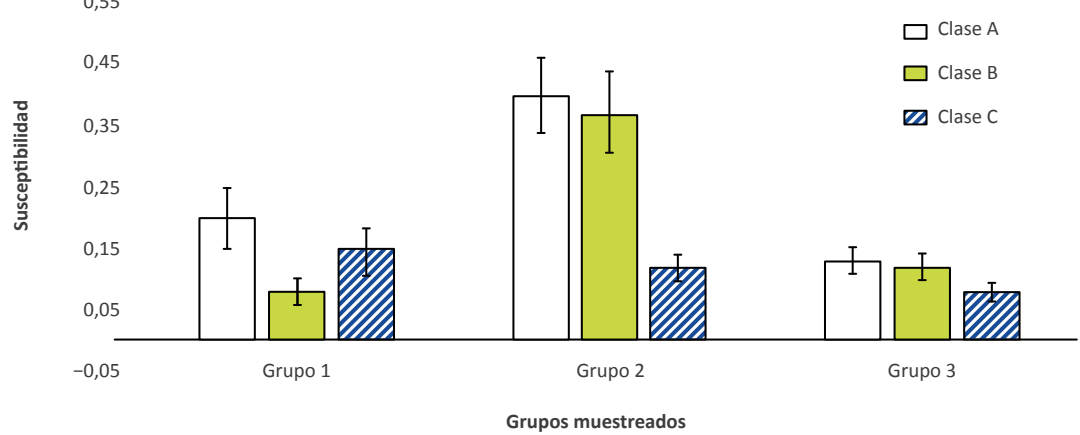

Figura 99. Medidas de susceptibilidad por grupos correspondientes a tres clases de elementos

Para cada elemento se incluye una estimación de la dispersión basada en la desviación estándar obervada en cada caso. 


\section{Ejemplo xx: tabla sencilla con encabezados en cada columna}

b Tabla 88. Desplazamientos ocurridos en el municipio de Cáqueza (Cundinamarca) a partir de 1966

\begin{tabular}{ccccc}
\hline $\begin{array}{c}\text { Tipo de movimiento } \\
\text { del primer movimiento }\end{array}$ & Fecha evento & Departamento & Municipio & Vereda \\
\hline Desplazamiento & $16 / 04 / 2012$ & Cundinamarca & Cáqueza & Cáqueza \\
Desplazamiento & $17 / 02 / 2012$ & Cundinamarca & Cáqueza & Cáqueza \\
Desplazamiento & $07 / 12 / 2011$ & Cundinamarca & Cáqueza & Cáqueza \\
Desplazamiento & $01 / 12 / 2011$ & Cundinamarca & Cáqueza & Cáqueza \\
Desplazamiento & $19 / 09 / 2009$ & Cundinamarca & Cáqueza & Cáqueza \\
Desplazamiento & $15 / 08 / 1999$ & Cundinamarca & Cáqueza & Cáqueza \\
Desplazamiento & $15 / 07 / 1997$ & Cundinamarca & Cáqueza & Cáqueza \\
Desplazamiento & $01 / 10 / 1996$ & Cundinamarca & Cáqueza & Cáqueza \\
Desplazamiento & $24 / 05 / 1989$ & Cundinamarca & Cáqueza & Cáqueza \\
Desplazamiento & $01 / 04 / 1986$ & Cundinamarca & Cáqueza & Cáqueza \\
\hline
\end{tabular}

Fuente: los datos han sido tomados del Sistema de Información de Movimientos en Masa (SIMMA) del SGC. http://simma.sgc.gov.co/

\section{Ejemplo xx: ecuaciones desplegadas del texto y su referencia}

c Dada la función $f: \mathrm{R} \rightarrow \mathrm{C}$, se define formalmente su trasformada de Fourier como la función variable real $f: R \rightarrow C$, definida como

$$
f(\varepsilon)=\frac{1}{2 \pi} \int_{-\infty}^{\infty} e^{-i \varepsilon x} f(x) d x, \varepsilon \in R .
$$

Como se aprecia en (3), la función de la transformada de Fourier corresponde a una integral de la función por un operador $e^{-i \varepsilon x}$

Figura 1. Identificación de los ejemplos del manual

a) Ejemplo de una figura; b) ejemplo de una tabla; c) ejemplo en forma de texto. 
2.

Estructura de los documentos científicos y divulgativos
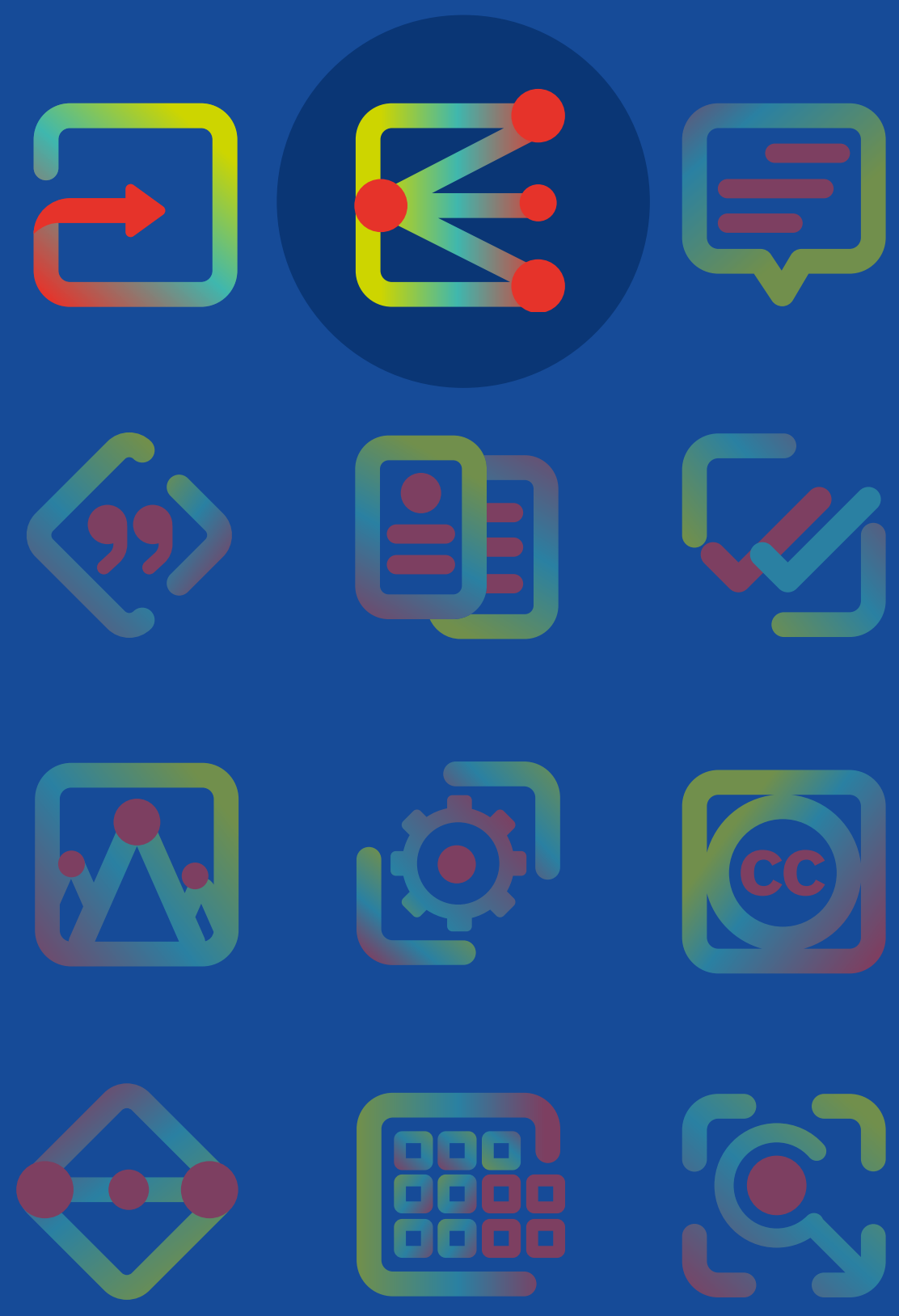


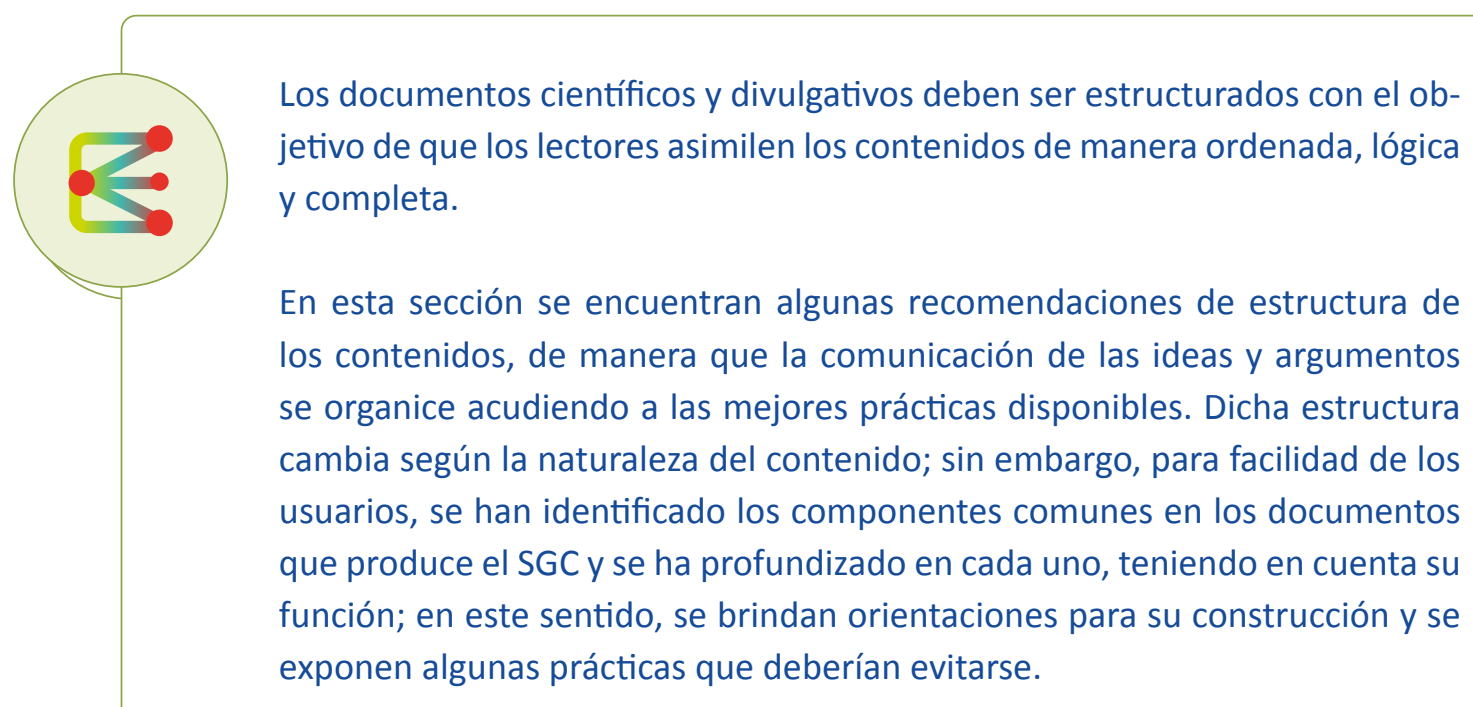

\subsection{Tipos de contenidos en el Sistema de Publicaciones del SGC}

Los contenidos del SGC se pueden clasificar en cinco categorías según su objetivo y audiencia, como se detalla en la tabla 1.

Tabla 1. Características de los tipos de contenidos del Sistema de Publicaciones del SGC

\begin{tabular}{|c|c|c|c|}
\hline Tipo de contenido & Propósito & Características principales & $\begin{array}{c}\text { Audiencia a la que está } \\
\text { orientado }\end{array}$ \\
\hline Artículo & $\begin{array}{l}\text { Comunicar hipótesis, datos, } \\
\text { reflexiones o revisiones } \\
\text { en cumplimiento de } \\
\text { requerimientos de calidad } \\
\text { editorial y académica, exigidos } \\
\text { por los sistemas de indexación. }\end{array}$ & $\begin{array}{l}\text { Presenta alta calidad científica, es un } \\
\text { valioso aporte a la disciplina o tema } \\
\text { específico, está bien escrito y evidencia el } \\
\text { dominio del tema por parte de los autores. } \\
\text { Maneja estructuras RIMRDyC (resumen, } \\
\text { introducción, metodología, resultados, } \\
\text { discusión y conclusiones) (Sánchez, 2016, } \\
\text { p. 26). }\end{array}$ & $\begin{array}{l}\text { Profesionales especializados } \\
\text { y de la industria, facultades } \\
\text { de universidades y sus } \\
\text { programas académicos, grupos } \\
\text { de investigación y revistas } \\
\text { científicas. }\end{array}$ \\
\hline Artículo tipo dato & $\begin{array}{l}\text { Comunicar la existencia de un } \\
\text { conjunto de datos y describirlo } \\
\text { sin proporcionar conclusiones } \\
\text { o interpretaciones, } \\
\text { en cumplimiento de } \\
\text { requerimientos de calidad } \\
\text { editorial y académica, exigidos } \\
\text { por los sistemas de indexación. }\end{array}$ & $\begin{array}{l}\text { Presenta alta calidad científica, es un } \\
\text { valioso aporte a la disciplina o tema } \\
\text { específico, está bien escrito y describe de } \\
\text { manera completa un conjunto de datos. } \\
\text { Incluye en su estructura básica un } \\
\text { resumen, palabras clave, introducción, } \\
\text { área de estudio, descripción de los } \\
\text { datos, materiales y métodos, acceso a } \\
\text { los datos, conflicto de interés, anexo con } \\
\text { datos suplementarios, reconocimientos y } \\
\text { referencias. Regularmente son documentos } \\
\text { cortos de } 4 \text { a } 6 \text { páginas. }\end{array}$ & $\begin{array}{l}\text { Profesionales especializados } \\
\text { y de la industria, facultades } \\
\text { de universidades y sus } \\
\text { programas académicos, grupos } \\
\text { de investigación y revistas } \\
\text { científicas. }\end{array}$ \\
\hline
\end{tabular}




\begin{tabular}{|c|c|c|c|}
\hline Tipo de contenido & Propósito & Características principales & $\begin{array}{c}\text { Audiencia a la que está } \\
\text { orientado }\end{array}$ \\
\hline Libro científico & $\begin{array}{l}\text { Comunicar hechos, datos, } \\
\text { reflexiones o revisiones } \\
\text { en cumplimiento de } \\
\text { requerimientos de calidad } \\
\text { editorial y académica exigidos } \\
\text { por los sistemas de indexación, } \\
\text { comunicando contenidos de } \\
\text { manera clara, lógica y agradable } \\
\text { (Beltrán, 2017, p. 152). }\end{array}$ & $\begin{array}{l}\text { Presenta alta calidad científica, está bien } \\
\text { escrito y constituye un aporte a un rango } \\
\text { más amplio de temas e intereses; evidencia } \\
\text { el dominio del tema por parte de los } \\
\text { autores. Usualmente incluye contenidos } \\
\text { preliminares (identificación de la obra, } \\
\text { página legal, tabla de contenido, índices, } \\
\text { abreviaturas, información de los autores), } \\
\text { un cuerpo (desarrollo del contenido, } \\
\text { conclusiones y opcionalmente epílogo y } \\
\text { apéndices), y contenidos finales (anexos, } \\
\text { referencias, índices, glosario y colofón) } \\
\text { (Beltrán, 2017, pp. 154-155). }\end{array}$ & $\begin{array}{l}\text { Profesionales especializados; } \\
\text { profesionales de otras } \\
\text { entidades o de la industria, } \\
\text { relacionados con los temas de } \\
\text { interés del SGC; estudiantes } \\
\text { de colegios y universidades; } \\
\text { facultades de universidades } \\
\text { y sus programas académicos; } \\
\text { grupos de investigación, y } \\
\text { revistas científicas. }\end{array}$ \\
\hline Libro divulgativo & $\begin{array}{l}\text { Interpretar y hacer accesible } \\
\text { el conocimiento científico } \\
\text { a la sociedad, es decir, a } \\
\text { las personas interesadas } \\
\text { en comprender un tema o } \\
\text { informarse sobre esa materia } \\
\text { en concreto, de manera general } \\
\text { y con vocabulario accesible. }\end{array}$ & $\begin{array}{l}\text { Presenta alta calidad técnica, está bien } \\
\text { escrito y constituye un aporte a un amplio } \\
\text { rango de temas e intereses. Usualmente } \\
\text { tiene un contenido sencillo que incluye } \\
\text { introducción, contenidos y conclusión. }\end{array}$ & Público en general. \\
\hline $\begin{array}{l}\text { Informes internos } \\
\text { técnicos y } \\
\text { científicos }\end{array}$ & $\begin{array}{l}\text { Comunicar hechos, datos, } \\
\text { análisis, resultados y } \\
\text { conclusiones de una manera } \\
\text { técnica y profesional sobre los } \\
\text { resultados de los proyectos } \\
\text { realizados por el SGC. }\end{array}$ & $\begin{array}{l}\text { Presenta alta calidad técnica, está bien } \\
\text { escrito y constituye un aporte a la temática } \\
\text { de énfasis del informe con nuevos datos } \\
\text { o análisis. Usualmente incluye estructuras } \\
\text { RIMRDyC (resumen, introducción, } \\
\text { metodología, resultados, discusión y } \\
\text { conclusiones) o similares. Estos contenidos } \\
\text { pueden tener anexos extensos y bases de } \\
\text { datos asociadas a los temas del informe. }\end{array}$ & $\begin{array}{l}\text { Profesionales especializados, } \\
\text { profesionales de otras } \\
\text { entidades o de la industria, } \\
\text { relacionados con los temas de } \\
\text { interés del SGC. }\end{array}$ \\
\hline
\end{tabular}

\subsection{Organización de secciones del texto según el tipo de publicación}

Para la disposición de los diferentes contenidos que se manejan en el sistema de publicaciones del SGC, se utilizarán las estructuras que se muestran en la tabla 2. En el caso de los artículos científicos, se recurre a una estructura RIMRDyC (resumen, introducción, método, resultados, discusión y conclusiones), también denominada IMRyD -traducida de Cargill y O'Connor (2009)-. En el caso de artículos tipo dato, no se incluyen interpretaciones ni conclusiones. Para libros e informes, se trabajan estructuras reconocidas como mejores prácticas y que tienen la ventaja de ser flexibles y adaptables. 
Tabla 2. Elementos utilizados en los tipos de contenido del SGC

\begin{tabular}{|c|c|c|c|c|c|}
\hline$\frac{\text { 은 }}{3}$ & Artículos científicos & Artículos tipo dato & Libros científicos & Libros divulgativos & $\begin{array}{l}\text { Informes internos } \\
\text { técnicos y científicos }\end{array}$ \\
\hline \multirow{17}{*}{ 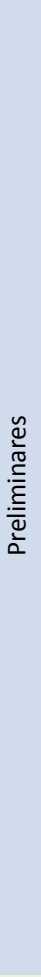 } & & & Cubierta & Cubierta & \\
\hline & $\begin{array}{l}\text { Título } \\
\text { Título en inglés }\end{array}$ & $\begin{array}{l}\text { Título } \\
\text { Título en inglés }\end{array}$ & $\begin{array}{l}\text { Portada } \\
\text { (incluye título) }\end{array}$ & $\begin{array}{l}\text { Portada } \\
\text { (incluye título) }\end{array}$ & $\begin{array}{l}\text { Portada (incluye título) } \\
\text { Título en inglés }\end{array}$ \\
\hline & & & Portadilla & Portadilla & \\
\hline & & & $\begin{array}{l}\text { Página legal/citación } \\
\text { sugerida y DOI* }\end{array}$ & $\begin{array}{l}\text { Página legal/citación } \\
\text { sugerida y DOI }\end{array}$ & $\begin{array}{l}\text { Página legal/citación } \\
\text { sugerida y DOI }\end{array}$ \\
\hline & & & Contenido & Contenido & Contenido \\
\hline & $\begin{array}{l}\text { Página legal/citación } \\
\text { sugerida y DOI }\end{array}$ & $\begin{array}{l}\text { Página legal/citación } \\
\text { sugerida y DOI }\end{array}$ & $\begin{array}{l}\text { Página legal/citación } \\
\text { sugerida y DOI }\end{array}$ & $\begin{array}{l}\text { Página legal/citación } \\
\text { sugerida y DOI }\end{array}$ & $\begin{array}{l}\text { Página legal/citación } \\
\text { sugerida y DOI }\end{array}$ \\
\hline & Resumen & Resumen & $\begin{array}{l}\text { Resumen } \\
\text { (para el sitio web) }\end{array}$ & $\begin{array}{l}\text { Resumen } \\
\text { (para el sitio web) }\end{array}$ & Resumen \\
\hline & Abstract & Abstract & & & Abstract \\
\hline & & $\begin{array}{l}\text { Tabla de } \\
\text { especificaciones }\end{array}$ & & & \\
\hline & Palabras clave & Palabras clave & $\begin{array}{l}\text { Palabras clave } \\
\text { (para el sitio web) }\end{array}$ & $\begin{array}{l}\text { Palabras clave } \\
\text { (para el sitio web) }\end{array}$ & $\begin{array}{l}\text { Palabras clave } \\
\text { (solo en el metadato) }\end{array}$ \\
\hline & Keywords & & Keywords & & $\begin{array}{l}\text { Keywords (para el sitio } \\
\text { web) }\end{array}$ \\
\hline & & & Prólogo & Prólogo & \\
\hline & & & Prefacio & Prefacio & \\
\hline & Agradecimientos & $\begin{array}{l}\text { Agradecimientos/ } \\
\text { Reconocimientos }\end{array}$ & Agradecimientos & Agradecimientos & Agradecimientos \\
\hline & & & $\begin{array}{l}\text { Cronología o línea de } \\
\text { tiempo }\end{array}$ & $\begin{array}{l}\text { Cronología o línea de } \\
\text { tiempo }\end{array}$ & $\begin{array}{l}\text { Cronología o línea de } \\
\text { tiempo }\end{array}$ \\
\hline & & & Lista de abreviaturas & Lista de abreviaturas & \\
\hline & & & $\begin{array}{l}\text { Nota técnica o } \\
\text { transliteraciones }\end{array}$ & $\begin{array}{l}\text { Nota técnica o } \\
\text { transliteraciones }\end{array}$ & \\
\hline \multirow{7}{*}{ 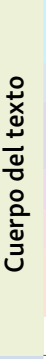 } & $\begin{array}{l}\text { Introducción } \\
\text { (estructurada) }\end{array}$ & $\begin{array}{l}\text { Introducción } \\
\text { (estructurada) }\end{array}$ & $\begin{array}{l}\text { Introducción } \\
\text { (estructurada) }\end{array}$ & $\begin{array}{l}\text { Introducción } \\
\text { (estructurada) }\end{array}$ & $\begin{array}{l}\text { Introducción } \\
\text { (estructurada) }\end{array}$ \\
\hline & Método & Método & & & Metodología \\
\hline & & $\begin{array}{l}\text { Especificaciones } \\
\text { de los datos }\end{array}$ & Capítulos del libro & Capítulos del libro & \\
\hline & Resultados & & & & Resultados \\
\hline & Discusión & & & & Discusión \\
\hline & Conclusiones & & $\begin{array}{l}\text { Conclusiones/ } \\
\text { recomendaciones }\end{array}$ & $\begin{array}{l}\text { Conclusiones/ } \\
\text { recomendaciones }\end{array}$ & $\begin{array}{l}\text { Conclusiones/ } \\
\text { recomendaciones }\end{array}$ \\
\hline & & & Epílogo & Epílogo & \\
\hline \multirow{6}{*}{$\frac{\tilde{y}}{\frac{\pi}{\frac{\pi}{4}}}$} & Glosario & Glosario & Glosario & Glosario & Glosario \\
\hline & Referencias & Referencias & Referencias & Referencias & Referencias \\
\hline & $\begin{array}{l}\text { Anexos (datos } \\
\text { suplementarios) }\end{array}$ & $\begin{array}{l}\text { Anexos (datos } \\
\text { suplementarios) }\end{array}$ & Anexos & Anexos & $\begin{array}{l}\text { Anexos } \\
\text { Índice de figuras } \\
\text { Índice de tablas }\end{array}$ \\
\hline & & & Índice de ecuaciones & & Índice de ecuaciones \\
\hline & & & Índice de anexos & Índice de anexos & Índice de anexos \\
\hline & & & Colofón & Colofón & \\
\hline
\end{tabular}

Nota: las secciones con rellenos en colores ayudan a ubicar la descripción específica de cada elemento en las figuras 2 a 11; * Identificador de objeto digital (Digital Object Identifier, DOI).

En la tabla 3 se indica el uso de los distintos elementos, según el tipo de publicación. Algunos de estos pueden ser obligatorios, opcionales o no requeridos. En la misma tabla se señala la sección o secciones de este manual en donde se aborda de manera específica el elemento mencionado. 
En algunos casos, hay secciones que reemplazan completamente otras; por ejemplo, cuando se tienen capítulos, es posible que no se requiera de método/metodología, resultados y discusión, sino que estos contenidos se desarrollen en cada capítulo.

Tabla 3. Elementos de las publicaciones y su uso, según el tipo de documento

\begin{tabular}{|c|c|c|c|c|c|c|c|}
\hline \multirow[b]{2}{*}{ 을 } & \multirow[b]{2}{*}{ Elemento } & \multicolumn{5}{|c|}{ Uso según tipo de documento } & \multirow[b]{2}{*}{ Ver sección } \\
\hline & & $\begin{array}{l}\text { Artículos } \\
\text { científicos }\end{array}$ & $\begin{array}{l}\text { Artículos } \\
\text { tipo dato }\end{array}$ & $\begin{array}{c}\text { Libros } \\
\text { científicos }\end{array}$ & $\begin{array}{c}\text { Libros } \\
\text { divulgativos }\end{array}$ & $\begin{array}{l}\text { Informes } \\
\text { técnicos y } \\
\text { científicos }\end{array}$ & \\
\hline \multirow{19}{*}{ 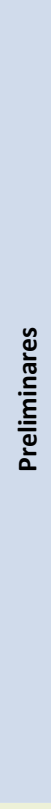 } & Cubierta & - & - & $\bullet$ & - & - & 5.1. \\
\hline & Título en español & - & $\bullet$ & - & - & - & 2.3.1. \\
\hline & Título en inglés & $\bullet$ & $\bullet$ & - & ० & ० & 2.3.1. \\
\hline & Portadilla & - & - & - & $\bullet$ & - & 5.2 \\
\hline & Portada & - & - & - & $\bullet$ & - & 5.1. \\
\hline & Dedicatoria & - & - & 0 & ○ & - & 5.5 . \\
\hline & Epígrafe & - & - & ○ & ○ & - & 5.6. \\
\hline & Contenido & - & - & - & - & - & 5.7. \\
\hline & Página legal/citación sugerida y DOI & - & $\bullet$ & - & $\bullet$ & ○ & 5.4., 10.1., 10.2. \\
\hline & Presentación o resumen en español & $\bullet$ & $\bullet$ & $\bullet$ & $\bullet$ & - & 2.3.2. \\
\hline & Presentación o resumen en inglés & - & - & - & ○ & - & 2.3.2. \\
\hline & Palabras clave en español & - & $\bullet$ & - & - & - & 2.3.3. \\
\hline & Palabras clave en inglés & $\bullet$ & $\bullet$ & - & - & - & 2.3.3. \\
\hline & Prólogo & - & - & ० & ○ & - & 5.8. \\
\hline & Prefacio & - & - & ० & $\circ$ & - & 5.9. \\
\hline & Agradecimientos/reconocimientos & - & $\bullet$ & 0 & $\circ$ & ० & 5.10. \\
\hline & Cronología o línea de tiempo & - & - & ० & ○ & ० & 5.11 \\
\hline & Lista de abreviaturas & - & - & ० & $\circ$ & ० & 5.12. \\
\hline & Nota técnica o transliteraciones & - & - & ○ & $\circ$ & - & 5.13. \\
\hline \multirow{8}{*}{ 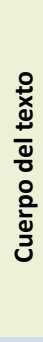 } & Introducción & • & $\bullet$ & - & $\bullet$ & - & 2.3.4. \\
\hline & Capítulos de libro & - & - & ० & ० & ० & \\
\hline & Método/metodología & - & $\bullet$ & ० & $\circ$ & - & 2.3.5. \\
\hline & Especificaciones de los datos & - & $\bullet$ & - & - & - & 2.3.6. \\
\hline & Resultados & - & - & ० & $\circ$ & ० & 2.3.7. \\
\hline & Discusión & $\bullet$ & - & o & $\circ$ & ○ & 2.3.8. \\
\hline & Conclusiones & - & - & 0 & ० & - & 2.3.9. \\
\hline & Epílogo & - & - & ○ & $\circ$ & - & 5.23 \\
\hline \multirow{9}{*}{$\frac{\underline{y}}{\frac{\tilde{v}}{\pi}}$} & Glosario & 0 & ○ & ○ & $\circ$ & ○ & 5.24 \\
\hline & Referencias & - & - & - & $\bullet$ & - & 2.3.10., 5.22, 8 . \\
\hline & Anexos & ० & ० & ० & $\circ$ & ० & 5.25 \\
\hline & Índice de figuras & - & - & - & - & - & 5.27 \\
\hline & Índice de mapas & - & - & - & - & ० & 5.28 \\
\hline & Índice de tablas & - & - & - & - & - & 5.29 . \\
\hline & Índice de ecuaciones & - & - & o & - & ० & 5.30. \\
\hline & Índice de anexos & - & - & 0 & $\circ$ & ○ & 5.31 \\
\hline & Colofón & - & - & ○ & ○ & - & 5.32 \\
\hline \multicolumn{8}{|c|}{ Convenciones sobre el uso del elemento } \\
\hline & Obligatorio & & Opcional & & & No reque & ido - \\
\hline
\end{tabular}




\subsection{Descripción de los elementos fundamentales de las publicaciones, recomendaciones y prácticas que deben evitarse}

A continuación, de manera resumida se exponen los elementos fundamentales presentes en las publicaciones, a la vez que se identifican sus funciones desde el punto de vista comunicativo. Además, se hacen recomendaciones según las mejores prácticas identificadas por diversos autores y se ponen de presente las prácticas más frecuentes que se deben evitar para lograr mejores resultados. Para una mejor referencia de estos elementos con respecto a la tabla 2 , el color de relleno del elemento coincide con el que se muestra en la franja de la parte izquierda de cada una de las figuras 2 a 11.

\subsubsection{Título}

El título es la frase que condensa la información del contenido de manera coherente y completa (Sánchez, 2011, p. 151), y que sirve como nombre propio del trabajo. Las características del título se resumen en la figura 2.

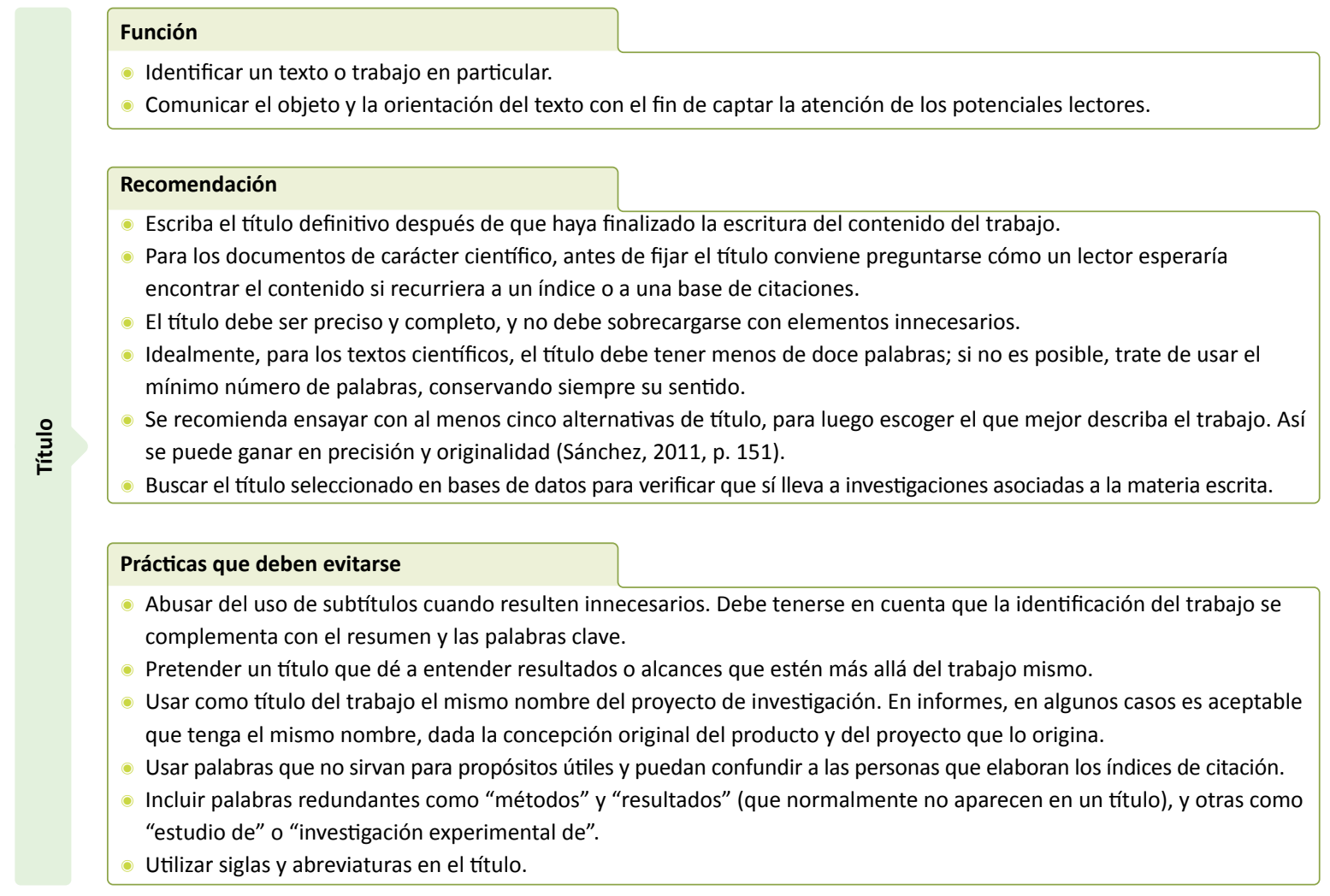

Figura 2. Elementos fundamentales de la sección Título

\subsubsection{Resumen}

El resumen es una presentación abreviada y concisa del contenido del documento, y constituye el párrafo más importante del trabajo. Debe funcionar como texto autónomo, debe tener sentido propio y 
brindar un panorama completo sobre el escrito (Sánchez, 2016, p. 231). Las propiedades del resumen se detallan en la figura 3.

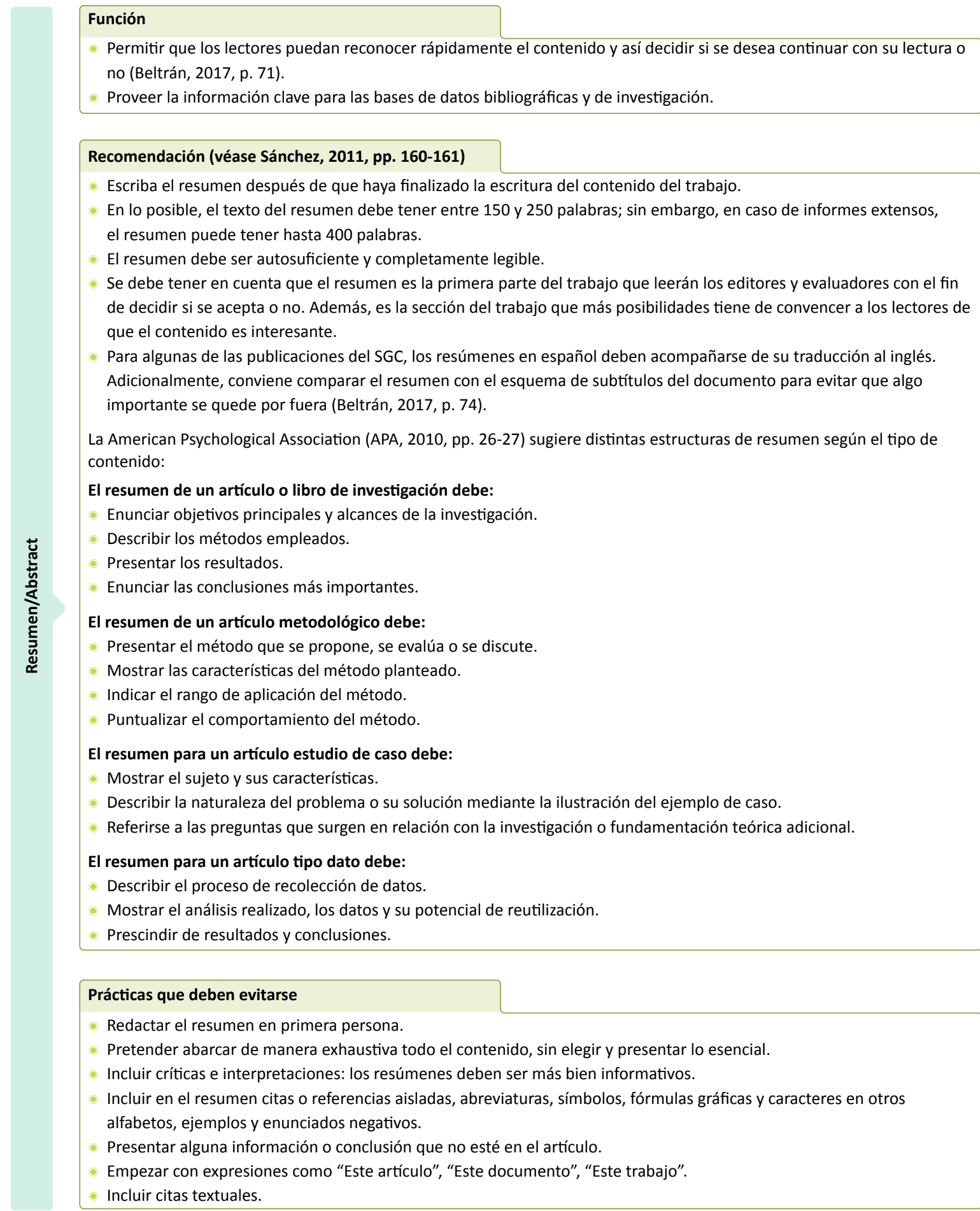

Figura 3. Elementos fundamentales de la sección Resumen 


\subsubsection{Palabras clave}

\section{Las palabras clave son los términos más relevantes que tienen desarrollo en el texto, no simplemente aquellos que se enuncian (Sánchez, 2011, pp. 161-162). Sus características se resumen en la figura 4.}

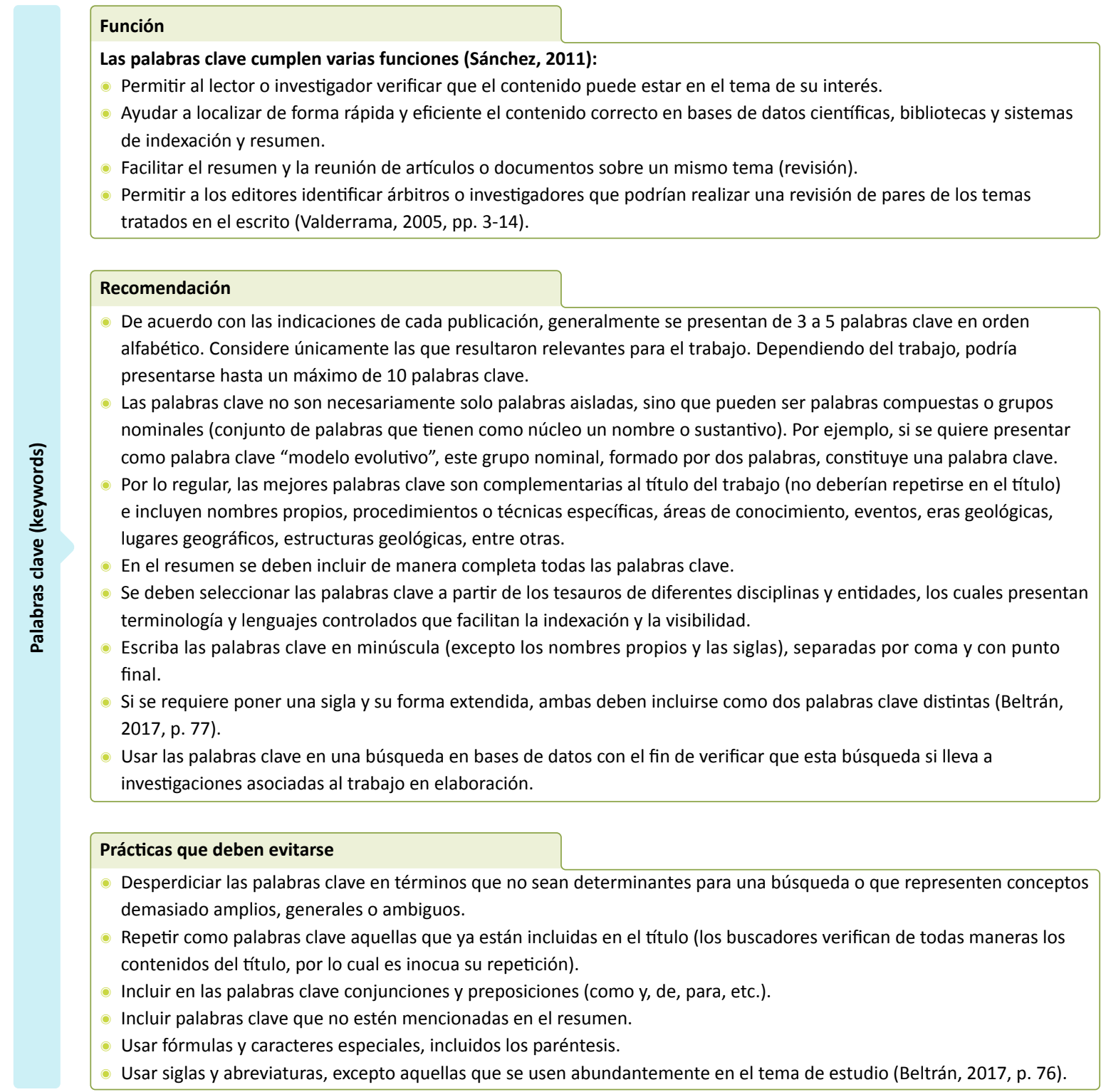

Figura 4. Elementos fundamentales de la sección Palabras clave 


\subsubsection{Introducción}

La introducción sitúa al lector y le da contextos útiles sobre el tema que aborda el trabajo, al tiempo que identifica los vacíos o faltantes que se pretenden resolver. Las características de la introducción se resumen en la figura 5 .

\section{Función}

Dar apertura al desarrollo del tema y, al mismo tiempo, resaltar su importancia, pertinencia y centralidad.

Ubicar el sitio geográfico al que se refiere el texto (si es del caso).

Reseñar de manera global las principales investigaciones que se conocen, mediante referencias a estudios previos.

Formular los objetivos del texto y explicar la estructura del documento (Sánchez, 2011, p. 161).

En artículos geocientíficos e informes, puede incluir contenidos del marco regional y contextos específicos relacionados con el tema en la zona de estudio.

En artículos tipo dato, debe incluir área de estudio y descripción de los datos.

\section{Recomendación}

La introducción puede estructurarse de manera ordenada mediante los siguientes elementos (sin que necesariamente se usen los identificadores de cada uno) (Sánchez, 2011):

Marco teórico: se citan y describen brevemente los principios o teorías que fundamentan la investigación.

- En artículos geocientíficos e informes, puede incluir localización del área de estudio y marco regional (geológico, estructural y otros).

- Planteamiento del problema: se describe brevemente el problema de investigación que se trata de resolver. Si se considera oportuno, deben proporcionarse mapas de ubicación geográfica e información de contexto del tema sobre la zona de estudio.

- Antecedentes del trabajo: se analizan estudios previos de otros autores sobre el mismo tema que se aborda en el trabajo. Se incluyen citas a dichos antecedentes.

Revisión crítica de trabajos previos (opcional): en caso de que se revisen trabajos relacionados, es conveniente profundizar y plantear un análisis crítico de los mismos. Así, por ejemplo, se deben puntualizar las semejanzas y diferencias entre los trabajos previos y el trabajo en construcción, las limitaciones de los anteriores que ahora se pretenden subsanar, etc.

- Objetivos del trabajo: deben estar formulados con claridad y deben ser coherentes con los resultados y las conclusiones obtenidas. En general, se escriben iniciando con un verbo en infinitivo.

- Presentación del trabajo: se indican los contenidos y estructura del texto, relacionándolos con la información teórica existente y el tema principal.

Cuando se trate de artículos de tipo dato, debe incluir lo siguiente:

- Antecedentes del trabajo: descripción general del diseño del estudio, los ensayos realizados y los datos generados, incluida cualquier información de fondo necesaria para colocar este estudio en el contexto de trabajos anteriores y la literatura, y debe hacer referencia a la literatura según sea necesario.

- Objetivos del trabajo: descripción breve de los objetivos más amplios que motivaron la recopilación de datos, así como su valor potencial de reutilización. Este ítem debe indicar por qué estos datos son útiles, quién puede beneficiarse de ellos y cómo podrían tener un impacto potencial en la sociedad.

Área de estudio: descripción del área donde se encuentran los datos. Localización con coordenadas geográficas. Se debe incluir figura.

\section{Prácticas que deben evitarse}

Redactar introducciones insuficientes o desproporcionadamente detalladas, que no comuniquen efectivamente los contextos que se le deben proveer al lector para que pueda entender de manera plena el sentido y la coherencia de los contenidos que se le presentan.

- Incluir en las introducciones información que estaría mejor ubicada en otra parte del trabajo (método, resultados, discusión o conclusiones).

Anticipar el resultado final, reduciendo así el interés del lector en el resto del contenido.

- Usar tiempos verbales inconsistentes (en general, debería usarse pasado para referencias y presente para el trabajo actual y su necesidad).

Figura 5. Elementos fundamentales de la sección Introducción 


\subsubsection{Método/metodología}

\section{Describe la forma en que se realiza el trabajo o investigación. Sus propiedades se detallan en la figura 6.}

\section{Función}

Presentar en detalle las herramientas, los materiales, las muestras, los participantes, los métodos, el alcance del trabajo y los procedimientos (conceptuales o informáticos/técnicos) que se requirieron para llegar a los resultados investigativos (Sánchez, 2011, p. 167).

\section{Recomendación}

El método/metodología puede incluir los siguientes elementos (Sánchez, 2011, p. 168):

- Descripción de materiales, observaciones o muestras de estudio utilizados en la investigación y mención de cómo fueron obtenidos.

Descripción de los procedimientos investigativos: explicación del procedimiento de documentación, relato y contextualización del proceso investigativo, además de una descripción detallada de este, con el fin de facilitar una posible replicación de estudios posteriores. Se puede complementar esta información con diagramas o ayudas gráficas que ilustren los aspectos clave de los procedimientos.

Detalles del equipamiento: especificaciones de los equipos relevantes en la investigación.

Detalles de la descripción estadística o analítica de los procedimientos.

En lo posible, ordene el método de la misma forma en la que se presentarán los resultados.

Otra forma de documentar el método es dando respuesta a las siguientes preguntas (Sánchez, 2011, p. 168):

Temática: ¿cuál es el tema?

Tipo de estudio: ¿qué clase de investigación es?

Hipótesis: ¿tiene alguna hipótesis o idea de partida?

Diseño: ¿cómo está diseñada la investigación?

Categorías conceptuales: ¿cuáles conceptos guiaron la investigación y fueron utilizados en el análisis de resultados y discusión? (Si es el caso).

- Conformación del conjunto de datos o del objeto de estudio para el análisis: ¿cómo se conformó el conjunto de datos o las muestras de estudio?

Criterios: ¿cuáles fueron los criterios para elegir el conjunto de datos?

- Descripción de las muestras tenidas en cuenta para el análisis: ¿cuáles fueron las técnicas utilizadas para la recolección de datos?

Sistematización de la información recolectada: ¿cómo se realizó esta parte?

Cuando se trate de artículos de tipo dato, se debe incluir el siguiente elemento:

Materiales y métodos: procedimientos utilizados para producir los datos, incluidos los ensayos de adquisición de datos y cualquier procesamiento computacional. Los métodos relacionados deben agruparse bajo los subtítulos correspondientes y los métodos deben describirse con suficiente detalle.

\section{Prácticas que deben evitarse}

Repetir en detalle la información que ya está contemplada en una guía publicada o en un procedimiento al cual podría referirse. Si el método utilizado presenta variantes, estas deberían ser indicadas en esta sección.

Figura 6. Elementos fundamentales de la sección Método/metodología 


\subsubsection{Especificaciones de los datos}

Da a conocer las principales características y el potencial de uso de un conjunto de datos de amplio interés. Esta sección aplica únicamente a los artículos tipo dato. La especificación de los datos puede verse en la figura 7.

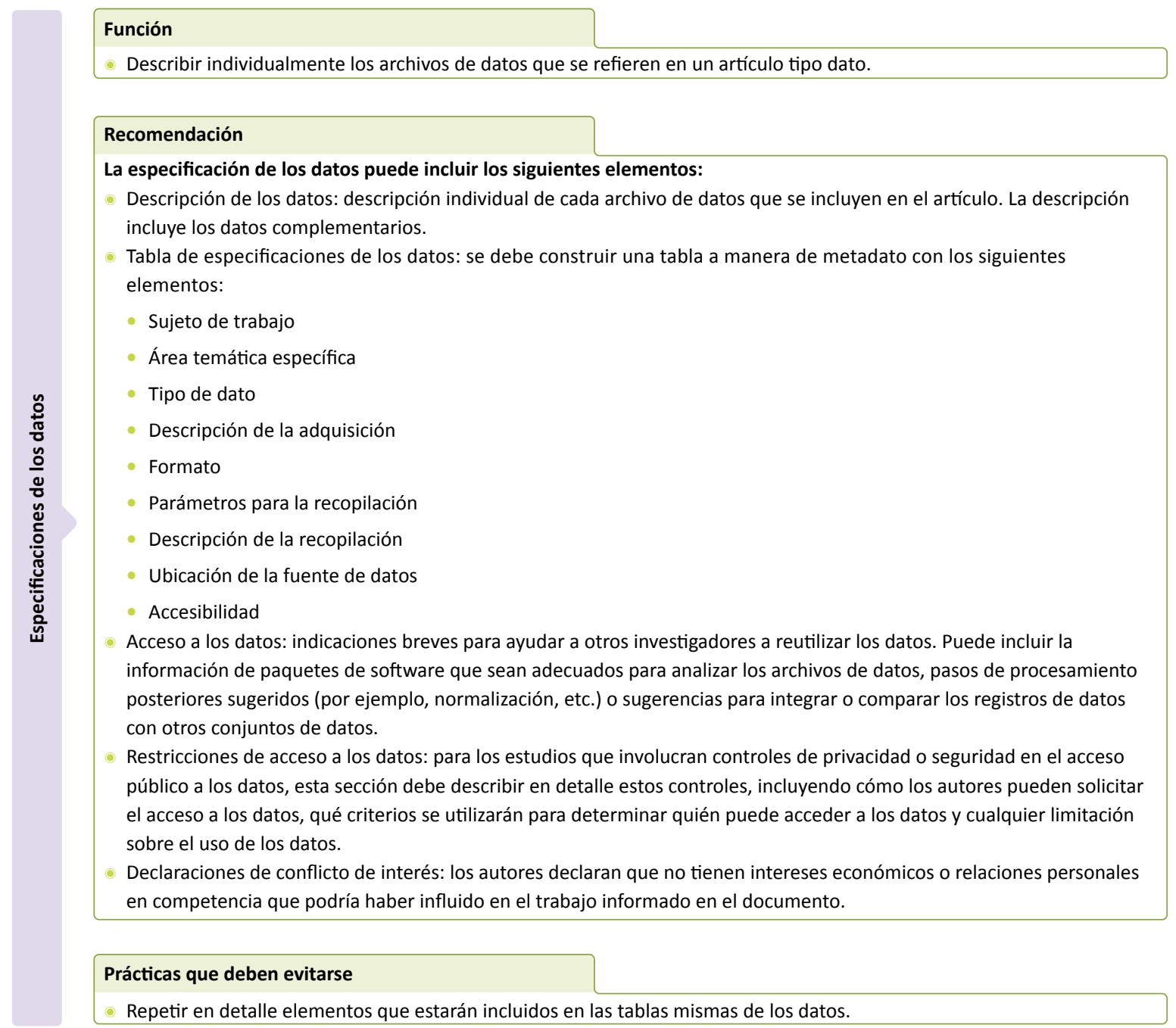

Figura 7. Elementos fundamentales de la sección Especificaciones de los datos Este componente es exclusivo de los artículos de tipo dato. 


\subsubsection{Resultados}

Presenta los aportes del trabajo en cuanto a datos o conocimiento aportado. Es uno de los apartados más breves, pero que más contribuyen al conocimiento. Este componente no es requerido en los artículos tipo dato. Sus características se ilustran en la figura 8.

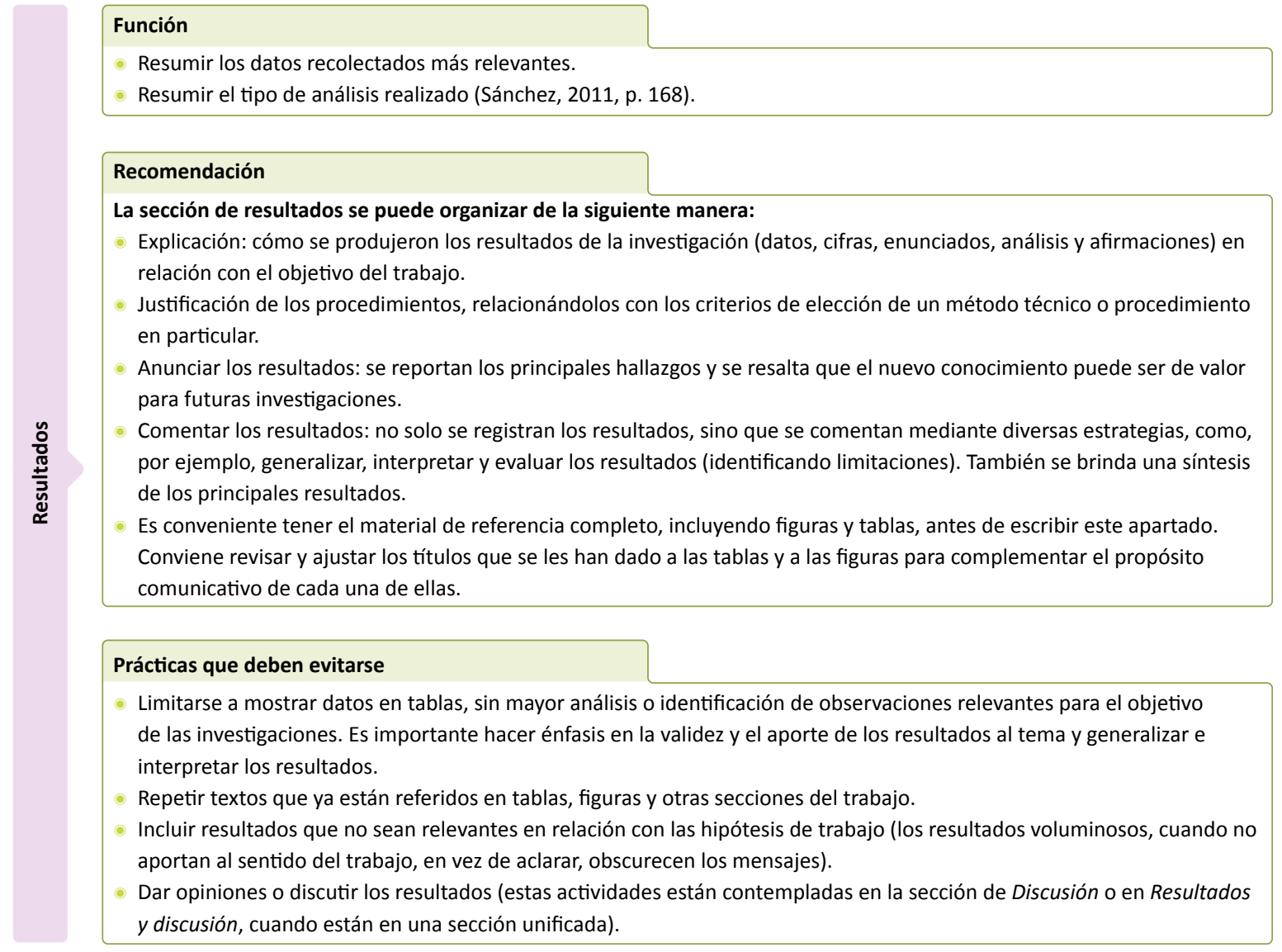

Figura 8. Elementos fundamentales de la sección Resultados 


\subsubsection{Discusión}

La discusión constituye la parte central que explica los resultados y las conclusiones posteriores, y, por tanto, es la que requiere mayor cuidado y esmero. Este componente no es requerido en los artículos tipo dato. Las características de la discusión se resumen en la figura 9.

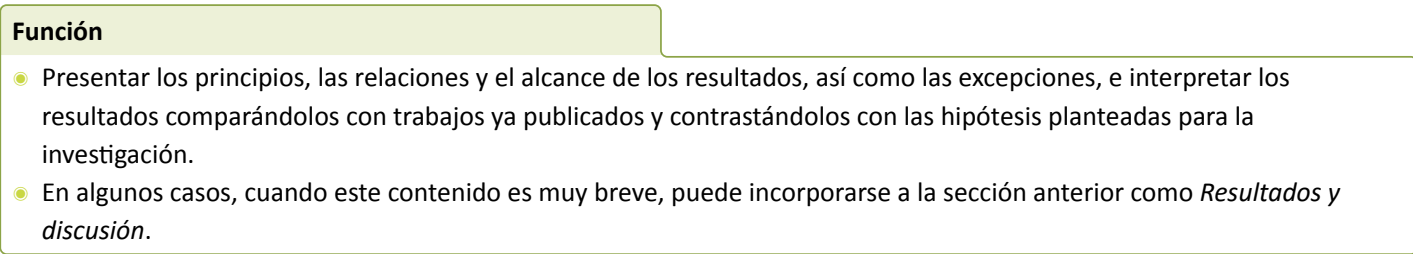

\section{Recomendación}

La sección de discusión se puede organizar de la siguiente manera:

- Contextualización del estudio: mediante el análisis de investigaciones previas relacionadas con el objeto de estudio, que permitan entender los resultados que se están presentando. También se generaliza, afirma y deduce cómo se relaciona la investigación con resultados de trabajos anteriores.

- Consolidación de los resultados: se resaltan las fortalezas del estudio y se defiende su importancia, mediante los siguientes pasos: retomar las fases esenciales del método, exponer los principales hallazgos, referir estudios previos por comparación, explicar diferencias o particularidades de los hallazgos y presentar afirmaciones abiertas o generalizaciones.

- Limitaciones del estudio: se explicitan los puntos de vista de los investigadores sobre las limitaciones del estudio en lo que respecta al método, los hallazgos y las afirmaciones realizadas con base en los hallazgos.

- Sugerencias relacionadas con la investigación: permite a los investigadores hacer recomendaciones para el desarrollo de futuros proyectos, así como preguntas de investigación para ser encauzadas o mejoradas en los aspectos metodológicos de otras indagaciones.

Para construir adecuadamente esta sección, Valderrama (2005) incluye de manera complementaria los siguientes pasos:

Presentar los principios, relaciones y alcance de los resultados.

Establecer excepciones, poner en evidencia falta de correlación y la existencia de puntos inciertos.

Interpretar los resultados comparándolos con los de trabajos ya publicados.

Discutir en forma clara las implicaciones del trabajo.

Cuidar que cada aspecto discutido esté demostrado por los resultados del trabajo.

\section{Prácticas que deben evitarse}

La ausencia de una buena discusión puede hacer que un artículo prometedor pueda ser rechazado o que tenga poco impacto.

- Una discusión larga y demasiado densa puede obscurecer el verdadero sentido de los hallazgos del contenido. Sentencias cortas y simples muestran sabiduría; lenguaje frondoso y palabras rebuscadas suelen encubrir conceptos oscuros y vagos (Valderrama, 2005).

Figura 9. Elementos fundamentales de la sección Discusión 


\subsubsection{Conclusiones}

Ofrecen una síntesis argumentativa e interpretativa, o "visión retrospectiva", de aspectos desarrollados en el trabajo, como el tratamiento dado al problema de investigación y "las deducciones lógicas que es posible derivar de la discusión de los "resultados" (Bolívar y Bolet, 2011, p. 106). Las conclusiones no constituyen una repetición de los resultados, sino un resumen de los resultados más importantes. Este componente no es requerido en los artículos de tipo dato. Las características de las conclusiones se resumen en la figura 10.

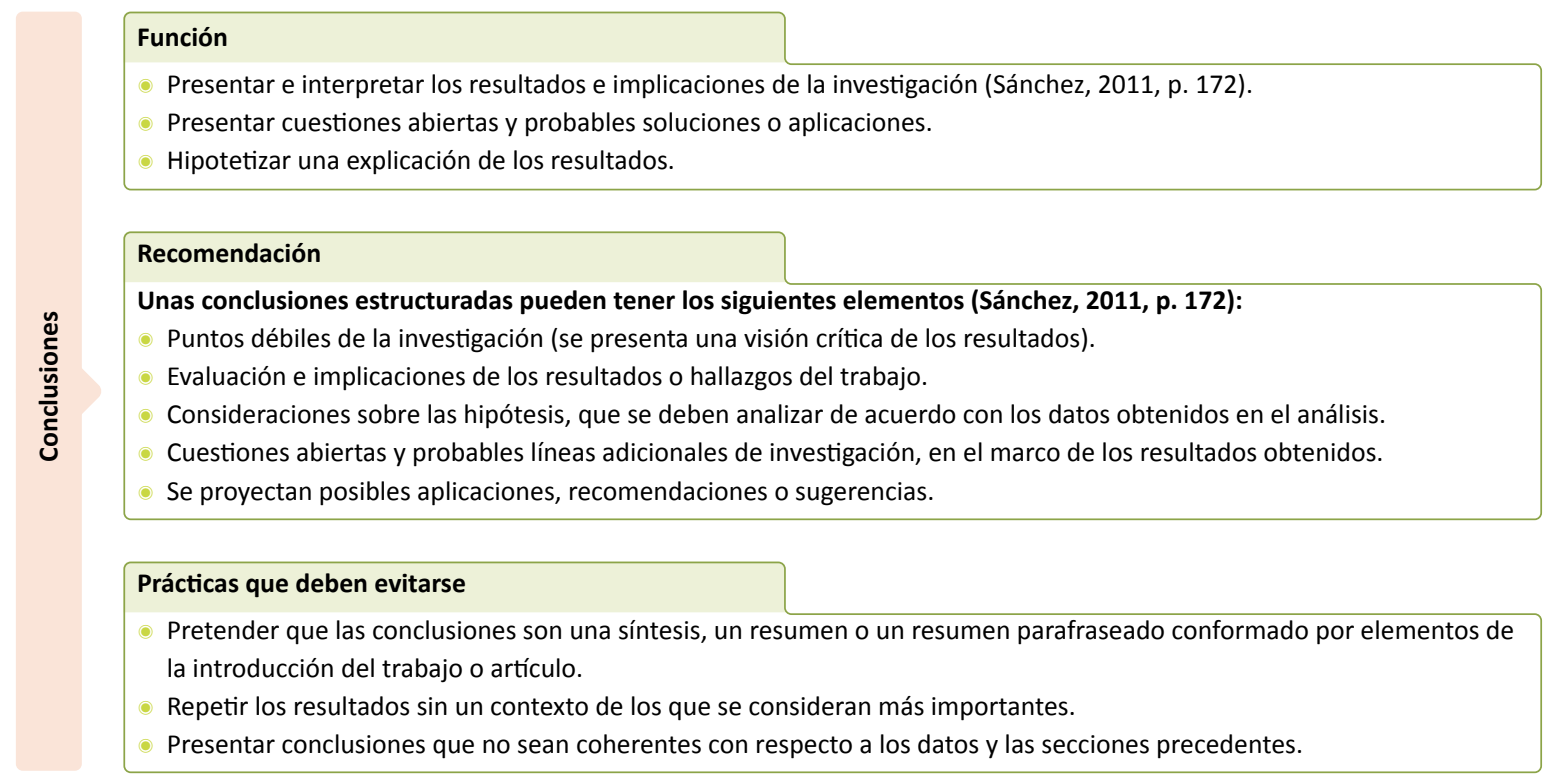

Figura 10. Elementos fundamentales de la sección Conclusiones 


\subsubsection{Referencias}

Dan cuenta del conocimiento de fuentes que se han utilizado en el estudio. Las características de las referencias se resumen en la figura 11.

\section{Función}

Presentar de manera precisa e inequívoca las fuentes de los recursos de información que el (los) autor(es) ha(n) citado en su estudio.

\section{Recomendación}

Siempre se deben entrecomillar ideas o citas textuales y dar la fuente completa, independientemente del sistema de citación que se utilice (APA, MLA, etc.). Todas las citas deben estar documentadas de forma adecuada para que el lector pueda ampliar o contrastar información (Sánchez, 2011, pp. 82-83).

En todos los casos hay que decirle al lector de dónde y de quién se ha tomado la información que utiliza en el trabajo.

Toda información que se extracte de internet tiene derechos reservados de autor y, en consecuencia, siempre debe citarse. No basta con ofrecer únicamente la dirección electrónica (http): es necesario brindar datos como autor, título y fecha, entre otros.

Las referencias deben estar en alfabeto romano.

Aunque existen diversos sistemas de citación, y cada publicación o institución tiene estándares sobre el particular, las publicaciones del SGC se acogen a la norma APA (véanse las secciones 5.21. y 5.22. de este manual).

- Para lograr una citación coherente, eficiente y sujeta a las normas es conveniente utilizar gestores de referencias como Mendeley (https://mendeley.com) o Zotero (https://zotero.org), entre otros, que desarrollan plantillas disponibles en procesadores de palabras como MS Word, para distintos estándares de citación. El capítulo 8 describe la forma de utilizar los gestores de referencias.

\section{Prácticas que deben evitarse}

- Usar una sola (o muy pocas) fuente(s) o autor(es) (esta práctica transmite una imagen de poco esfuerzo en la referenciación y búsqueda de la información).

- Incluir citas bibliográficas que no aportan al contenido.

- Presentar inconsistencias entre la bibliografía final y las citaciones (todas las citas deben tener su correspondencia en la lista de referencias y, al mismo tiempo, todas las fuentes de la lista de referencias deben tener una citación en el texto).

- Usar referencias desactualizadas o revaluadas, normalmente de hace varios años (conviene que en la revisión existan referencias lo más actualizadas posible. Es conveniente también verificar que los recursos en línea estén verdaderamente disponibles en la dirección o DOI suministrado).

- Usar sistemas de citación de manera inconsistente o ajustada al gusto de los autores (esto puede evitarse utilizando los gestores de referencias que se mencionan en el capítulo 8).

Entregar definiciones clave para el trabajo sin aclarar de dónde provienen (el lector podría necesitar algunos detalles adicionales y no sabría a dónde dirigirse).

Figura 11. Elementos fundamentales de la sección Referencias 
3.

Recomendaciones desde el punto de vista lingüístico para la composición de textos científicos y divulgativos
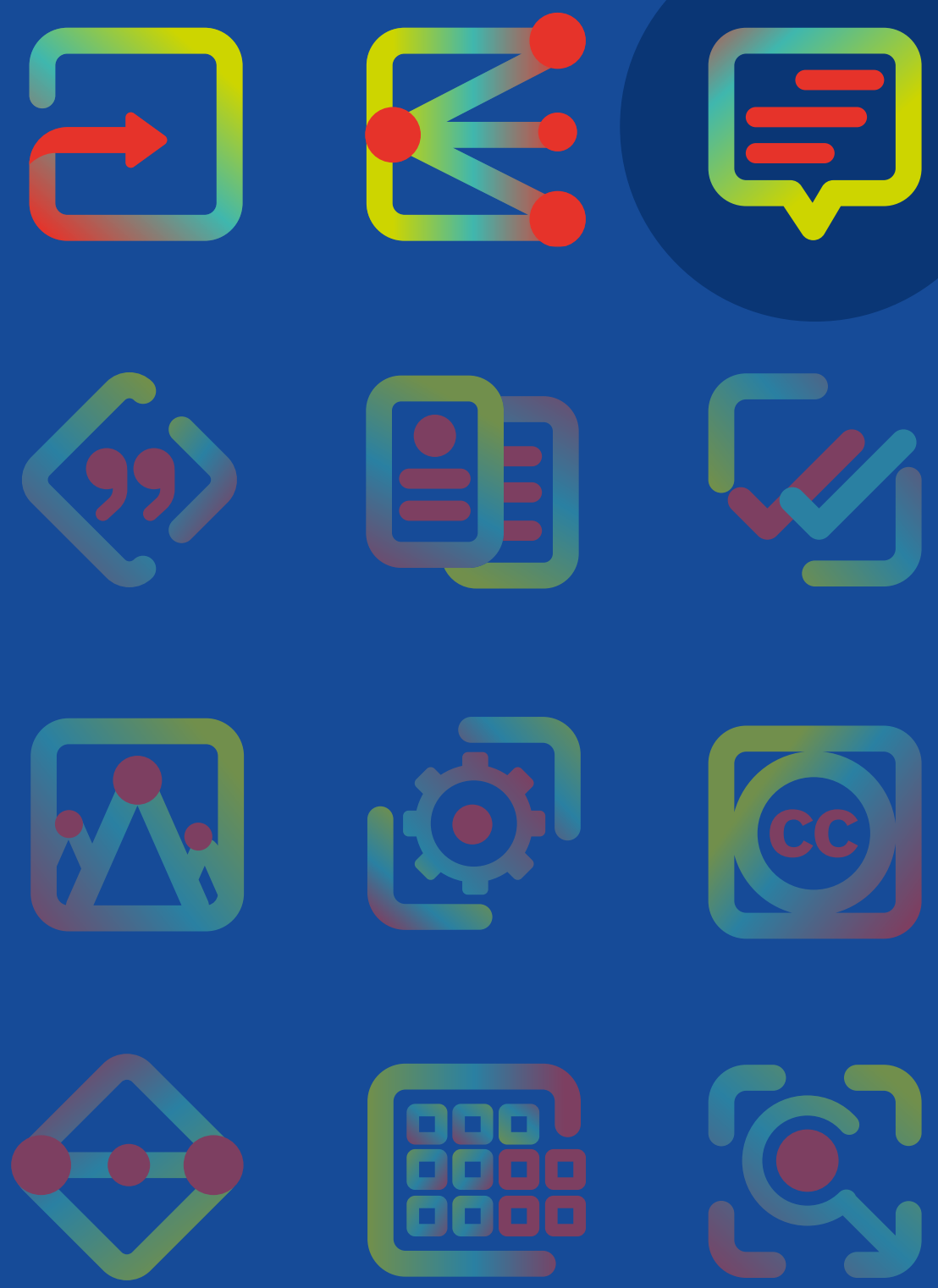


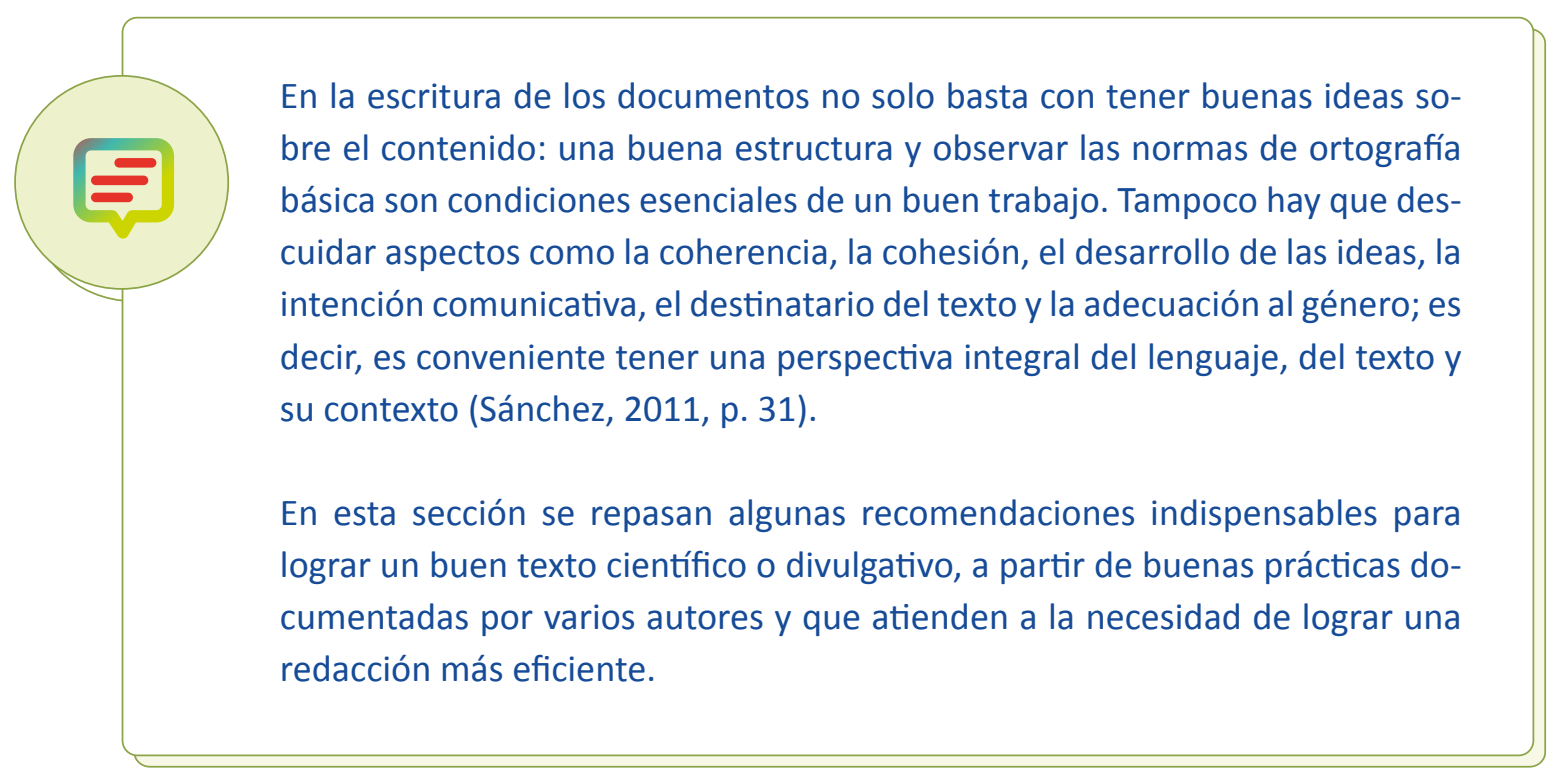

\subsection{Planear la escritura (prerredacción)}

Antes de comenzar a escribir se deben considerar las siguientes actividades (adaptado de Sánchez, 2011):

- Seleccionar y darle límites al tema de estudio: se define sobre qué se va a escribir de manera precisa y con qué alcance. Se puede intentar la escritura del tema en una oración simple: sujeto más verbo más complementos. Este ejercicio permite saber si se tiene claro el tema.

- Definir la intención del trabajo: se identifica el propósito de la escritura del trabajo y el efecto que se espera causar en los lectores.

- Establecer el objetivo del trabajo: se determina si se busca informar datos, explicar una situación, persuadir al lector sobre una teoría o hipótesis, argumentar a favor o en contra, realizar descripciones, narrar hechos o sucesos relevantes, o contrastar aspectos del objeto de estudio con respecto a otros. De esta intención depende el tono y el tratamiento en un trabajo. Por ejemplo, se definirá si el estilo del lenguaje es solo informativo o descriptivo, o si es más bien argumentativo.

- Identificar el público al que va dirigido el trabajo: se debe tener claridad para quién se escribe el trabajo y en qué circunstancias o escenarios serán leídos los textos.

- Buscar fuentes sobre el tema: se deben identificar las fuentes que aportan el sustento textual para la elaboración del trabajo. Estas pueden incluir observaciones directas, libros, artículos de revista, bases de datos científicas, enciclopedias, videos y conversaciones. En lo posible, debe procurarse contar con las fuentes más actualizadas disponibles. Estas también deben guardar estrecha relación con el tipo de trabajo que se va a abordar.

\subsection{Escoger adecuadamente entre figuras, tablas o textos}

Al comunicar ideas, existen tres tipos de recursos que pueden ser utilizados según la necesidad: figuras, tablas y textos. Escoger adecuadamente uno u otro depende del punto o significado que se pretenda 
transmitir al lector a partir de un conjunto de datos. Cada forma de mostrar los datos tiene fortalezas y debilidades.

De acuerdo con Cargill y O’Connor (2009), las tablas son más útiles para:

- registrar datos (crudos o procesados);

- explicar cálculos o mostrar componentes de datos calculados;

- mostrar los valores reales de los datos y su precisión, y

- permitir comparaciones múltiples entre elementos en muchas direcciones.

De la misma manera, las figuras son más útiles para:

- mostrar una tendencia general o esquema;

- lograr una comprensión del contenido mediante "formas" antes que números reales, y

- permitir comparaciones entre solo unos pocos elementos.

Estos conceptos están resumidos en la tabla 4.

Tabla 4. Escogencia de la opción de tablas o figuras para mostrar datos

\begin{tabular}{lll}
\hline \multicolumn{1}{c}{ Más útil cuando } & \multicolumn{1}{c}{ Tabla } & Figura \\
\hline Se trabaja con & Números & Formas \\
Se concentra en & Datos de valores individuales & Patrones generales \\
La precisión o exactitud de los valores reales es & Más importante & Menos importante \\
\hline
\end{tabular}

\subsection{Considerar algunas recomendaciones estilísticas básicas}

\subsubsection{Evitar el abuso de formas verbales}

En la escritura de textos es muy común la práctica de escribir más palabras de las necesarias, que hace que el mensaje se perciba acelerado y se torne extenso. Esta situación, además, lleva a que el lector pierda el interés.

En estos casos conviene revisar el texto y eliminar aquellos fragmentos que no aporten a la idea principal del escrito o que si se eliminaran no se vería alterada la intención de comunicación.

Ejemplos del abuso de formas verbales inadecuadas y su correspondiente simplificación pueden apreciarse en la tabla 5.

Tabla 5. Expresiones con verbosidad excesiva y sus equivalentes en versión simplificada

\begin{tabular}{ll}
\multicolumn{1}{c}{ Expresiones con verbosidad excesiva } & Expresión simplificada \\
\hline A pesar del hecho que & Aunque \\
Tiene un ritmo de crecimiento rápido & Crece rápido
\end{tabular}




\begin{tabular}{ll}
\multicolumn{1}{c}{ Expresiones con verbosidad excesiva } & Expresión simplificada \\
\hline Durante el transcurso de & Durante \\
Por un periodo de & Durante \\
Grandes cantidades de & Muchas \\
Un gran número de & Muchos \\
Con el fin de & Para \\
Con el propósito de & Para \\
Para poder analizar & Para analizar \\
Estudios realizados por Platt (1998) demostraron que & Platt (1998) demostró que \\
Fueron capaces de producir & Produjeron \\
Es capaz de & Puede \\
Posee la habilidad para & Puede \\
Tiene el potencial de & Puede \\
Se ha demostrado muchas veces & Se ha demostrado \\
\hline
\end{tabular}

Fuente: adaptada de Mari Mut (2013).

\subsubsection{Evitar las cacofonías}

Cacofonía es la repetición desagradable de algunos sonidos poco armónicos o la repetición exagerada de un mismo sonido en una frase. La tabla 6 muestra algunas de las más comunes y su forma alternativa de redacción.

Tabla 6. Cacofonías comunes y ejemplos de alternativas

\begin{tabular}{|c|c|c|}
\hline Caso & Ejemplo con cacofonía & Alternativa evitando la cacofonía \\
\hline Repetición de letras por conjunciones & $\begin{array}{l}\text { El instructor impartió teoría y instrucción } \\
\text { formal. }\end{array}$ & $\begin{array}{l}\text { El instructor impartió teoría e instrucción } \\
\text { formal. }\end{array}$ \\
\hline \multirow{5}{*}{ Uso innecesario de "que" } & $\begin{array}{l}\text { El jefe manifestó que está preocupado por } \\
\text { los retrasos, pero que está esperanzado en } \\
\text { que se entregará a tiempo el resultado por } \\
\text { el que estamos trabajando. }\end{array}$ & $\begin{array}{l}\text { El jefe manifestó su preocupación por los } \\
\text { retrasos, pero está esperanzado en que la } \\
\text { entrega se hará a tiempo. }\end{array}$ \\
\hline & $\begin{array}{l}\text { El laboratorio fue el lugar en el que se hizo } \\
\text { el ensayo de las muestras. }\end{array}$ & $\begin{array}{l}\text { El ensayo de las muestras se hizo en el } \\
\text { laboratorio. }\end{array}$ \\
\hline & $\begin{array}{l}\text { El resultado del ensayo se obtiene en el } \\
\text { momento en que menos se espera. }\end{array}$ & $\begin{array}{l}\text { El resultado del ensayo se obtiene cuando } \\
\text { menos se espera. }\end{array}$ \\
\hline & $\begin{array}{l}\text { Se debe hacer el trabajo de la manera en } \\
\text { que se acordó previamente. }\end{array}$ & $\begin{array}{l}\text { Se debe hacer el trabajo como se acordó } \\
\text { previamente. }\end{array}$ \\
\hline & $\begin{array}{l}\text { El jefe de proyecto, que ya tiene } \\
\text { experiencia en investigaciones de } \\
\text { carbones, resolvió repetir parte del trabajo. }\end{array}$ & $\begin{array}{l}\text { El jefe de proyecto, con experiencia en } \\
\text { investigaciones de carbones, resolvió } \\
\text { repetir parte del trabajo. } \\
\text { El jefe de proyecto, quien tiene experiencia } \\
\text { en investigaciones de carbones, resolvió } \\
\text { repetir parte del trabajo. }\end{array}$ \\
\hline \multirow[t]{2}{*}{$\begin{array}{l}\text { Múltiples “que" en una misma oración } \\
\text { (lo ideal es tener máximo dos por cada } \\
\text { párrafo. No se requiere eliminarlos todos.) }\end{array}$} & $\begin{array}{l}\text { Gustavo dijo que quedaron satisfechos } \\
\text { con el avance y que esperan la entrega del } \\
\text { informe que fue prometido en la fecha en } \\
\text { que se estipuló en el contrato. }\end{array}$ & $\begin{array}{l}\text { Gustavo dijo que quedaron satisfechos con } \\
\text { el avance y esperan la entrega del informe } \\
\text { prometido en la fecha estipulada en el } \\
\text { contrato. }\end{array}$ \\
\hline & $\begin{array}{l}\text { El proyecto incluyó los impuestos, que } \\
\text { suman el } 19 \% \text { y que aún se adeudan. }\end{array}$ & $\begin{array}{l}\text { El proyecto incluyó los impuestos, que } \\
\text { suman el } 19 \% \text { y aún se adeudan. }\end{array}$ \\
\hline
\end{tabular}

Fuente: adaptado de Criales (2019). 


\subsubsection{Evitar el mal uso del gerundio}

Gerundio es la forma verbal terminada en -ando/-endo que da continuidad a la acción de la oración, pero que no representa una nueva acción en sí misma. Actúa como adverbio, en especial de modo (Criales, 2019).

El abuso del uso de los gerundios denota pobreza de recursos, resta fluidez al discurso y muchas veces provoca ambigüedades. Lo anterior no significa que se dejen de usar, sino que se debe ser cuidadoso sobre cuándo recurrir a ellos.

Los casos de aplicación de los gerundios y ejemplos de uso correcto e incorrecto pueden verse en la tabla 7.

Tabla 7. Casos de aplicación de uso de los gerundios

\begin{tabular}{|c|c|c|}
\hline Caso de aplicación & Ejemplos de uso correctos & Ejemplos de uso incorrectos \\
\hline \multirow{2}{*}{$\begin{array}{l}\text { Con función adverbial o verbal } \\
\text { Es decir, que provea información acerca del } \\
\text { modo, lugar, tiempo u otras circunstancias de la } \\
\text { actividad expresada por el verbo. }\end{array}$} & $\begin{array}{l}\text { Lo demandó asegurando que su afirmación } \\
\text { era falsa. }\end{array}$ & $\begin{array}{l}\text { Lo demandó tras asegurar que su } \\
\text { afirmación era falsa. }\end{array}$ \\
\hline & $\begin{array}{l}\text { Juan realizó la socialización convenciendo } \\
\text { a las comunidades sobre la bondad del } \\
\text { proyecto. }\end{array}$ & $\begin{array}{l}\text { Juan realizó la socialización tras } \\
\text { convencer a las comunidades sobre la } \\
\text { bondad del proyecto. }\end{array}$ \\
\hline \multirow{3}{*}{$\begin{array}{l}\text { Cuando se expresa una acción simultánea } \\
\text { o anterior a la del verbo principal, o tan } \\
\text { inmediata que se percibe como simultánea }\end{array}$} & $\begin{array}{l}\text { Pronunciando una proclama, expresó su } \\
\text { voluntad suprema. }\end{array}$ & \\
\hline & $\begin{array}{l}\text { Terminó su intervención recibiendo un } \\
\text { fuerte aplauso. }\end{array}$ & \\
\hline & $\begin{array}{l}\text { Sabiendo las implicaciones del problema, } \\
\text { llamé a las autoridades. }\end{array}$ & \\
\hline
\end{tabular}

Cuando el sujeto del gerundio es el mismo que el del verbo principal o cuando se tiene un sujeto propio

Con verbos de percepción física (ver, oír, mirar, escuchar, oler), de comprensión (percibir, notar, contemplar, recordar, imaginar) o de representación (pintar, fotografiar), el sujeto puede ser el complemento directo del verbo principal.

No usar gerundio de posterioridad Si la oración indica una sucesión temporal (primero pasa una cosa y después otra), es incorrecto usar el gerundio.

\section{Gerundio de cualidad}

El gerundio actúa siempre como complemento circunstancial, es decir, es un modificador del verbo (explícito o elidido). Por lo tanto, si se usa un gerundio como un adjetivo especificativo o como una oración subordinada adjetiva, se considera galicismo y, por tanto, es incorrecto.
Lucía oyó al jefe dando la orden de finalización del día laboral.

No puedo recordar el grupo de trabajo que estuvo haciendo el muestreo.

\begin{tabular}{ll}
\hline $\begin{array}{l}\text { Visitó la estación } 1 \text { y documentó los } \\
\text { detalles encontrados al llegar. }\end{array}$ & $\begin{array}{l}\text { Visitó la estación 1, documentando los } \\
\text { detalles encontrados al llegar. }\end{array}$ \\
\hline $\begin{array}{l}\text { Estudió en París y obtuvo años más tarde } \\
\text { su título de la Sorbona. }\end{array}$ & $\begin{array}{l}\text { Estudió en París, obteniendo, años } \\
\text { más tarde su título de la Sorbona. }\end{array}$ \\
$\begin{array}{l}\text { Algunos trabajadores iban recogiendo las } \\
\text { muestras y otros iban empacándolas. }\end{array}$ & \\
\hline $\begin{array}{l}\text { Los archivos que contenían datos de } \\
\text { ubicación fueron verificados. }\end{array}$ & $\begin{array}{l}\text { Los archivos conteniendo datos de } \\
\text { ubicación fueron verificados. }\end{array}$ \\
\hline $\begin{array}{l}\text { El documento entregado que develó las } \\
\text { inconsistencias levantó mucha polémica. }\end{array}$ & $\begin{array}{l}\text { El documento entregado develando } \\
\text { las inconsistencias levantó mucha } \\
\text { polémica. }\end{array}$
\end{tabular}




\begin{tabular}{|c|c|c|}
\hline Caso de aplicación & Ejemplos de uso correctos & Ejemplos de uso incorrectos \\
\hline \multirow{2}{*}{$\begin{array}{l}\text { Gerundio con valor partitivo } \\
\text { En las construcciones partitivas, el uso del } \\
\text { gerundio modifica el total. Si se usa para } \\
\text { modificar solo una parte es incorrecto. }\end{array}$} & $\begin{array}{l}\text { Se recibieron cuarenta propuestas y ocho } \\
\text { de ellas eran de empresas extranjeras. }\end{array}$ & $\begin{array}{l}\text { Se recibieron cuarenta propuestas, } \\
\text { siendo ocho de ellas de empresas } \\
\text { extranjeras. }\end{array}$ \\
\hline & $\begin{array}{l}\text { Se recibieron cuarenta propuestas; ocho de } \\
\text { ellas, de empresas extranjeras. }\end{array}$ & \\
\hline \multirow{2}{*}{$\begin{array}{l}\text { En títulos de fotografías y obras de arte } \\
\text { Para el caso del SGC puede aplicarse a una } \\
\text { descripción de una fotografía que tiene una } \\
\text { acción. }\end{array}$} & Saturno devorando a sus hijos. & \\
\hline & $\begin{array}{l}\text { Grupo de geólogos del proyecto } \\
\text { levantando las columnas cerca al lecho del } \\
\text { río La Miel. }\end{array}$ & \\
\hline
\end{tabular}

\section{Gerundio semilexicalizado}

Muchos gerundios se han lexicalizado y se admite su uso asimilado a otras categorías de palabras (ardiendo, hirviendo).

\begin{tabular}{|c|c|c|}
\hline \multirow{3}{*}{$\begin{array}{l}\text { Los gerundios semilexicalizados } \\
\text { (colgando, incluyendo, excluyendo, } \\
\text { exceptuando, pasando por, dependiendo } \\
\text { de, tirando a) conservan algunas de sus } \\
\text { características verbales, por lo que se } \\
\text { desaconseja su uso. }\end{array}$} & $\begin{array}{l}\text { Traigan todas las muestras, excepto las de } \\
\text { geoquímica. }\end{array}$ & $\begin{array}{l}\text { Traigan todas las muestras, } \\
\text { exceptuando las de geoquímica. }\end{array}$ \\
\hline & $\begin{array}{l}\text { Según el tiempo que llevaba en espera, } \\
\text { gritaba o solo esperaba. }\end{array}$ & $\begin{array}{l}\text { Dependiendo del tiempo que llevaba } \\
\text { en espera, gritaba o solo esperaba. }\end{array}$ \\
\hline & $\begin{array}{l}\text { Al pasar por la ferretería recordé que debía } \\
\text { comprar unas herramientas. }\end{array}$ & $\begin{array}{l}\text { Pasando por la ferretería recordé que } \\
\text { debía comprar unas herramientas. }\end{array}$ \\
\hline \multicolumn{3}{|l|}{ Dos gerundios seguidos } \\
\hline $\begin{array}{l}\text { Aunque algunas fuentes lo consideran correcto, } \\
\text { el uso de dos gerundios seguidos resulta poco } \\
\text { estético. Debe evitarse siempre que se tenga }\end{array}$ & $\begin{array}{l}\text { Aún estaba analizando los datos del } \\
\text { experimento cuando nos llegaron más } \\
\text { datos relevantes. }\end{array}$ & $\begin{array}{l}\text { Estando analizando los datos del } \\
\text { experimento, nos llegaron más datos } \\
\text { relevantes. }\end{array}$ \\
\hline
\end{tabular}

Por favor traiga un poco de agua hirviendo.

Fuente: adaptado de la Real Academia Española (RAE) y de la Asociación de Academias de la Lengua Española (2009).

Una recomendación para saber si el gerundio se está usando de manera correcta es preguntarse cómo se ejecuta la actividad del verbo principal. Si la respuesta corresponde al gerundio, significa que está correctamente utilizado; si no, debe remplazarse por otro verbo conjugado (Criales, 2019), como se muestra en la tabla 8.

Tabla 8. Forma de saber si el gerundio se está usando de manera apropiada

\begin{tabular}{|c|c|c|c|c|}
\hline Oración & Acción & $\begin{array}{c}\text { Respuesta a la } \\
\text { pregunta “¿Cómo se realiza } \\
\text { la acción?" }\end{array}$ & $\begin{array}{l}\text { Uso correcto o } \\
\text { incorrecto del gerundio }\end{array}$ & Corrección \\
\hline La niña llegó caminando. & Llegó & Caminando & Correcto & \\
\hline $\begin{array}{l}\text { El volcán explotó produciendo } \\
\text { mucha ceniza. }\end{array}$ & Explotó & $\begin{array}{l}\text { No hay información sobre } \\
\text { cómo explotó }\end{array}$ & Incorrecto & $\begin{array}{l}\text { El volcán explotó y } \\
\text { produjo ceniza. }\end{array}$ \\
\hline $\begin{array}{l}\text { El río se desbordó dejando } \\
\text { desastres a su paso. }\end{array}$ & Se desbordó & $\begin{array}{l}\text { No hay información sobre } \\
\text { cómo se desbordó }\end{array}$ & Incorrecto & $\begin{array}{l}\text { El rio se desbordó y dejó } \\
\text { desastres a su paso. }\end{array}$ \\
\hline $\begin{array}{l}\text { Venillas delgadas de cuarzo } \\
\text { aparecen cortando la } \\
\text { estratificación. }\end{array}$ & Aparecen & Cortando & Correcto & \\
\hline $\begin{array}{l}\text { El cuarzo se encuentra también } \\
\text { en venillas formando contactos } \\
\text { suturados con los otros } \\
\text { componentes. }\end{array}$ & Se encuentra & $\begin{array}{l}\text { No hay información de } \\
\text { cómo se encuentra }\end{array}$ & Incorrecto & $\begin{array}{l}\text { El cuarzo se encuentra } \\
\text { también en venillas } \\
\text { y forma contactos } \\
\text { suturados con los otros } \\
\text { componentes. }\end{array}$ \\
\hline
\end{tabular}




\subsubsection{Privilegiar el uso del punto seguido}

Para formar un párrafo se requiere incluir oraciones que pueden estar enlazadas unas a otras mediante conectores, conjunciones, puntos y punto y coma, entre otros.

Para el caso de oraciones, lo más frecuente para separarlas es utilizar el punto seguido.

Cuando se escriben párrafos que incluyen oraciones demasiado extensas, el entendimiento de las ideas es más tortuoso, razón por la que sería apropiado separar esas oraciones muy largas en unas más cortas que sean más fáciles de comprender.

En general, un método para separar una oración en dos o más partes es mediante el punto seguido.

En el siguiente ejemplo, se tiene un párrafo con una sola oración excesivamente larga, la cual se ha simplificado en oraciones cortas que se han separado por punto seguido. Esto da como resultado un texto más fácil de leer.

\section{Ejemplo de texto en oraciones excesivamente extensas:}

Los materiales que conforman el Glacis del Quindío provienen de la cordillera Central, ubicada al oriente y nororiente de la zona de interés, están formados de depósitos que en su mayoría son producto de la actividad de los volcanes Nevados del Quindío, Santa Isabel y Cerro Santa Rosa (González y Núñez, 1991), cuyas erupciones generaron flujos piroclásticos e indujeron lahares por deshielo de los glaciares, descendiendo principalmente por los cauces de los ríos Quindío y Otún y demás corrientes que drenan el sector, depositando su carga en un antiguo valle o depresión intercordillerana, posiblemente de origen tectónico, localizada entre el piedemonte occidental de la cordillera Central, el río La Vieja al occidente, el sector de Caicedonia al sur y Pereira al norte.

Texto anterior expresado con oraciones más numerosas, pero más cortas:

Los materiales que conforman el Glacis del Quindío provienen de la cordillera Central, ubicada al oriente y nororiente de la zona de interés. Estos depósitos, en su mayoría, son producto de la actividad de los volcanes Nevados del Quindío, Santa Isabel y Cerro Santa Rosa (González y Núñez, 1991). Las erupciones volcánicas generaron flujos piroclásticos e indujeron lahares por deshielo de los glaciares que descendieron principalmente por los cauces de los ríos Quindío y Otún, y demás corrientes que drenan el sector. Estas depositaron su carga en un antiguo valle o depresión intercordillerana, posiblemente de origen tectónico, localizado entre el piedemonte occidental de la cordillera Central, el río La Vieja al occidente, el sector de Caicedonia al sur y Pereira al norte.

Por otra parte, el punto y coma se puede reemplazar más bien por un punto seguido, ya que fundamentalmente separa premisas o argumentos relacionados con una misma idea. Cuando estos argumentos o premisas están fuertemente asociados, se puede sustituir el punto y coma con punto seguido sin ningún problema. 


\subsubsection{Redactar oraciones cortas}

Cuando las oraciones son muy extensas es más difícil para el lector asimilar el mensaje que quiere transmitir el autor. Así, es preferible el uso de oraciones cortas, bien articuladas en párrafos más sencillos y digeribles. Algunas claves para simplificarlas pueden apreciarse en las secciones 3.3.1. y 3.6.

\subsubsection{Evitar párrafos de más de siete líneas}

Los párrafos demasiado extensos dan la sensación de complejidad, y predisponen al lector de manera inconveniente para el proceso de lectura. Para evitar esta situación, es procedente que los párrafos no tengan más de siete líneas cuando sean impresos, o más de cuatro líneas, si se trata de contenidos en medios virtuales (Criales, 2019).

\subsubsection{Preferir la voz activa}

La voz activa presenta el orden sujeto + verbo + complemento y resulta más clara para la comunicación científica y técnica. Por otra parte, con la voz pasiva se pierde precisión y claridad de la oración y hace que la lectura sea más compleja (Criales, 2019). Por esto, debe optarse la voz activa.

Cuando se emplea de manera repetida la voz pasiva ocurren los siguientes efectos:

1. Obliga a repetir muchas veces el verbo ser a lo largo del texto.

2. Provoca rimas internas entre los participios.

3. Hace que la prosa del texto suene artificial.

Las repeticiones y rimas internas son los errores de estilo más frecuentes, por eso, en lo posible, se deben evitar.

La voz pasiva da protagonismo al objeto que recibe la acción y despersonaliza al sujeto que la lleva a cabo. Esta solo tiene sentido cuando en realidad se quiera de manera deliberada lograr ese efecto.

Por ejemplo, si se tiene el siguiente texto:

Manuel fue consultado por muchos usuarios vía telefónica, dada su reconocida recursividad. Se trata de destacar el hecho de que Manuel es muy competente.

En el resto de los casos, es preferible usar la voz activa, como se muestra en la tabla 9. 
Tabla 9. Ejemplos en voz pasiva que se expresan mejor en voz activa

\begin{tabular}{ll}
\hline \multicolumn{1}{c}{ Frase en voz pasiva } & \multicolumn{1}{c}{ Frase en voz activa (preferida) } \\
\hline El profesor fue abordado por Enrique. & Enrique abordó al profesor. \\
\hline $\begin{array}{l}\text { En este trabajo la transformada de Gilbert fue utilizada por el } \\
\text { autor para analizar los componentes armónicos de la señal. }\end{array}$ & $\begin{array}{l}\text { En este trabajo, el autor utilizó la transformada de Gilbert para } \\
\text { analizar los componentes armónicos de la señal. }\end{array}$ \\
\hline $\begin{array}{l}\text { Los conjuntos de datos serán procesados por el analista y se } \\
\text { encontrarán evidencias objetivas de su naturaleza. }\end{array}$ & $\begin{array}{l}\text { El analista procesará los conjuntos de datos y encontrará } \\
\text { evidencias objetivas de su naturaleza. }\end{array}$ \\
\hline
\end{tabular}

\subsubsection{Evitar el abuso de adjetivos calificativos}

El adjetivo acompaña al sustantivo para ampliar su significado y asignarle una característica. El abuso de los adjetivos calificativos no es un error de forma, sino de fondo (Criales, 2019). Cuando se trata de informar al lector es preferible no usar adjetivos, pues constituyen una subjetividad marcada y excesiva por parte del autor. Es más recomendable dar información cuantitativa que califique o modifique el sustantivo de una manera más objetiva.

Por ejemplo, si se va a referir a la descripción de una columna de gases de una fumarola, se tienen las dos formas:

\section{Usando adjetivos calificativos:}

Se observa una fumarola de gases de color blanco, extremadamente alta y ancha, que cubre la parte superior del cráter.

Sin usar adjetivos calificativos:

Se observa una fumarola de gases de color blanco, de aproximadamente $8 \mathrm{~km}$ de alto y $1 \mathrm{~km}$ de ancho, que cubre la parte superior del cráter.

\subsection{Escribir con claridad}

Se debe tener en cuenta al lector final desde el primer momento. Con él debe establecerse un compromiso para que pueda captar de la mejor manera la información que se le está transmitiendo. Para lograr este objetivo, es necesario que se explique, se precise y se relate el sentido del trabajo, sin caer en explicaciones detalladas e innecesarias.

La claridad se debe reflejar en el uso de palabras sencillas o comunes, frases y párrafos cortos, lenguaje concreto, ejemplos que ilustren y estructuras que faciliten la lectura, como títulos enunciativos, subtítulos o títulos secundarios, resúmenes de información y recuadros explicativos (Sánchez, 2011, p. 35). Esta claridad debe complementarse con una adecuada estructura y numeración de los distintos títulos.

La claridad en los escritos se logra mediante palabras más familiares para el lector. Para lograrlo, conviene ponerse en su lugar y evitar términos extraños, que no aporten al entendimiento del texto. Por ejemplo, decir "habida cuenta" cuando se puede decir "puesto que" que es más adecuado. 
Con respecto a la claridad, Almanza et al. $(2015$, p. 13) afirman lo siguiente:

La claridad se refiere a evitar la ambigüedad, a no dejar cabida a que el lector pueda entender cosas diferentes o a que pueda entender más de una cosa a la vez. Este es el concepto más indispensable y valioso para escribir textos geológicos.

\subsection{Ser precisos en la escritura}

Las frases deben tener un correcto y lógico desarrollo, y deben emplearse las palabras adecuadas en cada caso. Para ganar precisión debe haber una buena clasificación y orden de las ideas que se exponen, con el uso de criterios cronológicos, espaciales, causales, de comparación o contraste.

Debe evitarse el lenguaje ambiguo o términos que expresen diferentes ideas y que puedan oscurecer el sentido. Como ejemplo, en lugar de escribir "hacer una columna", más preciso es "levantar una columna"; y en lugar de "tener proyectos", es mejor escribir "concebir proyectos", entre otras (Sánchez, 2011, p. 35).

Sobre la precisión en la escritura Almanza et al. (2015, p. 13) expresan lo siguiente:

Un geólogo debe escribir siempre de la forma más clara, precisa y eficiente; evitando al máximo la ambigüedad al expresar sus ideas y las de los demás. La falta de precisión y de claridad dificultan la comunicación -o la evitan del todo-, lo que muchas veces se traduce en un retraso en la labor científica durante la investigación y la gestión integral del conocimiento, que incluso puede provocar rechazo de parte de la comunidad geocientífica -además de ser un gasto innecesario de tiempo y dinero-.

\subsection{Ser concisos}

Según el Diccionario de la Real Academia Española (RAE, 2020a), concisión significa "brevedad y economía de medios en el modo de expresar un concepto con exactitud". Por tanto, se trata de escoger las palabras justas y necesarias para comunicar las ideas a los autores. Tampoco se debe caer en estilos telegráficos, caracterizados por la pobreza expresiva (Sánchez, 2011, p. 36).

A continuación se presentan algunas recomendaciones para ganar concisión:

- No repetir vocablos.

- Evitar las muletillas (clichés lingüísticos).

- Eliminar los comodines (palabras genéricas que encajan en cualquier parte del texto).

- Preferir las palabras concretas a las abstractas (las primeras favorecen la formación de imágenes mentales en el lector).

- Preferir vocablos cortos y sencillos.

- Esquivar los verbos copulativos como ser y estar, que restringen la variedad léxica de la frase. 
Adicionalmente, es importante el uso frecuente del punto seguido, pues da cierre a las oraciones y evita el abuso de subordinaciones o frases explicativas (ver el numeral 3.3.4.).

En la tabla 10 se muestran algunos ejemplos de palabras o expresiones que tienen el mismo significado, pero que pueden escribirse de manera más clara para el lector.

Tabla 10. Recomendaciones de uso de algunas expresiones comunes

\begin{tabular}{|c|c|}
\hline Expresión o palabra & Mejor use \\
\hline No tiene & Carece de \\
\hline Más grande & Mayor \\
\hline Meter presión & Presionar \\
\hline Se requiere dar un impulso a los proyectos & Se necesita impulsar los proyectos \\
\hline Procederemos a realizar una comprobación & Comprobaremos \\
\hline Se tratarán varios puntos en la reunión & Se tratarán varios asuntos en la reunión \\
\hline Volver a insistir & Reiterar \\
\hline Uso de verbos comodines & Sustituirlos por verbos específicos \\
\hline No hemos dicho nuestra opinión sobre el tema & No hemos expresado nuestra opinión sobre el tema \\
\hline El negocio tiene un momento difícil & El negocio pasa por un momento difícil \\
\hline Hacer una casa & Construir una casa \\
\hline Hacer un escrito & Redactar un escrito \\
\hline El expositor dio una clase magistral & El expositor impartió una clase magistral \\
\hline Me van a poner internet & Me van a instalar internet \\
\hline En el volcán, siguen habiendo fumarolas & En el volcán se siguen presentando fumarolas \\
\hline Redundancias (adaptado de Guerrero Salazar, 2000) & Simplificar para evitar la redundancia \\
\hline Casualidad imprevista & Casualidad \\
\hline Accidente fortuito & Accidente \\
\hline Chocar contra & Chocar con \\
\hline Sumergir bajo & Sumergir \\
\hline Salir al exterior & Salir \\
\hline Nunca antes & Nunca \\
\hline Requisito imprescindible & Requisito \\
\hline Tabla de madera & Tabla \\
\hline Autoridad pública & Autoridad \\
\hline Conjuntamente con & Conjuntamente \\
\hline Erradicar totalmente & Erradicar \\
\hline Minucia sin importancia & Minucia \\
\hline 120 países del mundo & 120 países \\
\hline 5:00 p. m. en punto & 5:00 p. m. \\
\hline El día de hoy & Hoy \\
\hline Funcionario público & Funcionario \\
\hline Erario público & Erario \\
\hline Mas sin embargo & Sin embargo \\
\hline El día 17 del mes de mayo del año 2020 & El 17 de mayo del 2020 \\
\hline $8 \%$ del total & $8 \%$ \\
\hline A continuación sigue /Sigue a continuación & A continuación \\
\hline A lo largo de todo el país & A lo largo del país \\
\hline A los dos días siguientes & A los dos días \\
\hline A partir del lunes comienza & A partir del lunes \\
\hline
\end{tabular}


El concepto de concisión de manera general se puede ilustrar con los siguientes textos, que muestran el contraste:

Si a un investigador le preguntan cómo resultó un experimento, este puede dar dos respuestas que se diferencian en la concisión:

Respuesta no concisa

"El experimento tuvo cinco meses de preparación, tanto de los insumos como del procedimiento en sí. Se realizó el 26 de octubre, empezó a las 10:30 a. m. y terminó a las 5:40 p. m. En el término de su ejecución había mucho ruido ambiental, lo cual fue molesto para el personal del laboratorio. Después de bastante trabajo se ejecutaron completamente las comprobaciones contempladas. Los resultados fueron recibidos y se comprobó que estaban en el rango de valores esperados de las guías utilizadas. Por lo tanto, puede afirmarse que fue exitoso".

\section{Respuesta concisa}

"El experimento se realizó de acuerdo con lo planeado y sus resultados fueron satisfactorios de acuerdo con las especificaciones".

\subsection{Escribir en forma impersonal}

Los escritos con contenidos técnicos o científicos deben ser escritos en forma impersonal. Esto se logra evitando el uso de la primera persona del plural (nosotros) - aunque existan varios autores-, y también el de la primera persona del singular (yo). De esta manera, se recomienda un estilo impersonal que se ilustra en la tabla 11.

Tabla 11. Uso de verbos en forma impersonal

\begin{tabular}{ll}
\hline \multicolumn{1}{c}{ Escriba } & \multicolumn{1}{c}{ En vez de } \\
\hline Se formula & Formulamos/formulo \\
Se discute & Discutimos/discuto \\
Se observa & Observamos/observo \\
Se postula & Postulamos/postulo \\
Se aprecia & Apreciamos/aprecio \\
Se concluye & Concluimos/concluyo \\
\hline
\end{tabular}

Conviene aclarar que con el uso del impersonal, quien se impersonaliza es el narrador no lo narrado, como se aprecia en los siguientes ejemplos:

\section{Correcto}

Se observó que el gobernador de la región no tomó los correctivos necesarios para evitar el accidente causado por el alud.

Incorrecto

Se observó que no se tomaron los correctivos necesarios para evitar el accidente causado por el alud. 
Dos excepciones a esta recomendación son la escritura de un prólogo, que puede estar en segunda o tercera persona, y la escritura de los agradecimientos, que pueden estar en primera persona del singular o del plural.

\subsection{Usar metáforas}

Las metáforas ayudan al científico a mirar el mundo de otra manera. Estas tienen una intención didáctica y pueden constituir un modelo descriptivo o explicativo de diferentes conceptos y fenómenos (Sánchez, 2011, p. 51).

En los textos de investigación, la metáfora no tiene efectos estéticos o accesorios, sino que su uso es completamente práctico. Este recurso está orientado, en gran medida, a hacer que las ideas y conceptos puedan ser comunicados efectivamente y que sean comprendidos.

De acuerdo con Ahmad (2005), los científicos, tanto literal como metafóricamente, crean un mundo de creencias por medio de una red de palabras - algunas prestadas y otras inventadas - con la que respaldan la propia confianza en sus creaciones, de una parte, y suprimen o modifican las creencias de otros, de otra.

Algunos ejemplos de metáforas científicas se muestran a continuación:

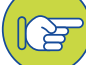

1) Charles Darwin (1856) (tomado de Blanco, 2008):

"Los registros geológicos han sido 'imperfectamente conservados', de cuya historia conservamos 'el último volumen', del cual nos quedan sólo 'algunos capítulos', y de éstos, solo 'algunas páginas', y de estas, solo 'unas pocas líneas saltadas'”.

\section{2) Charles Lyell, Principles of geology (tomado de Blanco, 2008):}

Escuchamos de violentas y repentinas revoluciones del globo, de elevaciones instantáneas de cadenas de montañas, de paroxismos de energía volcánica, en declinación según algunos, y en aumento en violencia según otros, desde las eras más antiguas hasta las más recientes. Se nos habla de catástrofes generales y de una sucesión de diluvios, de la alternancia de períodos de reposo y desorden, del enfriamiento del globo, de la aniquilación repentina de razas enteras de animales y plantas, y otras hipótesis, en las cuales vemos revivir el viejo espíritu de la especulación, y un deseo manifiesto de cortar, en lugar de desatar pacientemente, el nudo Gordiano [...] En nuestro intento de develar estos dificultosos problemas, adoptaremos un curso diferente, restringiéndonos a la operación de causas existentes conocidas [...] Por lo tanto no estamos autorizados, en la infancia de nuestra ciencia, a recurrir a agentes extraordinarios [...] [Las operaciones actualmente en acción] las consideramos como constituyentes del alfabeto y la gramática de la geología. 
3) Metáfora del tiempo fósil (tomado de Alonso, 2017):

"La evolución de la vida, desde el Precámbrico hasta la actualidad, fue dejando registros que se conservaron como singularidades espacio-temporales y que constituyen verdaderos mojones del tiempo geológico".

4) Metáfora de los eventos llamados "tornillos" en vulcanología (Narváez et al., 1997):

"Unusual low-frequency seismic events, called 'tornillos' ('screws') at the Observatorio Vulcanológico y Sismológico de Pasto (OVSP), have been observed at Galeras volcano during 1992-1993".

Una forma de construir metáforas es mediante el uso de los denominados experimentos mentales en los que se recurre a un escenario hipotético que ayuda a comprender cierto razonamiento o algún aspecto de la realidad. Esta aproximación ha sido trabajada, por ejemplo, en el entendimiento de la geología estructural con el uso de metáforas visuales, como puede evidenciarse en Davis y Fischer (2016).

\subsection{Ser coherente}

En términos de la preparación de contenidos científicos, la coherencia es la correlación entre el propósito del autor del texto, su contenido (estructura y progresión de la información), el sentido y la situación comunicativa (Sánchez, 2011, p. 57).

La coherencia da sentido a los textos y permite que sean comprensibles mediante la continuidad de significado, estabilidad y consistencia temática, y la explicitación de la intención comunicativa del autor (Calsamiglia y Tusón, 1999, p. 222).

Para ilustrar la diferencia entre un texto sin coherencia y el mismo ajustado para ser coherente, se aporta el siguiente ejemplo.

\section{Texto escrito sin coherencia}

"En la Mesa de los Santos hay sismos todos los días. La región pertenece al departamento de Santander. En Colombia hay 32 departamentos. La región está en una zona de amenaza sísmica alta. Las construcciones se hacen obedeciendo las recomendaciones antisísmicas y son seguras".

Cada frase por separado tiene un significado, pero no se conciben como parte integral de un texto, puesto que carecen de unidad semántica.

\section{Texto ajustado para ser coherente}

"En la Mesa de los Santos del departamento de Santander (uno de los 32 departamentos de Colombia) se sienten sismos todos los días; sin embargo, dado que esta región pertenece a una zona de amenaza sísmica alta, las construcciones se realizan siguiendo normas que garantizan su sismorresistencia". 
En el texto anterior, todas las frases se consideran partes integrantes del mensaje y se tiene una unidad semántica.

\subsection{Demostrar cohesión}

Según Sánchez (2011, p. 58), la cohesión (que es una de las manifestaciones de la coherencia) es la unidad textual interna del texto mediante una red de relaciones y estrategias que permiten que este no solo conserve su unidad, sino que progrese o avance temáticamente. Este autor recomienda algunas estrategias para conservar la cohesión:

- Reiteración: mecanismo de repetición, exacta o parcial, de ciertos elementos, con el fin de mantener el referente o tema.

- Uso de marcadores y conectores: elementos lingüísticos que relacionan de manera adecuada diversos segmentos textuales del artículo y guían la interpretación del sentido por parte del lector (Calsamiglia y Tusón, 1999, p. 247).

Se recomienda utilizar los conectores que se clasifican en la tabla 12:

Tabla 12. Conectores recomendados para darle cohesión a los textos

\begin{tabular}{|c|c|}
\hline Tipo de conector & Conectores recomendados \\
\hline & Noción de suma: además, y, también, asimismo, igualmente. \\
\hline & Matiz intensificativo: es más, más aun, todavía más, incluso, asimismo, \\
\hline Aditivos (expresan suma de ideas) & encima, de igual modo, de igual modo, de igual manera, igualmente, de \\
\hline \multirow{4}{*}{$\begin{array}{l}\text { El enunciado que sigue va a aportar nueva información } \\
\text { equivalente, o más importante que la anterior. }\end{array}$} & la misma manera, por otro lado, por otra parte, también, tampoco, al \\
\hline & mismo tiempo, sumando, al fin y al cabo, además, aparte de eso, para \\
\hline & colmo, en otro orden de cosas, paralelamente. \\
\hline & Grado máximo: incluso, hasta. \\
\hline
\end{tabular}

Concesión: a pesar de todo, aun así, ahora bien, al mismo tiempo, de cualquier modo.

Opositivos (expresan diferentes relaciones de contraste Restricción: no obstante, por el contrario, con todo, aun así, ahora bien, entre enunciados) sin embargo, de todas formas, de cualquier modo, después de todo, en

El enunciado a continuación modifica la argumentación u opone ideas del enunciado anterior. todo caso, en cualquier caso, en contraste, por otra parte, en cambio, tampoco, pero, más que.

Exclusión: por el contrario, en cambio.

Exclusión (usados con "sino"): más bien, antes bien.

Consecutivos: por tanto, de ahí que, por consiguiente, por eso,

Causativos/consecutivos (expresan relaciones de causa o entonces, de manera que, a continuación.

Causales: porque, ya que, debido a que, dado que, pues, pues bien, puesto que, por el hecho de que, entonces, así pues, por eso, por ello, a causa de esto, por ende, de hecho/en consecuencia, por consiguiente, de ahí que, entonces, de manera que, por esta razón, por eso, por ende, por lo tanto.

Concesivos/condicionales

El enunciado posterior establece una condición no esperada con el anterior. Este tipo de conector está

En vista de, concedido que, por supuesto, aunque, aun cuando, aun así, pese a que, con todo, a pesar de que. asociado a enunciados dependientes. 


\begin{tabular}{|c|c|}
\hline Tipo de conector & Conectores recomendados \\
\hline $\begin{array}{l}\text { Comparativos (subrayan alguna semejanza entre los } \\
\text { enunciados) } \\
\text { Establece entre los enunciados una comparación. } \\
\text { Normalmente el conector demuestra si esta comparación } \\
\text { es positiva o negativa. }\end{array}$ & $\begin{array}{l}\text { Del mismo modo, igualmente, análogamente, de modo similar, } \\
\text { contrariamente, inversamente, en cambio. }\end{array}$ \\
\hline $\begin{array}{l}\text { Reformulativos (indican que un enunciado posterior } \\
\text { reproduce total o parcialmente, bajo otra forma, lo } \\
\text { expresado en uno o más enunciados anteriores). } \\
\text { El enunciado a continuación reproduce total o } \\
\text { parcialmente, bajo otra forma, lo expresado en uno o más } \\
\text { enunciados anteriores. }\end{array}$ & $\begin{array}{l}\text { Explicación: es decir, o sea, esto es, a saber, en otras palabras. } \\
\text { Recapitulación: en resumen, en resumidas cuentas, en suma, total, } \\
\text { en una palabra, en otras palabras, dicho de otro modo, en breve, en } \\
\text { síntesis, finalmente, en definitiva, resumiendo, sintetizado, para concluir, } \\
\text { por último. } \\
\text { Ejemplificación: Por ejemplo, así, así como, verbigracia, } \\
\text { particularmente, específicamente, incidentalmente, para ilustrar, o sea, } \\
\text { es decir, sin ir más lejos, concretamente. } \\
\text { Corrección: mejor dicho, o sea, es decir. }\end{array}$ \\
\hline $\begin{array}{l}\text { Ordenadores (señalan las diferentes partes del texto que } \\
\text { sigue). }\end{array}$ & $\begin{array}{l}\text { Comienzo del discurso: en primer (segundo, tercer, etc.) lugar, ante } \\
\text { todo, para comenzar, inicialmente, en principio. } \\
\text { Cierre de discurso: por último, finalmente, terminando, para resumir. } \\
\text { Transición: llegado a este punto, por otro lado, por otra parte, en otro } \\
\text { orden de cosas, a continuación, acto seguido, después, con respecto a. } \\
\text { Cierre del discurso: finalmente, en fin, por último, en suma, finalmente, } \\
\text { terminando, para resumir, en conclusión, dicho de otro modo, } \\
\text { brevemente. }\end{array}$ \\
\hline $\begin{array}{l}\text { Temporales (establecen relaciones temporales de los } \\
\text { enunciados o entre los enunciados). }\end{array}$ & $\begin{array}{l}\text { Anterioridad: antes, hace tiempo, había una vez, al principio, al } \\
\text { comienzo, previamente, tiempo atrás, en primer lugar, inicialmente. } \\
\text { Simultaneidad: en este instante, al mismo tiempo, mientras tanto, a la } \\
\text { vez, entonces, simultáneamente, actualmente, mientras que, a medida } \\
\text { que. } \\
\text { Posterioridad: más tarde, luego, después, con el paso del tiempo, } \\
\text { posteriormente, después. }\end{array}$ \\
\hline $\begin{array}{l}\text { Espaciales (establecen relaciones espaciales de los } \\
\text { enunciados o entre los enunciados). }\end{array}$ & $\begin{array}{l}\text { Al lado, arriba, abajo, a la izquierda (derecha), en el medio, en el fondo, } \\
\text { junto a, por debajo de, aquí, allí, allá. }\end{array}$ \\
\hline
\end{tabular}

Fuente: adaptado de Solorio (2013).

A pesar de la importancia de utilizar conectores, se debe ser cuidadoso y no abusar de ellos; por ejemplo, no debe invertirse el orden de causa-efecto.

\subsection{Demostrar la intencionalidad}

Hay intencionalidad cuando el autor tiene un propósito consciente de lograr determinados objetivos con su mensaje (Sánchez, 2011, p. 58). Se manifiesta la actitud del autor respecto a su propósito de informar, transmitir conocimiento, lograr una meta específica, argumentar, analizar críticamente, etc.

La intención ayuda a estructurar la narrativa y se refleja en el texto, en su organización y estilo. Un redactor puede tener tres intenciones: informar, expresar o dar una orden (dirigir).

\subsection{Lograr la aceptación}

Mediante la coherencia y la cohesión se busca que el lector u oyente acepte el texto. Esto se logra si el receptor percibe que es relevante y útil para adquirir o fortalecer sus conocimientos, o porque le permite 
cooperar con su interlocutor (el autor del texto) en la consecución de una meta determinada (Sánchez, 2011, p. 59).

\subsection{Asegurar la informatividad en el texto}

Se logra mediante la novedad que representan las ideas o los hallazgos que se exponen en el texto. Si este se basa en un contenido ampliamente conocido, será de poco interés para los lectores, y probablemente no será aceptado para publicación, pues carecerá de interés.

\subsection{Implementar la intertextualidad}

La intertextualidad consiste en la adecuada utilización, en un texto, del conocimiento que se tenga de otros textos, lo cual tiene una relación directa con el modo como las comunidades científicas construyen su propio discurso (Beaugrande y Dressler, 1997; Marinkovich y Benítez, 2000).

Se trata de la actividad de construcción del propio texto con base en otros textos. La referencia a la bibliografía previa es fundamental para demostrar que el trabajo está relacionado con el conocimiento contextual, y que lo en él está expuesto constituye un aporte al conocimiento (Teberosky, 2007). 
4.

Normas editoriales

\section{de presentación general}
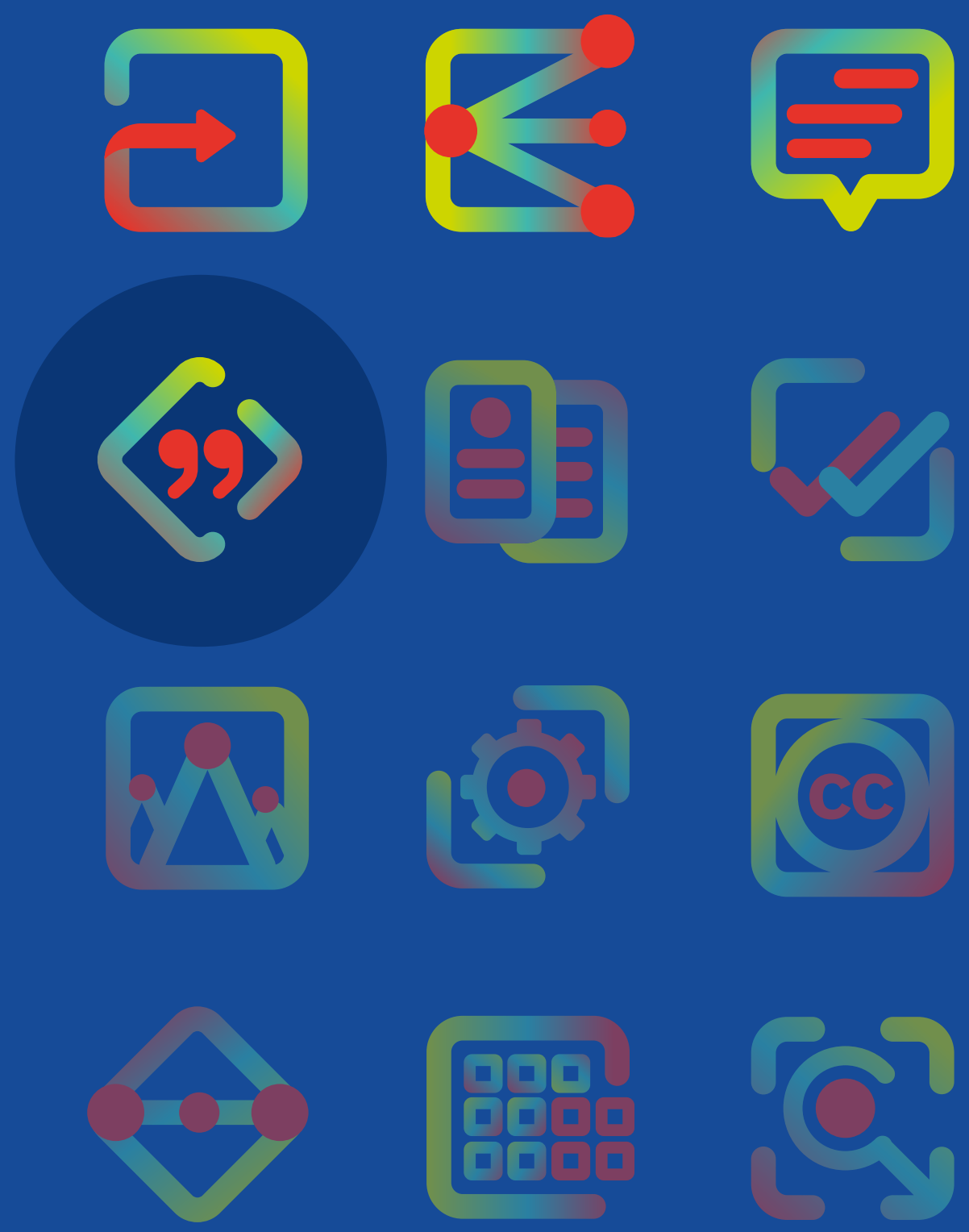


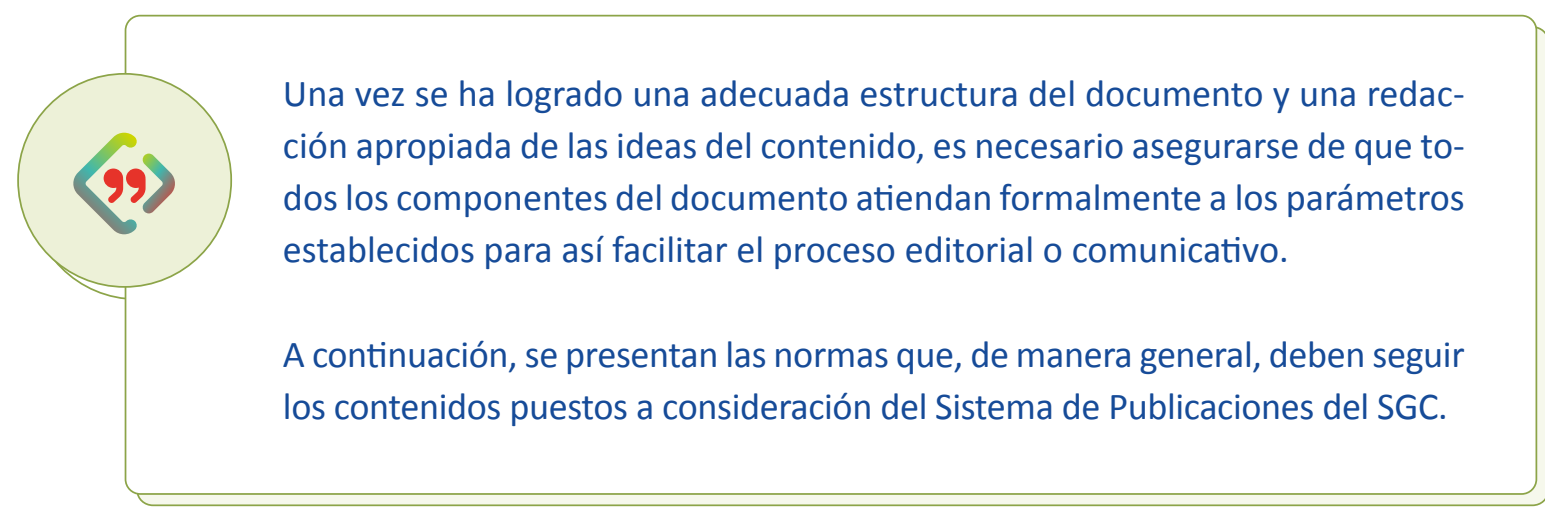

\subsection{Normas de presentación tipográficas y estructurales}

En este apartado encontrará algunas recomendaciones de asuntos de forma en los textos, las cuales se resumen en la tabla 13.

Tabla 13. Resumen de las normas de presentación de textos

\begin{tabular}{|c|c|}
\hline Elemento & Descripción \\
\hline Tipografía general & $\begin{array}{l}\text { Use fuentes sin serifas. Para la generalidad de contenidos se sugiere la fuente } \\
\text { Calibri en tamaño de } 11 \text { puntos. Esta ha sido optimizada para presentación } \\
\text { por pantalla y ha sido seleccionada por los productos Microsoft desde } 2007 \\
\text { como su fuente por defecto. Al usarla, se facilita el trabajo de los autores y sus } \\
\text { posteriores correcciones o ajustes. } \\
\text { Calibri es una fuente moderna, con sutiles redondeos en tallos y esquinas. } \\
\text { Presenta cursiva real, versalitas y múltiples conjuntos de números. Sus } \\
\text { proporciones permiten un alto impacto por igual en líneas ajustadas de texto } \\
\text { grande y pequeño, y un carácter cálido y suave. }\end{array}$ \\
\hline Espacios entre líneas & $\begin{array}{l}\text { Use un interlineado de espacio sencillo. No incluya espacios adicionales } \\
\text { automáticos entre párrafos (en el cuadro de diálogo “Párrafo” de Word, } \\
\text { en la sección “Espaciado", los valores deben ser de cero). Trabaje espacios } \\
\text { adicionales entre párrafos. Cree un espacio después de las tablas y de las figuras } \\
\text { para separar correctamente estos elementos del texto. Incluya espacio antes de } \\
\text { una lista en viñetas. }\end{array}$ \\
\hline $\begin{array}{l}\text { Espacios entre elementos diferentes de texto } \\
\text { normal }\end{array}$ & $\begin{array}{l}\text { Para separar correctamente ciertos elementos del texto normal, incluya un } \\
\text { espacio antes y después de los siguientes elementos: } \\
\text { 1. Tablas } \\
\text { 2. Figuras } \\
\text { 3. Títulos } \\
\text { 4. Subtítulos } \\
\text { 5. Listas encabezadas por viñetas (pero no entre los renglones que conforman la } \\
\text { lista, como puede apreciarse en esta misma lista) } \\
\text { 6. Citas textuales expuestas en párrafo aparte. }\end{array}$ \\
\hline Márgenes & Use márgenes de $2,54 \mathrm{~cm}$ en los cuatro costados del documento. \\
\hline $\begin{array}{l}\text { Encabezados de página } \\
\text { (cornisa superior para libros y revistas) }\end{array}$ & $\begin{array}{l}\text { Para informes, en todas las páginas a partir de la tabla de contenido, registre } \\
\text { como encabezado el título del informe. Use Calibri en } 10 \text { puntos, sin mayúsculas } \\
\text { sostenidas, justificado a la izquierda. } \\
\text { Para libros y revistas, la cornisa superior será definida en el proceso editorial. }\end{array}$ \\
\hline
\end{tabular}




\begin{tabular}{|c|c|}
\hline Elemento & Descripción \\
\hline $\begin{array}{l}\text { Pie de página y numeración de páginas } \\
\text { (cornisa inferior para libros y revistas) }\end{array}$ & $\begin{array}{l}\text { Para informes, en todas las páginas a partir de la tabla de contenido, incluya } \\
\text { como encabezado el texto "Servicio Geológico Colombiano". En caso de } \\
\text { informes en convenio, con igual participación de las entidades, registre los } \\
\text { nombres de las demás entidades. Use Calibri en } 10 \text { puntos, sin mayúsculas } \\
\text { sostenidas, justificado a la izquierda. } \\
\text { Incluya numeración de páginas en la esquina inferior derecha, en Calibri 10. En } \\
\text { informes, la numeración iniciará en } 1 \text {, pero solo será visible a partir de la página } \\
\text { en que se encuentre la tabla de contenido. } \\
\text { En libros y revistas, la cornisa inferior y la numeración definitiva y su estilo serán } \\
\text { establecidas en el proceso editorial. }\end{array}$ \\
\hline Alineación de párrafos & $\begin{array}{l}\text { Justificado (alineado por la izquierda y por la derecha). Para direcciones } \\
\text { URL extensas, no incluya saltos de página manuales. Los saltos incluidos } \\
\text { automáticamente por el procesador de palabras son permitidos. }\end{array}$ \\
\hline Página de título & $\begin{array}{l}\text { El título (en negritas), el título y las filiaciones deben centrarse en la página de } \\
\text { título. }\end{array}$ \\
\hline $\begin{array}{l}\text { Etiquetas de sección (por ejemplo, "Resumen", } \\
\text { "Referencias") }\end{array}$ & $\begin{array}{l}\text { Las etiquetas de sección deben estar centradas, en negritas y en tamaño de } 14 \\
\text { puntos. }\end{array}$ \\
\hline $\begin{array}{l}\text { Citación sugerida (que aparece en la portada o en } \\
\text { la página legal) }\end{array}$ & $\begin{array}{l}\text { No utilice ningún tipo de sangría para bloque de citación, alineado al margen } \\
\text { izquierdo. Si la cita abarca varias líneas, debe situarse de manera que se vea } \\
\text { como un bloque, como se ilustra en las figuras } 18,19,20,21,22 \text { y } 23 \text {. }\end{array}$ \\
\hline Títulos de nivel 1 & $\begin{array}{l}\text { Deben estar alineados a la izquierda, en negritas, con mayúscula únicamente la } \\
\text { primera letra. Use fuente en } 14 \text { puntos. Sangría francesa de } 1 \mathrm{~cm} \text {. }\end{array}$ \\
\hline Títulos de nivel $2,3,4$ y 5 ( 6 y 7 para informes) & $\begin{array}{l}\text { Deben estar alineados a la izquierda y en negritas. No se manejan sangrías. Use } \\
\text { fuente en } 11 \text { puntos. }\end{array}$ \\
\hline Tablas y figuras & $\begin{array}{l}\text { Números de tabla y figura (en negritas) y sus títulos (sin negritas) en tamaño } 10 \\
\text { puntos, justificados. } \\
\text { Las notas y los textos de "Fuente" deben estar justificados, y en tamaño } 10 \\
\text { puntos, sin negritas. } \\
\text { El texto interno de las tablas y figuras podrá estar entre tamaños de } 6 \text { a } 10 \\
\text { puntos. }\end{array}$ \\
\hline Referencias & $\begin{array}{l}\text { Las entradas de la lista de referencias deben tener una sangría francesa de } \\
0,85 \mathrm{~cm} \text { y con fuente en } 11 \text { puntos, sin negritas. }\end{array}$ \\
\hline Anexos & $\begin{array}{l}\text { Las etiquetas y títulos de los anexos deben estar centrados (y en negritas) con } \\
\text { tamaño en } 11 \text { puntos. El texto del contenido de los anexos estará en tamaño } \\
\text { de } 11 \text { puntos. Los elementos internos de los anexos deberán respetar los } \\
\text { lineamientos para los textos de los contenidos principales del documento. }\end{array}$ \\
\hline
\end{tabular}

\subsubsection{Formato de títulos y textos para las publicaciones}

La estructura de un escrito depende, en gran medida, de la distribución de títulos jerarquizados de forma conveniente y simple. En lo posible, evite las subdivisiones exageradas e innecesarias, pero mantenga una jerarquización que facilite el entendimiento y la comprensión global del texto.

Cada capítulo podrá identificarse con una numeración que sea consistente con el capítulo al que pertenece y el título o subtítulo correspondiente a su nivel o jerarquía. Según el tipo de libro, podrá trabajar números, letras u otras formas de identificación de títulos.

En general, utilice un máximo de cinco niveles de titulación, como se muestra en la tabla 14. 
Tabla 14. Descripción de los niveles de título para las publicaciones y ejemplo de aplicación

\begin{tabular}{|c|c|}
\hline Nivel & Formato \\
\hline Título general del trabajo & $\begin{array}{l}\text { Centrado, negritas, mayúscula solo en la primera letra del título y en los } \\
\text { sustantivos propios. No lleva punto final ni dos puntos. Tamaño de la tipografía: } \\
14 \text { puntos. }\end{array}$ \\
\hline Texto normal & $\begin{array}{l}\text { Justificado, sin negritas, mayúscula solo al principio de párrafos o en nombres } \\
\text { propios. Los párrafos terminan con punto. Tamaño de la tipografía: } 11 \text { puntos. }\end{array}$ \\
\hline Título nivel 1 & $\begin{array}{l}\text { Alineado a la izquierda, negritas, mayúscula en la inicial de la primera palabra y de } \\
\text { los sustantivos propios. No lleva punto final ni dos puntos. Tamaño de la tipografía: } \\
14 \text { puntos. El texto que no es parte del título inicia en un nuevo párrafo. }\end{array}$ \\
\hline Título nivel 2, 3, 4 y 5 & $\begin{array}{l}\text { Alineado a la izquierda, negritas, mayúscula en la inicial de la primera palabra } \\
\text { y de los sustantivos propios. No lleva punto final ni dos puntos. Tamaño de } \\
\text { la tipografía: } 11 \text { puntos. El texto que no es parte del título inicia en un nuevo } \\
\text { párrafo. Sangría francesa para nivel } 2 \text { de } 1,25 \mathrm{~cm} \text {; para nivel } 3 \text { de 1,75 cm; para } \\
\text { nivel } 4 \text {, de } 2,25 \mathrm{~cm} \text {; y para nivel } 5 \text {, de } 2,75 \mathrm{~cm} \text {. }\end{array}$ \\
\hline
\end{tabular}

Esta estructura se puede lograr con el procesador de palabras mediante herramientas que le permiten señalar el estilo del título y aplicarlo cada vez que así lo requiera. Para su facilidad, el SGC provee una plantilla para la jerarquización de títulos y otras funcionalidades complementarias. Se puede acceder a esta en el siguiente enlace:

\section{https://libros.sgc.gov.co/index.php/editorial/libraryFiles/downloadPublic/1}

La estructura de niveles se aplica de manera ordenada, por lo tanto, no es posible tener, por ejemplo, un título de nivel 3 sin que existan títulos de nivel 1 y 2 a los cuales pertenezca el mencionado título. En otras palabras, no se debe saltar ningún nivel cuando va de nivel bajo a un nivel alto.

En caso de que se requiera el uso de viñetas a diferentes grados de jerarquía, puede utilizar los niveles siguientes:

- Viñeta negra grande

Viñeta blanca

$\square$ Viñeta cuadrada

- Guion

En listas dentro de cuadros se prefieren los topos negros pequeños, como el siguiente:

- (No hay necesidad de reducir el tamaño de la fuente: esta viñeta aparece en la sección de viñetas del submenú de párrafo de Word).

Evite las viñetas en títulos o en párrafos. En este último caso es preferible jerarquizarlos con literales y numerales, manteniendo la sistematicidad de la elección y el modo de presentarlos en todo el documento.

En párrafos se prefiere el uso de numerales y de literales (letras minúsculas) como nivel subordinado.

Las reglas y la disposición del texto para las publicaciones pueden verse en la figura 12. 


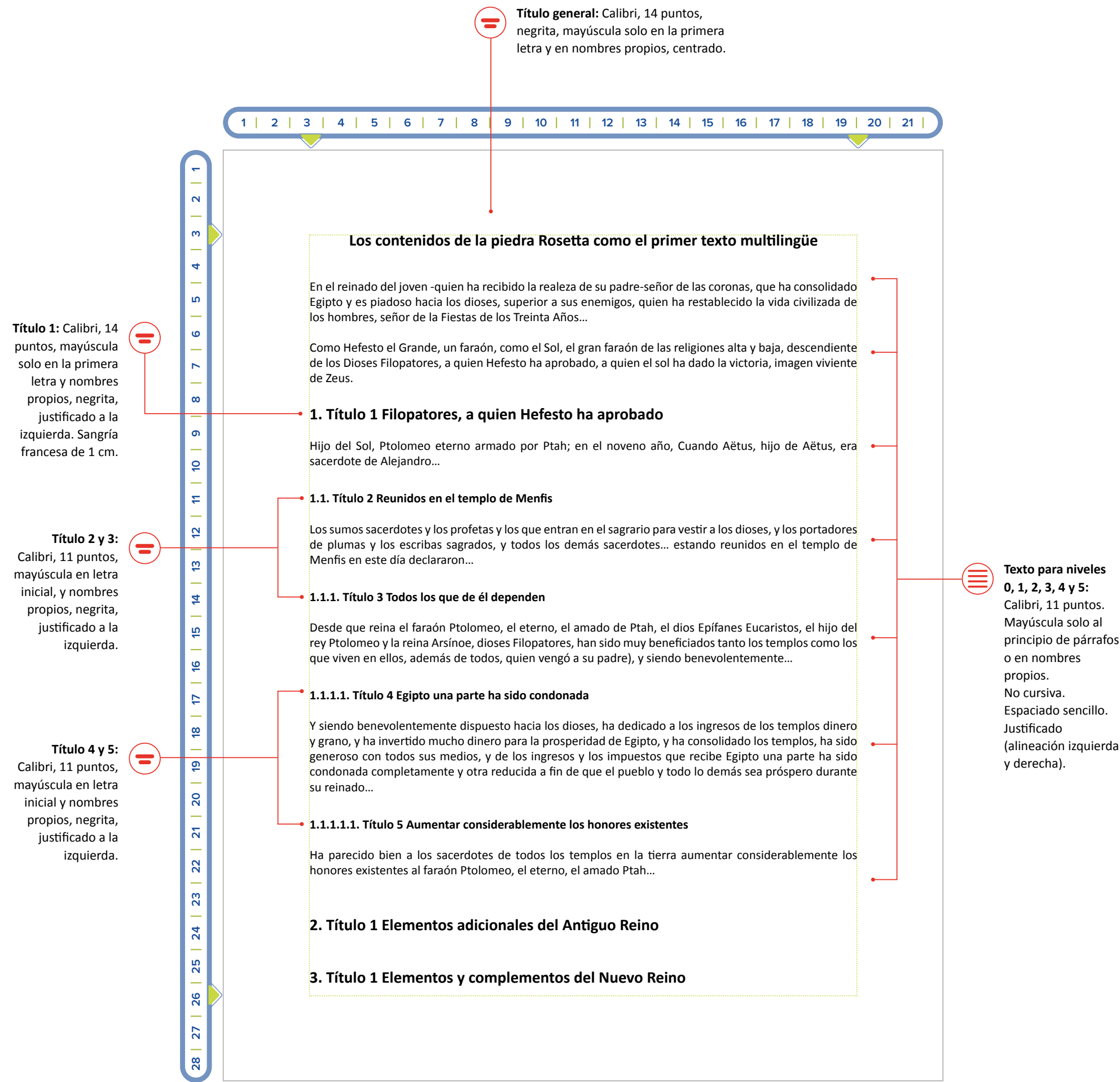

Figura 12. Disposición de la estructura de títulos y textos para las publicaciones 


\subsubsection{Jerarquía de títulos en los informes del SGC}

Algunos títulos que anteceden o que están después del cuerpo principal de un informe no requieren numeración como:

- Portada.

- Contraportada.

- Contenido.

- Resumen/Abstract.

- Índice de figuras, índice de tablas, índice de mapas e índice de anexos.

- Otros títulos que no son parte del cuerpo principal del informe.

Cada capítulo considerado cuerpo del informe deberá identificarse con una numeración que sea consistente con el capítulo al que pertenece y el título o subtítulo correspondiente a su nivel o jerarquía.

Los títulos considerados cuerpo del informe y que requieren numeración son los siguientes:

- Introducción.

- Capítulos con los contenidos técnicos.

- Conclusiones/Recomendaciones.

- Referencias.

En los informes que se presentan al SGC se utiliza la estructura que se muestra en la tabla 15.

La estructura de niveles se aplica de manera ordenada, por lo tanto, no es posible tener por ejemplo un título de nivel 3 sin que existan títulos de nivel 1 y 2 a los cuales pertenezca el mencionado título.

Tabla 15. Descripción de los niveles de títulos en informes preparados en el SGC

\begin{tabular}{|c|c|}
\hline Nivel & Formato \\
\hline Título general & $\begin{array}{l}\text { Centrado, negritas, mayúsculas solo en la primera letra o en sustantivos propios, } \\
\text { fuente Calibri en } 14 \text { puntos. Finaliza sin punto o dos puntos. }\end{array}$ \\
\hline Texto normal & $\begin{array}{l}\text { Justificado, sin negritas, mayúscula solo en la inicial de la primera palabra o en } \\
\text { sustantivos propios. Fuente Calibri en } 11 \text { puntos. Los párrafos terminan con } \\
\text { punto. El texto inicia en un nuevo párrafo. }\end{array}$ \\
\hline Título nivel 1 & $\begin{array}{l}\text { Título en mayúsculas solo en la primera letra o en sustantivos propios, negritas, } \\
\text { alineado a la izquierda, fuente Calibri en } 14 \text { puntos. El texto inicia en un nuevo } \\
\text { párrafo. La numeración tiene un punto al final. }\end{array}$ \\
\hline Título nivel $2,3,4,5,6$ y 7 & $\begin{array}{l}\text { Título en mayúscula solo en la primera letra o en sustantivos propios, negritas, } \\
\text { alineado a la izquierda, fuente Calibri tamaño } 11 \text {. Los párrafos van separados por } \\
\text { un renglón en blanco. La numeración tiene un punto al final. Sangría francesa } \\
\text { para nivel } 2 \text { de } 1,25 \mathrm{~cm} \text {; para nivel } 3 \text { de } 1,75 \mathrm{~cm} \text {; para nivel } 4 \text {, de } 2,25 \mathrm{~cm} \text {; para } \\
\text { nivel } 5 \text {, de } 2,75 \mathrm{~cm} \text {; para nivel } 6 \text { de } 0 \text {; y para nivel } 7 \text {, de } 0 .\end{array}$ \\
\hline
\end{tabular}

Las reglas y la disposición para las publicaciones se ilustran en la figura 13. 


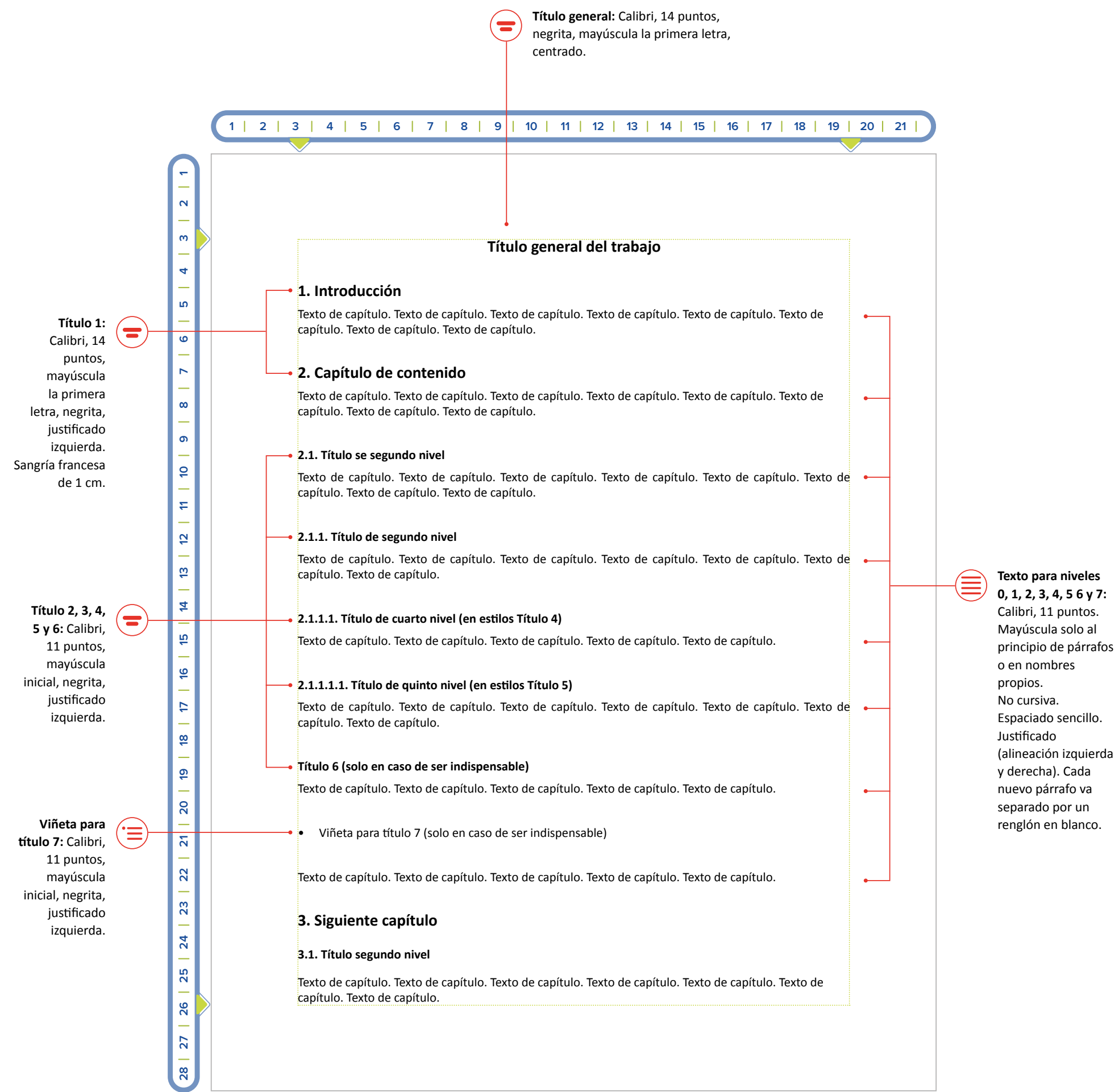

Figura 13. Disposición de la estructura de títulos y textos en los informes del SGC 


\subsection{Uso de algunos elementos clave en la escritura}

En esta parte se repasan algunos elementos clave, frecuentes en la elaboración de textos, en los que se presentan algunos errores. El objetivo es evitarlos para que el proceso de corrección de estilo sea más expedito.

\subsubsection{Tildes diacríticas}

En los casos en que la RAE acepte dos posibilidades de acentuación (con tilde o sin tilde), se prefiere el uso sin tilde en los siguientes ejemplos:

periodo en vez de período

guion, en vez de guión

cardiaco, en vez de cardíaco

Se exceptúa la palabra élite, que es más natural para los hablantes del entorno académico colombiano (Beltrán, 2017, p. 395).

Por otra parte, los demostrativos este, ese y aquel con sus variantes de género y número y el adverbio solo no se tildarán, salvo que existan ambigüedades que no puedan resolverse por su contexto.

\subsubsection{Uso de comillas}

Las comillas dobles (" ") se utilizan para los siguientes casos:

- En citas textuales que no superan las cuarenta palabras.

- Indicar el sentido irónico, impropio o especial a un vocablo o expresión. El sentido especial se refiere a una acepción no aceptada por la RAE, pero que es un tecnicismo o palabra propia de la temática del trabajo.

Conviene aclarar que el texto dentro de las comillas tiene puntuación independiente y lleva sus propios signos ortográficos, por tanto, cuando hay signos de interrogación o de exclamación, estos se escriben dentro de las comillas.

Las comillas sencillas (" ') se usan como un segundo nivel de entrecomillado. Por ejemplo: "Según lo dijo Maquiavelo 'El que menos ha confiado en el azar es siempre el que más tiempo se ha conservado en su conquista', es mejor no confiarse en el destino".

Cuando se requieren tres niveles de entrecomillado puede utilizarse los comillones o comillas latinas («»), los cuales pueden reproducirse usando $A / t+0171$ y $A / t+0187$, respectivamente. 


\subsubsection{Uso de los corchetes}

El signo rectangular [ ] se usa para exponer comentarios, observaciones o aclaraciones que el autor del documento incluye. Rara vez pueden aparecer como aclaraciones anidadas en anotaciones encerradas entre paréntesis. Los corchetes también pueden ser usados para agrupar elementos en una ecuación (véase la sección 5.16.).

Por otra parte, la RAE también los recomienda, por encima de los paréntesis, cuando se suprime un fragmento: [...].

Ejemplo 1: uso de corchetes aclarando una cita

Como lo menciona Gosens (2019), el mejor [y el único] ejemplo de secuencias de muestreo en la zona está en la región de Pedregal.

\subsubsection{Uso de los paréntesis}

Los paréntesis ( ) se usan para incluir en el texto un contenido que aclare las ideas expresadas, o información complementaria que se considera necesaria (RAE, 2020c).

Se debe tener en cuenta que el texto incluido entre paréntesis es independiente del texto principal; por tanto, puede tener signos de puntuación y su contenido no afecta en nada la construcción ni la puntuación de la oración en la que se incrusta. Si se ve la necesidad de incluir un signo de puntuación en las inmediaciones de la nota encerrada entre paréntesis, este irá después del paréntesis de cierre, no antes del de apertura.

Los paréntesis también pueden ser usados para agrupar elementos en una ecuación (véase la sección 5.16.).

Ejemplo 2: uso de paréntesis en una aclaración

Es conveniente indicar que los datos disponibles no son adecuados para una buena interpretación del tema (no hay suficiente certidumbre sobre su verosimilitud, exactitud y procedencia, así que no se tomarán en cuenta).

\subsubsection{Uso de cursivas}

De acuerdo con Fundéu BBVA (2017), las cursivas deben usarse en los siguientes casos:

- Cuando se haga uso de palabras, frases o abreviaturas en otros idiomas (incluido el latín) que no figuren en el diccionario español. Se exceptúan nombres propios de personas o lugares, de empresas o instituciones, de software, marcas y acrónimos.

- Cuando se usen letras como símbolos estadísticos o variables algebraicas. 
- Cuando se citen títulos de escritos, como títulos de publicaciones seriadas o libros (pero no irá en cursiva la coma que sigue a esos títulos).

- Significados de una escala estandarizada (pero no el número asociado).

- En casos de usos metalingüísticos, es decir, cuando con un término, una expresión o un enunciado no se pretende comunicar lo que ellos significan, sino decir algo sobre ellos.

Cuando las palabras que normalmente estarían en cursiva aparecen en un texto que ya está en cursiva, esas palabras deben tratarse en redonda (se le llama así al estilo de fuente estándar).

No deben usarse cursivas para citas textuales ni en nombres propios. Conviene aclarar que las cursivas y las comillas usadas a la vez son redundantes.

Ejemplo 3: uso de cursiva en los textos

En frases o abreviaturas de otro idioma que no estén en el diccionario español (Fundéu RAE, 2020): Una descripción completa de la zona puede verse en Manrique et al. (2018).

En expresiones algebraicas: La ecuación de Einstein $e=m c^{2}$ revolucionó el entendimiento del universo.

En extranjerismos: Los estudios de strong motion en Colombia se intensificaron con la Red Nacional de Acelerógrafos y la Red Sismológica Nacional de Colombia.

En títulos de libros: En el libro Albert Einstein y el $e=m c^{2}$ mágico se muestra una buena aproximación a la historia de la ciencia en el siglo XX.

En rangos estandarizados: Para entender los resultados del análisis, se clasificaron, por su verosimilitud, así: 40 \% (insuficiente), 70 \% (aceptable) y 80 \% o superior (adecuado).

En usos metalingüísticos: A esa unidad se le dio el nombre de Batolito de Sabanalarga. La expresión falla geológica hace referencia a una fractura de la corteza terrestre acompañada de deslizamiento de uno de los bordes.

\subsubsection{Uso de negritas}

El uso de negritas debe limitarse a títulos, algunas fórmulas, ecuaciones (véase la sección 5.16.) y datos relevantes en tablas o figuras. Deben evitarse para resaltar conceptos o expresiones destacadas dentro del texto.

Úselas para todos los encabezados de columnas en tablas y para las palabras Tabla y Figura en los títulos de estos elementos y su correspondiente número, pero no para el título correspondiente.

\subsubsection{Uso de mayúsculas y minúsculas}

El uso de mayúsculas y minúsculas ha sido adaptado y completado a partir de las recomendaciones de Fundéu BBVA (2016). El uso de mayúsculas sostenidas debe restringirse únicamente a los casos descritos en la tabla 16, siempre con su debida acentuación. 
Tabla 16. Uso de mayúsculas y minúsculas

\begin{tabular}{lcl}
\hline \multicolumn{2}{c}{ Casos en los que se deben usar mayúsculas sostenidas } \\
\hline Descripción del caso & Ejemplos \\
\hline
\end{tabular}

Siglas

Palabra formada por las iniciales de los términos que integran una expresión compleja de hasta cuatro letras. Solo se excusan más letras en caso de que el término no pueda pronunciarse como una palabra, sino que obligue al deletreo.

Con respecto a las siglas, estas se hicieron para abreviar expresiones largas, no para alargarlas más todavía. Por ello, si se usan junto con la expresión que les da origen, conviene hacerlo una vez, y, en adelante, utilizar la expresión desarrollada o únicamente la sigla, pero no las dos. Contrario de lo que suele creerse, la sigla no forma parte del nombre de una entidad, sino que es una forma abreviada de mencionarla. Las siglas no deben llevar puntos.

\section{Símbolos de los puntos cardinales}

Nota: no obstante, la palabra completa se escribe en minúscula: norte, E, S, W, N, W, NE, SW

sur, este, oeste, occidente, oriente, noreste, suroeste

\section{Números romanos}

Por ejemplo, cuando se hace referencia a un siglo o al número o edición siglo XXI, IV Congreso de Mineralogía

de un certamen

Títulos de documentos o libros, o títulos de capítulos

(Según las instrucciones específicas del editor en una publicación.

Cuando se trata de la mera mención de esos títulos en un texto no se debe usar mayúsculas sostenidas)

Textos de carácter informativo

ANH, SGC, OPEP, RAE, ISBN, DOI

TÍTULO DE LIBRO SEGÚN INSTRUCCIÓN DEL EDITOR ESTERILIZACIÓN
Casos en los que se debe usar mayúscula inicial

\section{Descripción del caso}

\section{Nombres propios de personas e instituciones}

Topónimos o nombres de lugares, accidentes geográficos naturales o artificiales, espacios naturales protegidos, divisiones territoriales de carácter administrativo (en todos estos casos, la denominación genérica que suele acompañarlos se escribe en minúscula)

\section{Nombres geográficos y ecorregiones}

Áreas geopolíticas

Nota: los puntos cardinales se escriben con minúscula, salvo que formen parte del nombre de un área geopolítica.

Marcas, nombres de software y programas

Siglas de más de cuatro letras y acrónimos

(términos formados por fragmentos de un nombre, que se pueden leer como palabras).

Notas:

1) Expresiones comunes que dan lugar a siglas se escriben con minúscula.

2) Si la palabra resultante lo exige, debe tildarse.

3) Los ministerios de Colombia usan una mayúscula intermedia en el acrónimo.

\section{Periodos geológicos y paleontológicos}

Notas:

1) Llevan mayúscula los adjetivos que pueden acompañarlos, de acuerdo con la Tabla Cronoestratigráfica Internacional (Cohen et al., 2013).

2) Si el periodo geológico se expone como un adjetivo que acompaña a un sustantivo genérico, ambos términos irán en minúscula.

\section{Costas}

Se escriben con mayúscula inicial, incluso en el genérico.

Títulos de artículos o informes

Solo lleva mayúscula la inicial de la primera palabra
PROHIBIDO ENTRAR SIN REALIZAR EL PROCESO DE

\section{Ejemplos}

Rodrigo Rivera, Procuraduría General de la República. cañón del Chicamocha, cordillera de los Andes, océano Pacífico, selva del Amazonas, río Magdalena, embalse de Betania, parque nacional natural Chiribiquete, santuario de fauna y flora Malpelo, sabana de Bogotá, municipio de Gramalote, departamento de Bolívar, Magdalena medio América, Colombia, Amazonas, Orinoquia, Patagonia.

América Latina, América Central, Hispanoamérica, Europa del Este, Oriente Medio, Cono Sur, Occidente.

Apple, Windows, Word

Ingeominas, Unicef, Ecopetrol, Minminas, Corantioquia. índice de precios al consumidor (IPC), producto interno bruto (PIB), impuesto al valor agregado (IVA). Bancóldex, Fundéu.

MinMinas, MinCultura, MinVivienda, MinTransporte

Precámbrico, Mioceno, Jurásico, Paleozoico

Jurásico Superior, Mioceno Medio, Cretácico Inferior era cenozoica, era cuaternaria, periodo carbonífero.

Costa Azul, Costa Brava, Costa Atlántica

En el artículo "Sedimentación cíclica en el geosinclinal cretáceo de la cordillera Oriental de Colombia" ya se detallaban varios hallazgos relevantes. 


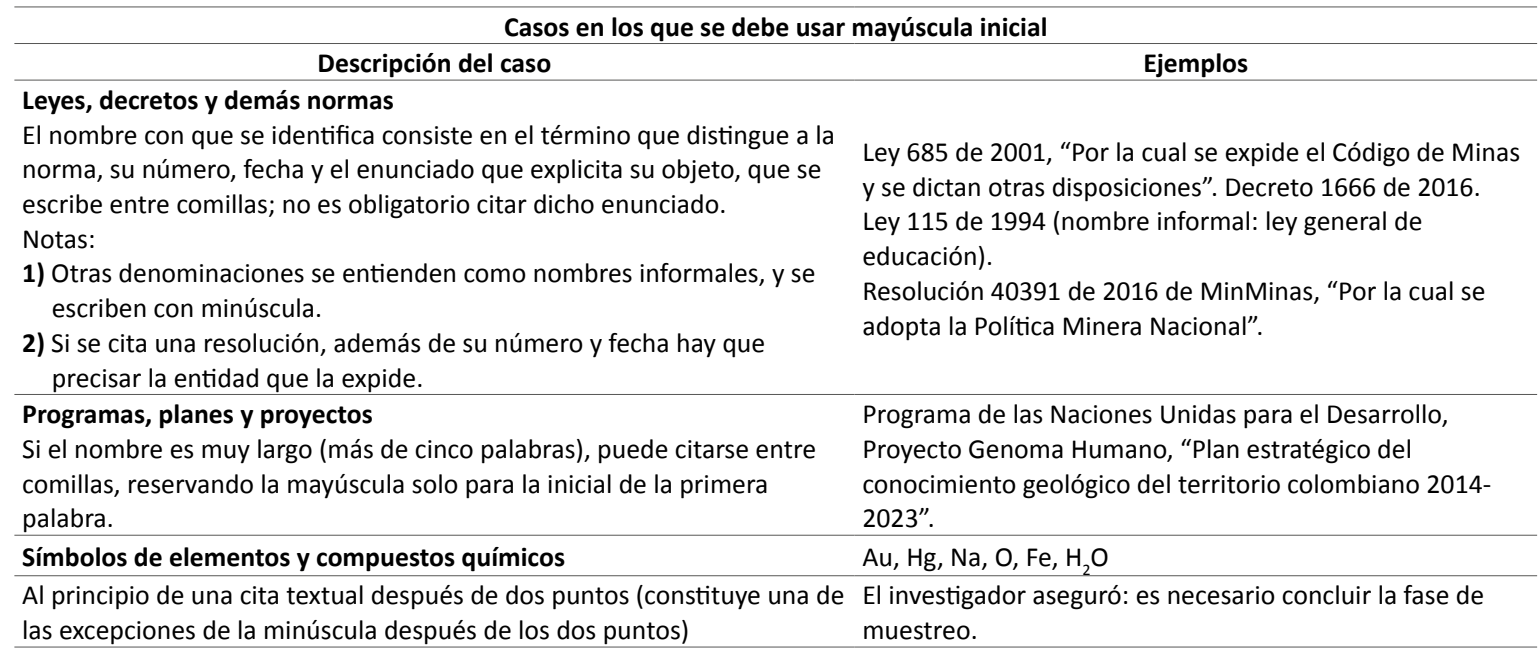

Sobre las mayúsculas en los nombres de unidades geológicas

Para la denominación de las unidades geológicas se recomienda el uso de los criterios del North American Commission on Stratigraphic Nomenclature (NACSN, 2005), un documento regulatorio de carácter regional para la nomenclatura estratigráfica de Estados Unidos, Canadá y México, cuyo uso también se ha adoptado en Colombia.

Según los trabajos de la Comisión Norteamericana de Nomenclatura Estratigráfica (2010), se escriben con mayúscula las primeras letras de todas las palabras de los nombres de las unidades geológicas formales (excepto los términos que aluden a las especies triviales y las subespecies del nombre de una unidad bioestratigráfica). Por otra parte, las unidades geológicas informales se designan mediante sustantivos, adjetivos, nombres geográficos y nombres litológicos o de unidades escritos sin mayúscula inicial (por ejemplo, formaciones o estratos calcáreos, carbón, etc.). Estas consideraciones pueden observarse en la tabla 17.

Tabla 17. Consideraciones temáticas para el uso de mayúsculas y minúsculas

\begin{tabular}{ccc}
\hline Casos de uso de mayúsculas en los nombres de unidades geológicas \\
\hline Descripción del caso & Ejemplos \\
\hline
\end{tabular}

\section{Unidades geológicas formales}

En las unidades que han sido reconocidas por la autoridad geológica competente se deben usar mayúsculas en la primera letra de todas las palabras significativas del nombre de la unidad.

Hay que tener presente que, según las reglas ortográficas del español, las palabras que llevan mayúscula sin ser nombres propios la pierden si de ellas se hace referencia en plural, de modo genérico o en menciones anafóricas.

Por ejemplo, si se habla de las formaciones Lodolitas de Aguacaliente y Arenitas de San Luis de Gaceno, el plural obliga a tratar en minúscula el término que especifica la unidad estratigráfica. En un enunciado como el siguiente se tendría una mención genérica, que también obliga al uso de minúsculas: Una formación como las que se presentan en Latinoamérica merece especial atención. Las menciones anafóricas se caracterizan por no estar introducidas por los artículos el o la, sino por artículos indeterminados como un o una; demostrativos como esta, esa, este, ese; expresiones como el susodicho, la mencionada, dicho, etc. Pese a que pueda estarse haciendo referencia a un elemento específico y perfectamente reconocible, el carácter anafórico de la mención obliga al uso de la minúscula: La mencionada formación tiene un origen indeterminado (RAE, 2010).
El Grupo Guadalupe del piedemonte llanero se divide en tres unidades litoestratigráficas que de base a tope se denominan Formación Arenitas de San Antonio, Formación Lodolitas de Aguacaliente y Formación Arenitas de San Luis de Gaceno. Se analizaron catorce secciones delgadas del Granito de Pescadero. 


\begin{tabular}{ll}
\hline \multicolumn{1}{c}{ Casos de uso de mayúsculas en los nombres de unidades geológicas } \\
\hline \multicolumn{1}{c}{ Descripción del caso } & \multicolumn{1}{c}{ Ejemplos } \\
\hline $\begin{array}{l}\text { Unidades geológicas informales } \\
\text { No se usan mayúsculas en la designación de las unidades informales o no reconocidas } \\
\text { por una autoridad geológica competente. Se designan por sustantivos, adjetivos, } \\
\text { nombres geográficos y nombres litológicos o de unidades escritos sin mayúscula } \\
\text { inicial. Solo van en mayúscula los nombres propios }\end{array}$ & $\begin{array}{l}\text { La llamada arenisca del Neme es una } \\
\text { unidad informal... Por otra parte, otra nueva } \\
\text { estructura es reconocida informalmente } \\
\text { como arenisca La Guía }\end{array}$ \\
\hline
\end{tabular}

Otros casos adicionales del uso de mayúsculas y minúsculas se pueden ver en la tabla 18.

Tabla 18. Otros casos de uso de mayúsculas y minúsculas

\begin{tabular}{ll}
\hline \multicolumn{1}{c}{ Casos en los que se debe usar mayúscula en todas las palabras significativas } \\
\hline \multicolumn{1}{c}{ Descrión del caso } & \multicolumn{1}{c}{ Ejemplos } \\
\hline Nombres de documentos oficiales & Constitución Política de Colombia, Código de Minas \\
\hline Nombres de revistas y otras publicaciones periódicas & $\begin{array}{l}\text { Revista Investigaciones y Aplicaciones Nucleares } \\
\text { Boletín Geológico }\end{array}$ \\
\hline \multicolumn{1}{c}{ Casos en los que se debe usar minúsculas } \\
\hline Cargos, títulos, profesiones (Fundéu BBVA, 2016) & Eresidente, director, investigador, coordinadora, jefe, químico, \\
& ingeniero, geóloga, médica \\
\hline Denominaciones genéricas de accidentes geográficos & $\begin{array}{l}\text { volcán, cordillera, serranía, sierra, formación (cuando no es parte } \\
\text { del nombre de una unidad formalmente reconocida), río, mar, } \\
\text { isla, valle, macizo, océano, falla } \\
\text { La falla de Altamira dio origen a un terremoto en 1827 }\end{array}$ \\
\hline Gentilicios & colombiano, boyacense \\
\hline Secciones de cuencas hidrográficas & superior, alto, medio, bajo \\
& valle medio del Magdalena, alto Orinoco, bajo Cauca \\
\hline Meses y días de la semana & enero, abril, diciembre, lunes, miércoles \\
\hline Enfermedades & covid 19, paludismo \\
\hline Puntos cardinales & este, oeste, norte, sur \\
\hline Índices & ... el DANE calcula mensualmente el índice de precios al \\
\end{tabular}

\subsubsection{Uso de signos de puntuación en las enumeraciones}

Las enumeraciones suelen tener algún tipo de introducción. Los elementos de la lista deben tener una forma gramatical coherente y no se deben mezclar oraciones completas con partes de oraciones. Cuando la introducción no es una oración completa, los elementos deben darle continuidad sintáctica.

En el siguiente ejemplo de enumeración seguida de dos puntos, los tres primeros elementos son correctos, pero el cuarto y el quinto no lo son, dado que no tienen continuidad sintáctica.

Los elementos fundamentales para localizar un sismo son:

- La ubicación de un grupo de estaciones alrededor de la zona de estudio

- Las lecturas de tiempos de llegada de ondas P y S

- El uso de un algoritmo que localice el punto más probable de ocurrencia 
× Es importante tener en cuenta la calibración de los tiempos de arribo

- El resultado depende de la calidad del dato

Las enumeraciones pueden estar integradas en el párrafo, sin separación visual del resto del texto. Cuando en estas listas se anticipa el contenido de lo que se enumera, se escriben dos puntos. Si no se anticipa, la enumeración no va precedida de dos puntos, como se observa a continuación:

Escribimos la introducción, el método y los resultados.

Escribimos tres partes principales: la introducción, el método y los resultados.

Revisamos los datos de Nariño, Cauca y Putumayo.

Revisamos los datos de tres departamentos: Nariño, Cauca y Putumayo.

Los elementos se separan con coma, salvo el último, si está unido con una conjunción como y u o. Si son complejos o tienen a su vez comas u otras conjunciones, se separan con punto y coma, salvo el último, si está unido con una conjunción como y u $o$, que se separa preferiblemente con coma (aunque se admite también el punto y coma).

En la siguiente enumeración, se admite tener una conjunción antes de la última entrada y una separación con punto y coma en cada caso:

Cuatro frases famosas de Albert Einstein son las siguientes:

- Cada día sabemos más y entendemos menos;

- el mundo no está en peligro por las malas personas sino por aquellas que permiten la maldad;

- hay dos cosas que son infinitas: el universo y la estupidez humana; de la primera no estoy muy seguro; $y$

- una velada en que todos los presentes estén absolutamente de acuerdo es una velada perdida.

\subsubsection{Particularidades sobre algunos signos y símbolos}

\subsubsection{Los guiones}

De acuerdo con Fundéu RAE (2020) hay tres signos que habitualmente se perciben como guiones, y que se suelen denominar guion corto, guion mediano y guion largo, si bien se trata del guion propiamente dicho (-), del signo menos (-) y de la raya (-), llamándolos por sus nombres reales.

En realidad, estos son signos diferentes con usos distintos: el guion es una cuarta parte más pequeño que la raya, y el signo menos es la mitad de largo que la raya.

En la tabla 19 se ilustra la apariencia, la forma de escribirlos en Word y su función. 
Tabla 19. Resumen sobre la forma de escribir y la función de tres tipos de guiones

\begin{tabular}{|c|c|c|c|}
\hline Nombre & Presentación & Forma de escribirlo en Word & Funciones \\
\hline El guion & - & $\begin{array}{l}\text { Presionar la respectiva } \\
\text { tecla (-). }\end{array}$ & $\begin{array}{l}\text { Dentro de una palabra, separar; entre dos palabras, unir. En } \\
\text { ambos casos, no hay espacio de separación entre los elementos } \\
\text { separados o unidos. } \\
\text { Uniendo, se utiliza para formar palabras compuestas (dos } \\
\text { palabras que funcionan como una sola): en el caso de dos } \\
\text { adjetivos que se aplican a un nombre, se aplica siempre que } \\
\text { cada uno de ellos conserve su forma plena: técnico-científico } \\
\text { [lección] teórico-práctica. En estos casos, el primer adjetivo } \\
\text { permanece invariable en forma masculina singular, mientras que } \\
\text { el segundo concuerda en género y número con el sustantivo al } \\
\text { que se refiere. Otros ejemplos son costo-beneficio, separación } \\
\text { lglesia-Estado. También sirve para unir varios gentilicios } \\
\text { (frontera colombo-venezolana, convenio franco-hispano- } \\
\text { canadiense). } \\
\text { Del mismo modo, se utiliza para unir apellidos compuestos } \\
\text { (cuando alguien adopta los dos apellidos de uno de sus } \\
\text { progenitores), como en Ana Gómez Sanín-Cano. Algunos } \\
\text { sistemas de referenciación, como el Vancouver, exigen unir los } \\
\text { dos apellidos de un autor con un guion. Hay que tener en cuenta } \\
\text { que en las normas APA ese requisito no existe, y que separar con } \\
\text { un guion dos apellidos en español es una práctica que tiende } \\
\text { a interpretarse como un caso de apellido compuesto, lo que } \\
\text { implica que se estaría alterando el nombre de una persona. } \\
\text { En su función de separación, el guion se utiliza para dividir una } \\
\text { palabra en sílabas (hi-po-té-ti-co) o para cortar una palabra al } \\
\text { final de renglón, atendiendo a su división silábica. } \\
\text { En gramática, se utiliza para señalar la posición de un prefijo } \\
\text { o sufijo (sub- es un prefijo que afecta a sustantivos, y la } \\
\text { terminación -mente es un sufijo para formar adverbios). Este } \\
\text { temelevante, etc. }\end{array}$ \\
\hline
\end{tabular}

Comando Ctrl + - (el último

El signo menos signo en el teclado numérico) o, en cualquier programa, con el comando $A / t+0150$.
Solo se usa en la operación de resta (en este caso, como pasa con el resto de los operadores matemáticos, le antecede y le sigue un espacio) o para enunciar cantidades negativas (en este caso va unido al número).

Nunca debe representarse el signo menos con un guion corto ni una raya con el signo menos.

Se utiliza con las mismas funciones de los paréntesis, o sea, para enmarcar un comentario incidental, por lo cual, es un signo doble: debe haber una raya de apertura y otra de cierre, y ambas deben ser el mismo signo (una aclaración o inciso no puede abrirse con raya y cerrarse con signo menos o con guion). Así pues - como puede observarse en esta misma frase-, las rayas van unidas, la primera a la palabra que le sigue, y la última, a la palabra que le precede. Las rayas también se usan en textos literarios para indicar el inicio del parlamento de un personaje.

\section{La forma de reproducir estos y otros símbolos mediante comandos se aborda en el capítulo 11.}




\section{Errores comunes en el uso del guion}

A continuación, se enuncian los errores más comunes en relación con los guiones:

- Usarlo como signo menos o como raya. (Erróneo: -743, -743. Correcto: -743).

- Utilizarlo para reemplazar algún signo de puntuación, como el punto, la coma, los dos puntos o el punto y coma. (Erróneo: Se extiende por tres departamentos - Cundinamarca - Boyacá - Santander; correcto: Se extiende por tres departamentos: Cundinamarca, Boyacá y Santander).

- Separar con guion el nombre de una entidad de su sigla o acrónimo. Cuando se quiera aclarar que determinada sigla corresponde al nombre de una entidad, debe escribirse entre paréntesis. Incorrecto: El Servicio Geológico Colombiano-SGC es una entidad pública; correcto: El Servicio Geológico Colombiano (SGC) es una entidad pública.

\subsubsection{Signo et (\&) (en inglés, ampersand)}

El signo \& que proviene de la palabra et es un término latino que en ese idioma hacía las veces de la conjunción y. En la escritura del latín, dicha palabra experimentó una evolución que culminó en la forma de este signo. En inglés se adoptó para abreviar la palabra and escribiéndola con un solo signo. En español, la conjunción y no se puede abreviar, en vista de que es una palabra que consiste en una única letra y es más fácil de producir en el teclado. Por eso, resulta innecesario ese reemplazo, más teniendo en cuenta que la palabra y en español no es intercambiable por ningún signo, así que no solo es un calco del inglés, sino, además, un error ortográfico hacer pasar \& por y. Como recurso gráfico (por ejemplo, en marcas) puede ser correcto, pero en texto corrido su uso es desaconsejable (como, por otra parte, lo es incluso en inglés) (Fundéu RAE, 2020).

En algunos estándares de citación suele pedirse que, en las referencias bibliográficas, si varios autores participan conjuntamente en la escritura de algún texto, los apellidos de los dos últimos aparezcan unidos con el signo et. Hay que tener en cuenta que el espíritu que mueve a tomar esa determinación es el deseo de abreviar las referencias, y, además, que dichas normas originalmente se han escrito en inglés, idioma en el que el reemplazo de la conjunción copulativa and por \& es aceptado y tiene sentido. Pero en el idioma español no solo no tiene sentido, sino que es ortográficamente incorrecto. Por lo anterior, existen plantillas para los gestores de referencias que reemplazan adecuadamente el símbolo \& por la letra y (véanse las secciones 8.2. y 8.3.).

\subsubsection{El signo de porcentaje (\%)}

Se usa para sustituir la expresión "por ciento", que, si se escribiera junto a un número, iría separada de este por un espacio fino. Igual que ocurre con las unidades de medida, este signo también debe escribirse separado por un espacio de las cifras a las que acompaña, según la decisión adoptada por la Oficina Internacional de Pesos y Medidas. No obstante, quienes no están habituados a esa separación pueden 
hacerla mediante un espacio fino ( $A / t+08201$ en el teclado completo en su parte numérica) o incluso por un espacio superfino $(A / t+08202)$.

\subsubsection{Signo de pesos (\$)}

Contrario al caso del signo de porcentaje, no va separado de los números a los que antecede $(\$ 4576)$.

Cada moneda del mundo se puede representar mediante un símbolo alfabetizable (USD por dólar estadounidense, CAD por dólar canadiense, EUR por euro, JPY por yen japonés, COP por peso colombiano, etc.). Cuando se opta por ese símbolo, se omite la escritura del signo $\$$, pues resulta redundante la confluencia de las dos formas de aludir a una moneda. Por ejemplo, para dólares de Estados Unidos puede escribirse 4676 USD.

\subsubsection{Símbolos alfabetizables}

Como en el caso de las monedas, se trata de agrupaciones de letras que reemplazan una palabra. Prácticamente todas las unidades de medida, y también los elementos químicos, se representan mediante símbolos alfabetizables.

En cuanto a los símbolos, se diferencian de las abreviaturas en tres particularidades: no llevan punto final, son invariables - no se pluralizan agregándoles una ese- y son inmodificables, así que en ellos el uso de las mayúsculas y minúsculas es estable, por lo que incluso pueden comenzar un párrafo con minúscula. La modificación caprichosa de mayúsculas o minúsculas o de agre-

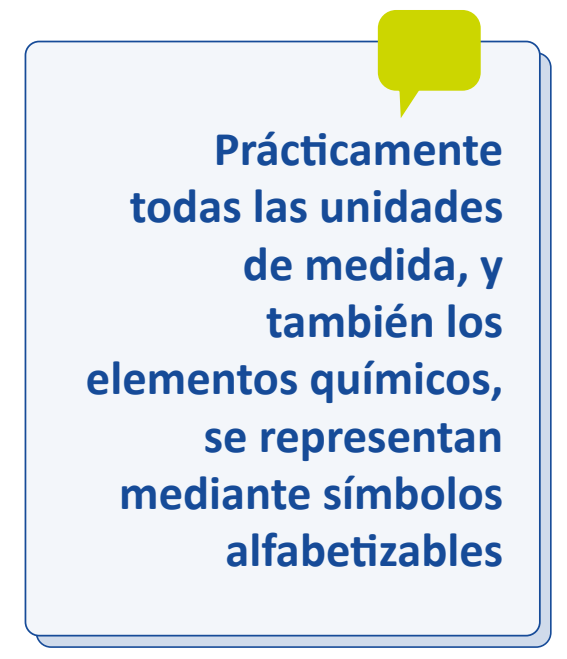

gar o quitar letras puede dar lugar al intercambio de símbolos. Por ejemplo, ac es el símbolo de acre, y $A c$ es el símbolo del actinio; $b$ es símbolo de bit, y $B$ es el símbolo del boro; $c d$ es el símbolo de candela, y $C d$ es el símbolo del cadmio; $\mathrm{cm}$ es el símbolo de centímetro, y $\mathrm{Cm}$ es el símbolo del curio; $h$ es el símbolo de hora, y $\mathrm{H}$ es el símbolo del hidrógeno; $m$ es el símbolo de metro, y $\mathrm{M}$ es el símbolo de milla náutica; $m g$ es el símbolo de miligramo y $\mathrm{Mg}$ es el símbolo del magnesio; $t$ es el símbolo de tonelada, y $T$ es el símbolo de tesla.

Por tanto, es erróneo escribir Cms o cms o cents. por centímetros; la única forma válida es $\mathrm{cm}$. Es erróneo escribir Mts o $m t s$ por metros: la única forma válida es $m$. Es erróneo escribir Tons o $T$ por tonelada; la única forma válida es $t$, sin importar que se trate de un número plural de toneladas.

\subsubsection{Apóstrofo (no apóstrofe) (')}

No se marca con una tilde ('), sino con una comilla sencilla ('), ubicada, en el teclado, al lado derecho del cero. 
Básicamente se utiliza para poner en evidencia que alguna letra o sílaba de una palabra se ha eliminado en la pronunciación (Venga pa'cá).

Jamás se lo utiliza para formar un plural con el agregado de la letra ese después del apóstrofo. Así pues, las siguientes expresiones son erróneas:

- En el '91 se aprobó la nueva Constitución de Colombia;

- en los '40's del siglo pasado se desató la violencia que aún vivimos;

- ONG's, DVD's, URL's, etc.

Respecto al último caso, cabe aclarar que las siglas son invariables: no admiten modificación para formar el plural, aunque en el lenguaje oral es común mencionarlas en plural.

\subsubsection{Distintos tipos de espacio}

Como se ha mencionado en otros apartes, además del espacio normal existen el espacio fino (en el teclado completo en su parte numérica: $A / t+08201$ ) y el espacio superfino ( $A / t+08202)$, a los que se sumaría el espacio duro (Ctrl + May + espacio), con igual grado de separación que un espacio normal.

Estos espacios corresponden a espacios duros, expresión que alude a aquellos que, a pesar de separar dos elementos, los mantiene vinculados como si se tratara de un elemento irrompible. Así pues, si la expresión unida por un espacio duro se encuentra en el límite derecho de un renglón, los dos elementos que la conforman pasarán al siguiente renglón.

Esta cualidad es especialmente útil cuando se escriben símbolos alfabetizables, o unidades de medida, o signos como el de porcentaje o siglas plurales conformadas por parejas de letras repetidas, o números de muchas cifras separadas con espacio fino, pues mantiene siempre vinculados en un solo renglón los elementos separados con uno de esos espacios, por lo que se aconseja su uso en dichos casos.

La generación de estos espacios se simplifica mediante las funcionalidades de la plantilla del SGC que se aborda en el capítulo 11. 
5.

Estándares para

la construcción de

los elementos de las

publicaciones
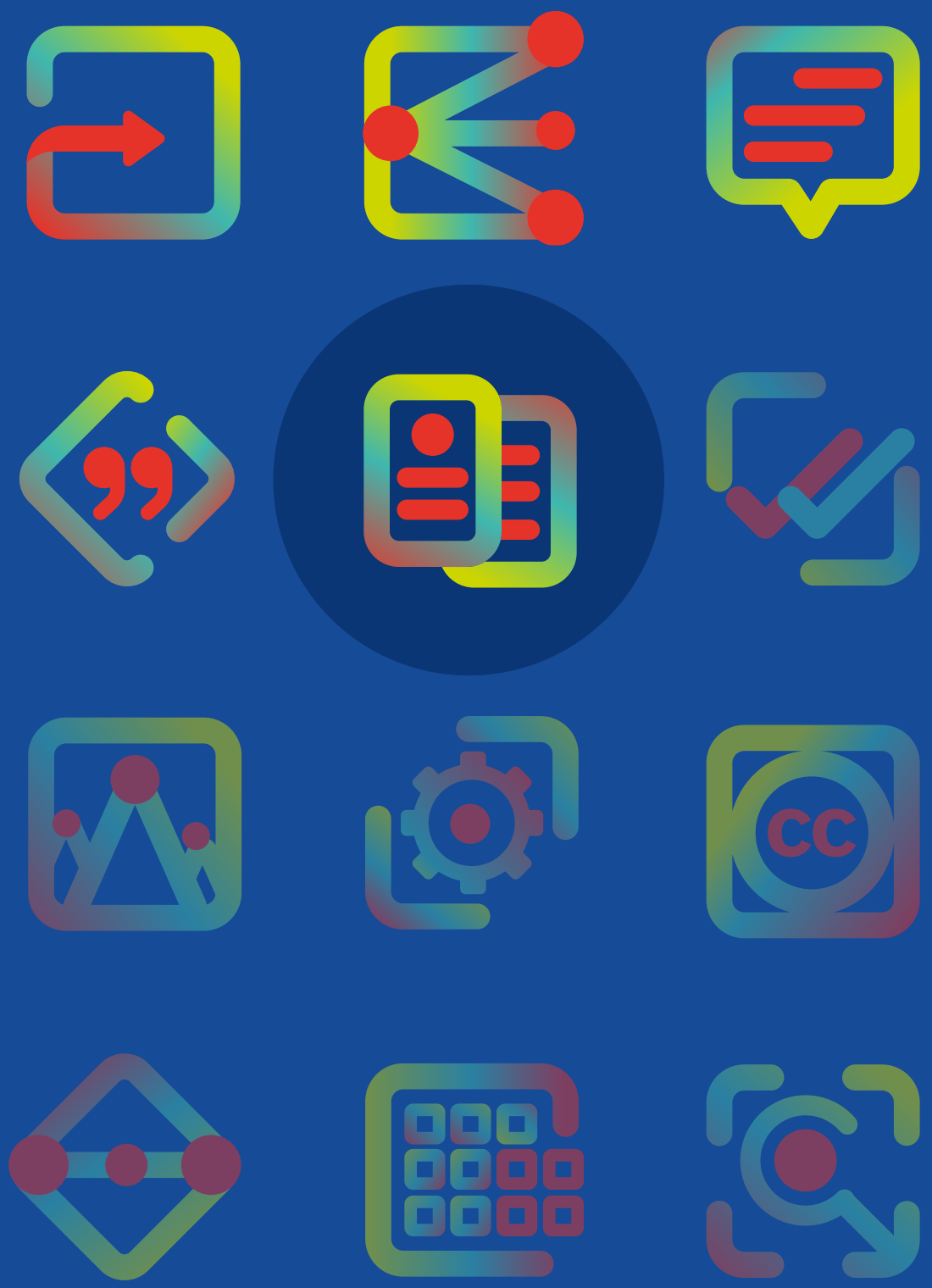


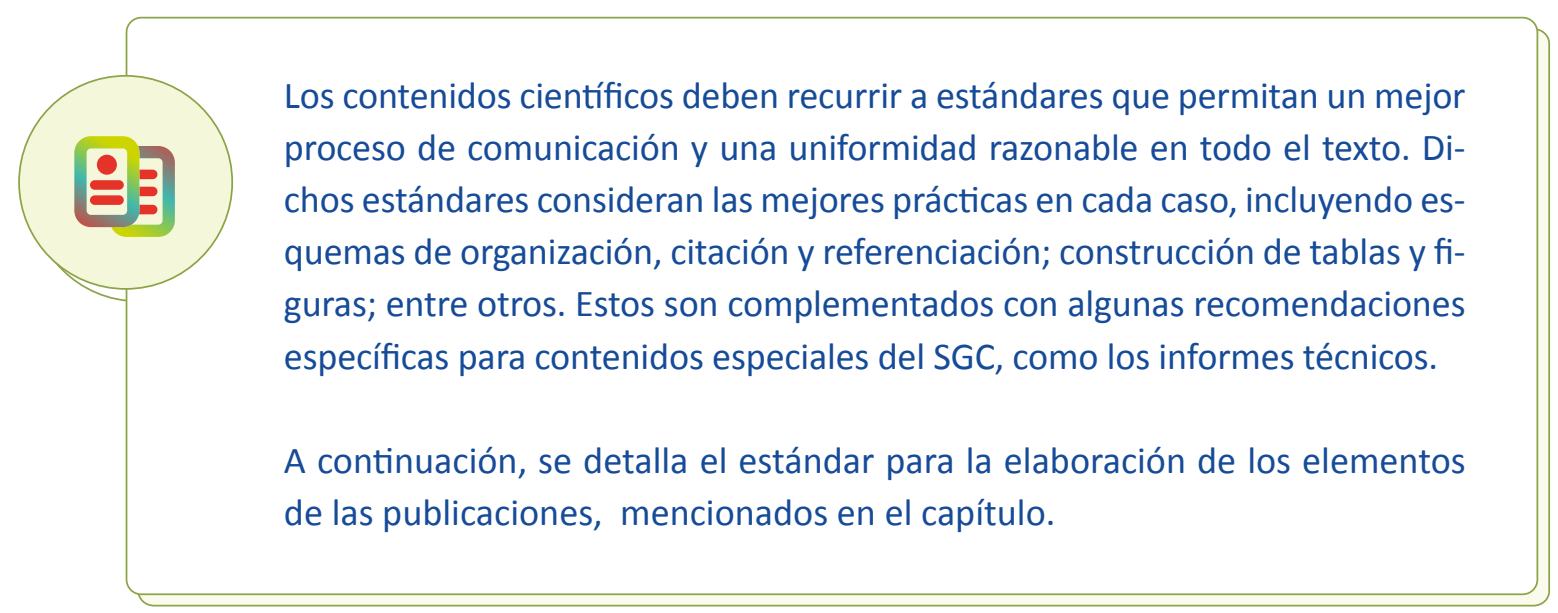

\subsection{Cubierta}

La cubierta es la parte exterior de un libro. En ella figura el título completo, el nombre del autor y el pie de imprenta. La portada en libros o trabajos escritos, en cambio, está en la parte interior y reproduce los datos de la cubierta.

En la figura 14 se brinda un ejemplo de una cubierta.

\subsection{Portadilla}

La portadilla, o anteportada, es aquella hoja que antecede a la portada. Es la primera página impresa del libro. Reproduce solo el título del libro, así como su subtítulo (si lo tiene), con una tipografía de cuerpo más pequeño que el de la cubierta.

La portadilla no es necesaria en el caso de los informes. La portadilla para un libro puede verse en la figura 15.

\subsection{Portada}

La portada contiene el título y el subtítulo de la obra y algunas imágenes que puedan ayudar en la identificación del contenido. Cuando se trata de libros, esta incluye el nombre del (de los) autor(es) (o editor).

En las figuras 16, 17, 18 y 19 se exponen los diversos esquemas de organización de portadas de informes, de visitas de emergencia y de memorias de planchas geológicas que se generan en el SGC. En cada caso, se incluye una regla en centímetros, orientada de la misma manera que se presenta en el programa Word, para facilitar la ubicación de los distintos elementos.

Es de anotar que, en el caso de convenios con otras entidades, solo se usarán en la portada y en la página legal los logos oficiales de estas. No se deberán usar logos de grupos particulares, ni del SGC, ni de las entidades cooperantes. 
Los logos del SGC serán los aprobados por los manuales de identidad visual de la institución. A estos se puede acceder en la dirección: https://srvags.sgc.gov.co/PortalWeb/Comunicaciones/LogosInformes-SGC.zip

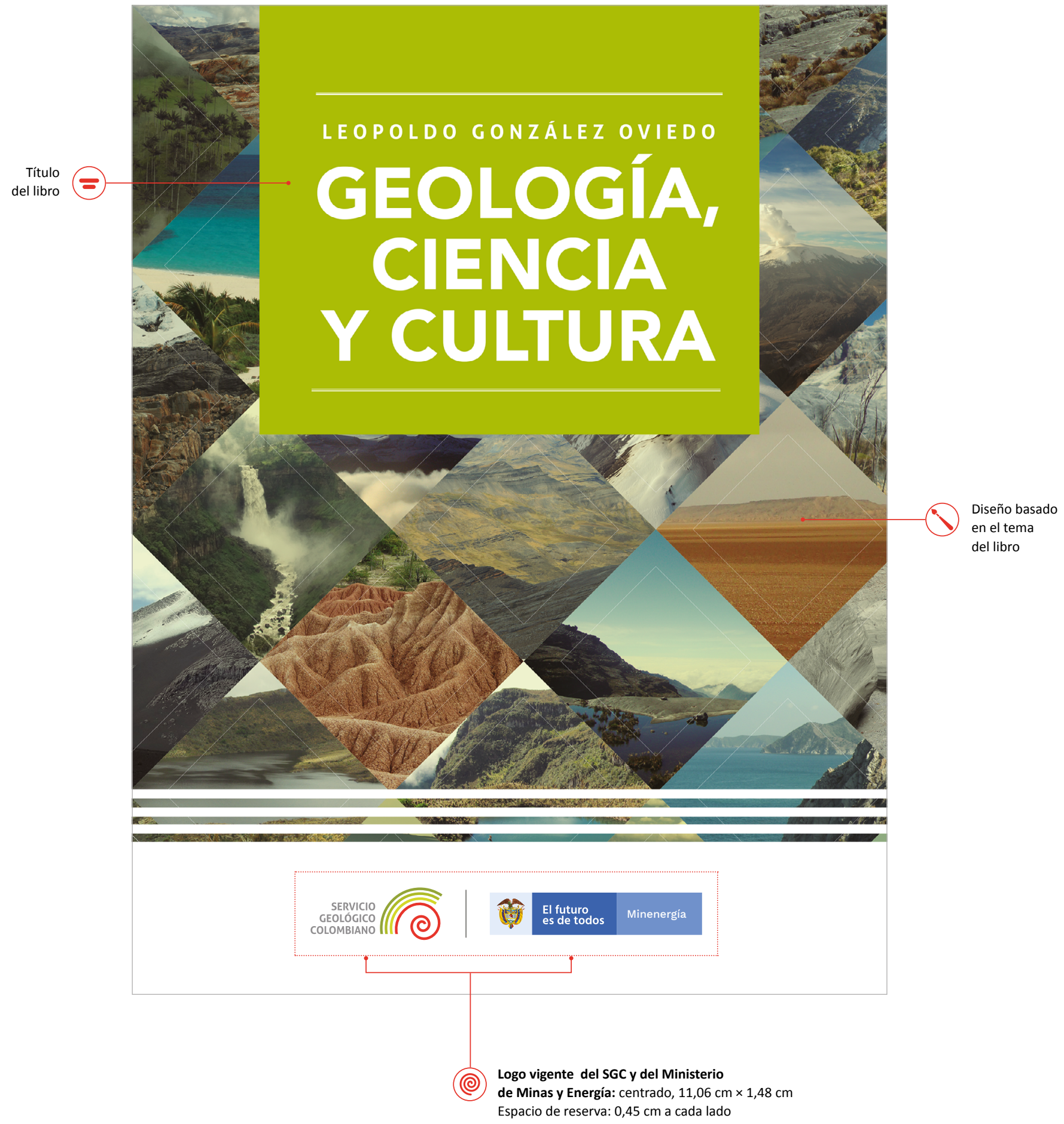

Figura 14. Ejemplo de cubierta de libro del SGC 


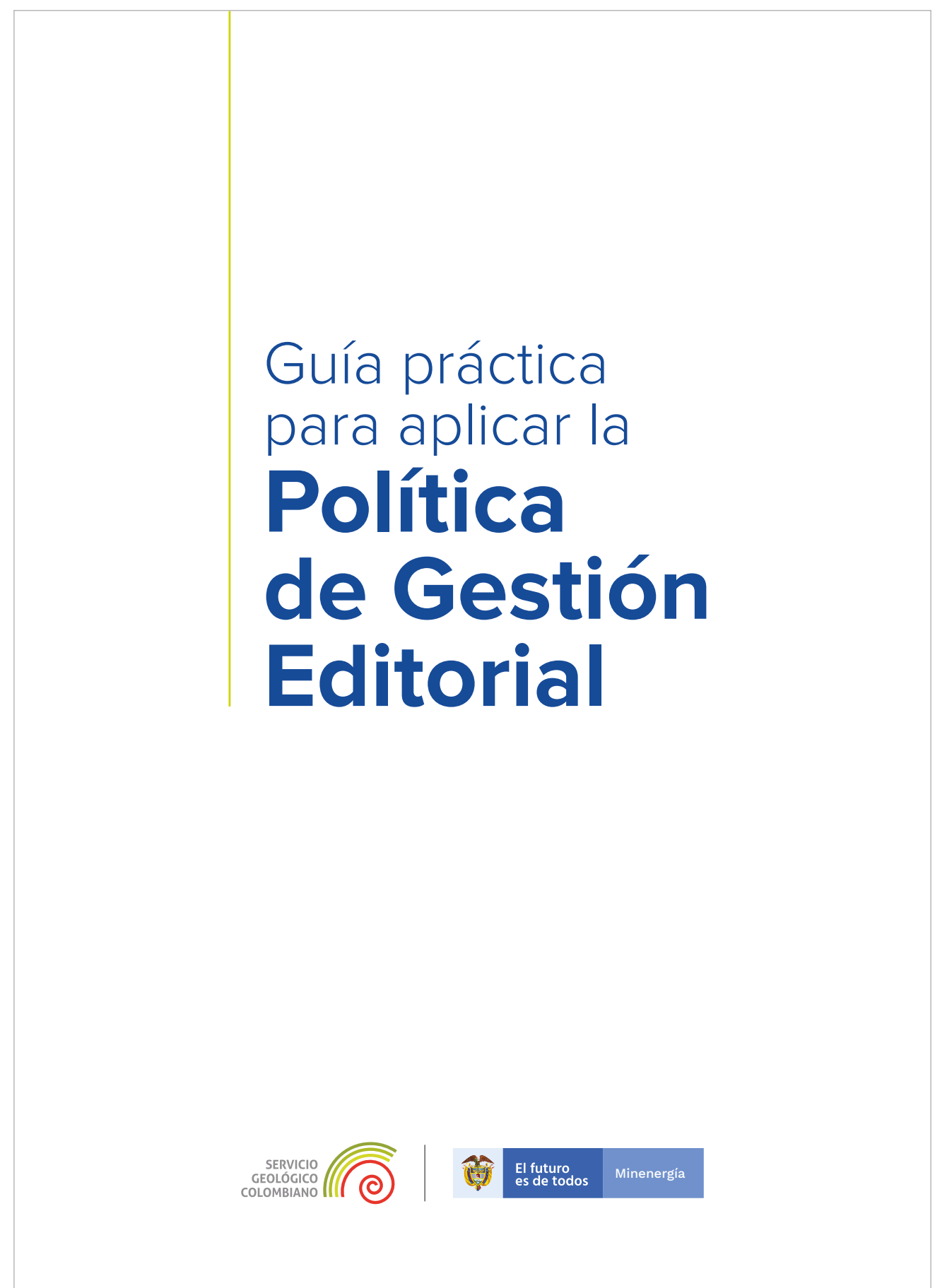

Figura 15. Ejemplo de una portadilla de un libro del SGC 


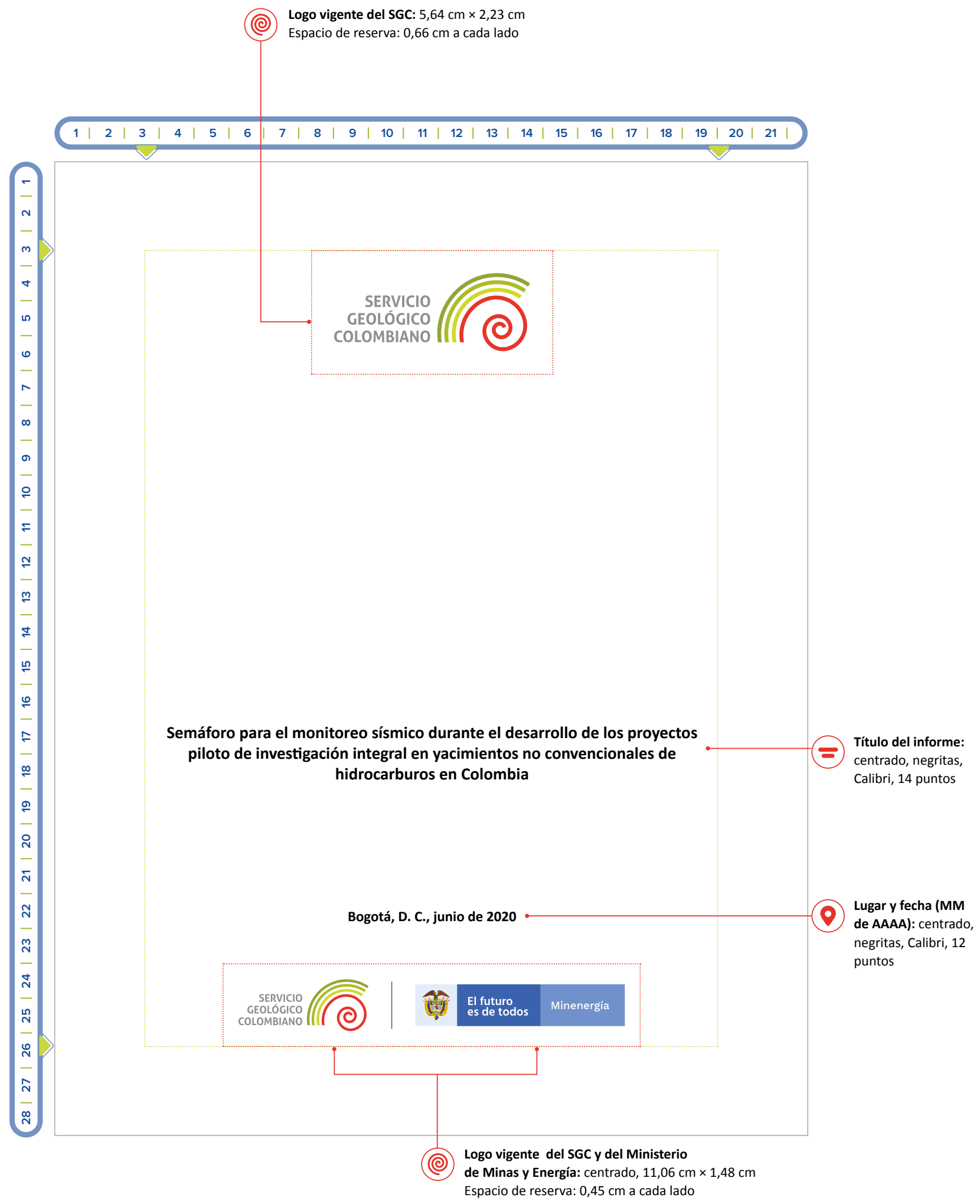

Figura 16. Esquema de organización de portada de informes del SGC (sin convenio o contrato externo) Fuente: adaptado de Dionicio et al. (2020). 


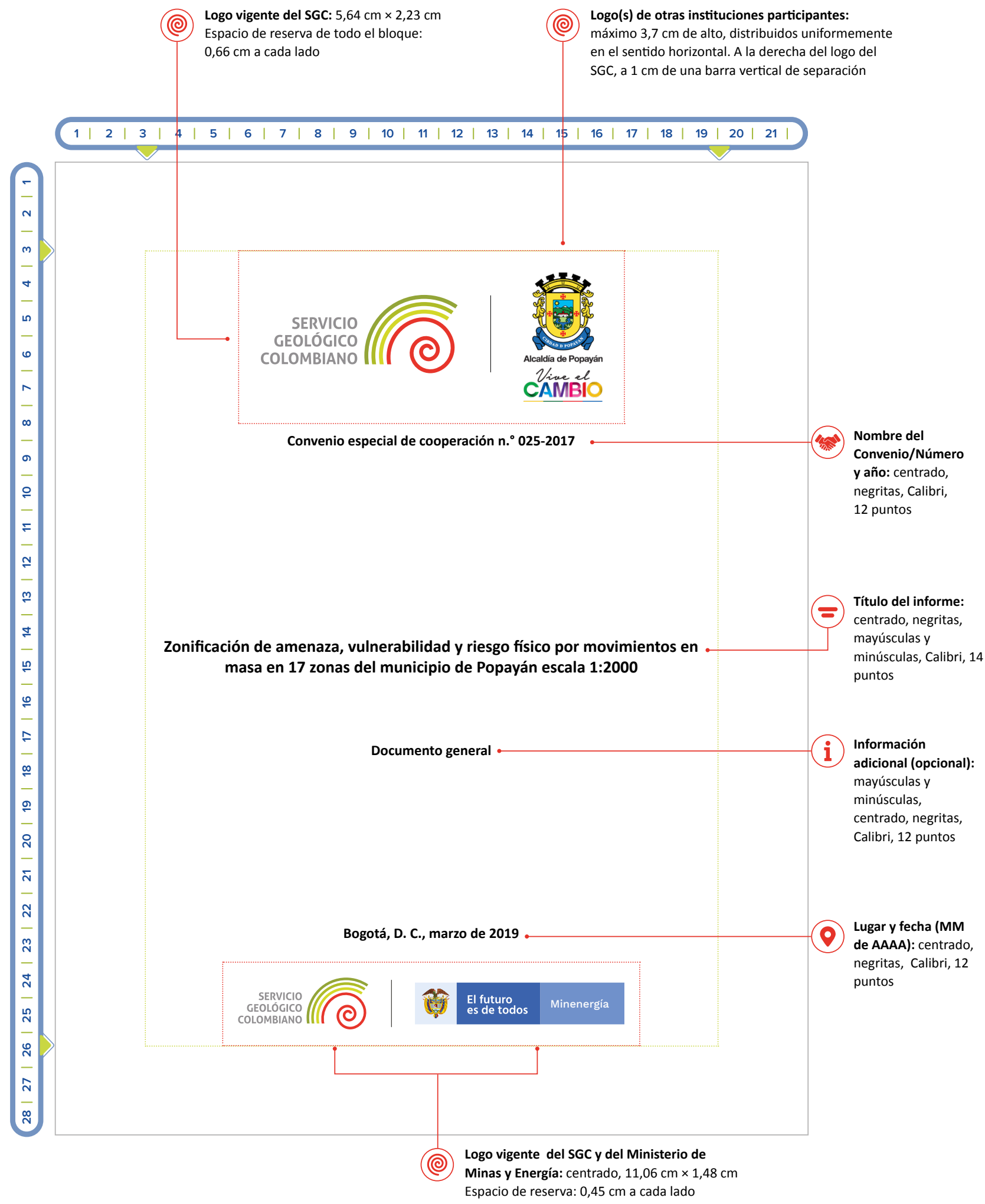

Figura 17. Esquema de organización de portada de informes del SGC, elaborados en la modalidad de convenio

Fuente: adaptado de Ruiz et al. (2019). 


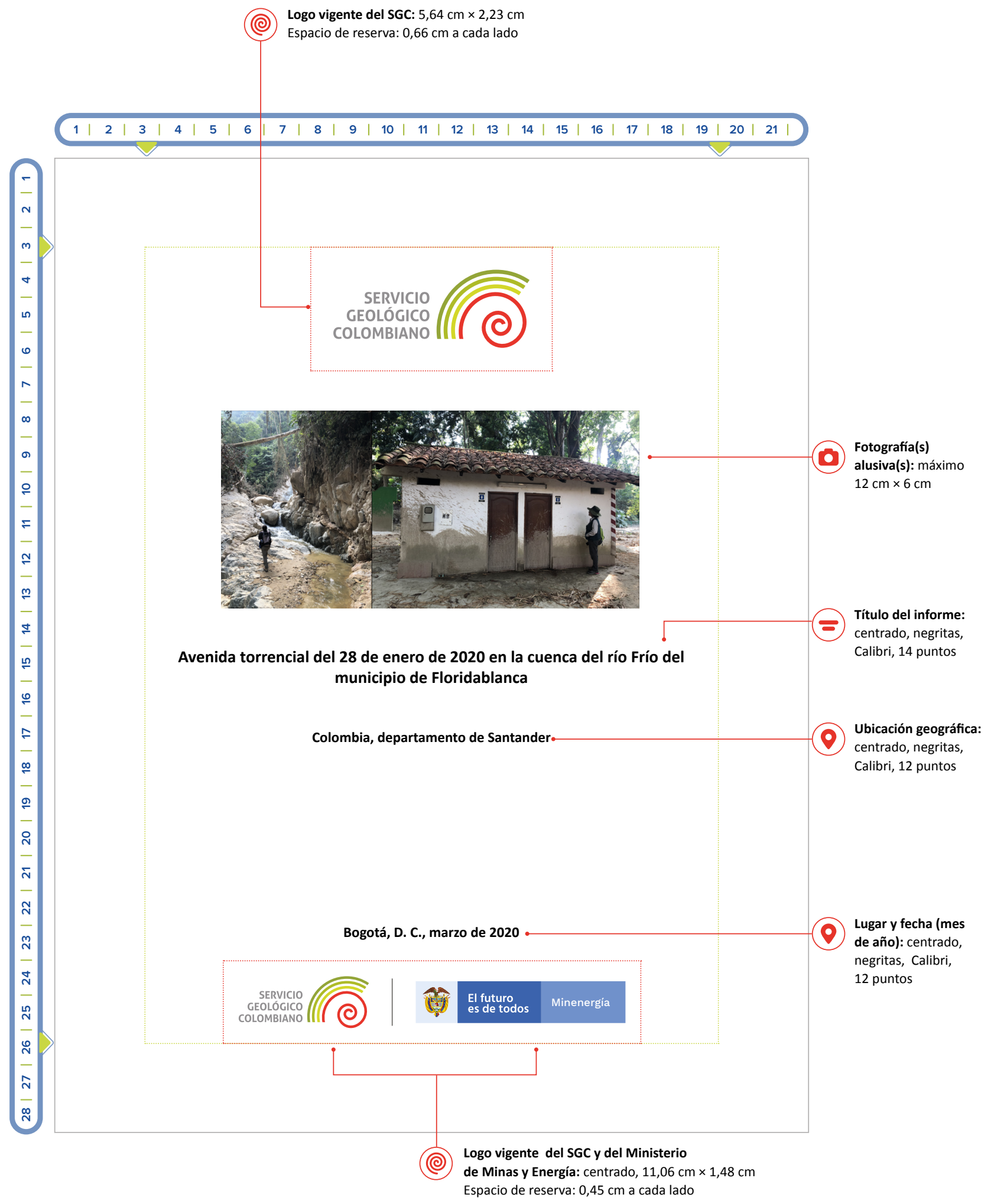

Figura 18. Esquema de organización de portadas de visitas de emergencia Fuente: adaptado de Castro et al. (2020). 


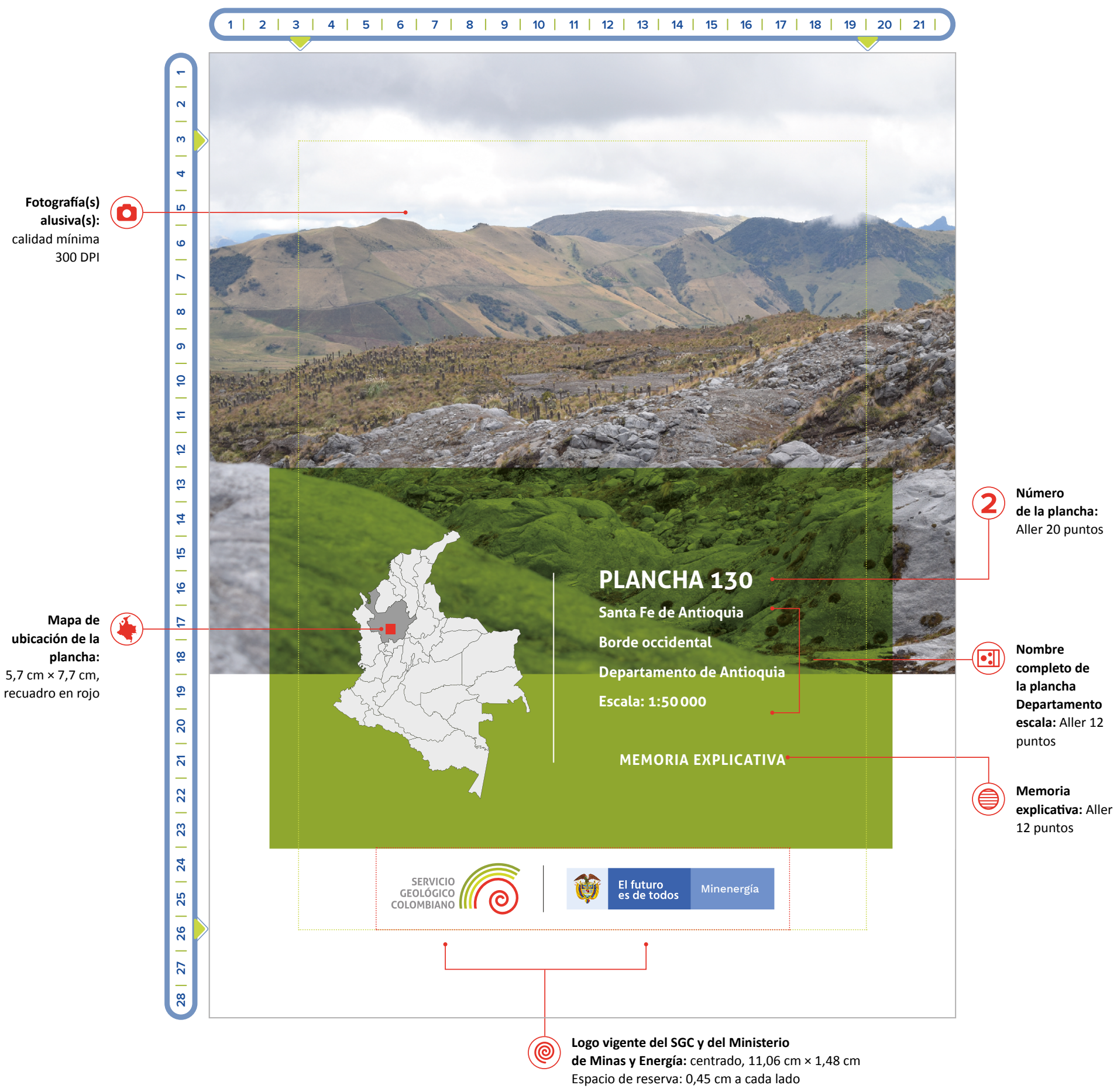

Figura 19. Esquema de organización de portada de memorias de planchas geológicas

Las portadas de planchas geológicas tienen un diseño que puede ser apoyado por el Comité Editorial con una solicitud remitida al correo ceditorial@sgc.gov.co. El usuario debe suministrar el mapa de ubicación (en lo posible preparado en el software $\mathrm{SIG}$ ) con una dimensión de 4,25 cm de ancho por 5,80 cm de alto, la foto representativa de la zona de estudio en calidad mínima de $300 \mathrm{DPI}, \mathrm{y}$ los datos completos de identificación de la plancha. 


\subsection{Página legal, citación sugerida y DOI}

La página legal busca informar sobre aspectos institucionales, normativos, organizativos y editoriales. Cada libro tiene una página de créditos o página legal, donde se reúnen datos relativos al copyright del autor y de la editorial, así como el Número Estándar Internacional de Libros (ISBN) y la reserva de derechos. En esta página también se indica la citación sugerida de los contenidos, el tipo de licencia que se otorga a los lectores y el respectivo enlace al DOI de la obra.

En las publicaciones del SGC se trabajan los esquemas de licenciamiento de Creative Commons (s. f.) que utilizan una representación gráfica estándar y unos tipos de licencia de amplio reconocimiento en las publicaciones de acceso abierto. Detalles sobre las licencias y el tipo de publicaciones a las que son aplicables pueden verse en el capítulo 9.

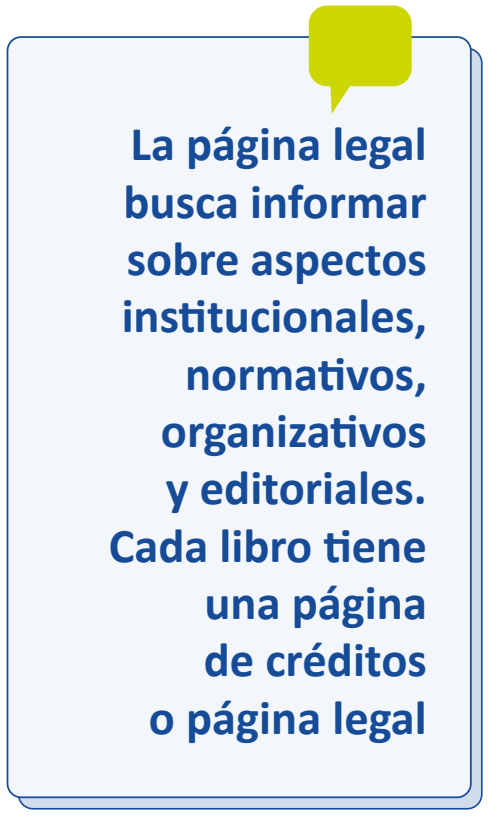

Cada publicación del SGC debe contar con información completa de los autores (es decir, personas que hayan contribuido de forma activa y sustancial a su contenido intelectual y al análisis o interpretación de los datos). La lista de autores debe estar ordenada, indicando en primer término los que hayan realizado mayores contribuciones, y al final, los de menor participación. Cada autor deberá aportar su nombre completo y su filiación institucional. Por cada trabajo deberá aportarse un correo electrónico de contacto.

Para trabajos colaborativos con autores de dos o más instituciones, el orden de estos deberá mantener la directriz descrita, sin importar las divisiones por instituciones.

De la misma manera, se deben otorgar los créditos a aquellos que hayan realizado aportes creativos o intelectuales a la obra, como ilustradores, diagramadores, correctores de estilo, traductores, etc.

Para el caso de artículos, en la tabla 20 se detallan los contenidos que se incluyen en la página de autores.

Tabla 20. Información que debe entregarse en los artículos

\begin{tabular}{lll}
\hline $\begin{array}{c}\text { Elemento de la } \\
\text { portada del trabajo }\end{array}$ & \multicolumn{1}{c}{ Formato } \\
\hline & $\begin{array}{l}\text { Escriba el título tres o cuatro líneas hacia abajo desde } \\
\text { la parte superior de la página del título. Céntrelo y } \\
\text { resáltelo en negritas. Las mayúsculas deben limitarse } \\
\text { a la primera letra del título y a las iniciales de los }\end{array}$ \\
nítulo del trabajo & nombres propios que contenga. El título principal y el & nefelínica de San José del Guaviare y su \\
& subtítulo deben ir en diferentes renglones, separados & datación U/Pb mediante LA-ICP-MS \\
& a espacio sencillo, si lo desea. No hay una longitud & \\
& máxima para los títulos; sin embargo, mantenga los & \\
& títulos enfocados e incluya términos clave en ellos. & \\
\hline
\end{tabular}




\begin{tabular}{|c|c|c|}
\hline $\begin{array}{l}\text { Elemento de la } \\
\text { portada del trabajo }\end{array}$ & Formato & Ejemplo \\
\hline Nombres de autores & $\begin{array}{l}\text { Deje una línea en blanco a espacio sencillo entre el } \\
\text { título del artículo y los nombres de los autores. Centre } \\
\text { los nombres de los autores en su propia línea. Si hay } \\
\text { dos autores, use la palabra y entre sus nombres; si hay } \\
\text { tres o más, coloque una coma entre los nombres de } \\
\text { los autores y use la conjunción y antes del nombre del } \\
\text { último autor. }\end{array}$ & $\begin{array}{l}\text { Jimmy Alejandro Muñoz Rocha }{ }^{1} \\
\text { Alejandro Piraquive Bermúdez }^{1} \\
\text { José Alejandro Franco Victoria }{ }^{2} \\
\text { Amed Bonilla Pérez }^{2} \\
\text { Mary Luz Peña Urueña }{ }^{1} \\
\text { Thomas Cramer } \\
\text { Nicolás Villamizar Escalante }^{1}\end{array}$ \\
\hline Filiación de los autores & $\begin{array}{l}\text { La filiación es la institución en la que trabajan o con } \\
\text { quien colaboran quienes realizaron la investigación. } \\
\text { Tanto el nombre de las dependencias como el de las } \\
\text { demás instituciones deben ir separados por una coma. } \\
\text { Incluya también la ciudad y el país correspondiente } \\
\text { a cada institución. Centre la filiación en la siguiente } \\
\text { línea a espacio sencillo, después de los nombres de los } \\
\text { autores; cuando haya múltiples filiaciones, centre cada } \\
\text { una en su propia línea. } \\
\text { Cuando diferentes autores tienen diferentes filiaciones, } \\
\text { use números en superíndice al final del nombre } \\
\text { de cada autor, para conectarlas con los autores } \\
\text { apropiados. No utilice esta notación si todos los } \\
\text { autores comparten la misma filiación }\end{array}$ & $\begin{array}{l}1 \text { Servicio Geológico Colombiano } \\
2 \text { Universidad Nacional de Colombia }\end{array}$ \\
\hline 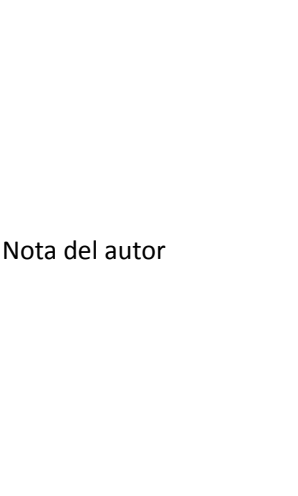 & $\begin{array}{l}\text { Coloque la nota del autor en la mitad inferior de } \\
\text { la página del título. Centre y escriba en negritas la } \\
\text { etiqueta Nota del autor. Alinee los párrafos de la nota } \\
\text { del autor a la izquierda. } \\
\text { En la nota del autor puede incluir información como } \\
\text { dirección de la institución principal, correo electrónico } \\
\text { de contacto, identificadores de Orcid, y registros, } \\
\text { prácticas de acceso abierto de los contenidos, entre } \\
\text { otras. }\end{array}$ & $\begin{array}{l}\text { Jimmy Alejandro Muñoz Rocha https://orcid. } \\
\text { org/0000-0002-1011-383X } \\
\text { Alejandro Piraquive Bermúdez https://orcid. } \\
\text { org/0000-0002-0892-9928 } \\
\text { Jimmy Alejandro Muñoz Rocha es ahora } \\
\text { funcionario del Servicio Geológico } \\
\text { Colombiano } \\
\text { La correspondencia relacionada con } \\
\text { este artículo puede remitirse a Jimmy } \\
\text { Alejandro Muñoz Rocha, Servicio Geológico } \\
\text { Colombiano, Diagonal } 53 \text { n. }{ }^{\circ} 34-53, \text { Bogotá, } \\
\text { D. C., Colombia. Email: jamunoz@sgc.gov.co }\end{array}$ \\
\hline
\end{tabular}

Fuente: adaptado de APA (2020).

Dependiendo del tipo de documento, habrá una página legal o de autores para artículos (de investigación o de tipo dato), libros, informes internos, informes en convenios e informes de trabajos por contrato.

Los esquemas de presentación de los autores para las revistas Boletín Geológico y Revista Investigaciones y Aplicaciones Nucleares pueden verse en las figuras 20 y 21 , respectivamente.

Los esquemas de página legal de libros e informes pueden verse en las figuras $22,23,24$ y 25 . Para los informes, y en aras de facilitar la ubicación de los elementos en la página, se incluye una regla en centímetros. 


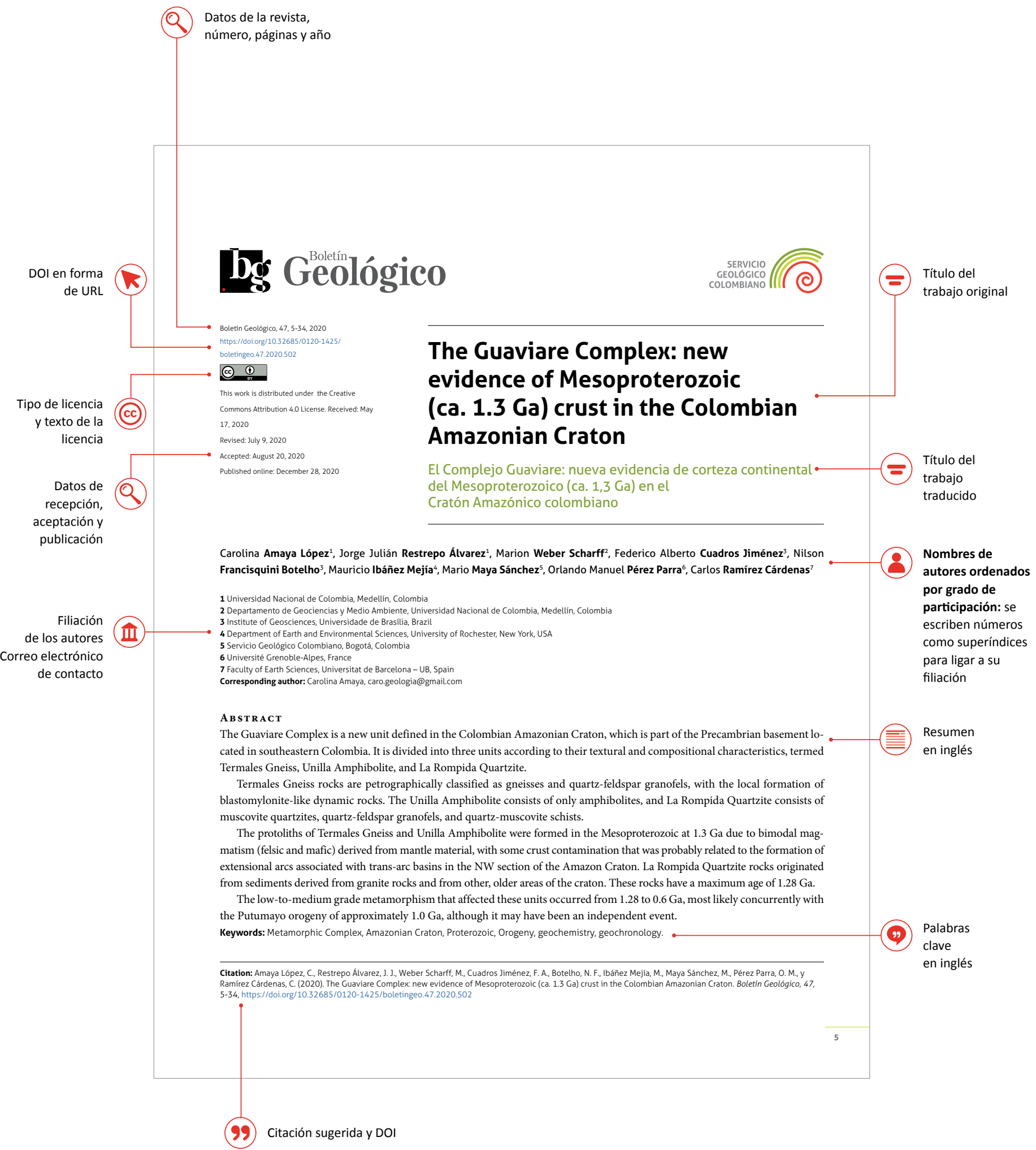

Figura 20. Esquema de presentación de la primera página de un artículo para el Boletín Geológico 


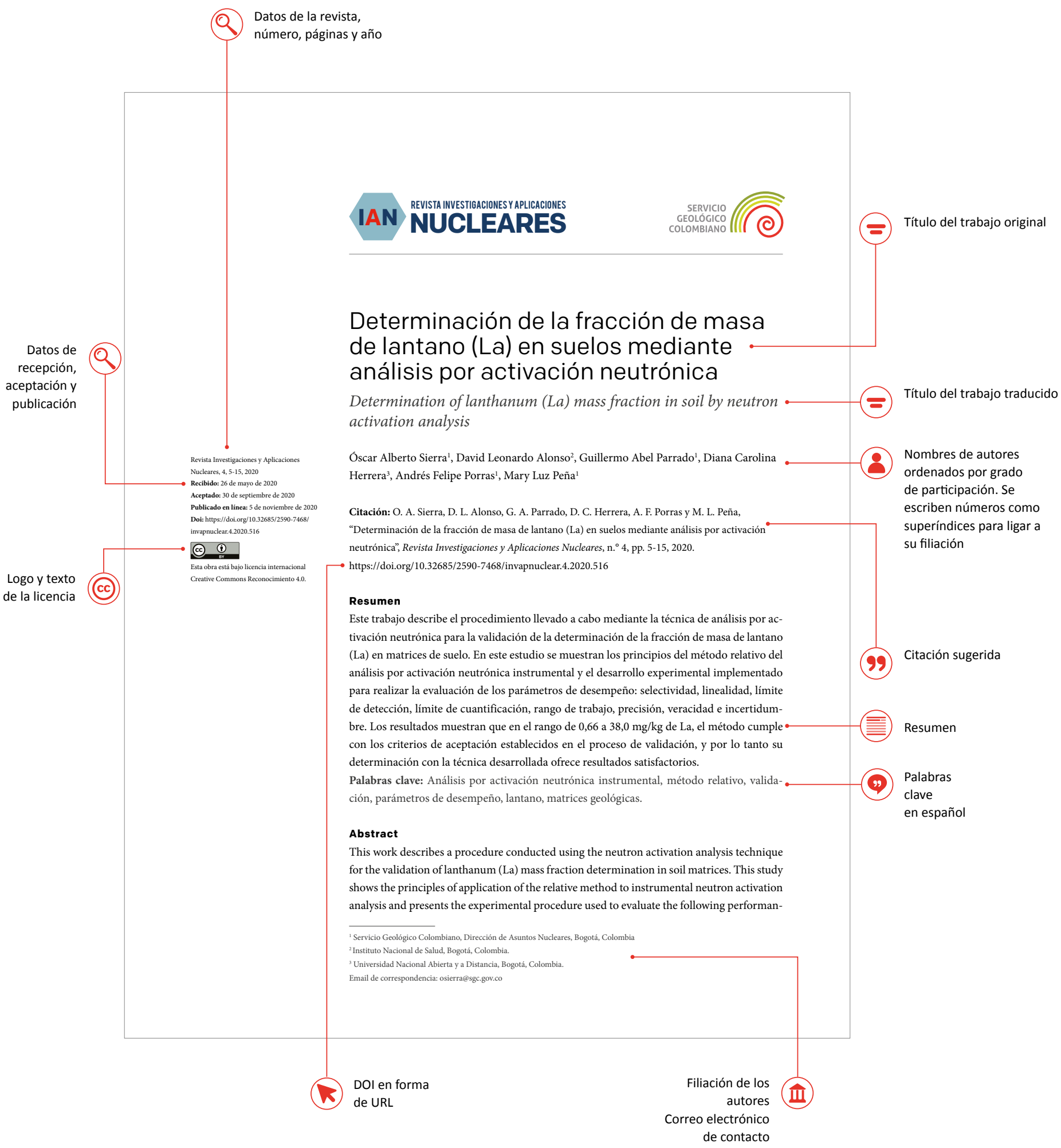

Figura 21. Esquema de presentación de la primera página de un artículo para la Revista Investigaciones y Aplicaciones Nucleares 


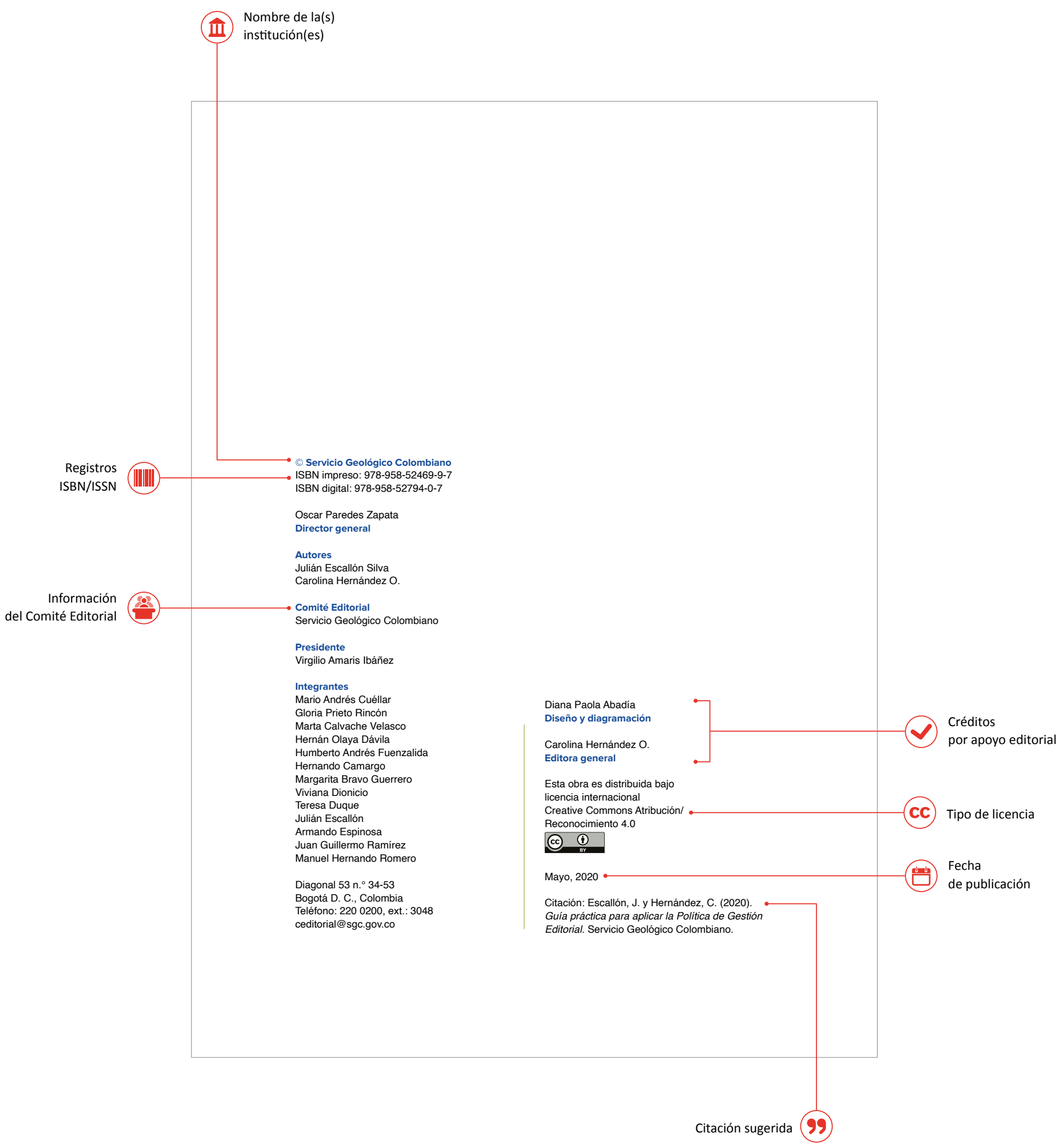

Figura 22. Esquema de organización de página legal para libros 


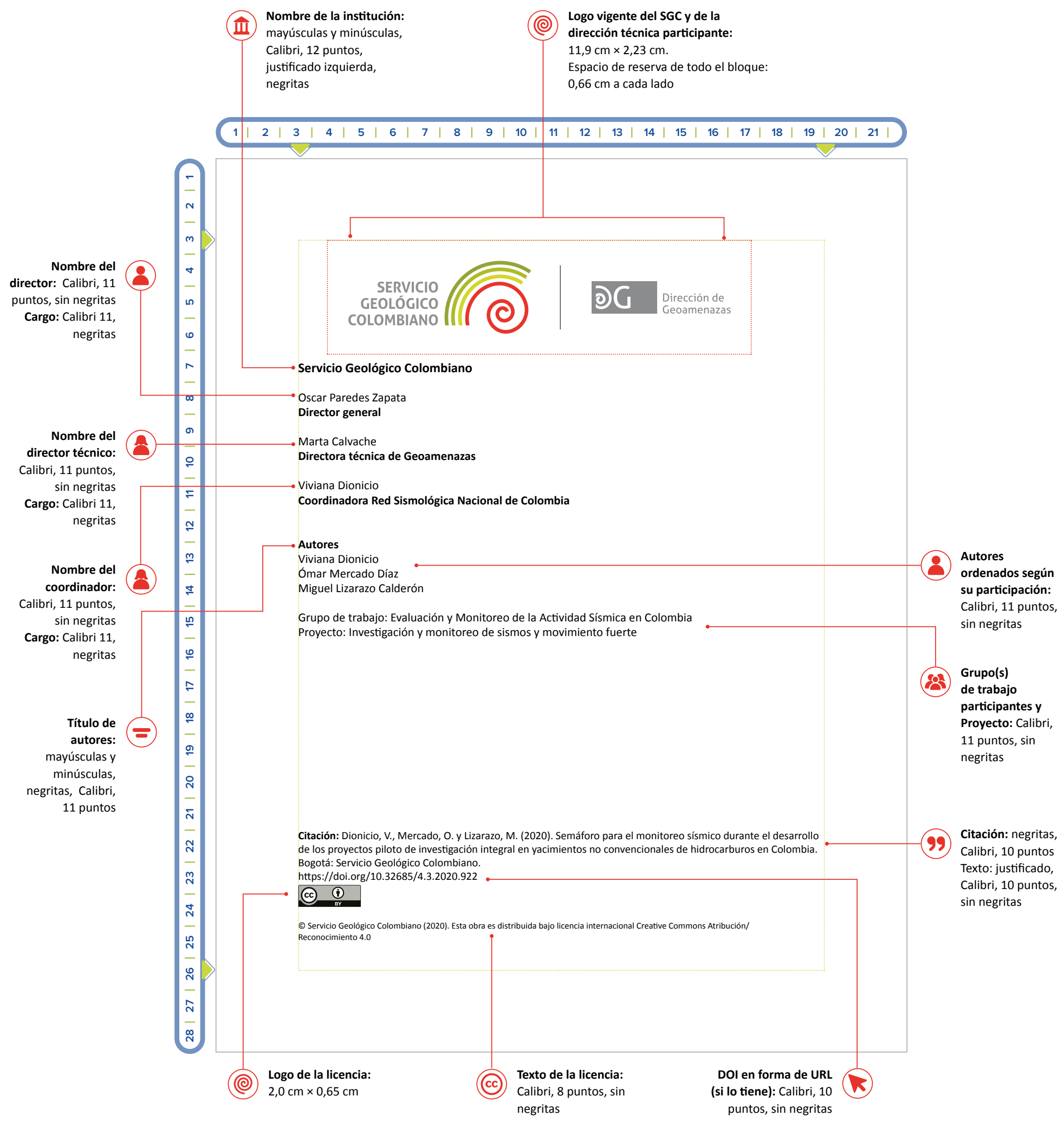

Figura 23. Esquema de página legal de informe técnico del SGC e información de autores Fuente: adaptado de Dionicio et al. (2020). 


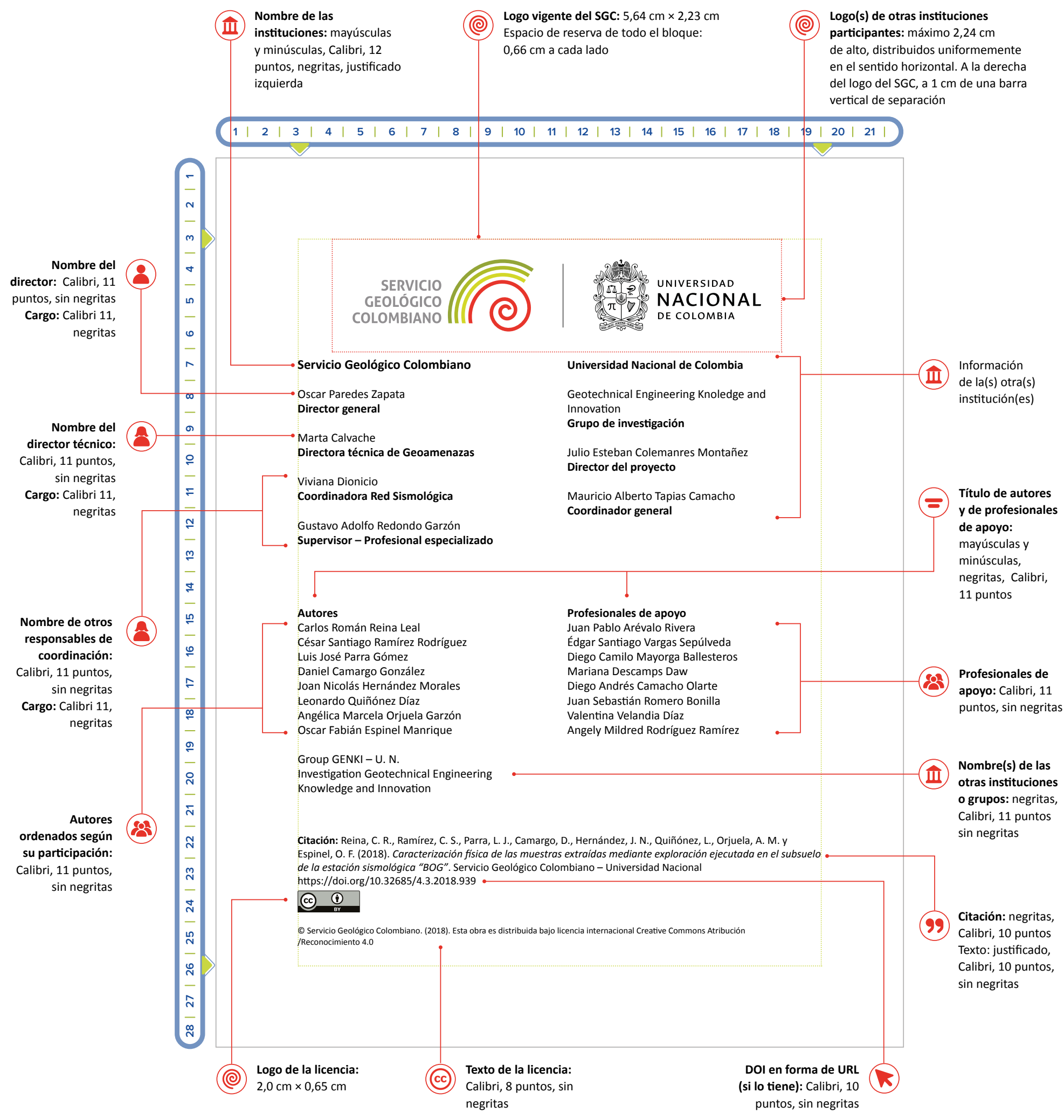

Figura 24. Esquema de presentación de página legal para informes de trabajos en convenio Fuente: adaptado de Reina et al. (2018). 


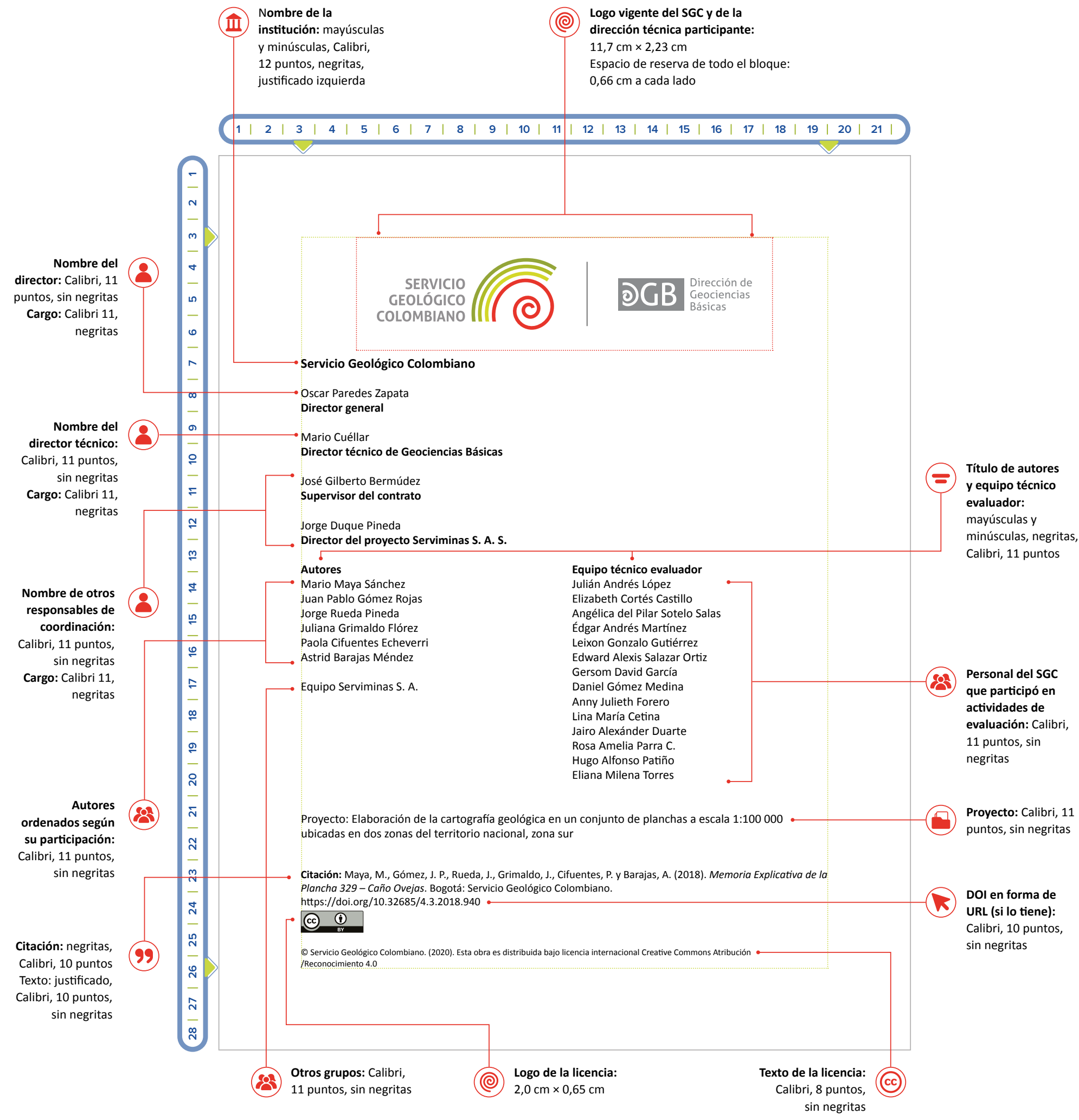

Figura 25. Esquema de presentación de página legal para informes de trabajos por contrato Fuente: adaptado de Maya et al. (2018). 
En informes extensos, se puede presentar una tabla de autores por cada capítulo, bien en la página legal o después de la página de separación del respectivo capítulo.

\subsection{Dedicatoria}

La inclusión de dedicatorias constituye una decisión personal de los autores. Un libro de varios autores podrá contener una dedicatoria solo cuando la misma procede de todos ellos.

Según Beltrán (2017), la dedicatoria no lleva título y se puede escribir en cursiva o redondas con margen a la derecha en la parte media o superior de la página.

\subsection{Epígrafe}

Constituye una frase de un autor destacado que se antepone a toda la obra. Sirve para darle un homenaje al autor de la frase y para transmitirle a los lectores la especial significación de dicho pensamiento para la concepción y el desarrollo del libro (Beltrán, 2017, p. 168).

También puede haber epígrafes de partes o de capítulos.

El texto del epígrafe no lleva título. Se suele escribir en la parte superior derecha de la página a un tamaño dos puntos por debajo del texto normal. Inmediatamente después de la última línea, se añaden los créditos con nombre y apellido del autor (o solo apellido). En algunos casos también se agrega el año. No es necesario utilizar ningún tipo de citación formal ni que aparezca en la lista de referencias.

\subsection{Contenido}

En los libros y los informes es necesario generar una tabla de contenido.

Para los libros, se sugiere mostrar únicamente los títulos y subtítulos principales (hasta el nivel 3) presentes en el cuerpo del documento. No utilice sangría para diferenciar cada nivel de subtitulo y aplique sangría francesa de $1,25 \mathrm{~cm}$ en todas las entradas. Identifique a la derecha el número de página donde cada encabezado y subtítulo comienzan. En la tabla de contenido las márgenes deben ser de una pulgada $(2,54 \mathrm{~cm})$ en todos los lados, y el mismo tipo y tamaño de fuente para el resto del texto, e interlineado sencillo.

Como título de la sección escriba Contenido en mayúscula solo la primera letra, en fuente Calibri 14 puntos, centrado en la parte superior de la página.

Un ejemplo de tabla de contenido para libros se muestra a continuación: 


\section{Contenido}

1. Introducción 13

2. Estructura de los documentos científicos y divulgativos 17

2.1. Organización de secciones del texto según el tipo de publicación 19

2.2. Descripción de los elementos fundamentales de las publicaciones, recomendaciones y prácticas que deben evitarse $\quad 22$

2.2.1. Título 22

2.2.2. Resumen 22

3. Recomendaciones desde el punto de vista lingüístico para la composición de textos científicos y divulgativos 32

3.1. Planear la escritura (prerredacción) 33

3.2. Escribir con claridad 33

4. Gestores de referencias 180

5. Licencias de uso de las publicaciones 188

$\begin{array}{ll}\text { 6. Glosario } & 218\end{array}$

7. Referencias 223

$\begin{array}{ll}\text { Anexo } 1 & 228\end{array}$

$\begin{array}{lr}\text { Anexo } 2 & 230\end{array}$

\subsection{Prólogo}

En algunos libros se escriben textos introductorios al trabajo para animar a los lectores a conocer la obra. Dichos textos son, por lo general, escritos por personas diferentes al autor, que pueden dar una perspectiva adicional o que pueden resaltar algunos elementos útiles o aplicables en algún campo de su conocimiento. En lo posible, deben ser cortos, concisos y enfocados en el tema que desarrolla el libro o sus aplicaciones. Su redacción puede estar en segunda o tercera persona.

\subsection{Prefacio}

Es un texto escrito por el mismo autor del libro o por el editor (cuando son varios autores) que es corto y de carácter general que muestra qué tipo de material tiene el lector en sus manos. Brinda una visión del libro como un todo en relación con las publicaciones y lectores de la disciplina o especialidad a la cual pertenece (Beltrán, 2017, p. 174).

\subsection{Agradecimientos}

Cuando los autores reconocen toda la ayuda recibida durante su investigación, demuestran su integridad como investigadores, lo que fomenta la colaboración continua.

En los agradecimientos, los autores mencionan a las personas que ayudaron con el estudio o la preparación del documento, sin que los mismos puedan considerarse coautores. Por lo general, se agradece a 
personas con quienes hayan tenido discusiones útiles o que hayan provisto alguna colaboración valiosa. La redacción debe darse en primera persona del singular (un solo autor) o del plural (varios autores).

Los agradecimientos no deben darse a personas que participan en la ejecución de la investigación o del proceso editorial (comités de ética, comités de investigación, revisores editoriales, a la revista o a los otros autores).

Esta sección puede ubicarse después de la página legal o al final, antes de las referencias.

Un ejemplo de agradecimientos para una publicación se muestra a continuación:

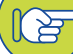

\section{Agradecimientos}

Agradecemos al Ministerio de Ciencia, Tecnología e Innovación por la financiación del presente estudio con recursos del Fondo Nacional de Regalías.

Igualmente, expresamos nuestra gratitud al grupo de analistas de muestreo por la supervisión de las operaciones y su colaboración con nuestro grupo de investigadores.

Agradecemos al señor Manuel Cepeda Martínez por su acertada asistencia en la redacción del presente trabajo.

Expresamos nuestro reconocimiento al profesor Hernando Viveros por facilitarnos el procesamiento de datos con los estudiantes de maestría de la Universidad del Norte.

Finalmente, manifestamos nuestra gratitud al grupo de trabajo de elaboración de figuras por su compromiso y sus esfuerzos valiosos para contar con presentaciones de primer nivel.

\subsection{Cronología o línea de tiempo}

Esta parte deberá incluirse cuando sea importante para los lectores el conocimiento de hechos o hitos destacados que ayuden a contextualizar los contenidos. Se deben ordenar de manera cronológica y pueden tener un componente gráfico que ilustre de mejor manera el mensaje. El título puede ser cualquiera de los dos (Cronología o Línea de tiempo). Algunos ejemplos y plantillas para crear líneas de tiempo pueden apreciarse en McGuire (2020).

\subsection{Lista de abreviaturas y lista de siglas}

Una abreviatura es la representación gráfica reducida de una palabra o grupo de palabras, obtenida por eliminación de algunas de las letras o sílabas de su escritura completa y que siempre se cierra con un punto (RAE, 2020b). 
Cuando en el texto se usan de manera repetitiva abreviaturas o siglas, es conveniente incluirlas en una lista. Es posible que estén en dos secciones distintas. Dicha lista tiene como objetivo evitar la proliferación de notas de pie de página o paréntesis recurrentes a lo largo del texto (Beltrán, 2017, p. 178).

A continuación, se presentan algunas consideraciones importantes sobre las abreviaturas aceptadas en el idioma español, según RAE (2020a).

Para la formación de abreviaturas, deberá suprimir como mínimo dos letras de la palabra abreviada (mejor, tres, si la palabra es suficientemente larga, para poder ahorrar, al menos, dos caracteres, ya que una de las letras suprimidas es reemplazada por el punto de cierre).

Se identifican dos procedimientos para formar abreviaturas:

a) Por truncamiento: se suprimen letras o sílabas finales: cód. por código, art. por artículo. En este caso, la abreviatura nunca debe terminar en vocal: pról., y no pró. ni prólo., como abreviatura de prólogo. En aquellas que corresponden a fórmulas fijas, se abrevian todas y cada una de las palabras que las integran, incluso artículos, preposiciones o conjunciones, reduciéndolos a la letra inicial: s. e. u o. por salvo error u omisión, q. e. p. d. por que en paz descanse.

b) Por contracción: se eliminan letras centrales y se conservan solo las más representativas: dpto. o depto. por departamento, admr. por administrador. Entre aquellas formadas por contracción están las que presentan la letra o letras finales voladas: $n .{ }^{\circ}$ por número, af. ${ }^{\text {mo }}$ por afectísimo.

Para formar el femenino de una abreviatura, si la abreviatura del masculino termina en -o, el femenino se forma sustituyendo esta vocal por una -a: Lcdo., Lcda. (licenciado, licenciada); si el masculino termina en consonante, se le añade una $a$, volada o no; no obstante, hay abreviaturas que sirven tanto para el masculino como para el femenino: Lic. (licenciado o licenciada), izq. (izquierdo o izquierda). Cuando el masculino termina en consonante, hay que tener en cuenta lo siguiente:

a) Las abreviaturas obtenidas por truncamiento forman el femenino añadiendo una $a$ volada, que puede escribirse subrayada o sin subrayar: Dir. para director y Dir. ${ }^{a}$ para directora.

b) Las abreviaturas obtenidas por contracción admiten las tres posibilidades señaladas para la formación del femenino: Sr. para señor, y Sra., Sr.a para señora.

Sobre el plural de las abreviaturas, depende de su método de formación:

a) Si la abreviatura se obtuvo por truncamiento, se añade -s: págs. por páginas. Se exceptúa el plural de las abreviaturas cent. (centavo, centésimo) y cént. (céntimo), que es cts., y no cents. ni cénts. (no debe confundirse la abreviatura cent. con la palabra cent, cuyo plural sí es cents). En abreviaturas formadas por una sola letra, el plural se expresa duplicando esta: ss. por siguientes, EE. UU. por Estados Unidos.

b) Si la abreviatura se obtuvo por contracción, se aplican las reglas generales de formación del plural y se añade -s o -es según sea la terminación: dptos. o deptos. por departamentos, admones. 
por administraciones. Como excepción, Ud. (usted) forma el plural en -s: Uds. (ustedes). El plural de las abreviaturas con letras voladas debe representarse con este mismo tipo de letras: $n$.os por números.

c) Si la abreviatura corresponde a una forma verbal, para el plural se usa la misma forma que para el singular: $c p$. vale como abreviatura de compárese y de compárense; D. E. P. puede abreviar tanto descanse en paz como descansen en paz.

En cuanto a la ortografía de las abreviaturas, se tiene lo siguiente:

a) Las abreviaturas mantienen la tilde en caso de incluir la vocal que la lleva en la palabra desarrollada: pág. por página, íd. por ídem, cia por compañía.

b) En general, las abreviaturas se escriben con mayúscula o minúscula según corresponda a la palabra o expresión abreviadas; así, se escriben con inicial mayúscula las abreviaturas de aquellos nombres o expresiones que se escriben de este mismo modo cuando se desarrollan: Bs. As. por Buenos Aires, FF. AA. por Fuerzas Armadas, mientras que las abreviaturas de nombres comunes se escriben normalmente con minúscula (salvo si van después de punto o al principio de un enunciado): pág. por página, c. e. por correo electrónico. No obstante, existen numerosas excepciones, y así, siempre se escriben con inicial mayúscula las abreviaturas de fórmulas de tratamiento, incluso las que se escriben con minúscula cuando se desarrollan: S. S. por Su Santidad, S. A. R. por Su Alteza Real, Excmo. por Excelentísimo, Ud. por usted, Sr. por señor, D. por don; también, por tradición, se escriben con mayúscula las abreviaturas de algunos nombres comunes: P. V. P. por precio de venta al público, D. L. por depósito legal. Existen asimismo usos dobles, como P. O. у p. o. (por orden) o Q. D. G. y q. D. g. (que Dios guarde).

c) Cuando la abreviatura corresponde a una expresión compleja, se separan mediante un espacio las letras que representan cada una de las palabras que la integran: b. I. m. por besa la mano. Cuando las abreviaturas van precedidas de un número, se escriben separadas de este por un espacio: 15 págs., salvo las referidas al vuelto y al recto de un folio, que van pegadas: $15 v^{\circ}, 15 r^{\circ}$.

d) Se escribe siempre punto detrás de las abreviaturas, salvo en el caso de aquellas en las que el punto se sustituye por una barra: $c /$ por calle, $c / c$ por cuenta corriente, $d / f$ por días fecha, $d / v$ por días vista (no debe dejarse espacio entre las letras y la barra; si la abreviatura se compone de dos letras, el segundo elemento tampoco lleva punto, salvo que se trate del que marca el final del enunciado). Otra excepción son las abreviaturas que van entre paréntesis, que también se escriben sin punto: (a) por alias. En las abreviaturas que llevan letras voladas, el punto se escribe delante de estas: $\mathrm{Sr}_{.}{ }^{a}, 3^{\mathrm{er}}$. Si una abreviatura coincide con final de oración o de párrafo, el punto de la abreviatura sirve de punto final, de modo que solo se escribirá un punto y no dos. Los otros signos de puntuación (coma, punto y coma, puntos suspensivos, signo de interrogación, etc.) sí deben escribirse tras el punto de la abreviatura; por lo tanto, si tras una abreviatura hay puntos suspensivos, se escriben cuatro puntos: algunas abreviaturas con tilde son pág., cód., admón. Las abreviaciones de las unidades de medida ( $\mathrm{m}, \mathrm{km}, \mathrm{g}$, l, etc.) y las de los nombres de los libros de la Biblia (Gn, Ex, Lv, etc.) son símbolos, no abreviaturas; de ahí que se escriban sin punto.

e) Las abreviaturas nunca deben dividirse mediante guion de final de línea: ad- / món. 
f) Cuando la abreviatura se compone de varios elementos, no deben separarse estos en líneas diferentes: $p$. / ej. Tampoco deben aparecer en renglones diferentes la abreviatura y el término del que depende: 15 / págs., Sr. / Pérez.

g) Una abreviatura nunca debe quedar como único componente de una línea de texto; en esos casos, debe escribirse la palabra completa:

En las librerías se venden libros, carpetas,

bolígrafos, etc.

Lo adecuado es:

En las librerías se venden libros, carpetas, bolígrafos, etcétera.

La lectura de una abreviatura debe restablecer todas las letras eliminadas en su escritura, esto es, debe leerse la palabra completa que la abreviatura representa.

En la tabla 21 se resumen las abreviaturas más utilizadas. Por regla general, las abreviaturas terminan en punto (.), con excepción de las que terminan en ${ }^{\circ} \mathrm{o}$ en /. El punto no se utiliza como signo de puntuación, sino como signo que pone en evidencia el sitio donde se han eliminado letras.

Tabla 21. Abreviaturas más utilizadas en textos

\begin{tabular}{|c|c|c|c|}
\hline Abreviaturas & Significados & Abreviaturas & Significados \\
\hline acrón. & acrónimo & geol. gral. & geología general \\
\hline acept. & aceptación & gral. ib. ibíd. Ibíd. & general también \\
\hline admón. & administración & id. & el mismo, lo mismo (ídem) \\
\hline a. m. & antes del mediodía (ante meridiem) & Inc. & Incierto \\
\hline ap. & aparte & Imp. & imprenta \\
\hline art. & artículo & indet. & Indeterminado \\
\hline atóm. & atómico & indic. & Indicativo \\
\hline aux. & auxiliar; verbo auxiliar & Ingen. & Ingeniería \\
\hline biol. & biología & Ít. & Ítem \\
\hline bioquím. & bioquímica & I. & a veces ley o libro \\
\hline C. & Complejo (en geología) & I. c. & lugar citado (loco citato) \\
\hline c/ , cgo. & cargo & lib. & libra \\
\hline ca. & alrededor (circa) & m. a. & millones de años \\
\hline cant. & cantidad & Morf. & morfología \\
\hline cient. & científico & M. Sc & magíster en ciencias (master of science) \\
\hline Cía. & compañía & Mtro., Mro. & maestro \\
\hline cap. & capítulo & num. & numeral \\
\hline c/c, cta. cte. & cuenta corriente & núm., n. ${ }^{\circ}$ & número \\
\hline col. & columna & ntro./, ntra. & nuestro/, nuestra \\
\hline Col. & Colombia & occid. & occidental \\
\hline Cronol. & cronología & or. & origen \\
\hline D., D. ${ }^{a}$ & don - doña & ord. & de orden \\
\hline$d / f$ & días fecha & orient. & oriental \\
\hline Der. & derecho & p. & página \\
\hline desc. & desconocido & p.d. & posdata \\
\hline $\mathrm{Dr} / \mathrm{a}$ & doctor/doctora & P. S. & post scriptum \\
\hline doc. & documento & pdo. & pasado \\
\hline
\end{tabular}




\begin{tabular}{|c|c|c|c|}
\hline Abreviaturas & Significados & Abreviaturas & Significados \\
\hline dupdo. & duplicado & p. ej., p. e. & por ejemplo \\
\hline ed. & edición & p. m. & después del mediodía (post meridiem) \\
\hline ef/ & efecto & p/o. p. o. & por orden \\
\hline elem. & elemento & p. & páginas \\
\hline Estad. & estadística & Ph. D. & Doctor en filosofía (Philosophy Doctor) \\
\hline e. $g$. & dado como ejemplo (exempli gratia) & pral. & principal \\
\hline et al. & y otros (et alii) & prof. & profesor \\
\hline etc. & Y lo demás (etcétera) & pról. & prólogo \\
\hline ext. & extensión & prov. & provincia \\
\hline flt & falla (en geología) & Quím. & química \\
\hline Fm. & Formación (en geología) & s. f. & sin fecha \\
\hline f. $c$. & ferrocarril & s. a. & $\sin$ año \\
\hline fol. fo & folio & S. A. & sociedad anónima \\
\hline fotogr. & fotografía & s. e. u. o. & salvo error u omisión \\
\hline geogr. & geografía & sig. & siguiente \\
\hline G. & Grupo (en geología) & símb. & símbolo \\
\hline Sr./a. & señor/a & topogr. & topografía \\
\hline Sras. & señoras & trad. & traducción \\
\hline Srs. Sres. & señores & Ud., Uds./s. & usted/ustedes \\
\hline Sras. & señoras & v. trad. & véase traducción \\
\hline Srta. & señorita & v. & vease \\
\hline tecnol. & tecnologías & v. gr. & por ejemplo (verbi gratia) \\
\hline
\end{tabular}

Fuente: adaptado de RAE (2020b).

Dado que las abreviaturas muchas veces tienen una significación ligada a contextos locales, la recomendación es evitar su uso en contextos informativos, empresariales y noticiosos, a menos que haya seguridad de que el lector las entienda; por ejemplo, elaborando un glosario de abreviaturas (Criales, 2019).

Para las revistas del SGC existen títulos abreviados aceptados oficialmente, según su Número Internacional Normalizado de Publicaciones Seriadas (ISSN), como se muestra en la tabla 22. Estas abreviaturas deben observarse de manera estricta, para evitar confusiones con revistas similares.

Tabla 22. Abreviaturas de las revistas del Servicio Geológico Colombiano (radicadas en el respectivo registro ISSN)

\begin{tabular}{ll} 
Nombre de la revista & Abreviatura oficial del título, según el registro ISSN \\
\hline Boletín Geológico & Bol. Geol. \\
Revista Investigaciones y Aplicaciones Nucleares & rev. investig. apl. nucl.
\end{tabular}

\subsection{Nota técnica o transliteraciones}

Esta parte es casi siempre preparada por el autor (o por el editor, en caso de libros de varios autores) y busca aclarar el uso de algunos elementos para ayudar en la comprensión de los lectores sobre algunos aspectos técnicos del contenido que no se abordan en ninguna otra parte del texto. Entre los contenidos usuales están las aclaraciones que se tengan sobre el plan de la obra, las convenciones especiales o específicas en el uso de variables lógicas o consideraciones metodológicas aplicadas en la obra. 
Cuando se trate exclusivamente de las normas de representación de sistemas de escritura o grafemas ajenos al alfabeto latino, podrán simplemente titularse Transliteraciones (Beltrán, 2017, p. 179).

\subsection{Tablas}

\section{Reglas generales para las tablas y algunos consejos}

- Se deben presentar en formato editable, no como imágenes.

- Deben visualizarse después de haberse mencionado en el texto.

- Debe tener un título breve y explicativo, situado fuera del área de la tabla, y debe estar referenciada en el texto.

- En lo posible, organice el texto de manera que no sobrepase el ancho de la tabla.

- Deben explicar o ampliar parte del argumento del documento.

- La descripción de las tablas debe ir en las notas; si se ubica en el texto del trabajo, se le resta agilidad a la lectura.

- En las menciones que haga de la tabla dentro del texto, escriba la palabra tabla con minúscula, excepto cuando esta palabra inicie la línea.

- Si menciona varias tablas, use el plural tablas seguido de los números de los respectivos elementos: esta información se presenta en las tablas 1, 2, 3 y 4. No escriba esta información se presenta en la tabla 1, tabla 2, tabla 3 y tabla 4.

- Si el texto corresponde a un capítulo de un libro o de un documento que vaya a diagramarse, no mencione las tablas (o figuras) como En la siguiente tabla (o figura) se puede apreciar... ya que, por exigencias o limitaciones de diseño, es poco probable que dicho elemento quede inmediatamente después del párrafo donde aparece dicha mención. Así pues, debe mencionarlas de esta forma: En la tabla $x$ (o figura $x$ ) se puede apreciar... (en lugar de la $x$ irá el número que corresponda).

- Si está trabajando la tabla en Excel y necesita crear un nuevo párrafo dentro de una celda, presione la tecla Enter mientras tiene activada la tecla Alt (no AltGr).

- Si necesita utilizar viñetas manuales dentro de una tabla, teclee el número 7 en el teclado numérico mientras tiene presionada la tecla Alt.

En la figura 26 puede verse el esquema para la organización de las tablas, con la ubicación de cada uno de sus componentes. 


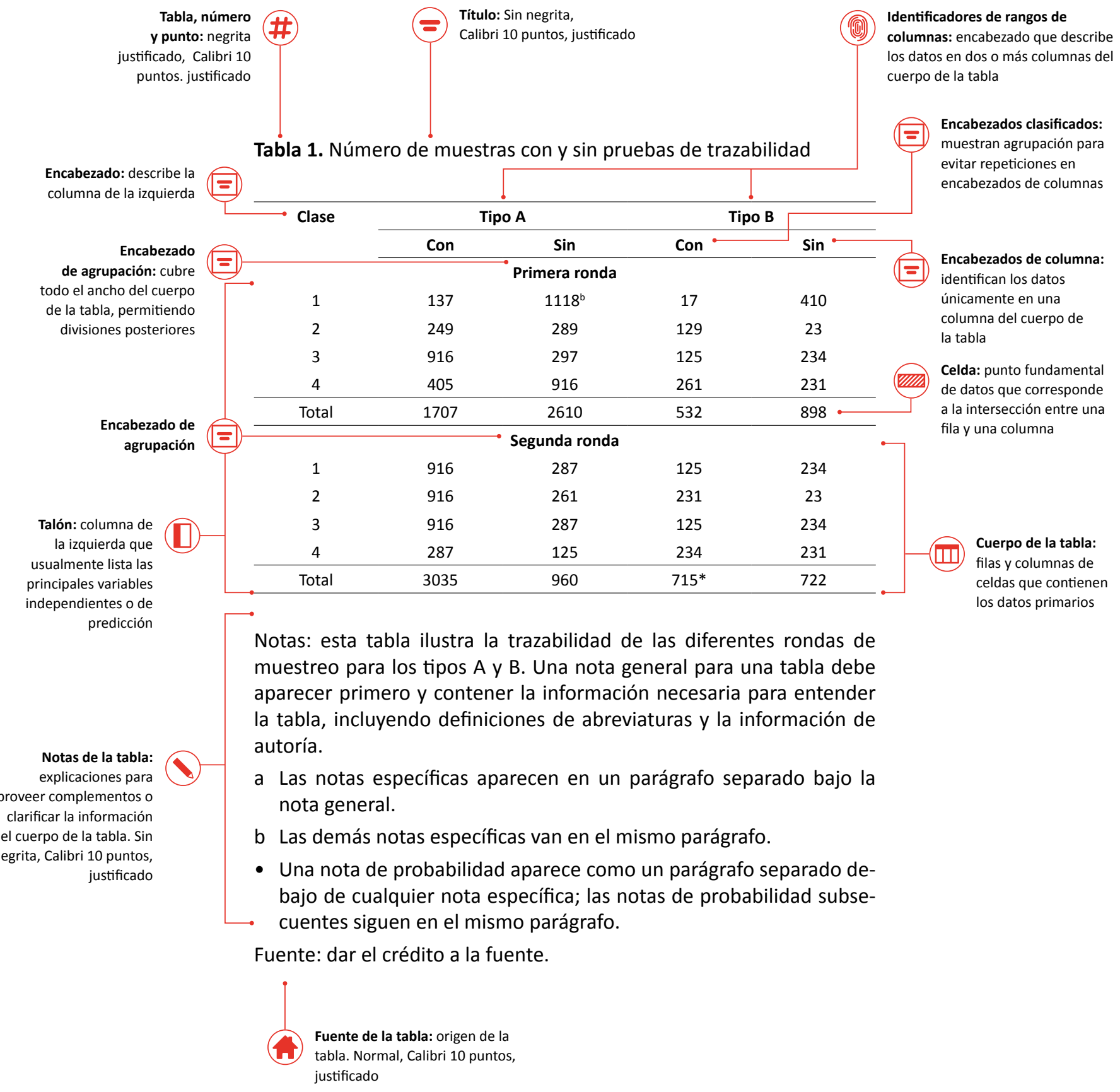

Figura 26. Esquema de organización de las tablas 


\section{Reglas de presentación de las tablas}

- Alinee la tabla (no el contenido de la tabla) en el centro.

- Se deben numerar las tablas en orden de aparición con el texto Tabla seguido de un número consecutivo y un punto en negritas. A continuación debe escribirse el título en la misma línea después del punto, y deben estar en fuente 10 puntos, sin punto final. Asigne a cada tabla un título breve pero descriptivo, y use mayúscula solo a la primera letra (y también a los nombres propios). El número de la tabla y el título deben estar justificados. Deje un espacio en blanco entre el punto y el título de la tabla. Solo en contenidos con muchas figuras o tablas, o en obras de distintos autores, es pertinente una numeración independiente en cada capítulo o parte del contenido (Beltrán, 2017, p. 382).

- Todo el texto relativo a las notas de tabla y fuente de información se escribirá con tipografía 10 puntos, justificado.

- El texto dentro de la tabla debe estar como mínimo en 6 puntos y máximo en 10. Se recomienda optar siempre por el mayor tamaño de fuente posible para favorecer la legibilidad.

- El encabezado debe estar escrito en negritas y minúsculas, salvo la inicial de la primera palabra y de los sustantivos propios, que irán en mayúscula inicial. Si un encabezado comienza por un símbolo, la siguiente palabra irá en minúscula, pues se entiende que el símbolo es la primera palabra.

- Evite el sombreado de las celdas, excepto para dar un énfasis necesario, lo cual debe explicarse en una nota.

- No utilice líneas verticales en la tabla.

- Evite utilizar líneas horizontales en la zona de datos, excepto cuando sea estrictamente necesario; por ejemplo, cuando deba separar lotes de datos o incluir subtotales o similares.

- Utilice línea superior encima de la primera fila de la tabla.

- Utilice línea inferior debajo de cada título en las casillas que corresponda únicamente.

- Utilice una línea inferior debajo de la última fila de la tabla.

- Si la tabla se prolonga por más de una página, se debe habilitar la opción de presentación para repetir filas de títulos. Para lograrlo en Word, seleccione toda la tabla, haga clic sobre ella con el botón alternativo del mouse, diríjase a Propiedades de tabla, y en el cuadro de diálogo que aparece, seleccione la pestaña Fila y marque la casilla Repetir como fila de encabezado en cada página.

- La alineación horizontal de las columnas con texto debe hacerse a la izquierda, para evitar grandes espacios en blanco entre palabras (calaveras, como se conoce en el mundo editorial). Si las columnas ofrecen solo información numérica o de escasos caracteres, la información debe centrarse.

- La alineación vertical debe ser centrada. Para lograrlo en Word, seleccione toda la tabla, haga clic sobre ella con el botón alternativo del mouse, en el menú que se despliega elija Propiedades de tabla, y en el cuadro de diálogo que aparece diríjase a la pestaña Celda, y seleccione Centro.

- Notas: si las tablas requieren un pie de tabla para aclarar una convención o realizar una aclaración, esta información debe estar debajo de la tabla en forma de notas. Escriba las notas que considere necesarias, con alineación justificada. 
- Fuente de la tabla: después del último punto de la nota o en el renglón siguiente a la tabla, después de las notas de tabla, se debe aportar la fuente, también justificada. Inicie con el texto Fuente: y a continuación escriba la fuente de donde ha sido tomada o adaptada la tabla. En caso de que la fuente sea el mismo autor, o autores, no se requerirá esta información.

- Deje un renglón en blanco a espacio sencillo entre los componentes de las notas y Fuente de la tabla y el resto del texto del documento, para delimitar con claridad el área que contiene toda la información relativa a la tabla.

- Ubicación de las tablas en un trabajo: hay dos opciones para situar, tanto tablas como figuras, en un texto. La primera es incrustar las tablas en el texto después de que cada una se mencione por primera vez; el segundo es colocar cada tabla en una página separada después de las referencias.

\section{Sobre las notas para las tablas}

Aunque no es necesario identificarlas como tales, es importante advertir que pueden darse diferentes tipos de notas, dependiendo de su contenido o función. Estas pueden ser:

- Nota general: califica, explica o proporciona información relacionada con la tabla en su conjunto y termina con una explicación de cualquier abreviatura, símbolo o elementos similares.

- Nota específica: se refiere a una columna, fila o celda en particular. Está indicado por supe-

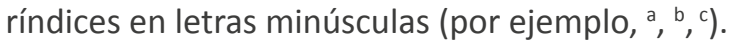

- Nota de probabilidad: indica cómo se utilizan los asteriscos y otros símbolos en una tabla para indicar los valores de probabilidad y, por lo tanto, los resultados de las pruebas de hipótesis estadísticas.

Importante: siempre que se presenten datos numéricos, se debe tener en cuenta que en español se usa la coma para los decimales. El uso del punto corresponde al idioma inglés y, por tanto, no se debe usar como separador decimal, a menos de que sea un documento completo en lengua inglesa. La forma de escribir números se detalla en la sección 5.18.

Estas reglas se ilustran en los siguientes ejemplos:

\section{Ejemplo 4: tabla sencilla con encabezados en cada columna}

Tabla 88. Deslizamientos ocurridos en el municipio de Cáqueza (Cundinamarca) a partir de 1966

\begin{tabular}{ccccc}
\hline Tipo de movimiento & Fecha evento & Departamento & Municipio & Vereda \\
\hline Deslizamiento & $16 / 04 / 2012$ & Cundinamarca & Cáqueza & Cáqueza \\
Deslizamiento & $17 / 02 / 2012$ & Cundinamarca & Cáqueza & Cáqueza \\
Deslizamiento & $07 / 12 / 2011$ & Cundinamarca & Cáqueza & Cáqueza \\
Deslizamiento & $01 / 12 / 2011$ & Cundinamarca & Cáqueza & Cáqueza \\
Deslizamiento & $19 / 09 / 2009$ & Cundinamarca & Cáqueza & Cáqueza
\end{tabular}




\begin{tabular}{ccllc}
\hline Tipo de movimiento & Fecha evento & Departamento & Municipio & Vereda \\
\hline Deslizamiento & $15 / 08 / 1999$ & Cundinamarca & Cáqueza & Cáqueza \\
Deslizamiento & $15 / 07 / 1997$ & Cundinamarca & Cáqueza & Cáqueza \\
Deslizamiento & $01 / 10 / 1996$ & Cundinamarca & Cáqueza & Cáqueza \\
Deslizamiento & $24 / 05 / 1989$ & Cundinamarca & Cáqueza & Cáqueza \\
Deslizamiento & $01 / 04 / 1966$ & Cundinamarca & Cáqueza & Cáqueza \\
\hline
\end{tabular}

Nota: los datos mostrados están limitados únicamente al tipo deslizamiento. Fuente: los datos fueron tomados del Sistema de Información de Movimientos en Masa (SIMMA) del SGC. http://simma.sgc.gov.co/

\section{Ejemplo 5: tabla con encabezados de diferentes niveles}

Tabla 88. Ubicación del sismo principal y réplicas del terremoto del Quindío del 25 de enero de 1999

\begin{tabular}{|c|c|c|c|c|c|c|c|c|}
\hline \multirow[b]{2}{*}{ Fecha } & \multirow[b]{2}{*}{$\begin{array}{l}\text { Hora } \\
\text { (UTC) }\end{array}$} & \multicolumn{3}{|c|}{ Ubicación del sismo } & \multicolumn{2}{|c|}{$\begin{array}{l}\text { Magnitudes } \\
\text { reportadas }\end{array}$} & \multicolumn{2}{|c|}{$\begin{array}{l}\text { Entidad territorial de } \\
\text { ocurrencia }\end{array}$} \\
\hline & & $\begin{array}{l}\text { Latitud } \\
\text { (grados) }\end{array}$ & $\begin{array}{l}\text { Longitud } \\
\text { (grados) }\end{array}$ & $\begin{array}{l}\text { Profundidad } \\
\quad(\mathrm{km})\end{array}$ & $\begin{array}{l}\text { Magnitud } \\
(\mathrm{ml})\end{array}$ & $\begin{array}{l}\text { Magnitud } \\
(\mathrm{Mw})\end{array}$ & Departamento & Municipio \\
\hline $1999-01-25$ & $18: 19: 17$ & 4,439 & $-75,698$ & 0,0 & 6,3 & & Quindío & Córdoba \\
\hline $1999-01-25$ & 18:51:05 & 4,461 & $-75,744$ & 0,8 & 2,9 & & Quindío & La Tebaida \\
\hline $1999-01-25$ & 19:01:02 & 4,388 & $-75,631$ & 4,3 & 2,5 & & Quindío & Córdoba \\
\hline $1999-01-25$ & $23: 33: 47$ & 4,467 & $-75,700$ & 2,8 & 2,8 & & Quindío & Armenia \\
\hline
\end{tabular}

Notas: Los datos de magnitud Mw no se suministran, debido a que en las fechas de ocurrencia del sismo no se calculaba dicho tipo de magnitud. Fuente: los datos fueron tomados del Catálogo de sismicidad de la Red Sismológica Nacional de Colombia. https://www2.sgc.gov.co/sgc/sismos/Paginas/ catalogo-sismico.aspx

\section{Ejemplo 6: tabla con información voluminosa entre filas que se separa usando líneas horizontales}

Tabla 88. Edades U-Pb para las muestras del experimento 1

\begin{tabular}{|c|c|c|c|c|c|c|}
\hline IGM & N. ${ }^{\circ}$ campo & N & w & Clasificación & $\begin{array}{l}\text { Edad U-Pb } \\
\text { (Ma) }\end{array}$ & Edades heredadas \\
\hline 900962 & TCR-376 & 1231161 & 1124265 & Monzogranito & $202,5 \pm 1,3$ & $(880 \pm 15, n=1)$ \\
\hline 900944 & MIA-638 & 1217144 & 1126040 & Monzogranito & $200,4 \pm 2,2$ & $\begin{array}{c}(1627 \pm 77, n=1 ; 1120 \pm 79, n \\
=1 ; 316,9 \pm 6,8, n=1 ; 234,4 \pm \\
7,1, n=1)\end{array}$ \\
\hline 900927 & LMC-075 & 1208090 & 1131045 & Monzogranito & $195,7 \pm 3,9$ & $\begin{array}{c}(1230 \pm 43, n=1 ; 1040-1020 \pm \\
34, n=2 ; 248,5 \pm 10, n=1)\end{array}$ \\
\hline 901525 & AMC-0162 & 1206436 & 1137867 & $\begin{array}{c}\text { Monzogranito } \\
\text { deformado }\end{array}$ & $\begin{array}{l}199,6 \pm 1,8 \\
(211,8 \pm 3,8 \\
199,6 \pm 2,6 \\
189,1 \pm 3,6)\end{array}$ & $\begin{array}{c}(1290-115, n=4 ; 970, n=2 ; \\
800-735, n=3 ; 680-650, n=2 ; \\
585, n=2 ; 513, n=1 ; 459-451, \\
n=5 ; 445-437, n=5 ; 420-395, \\
n=5 ; 386-376, n=5 ; 360-338, \\
n=6 ; 298-270, n=5 ; 252-248, \\
n=2 ; 234-231, n=4 ; 224-222, \\
n=2 ;)\end{array}$ \\
\hline
\end{tabular}

Notas: el campo IGM corresponde a una codificación interna del SGC. 


\section{Ejemplo 7: tabla con divisiones entre grupos de datos y totales parciales}

Tabla 88. Número de muestras con y sin pruebas de trazabilidad

\begin{tabular}{lllll}
\hline \multirow{2}{*}{ Clase } & \multicolumn{2}{c}{ Tipo A } & \multicolumn{2}{c}{ Tipo B } \\
\cline { 2 - 5 } & \multicolumn{1}{c}{ Con } & \multicolumn{1}{c}{ Sin } & Con & \multicolumn{1}{c}{ Sin } \\
\hline \multirow{4}{*}{$\begin{array}{l}\text { Primera ronda } \\
1\end{array}$} & $137^{\text {a }}$ & $1.118^{\text {b }}$ & 17 & 410 \\
2 & 249 & 289 & 129 & 23 \\
3 & 916 & 287 & 125 & 234 \\
4 & 405 & 916 & 261 & 231 \\
\hline Total & 1707 & 2610 & 532 & 898 \\
\hline & & Segunda ronda & \\
1 & 916 & 287 & 125 & 234 \\
2 & 916 & 261 & 231 & 23 \\
3 & 916 & 287 & 125 & 234 \\
4 & 287 & 125 & 234 & 231 \\
\hline Total & 3035 & 960 & $715^{*}$ & 722 \\
\hline
\end{tabular}

Notas: esta tabla ilustra la trazabilidad de las diferentes rondas de muestreo correspondientes a los tipos A y B.

a Cada uno de los datos de los que se tiene evidencia de trazabilidad cuentan con un informe descriptivo completo.

${ }^{\mathrm{b}}$ Los datos sin evidencia de trazabilidad no tienen informes o metadatos asociados y verificables.

* Tenga en cuenta que este valor está calculado como la suma simple de los datos de cada ronda.

\subsection{Figuras}

\section{Reglas generales para las figuras}

- Todas las imágenes, ya sean diagramas, fotografías, mapas, dibujos o infografías, se deben titular como figuras, y se deben numerar en orden de aparición. Cada figura debe tener un título breve y explicativo, y debe estar mencionada en el texto -ejemplo: (figura 1) En lo posible, organice el texto de manera que no sobrepase el ancho de los márgenes del documento.

- Todos los elementos de la figura, incluyendo leyendas, textos de ejes y otros elementos de texto deben ser legibles en el tamaño normal de la figura. Se recomienda usar tamaños de fuente no menores de 6 puntos ni mayores de 11 .

- Cuando se trate de imágenes, su resolución mínima debe ser de 300 DPI; sin embargo, lo recomendable es que sea de $600 \mathrm{DPI}$.

- Si la figura contiene un mapa, incluya la información necesaria que permita georreferenciarlo, orientarlo (dirección del norte u otro punto cardinal), darle una escala gráfica o en números y las convenciones necesarias para darle sentido. Para mayor información, refiérase al capítulo 6 .

- La descripción de las figuras va en las notas de la figura y no en el texto, ya que la descripción en el texto resta agilidad a la lectura. 
En la figura 27 puede verse el esquema de organización de las figuras, con la ubicación de cada uno de sus componentes.

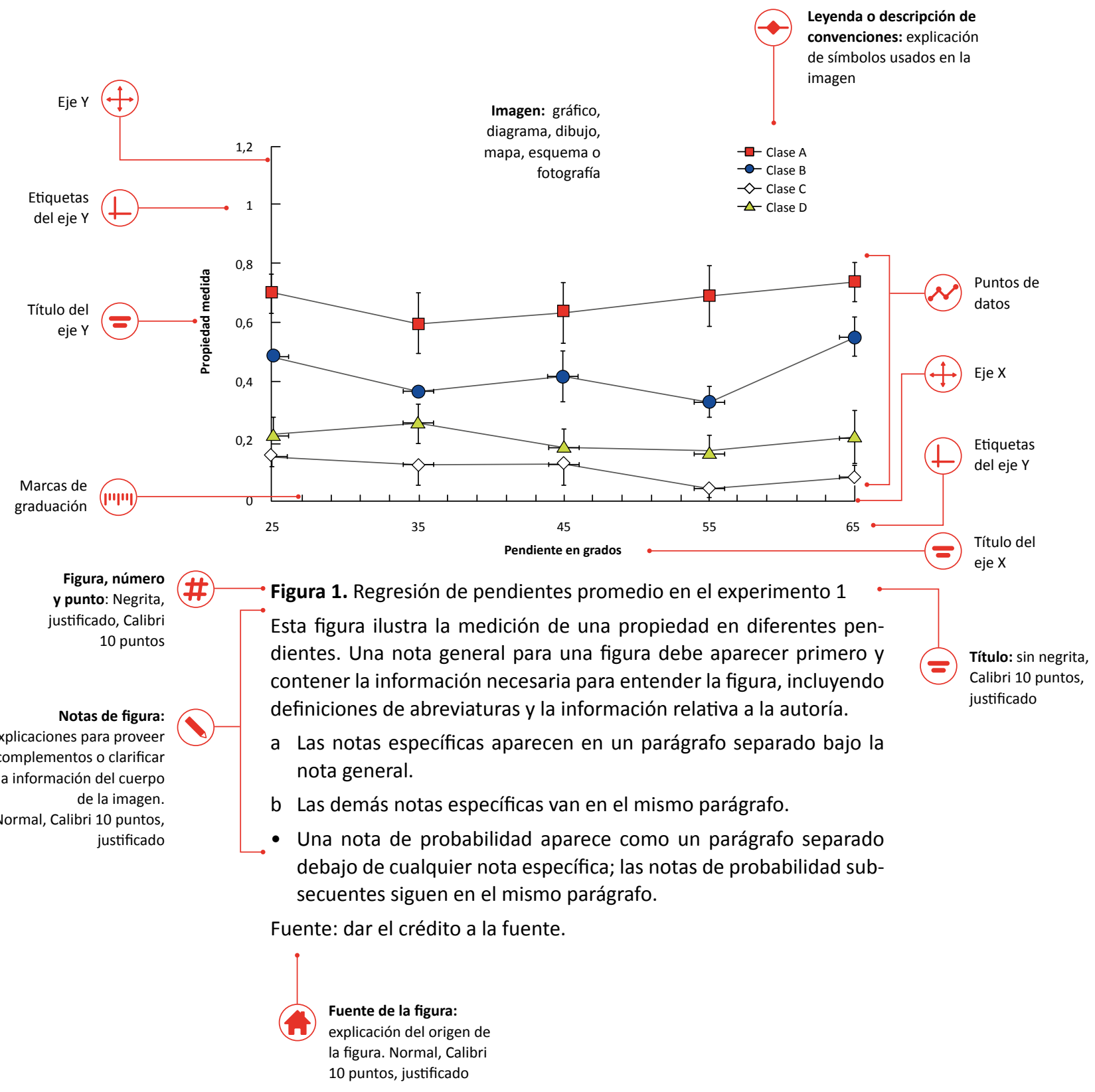

Figura 27. Esquema de organización de las figuras 


\section{Reglas de presentación de las figuras}

- Se deben numerar las figuras en orden de aparición con el texto Figura seguido del número consecutivo, un punto en negritas y fuente en 10 puntos. A continuación debe escribirse el título de la figura en la misma línea, sin punto final y sin negritas. Asigne a cada figura un título breve pero descriptivo, y escríbalo utilizando mayúscula solo en la inicial de la primera palabra y de los nombres propios. La palabra Figura, el número y el título deben estar justificados debajo de la imagen de la figura. No incluya el título en el interior de la figura. Solo en contenidos con muchas figuras o tablas o en obras de distintos autores, es necesaria una numeración independiente en cada capítulo o parte del contenido (Beltrán, 2017, p. 382).

- Imagen: la parte de la imagen de la figura es el gráfico, cuadro, fotografía, dibujo u otra ilustración en sí. Utilice justificación central para la imagen. Si aparece texto en la imagen de la figura (por ejemplo, etiquetas de los ejes), use una fuente sin serifas (preferiblemente Calibri) con tamaño no menor de 6 puntos ni mayor de 11.

- Si se trata de una imagen dividida en varias partes, deberá tenerse un solo número de figura y sus partes se identifican con una letra minúscula que deberá estar en un recuadro con fondo blanco y sin borde, con un tamaño entre 6 y 10 puntos y en negritas. El recuadro no podrá tener más de $0,5 \mathrm{~cm}$ de lado. El conjunto de figuras también tendrá una sola sección de notas.

- Leyenda: una leyenda de figura, o clave, si está presente, debe colocarse dentro de los límites de la figura. Se usa para explicar cualquier símbolo usado en la imagen. Escriba con mayúscula únicamente la primera letra del título de la leyenda, que irá justificado.

- Notas: las notas de pie de figura no deben formar parte del título, y deben estar en línea aparte, debajo del título de la figura y justificado. Aunque no es necesario distinguirlas en el texto, se identifican tres tipos de notas (general, específica y de probabilidad), que pueden aparecer debajo de la figura para describir los contenidos que no se pueden entender a partir del título, la imagen o la leyenda de la figura, únicamente (p. ej., definiciones de abreviaturas, atribución de derechos de autor, explicaciones del uso de asteriscos para indicar valores). Incluya notas de figuras solo cuando sea necesario. Tanto la nota de pie de figura como la fuente deberán estar en tipografía de 10 puntos, sin negritas.

- Si se considera apropiado, las notas deben incluir las unidades de mediciones representativas de los tipos de datos, duración del experimento, etc.

- Cuando se requieran notas que se refieran a partes de las figuras, se usarán letras minúsculas entre paréntesis. Las diferentes descripciones se separarán por coma (,), punto y coma (;), o punto (.), dependiendo del contexto presentado.

- En caso de que se presenten dos o más figuras iguales con diferentes variables, se debe indicar que es igual y matizar la diferencia; por ejemplo: "Ídem que en la figura 5, pero para la humedad relativa".

- Fuente de la figura: las imágenes no realizadas por los autores del contenido deben contar con la autorización del autor de la imagen original, estar libres de conflictos de derechos de autor o tener licencia Creative Commons (consultar https://co.creativecommons.org/). Indique claramente la procedencia de la figura después de la palabra Fuente:, en texto justificado de 10 puntos. La fuente puede indicarse después del último punto de la nota o en el 
renglón siguiente. Las imágenes tomadas de internet, de libros o publicaciones periódicas deben contar con el permiso de autor para su reproducción. No es correcto pensar que por referenciar la web o la publicación de la que se tomaron ya se están dando los créditos suficientes. En caso de que la fuente sea(n) el (los) mismo(s) autor(es), no se requerirá la información de Fuente.

- Los mapas, fotografías aéreas e imágenes de satélite deben incluir una escala gráfica, coordenadas, orientación y, de ser necesario, parámetros de georreferenciación y unidades de los ejes $\mathrm{X}$ y $\mathrm{Y}$. Las recomendaciones específicas de distintos tipos de figuras pueden apreciarse en el capítulo 6.

- En cuanto al tratamiento de fotografías de campo, deberá acoger las recomendaciones de la sección 6.4.6. Para el tratamiento de imágenes de petrografía, deberán seguir lo estipulado en la sección 6.5.

- Ubicación de las figuras en un trabajo: hay dos opciones para colocar figuras (y tablas) en un texto. La primera es incrustarlas en el texto después de que cada una de ellas se menciona por primera vez; la segunda es colocar cada figura en una página separada después de las referencias.

- Una figura incrustada puede ocupar una página completa; si la figura no ocupa mucho espacio, sin embargo, el texto puede aparecer en la misma página que la figura. En este caso, coloque la figura en la parte superior o inferior de la página, y no en el medio. Las sugerencias de tamaños de figuras pueden apreciarse en la sección 6.1.3.

Mayores detalles de diseño y construcción de figuras pueden observarse en el capítulo 6.

Las reglas que rigen para las figuras se ilustran en los siguientes ejemplos:

Ejemplo 8: figura de diagrama de barras comparativo con medidas de dispersión de mediciones

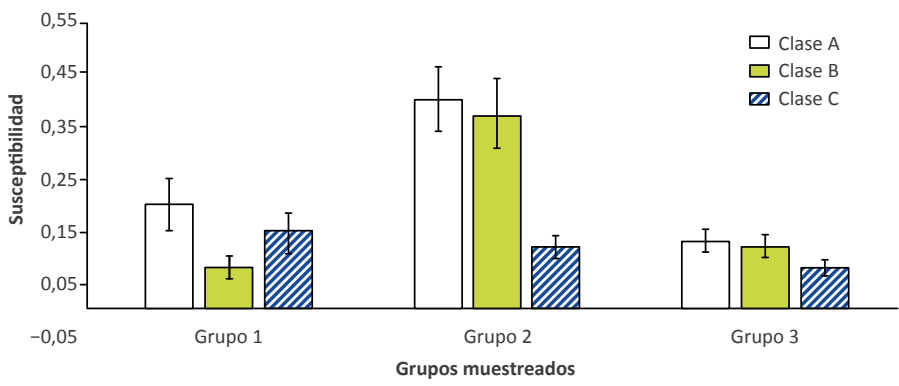

Figura 99. Medidas de susceptibilidad por grupos correspondientes a tres clases de elementos Para cada elemento se incluye una estimación de la dispersión basada en la desviación estándar observada en cada caso. 
Ejemplo 9: diagrama de puntos para comparar diferentes tendencias

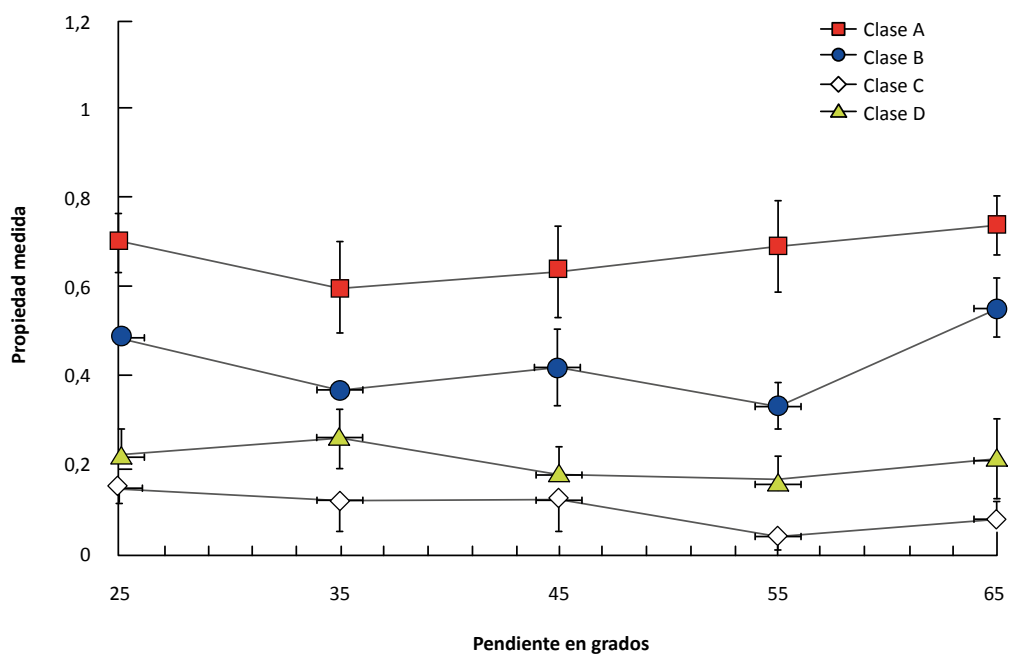

Figura 99. Regresión de pendientes promedio en el experimento 1 Para cada elemento se incluye una estimación de la dispersión basada en la desviación estándar observada en cada caso.

\section{Ejemplo 10: mapa geológico}

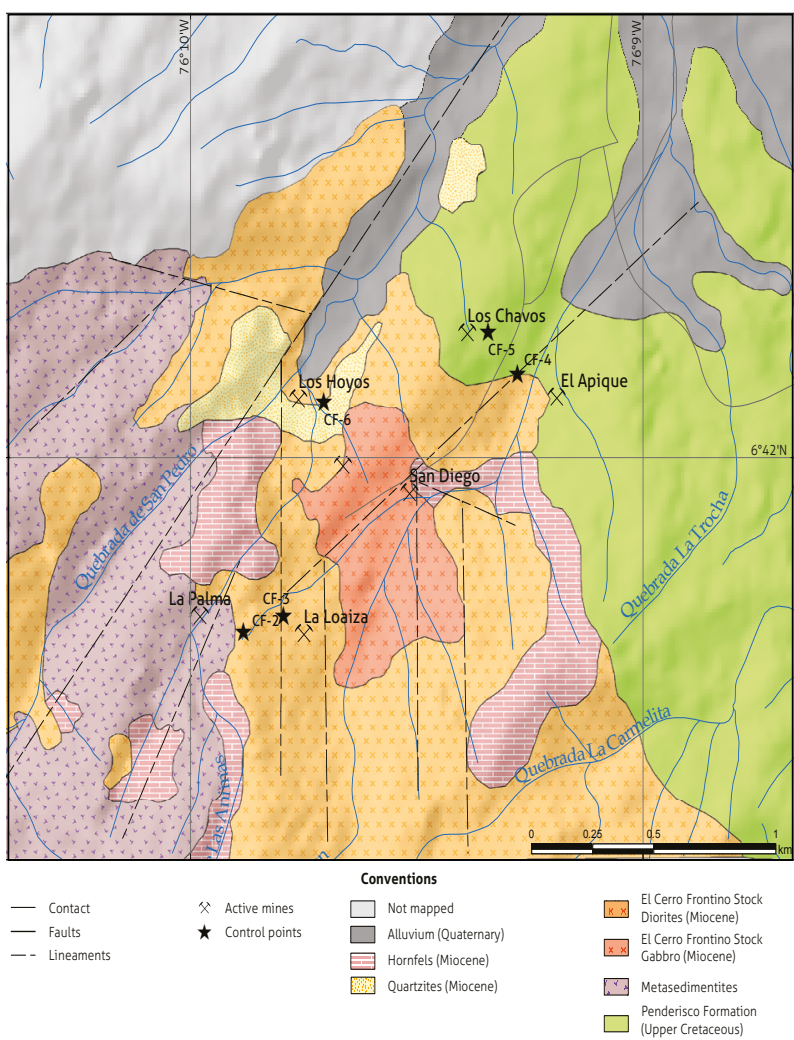

Figure 99. Geological map of the El Cerro Frontino stock with the main mineralized structures relating to this study Source: modified from Arrubla-Arango and Silva-Sánchez (2021). 


\section{Ejemplo 11: mapa de accesos a una región}

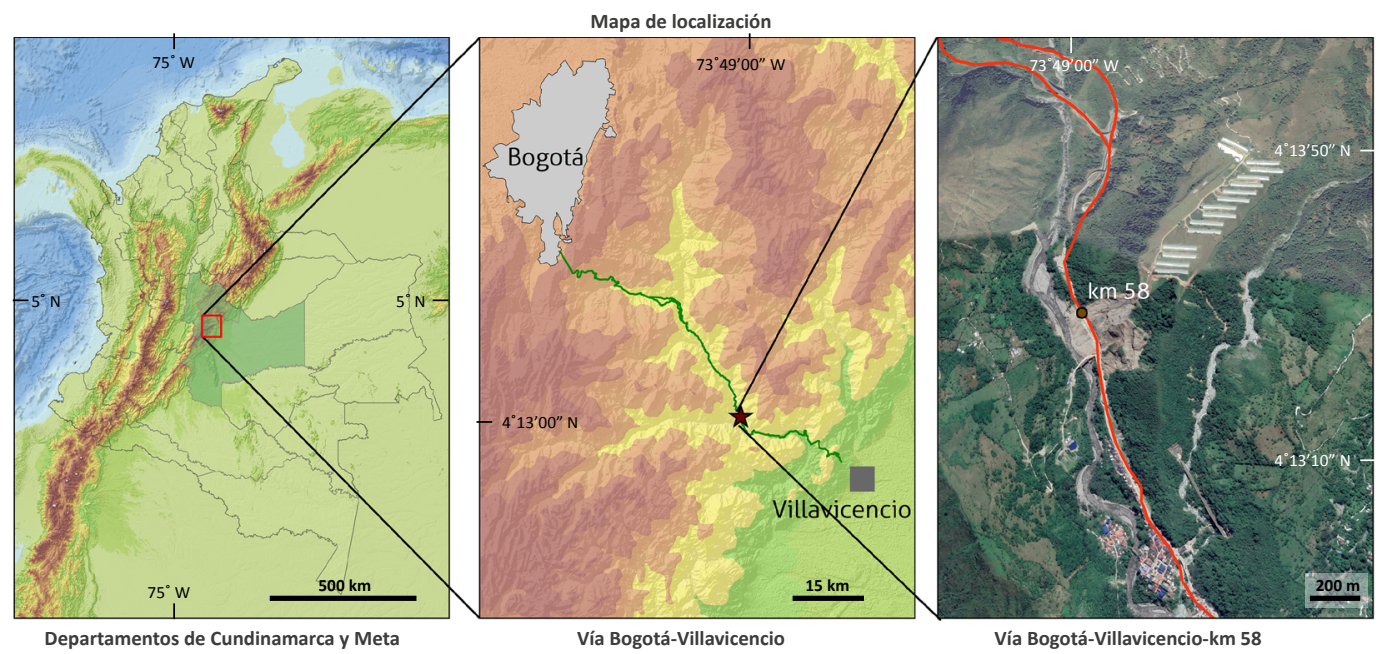

Figura 99. Localización regional del km 58 vía Bogotá-Villavicencio Fuente: adaptado de Navarro et al. (2019).

\section{Ejemplo 12: mapa temático con leyenda en colores}

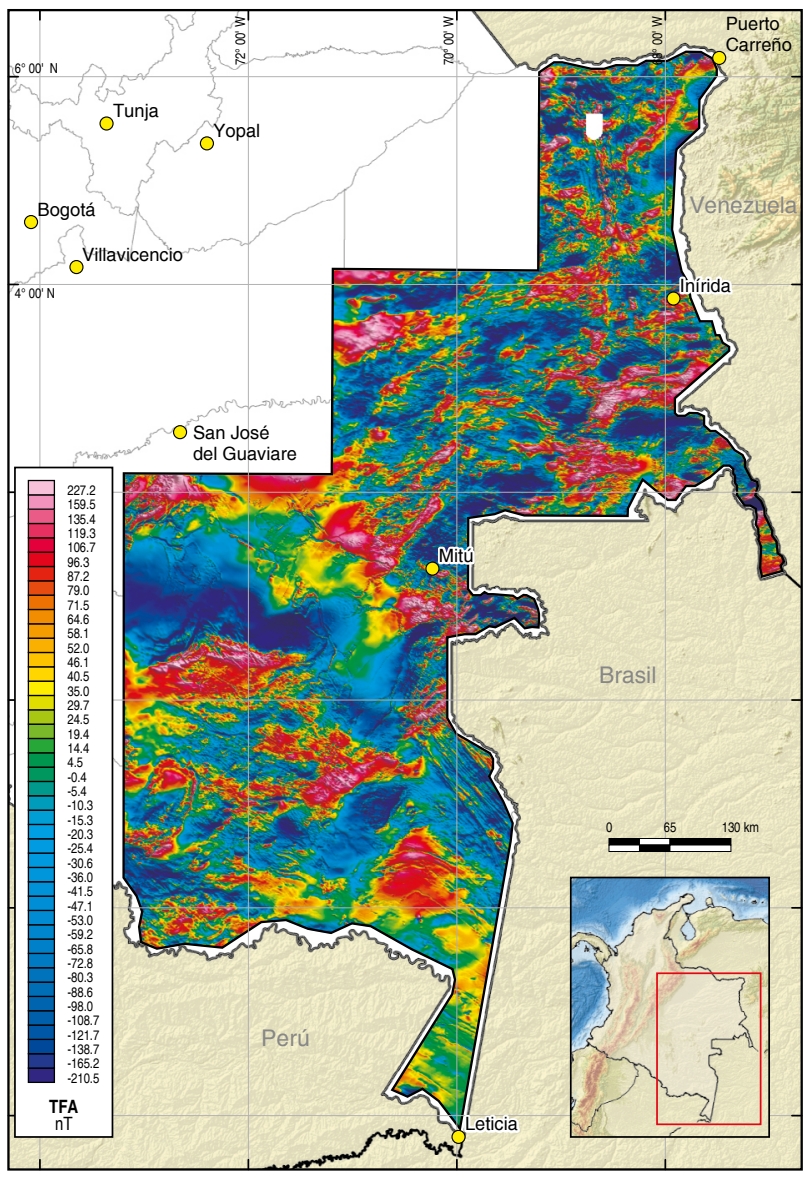

Figure 99. TFA map of eastern Colombia

Source: adapted from Moyano et al. (2016). 
Ejemplo 13: diagramas, infografías y dibujos
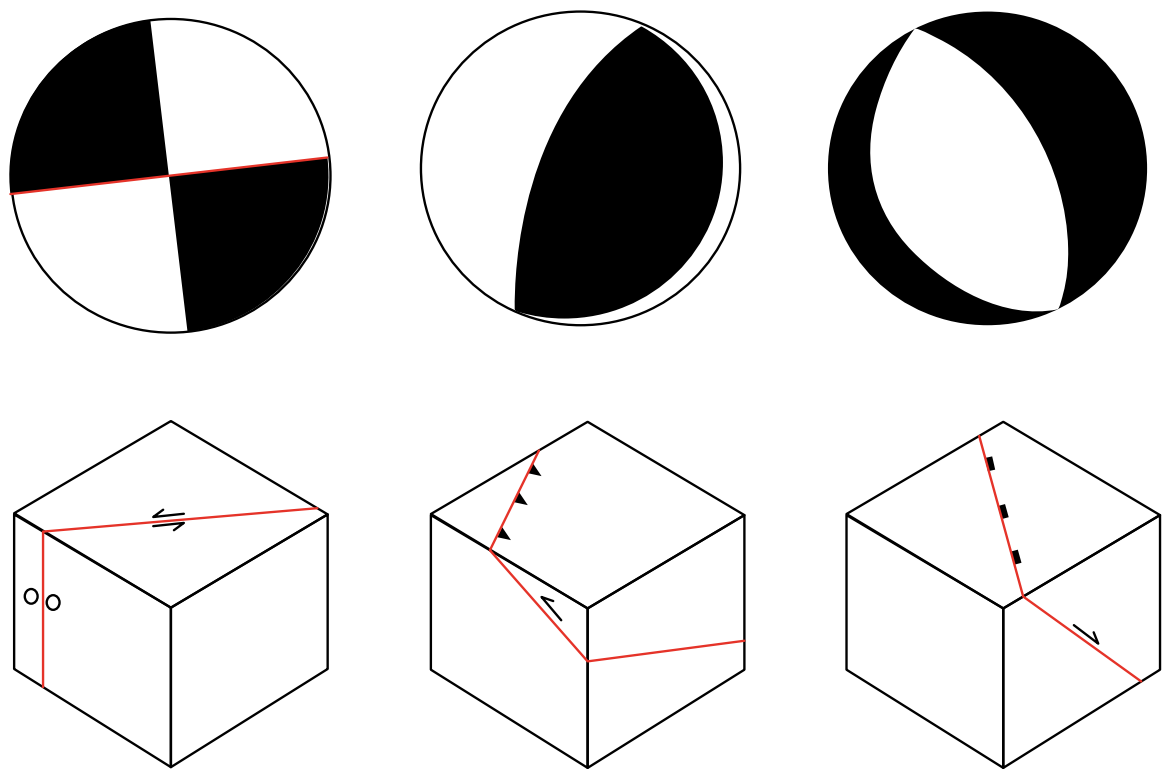

Figura 99. Mecanismos focales identificados en el campo 4 Fuente: adaptado de Cox y Hart (1986).

Ejemplo 14: diagrama de concordia e histograma de edades

a

Diagrama de concordia Wetherill para Dromedary

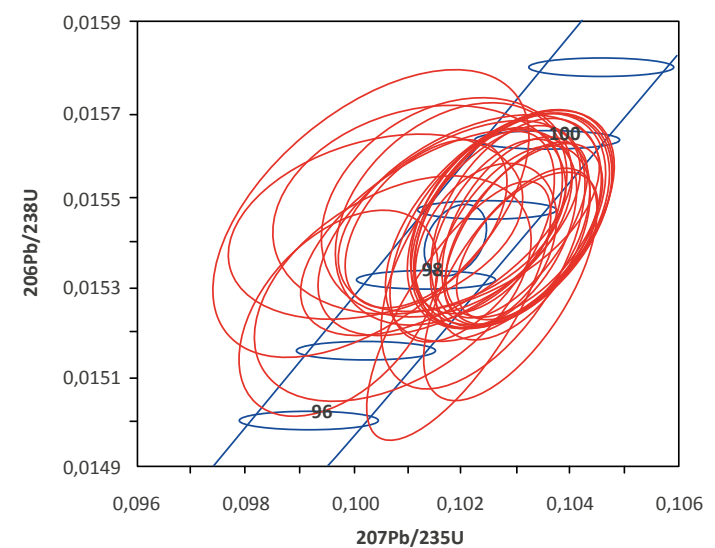

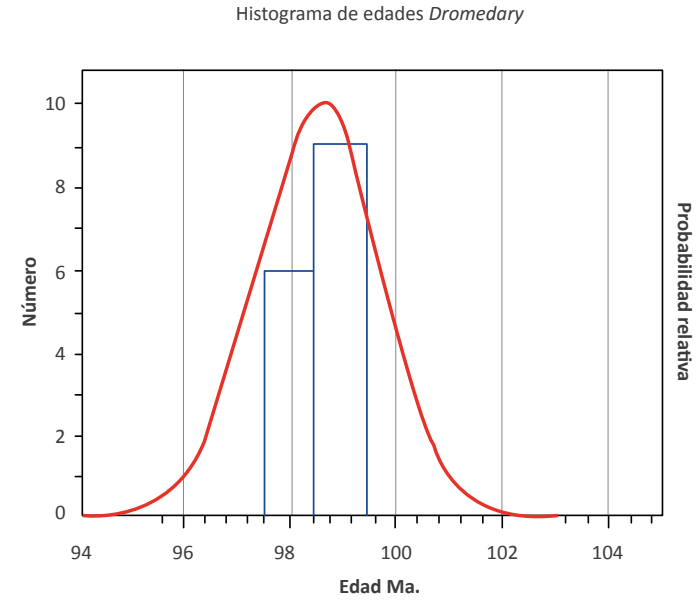

Figura 99. Diagrama de concordia de Wetherill para Dromedary

a) Diagrama de concordia Wetherill; b) histograma de edades en material de referencia Mount Dromedary, según el sistema 206Pb/238U. Fuente: tomado de Peña et al. (2018). 


\section{Ejemplo 15: fotografía de sección delgada}

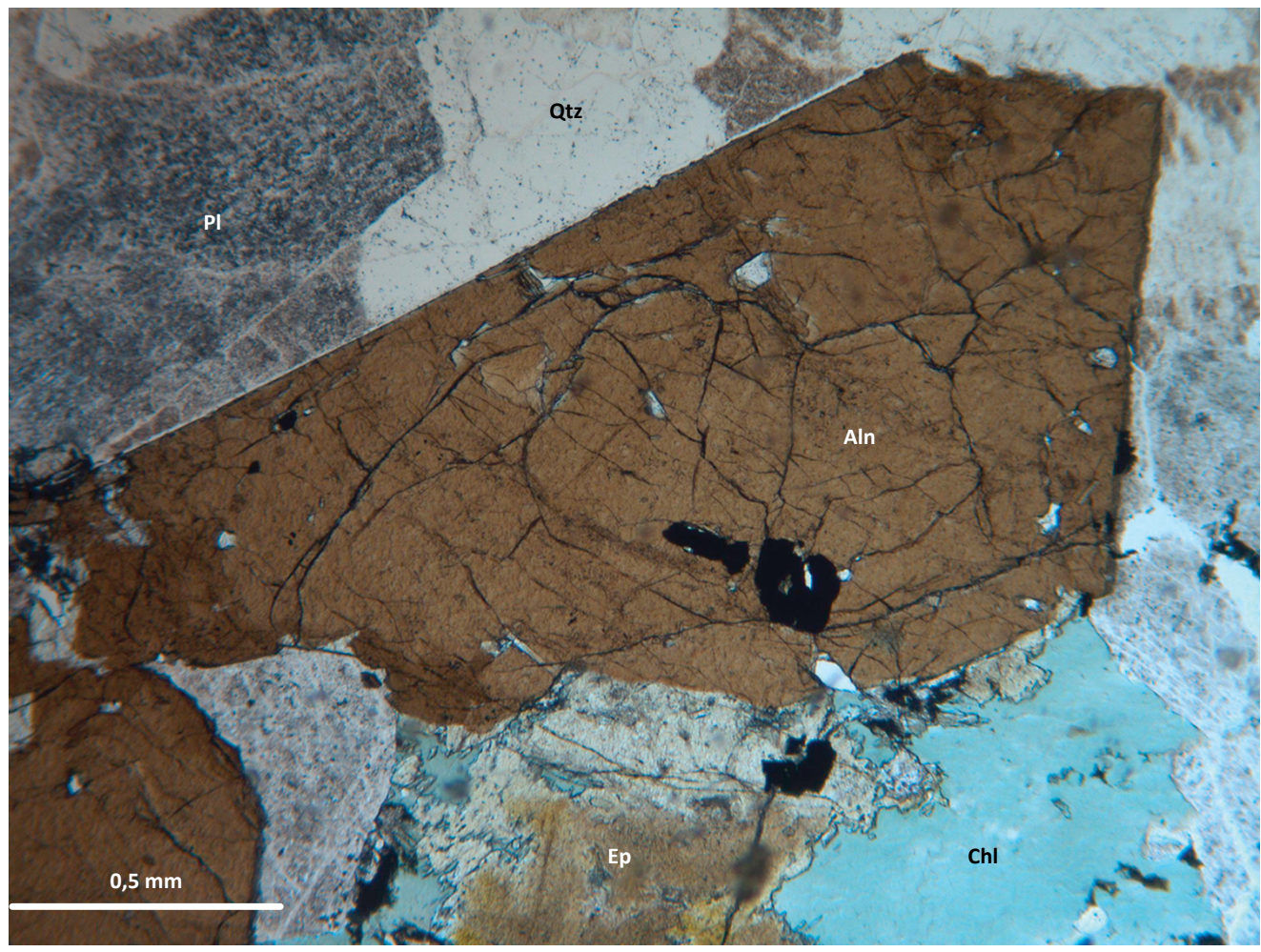

Figura 99. Microfotografía de un cristal de allanita de los monzogranitos del Batolito de Mogotes. IGM10905. Cristal subhedral de allanita (Aln). Nícoles paralelos. Fuente: tomado de Rodríguez et al. (2020).

\section{Ejemplo 16: fotografías de campo}
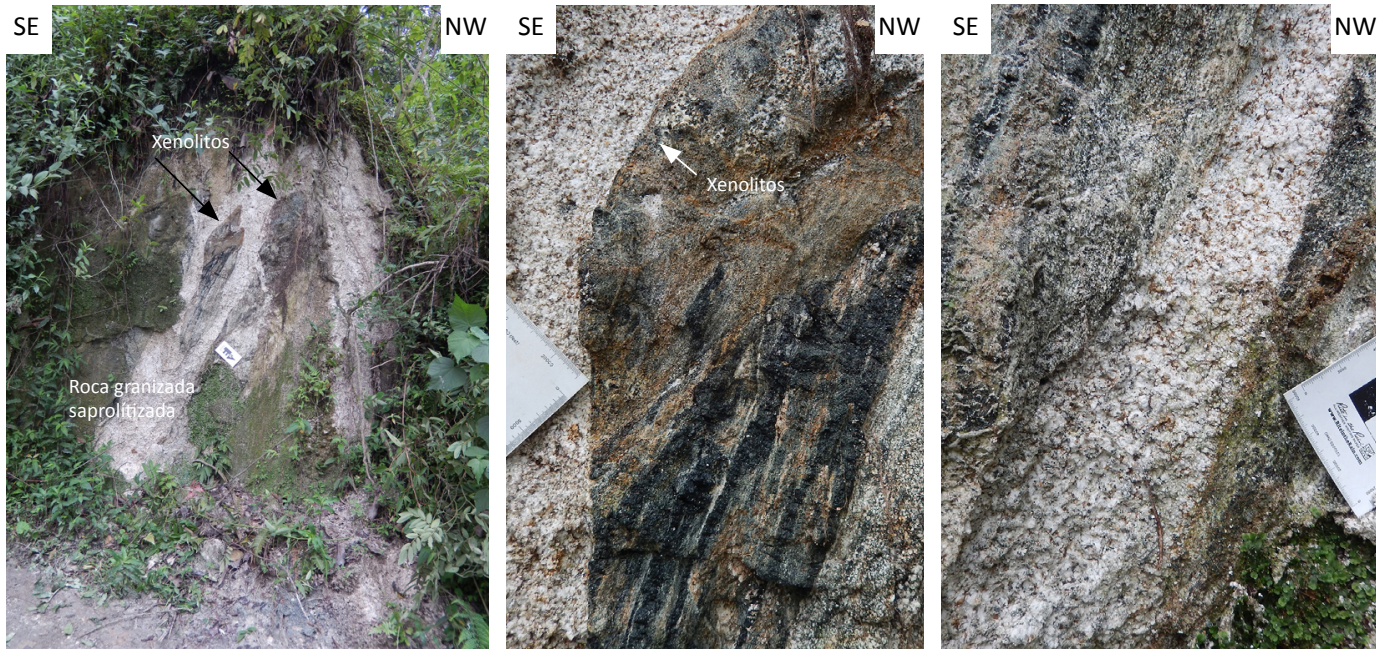

Figura 99. Carreteable hacia las Cascadas de Marinca

Estación PAR0016/ECC0007A. Ejemplo de orientación de fotografías. Fuente: cortesía de Elizabeth Cortés Castillo. 


\section{Ejemplo 17: fotografía de equipos o montajes para ensayos}

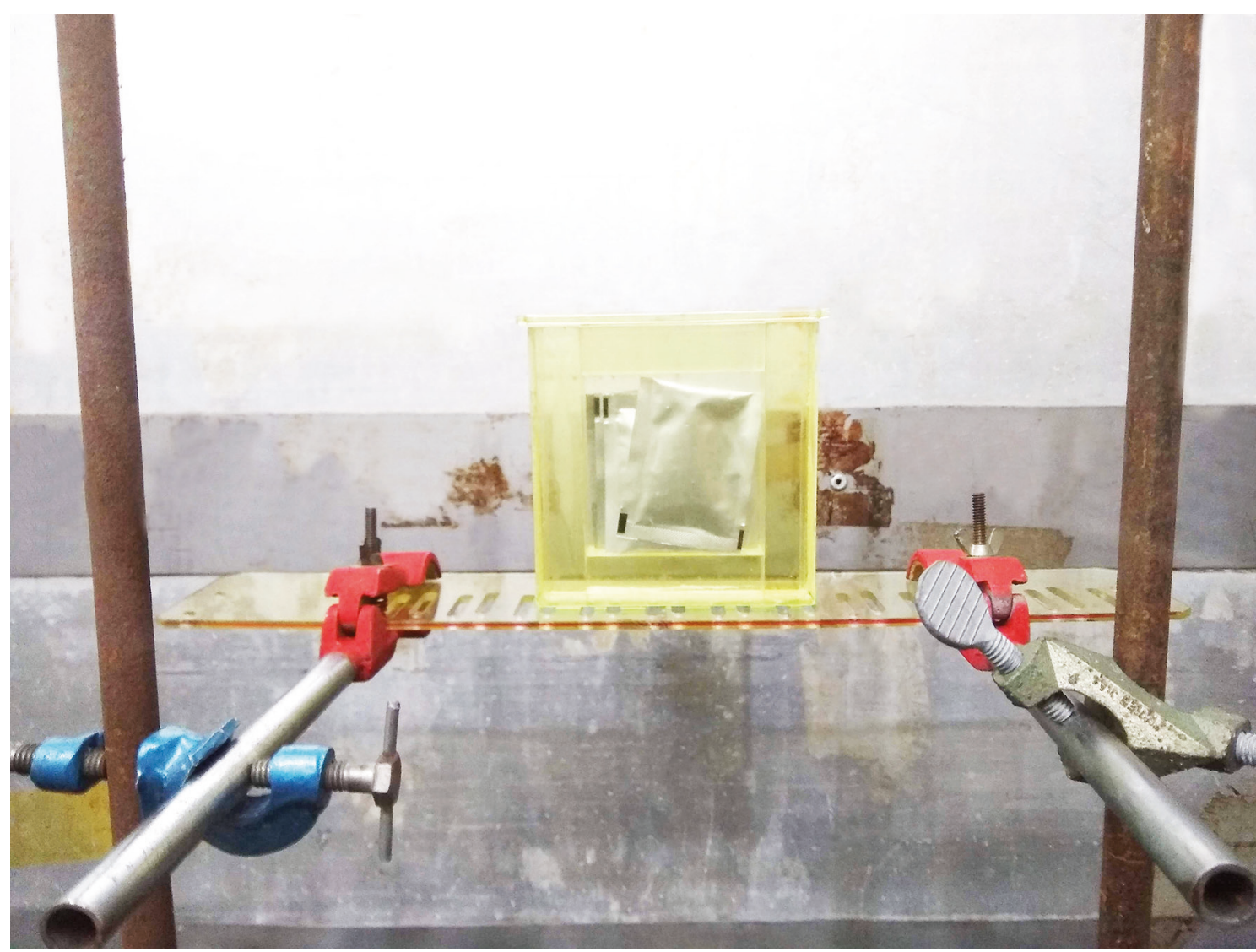

Figura 99. Montaje para irradiar los ítems de ensayo Fuente: tomado de Abril et al. (2019).

\section{Recomendación especial cuando se tengan figuras repetitivas}

En aquellos casos en que exista una gran cantidad de figuras con pequeñas diferencias, conviene evaluar si es posible mostrar los resultados en una sola que resuma la situación.

Por ejemplo, en lugar de incluir en el trabajo de manera individual varias figuras para el mismo tipo de ejes, considere la elaboración de una sola en la que se pueda apreciar el valor de todas las variables o funciones y sus diferencias o contrastes. 


\section{Ejemplo 18: presentación consolidada en una sola figura de varios resultados}

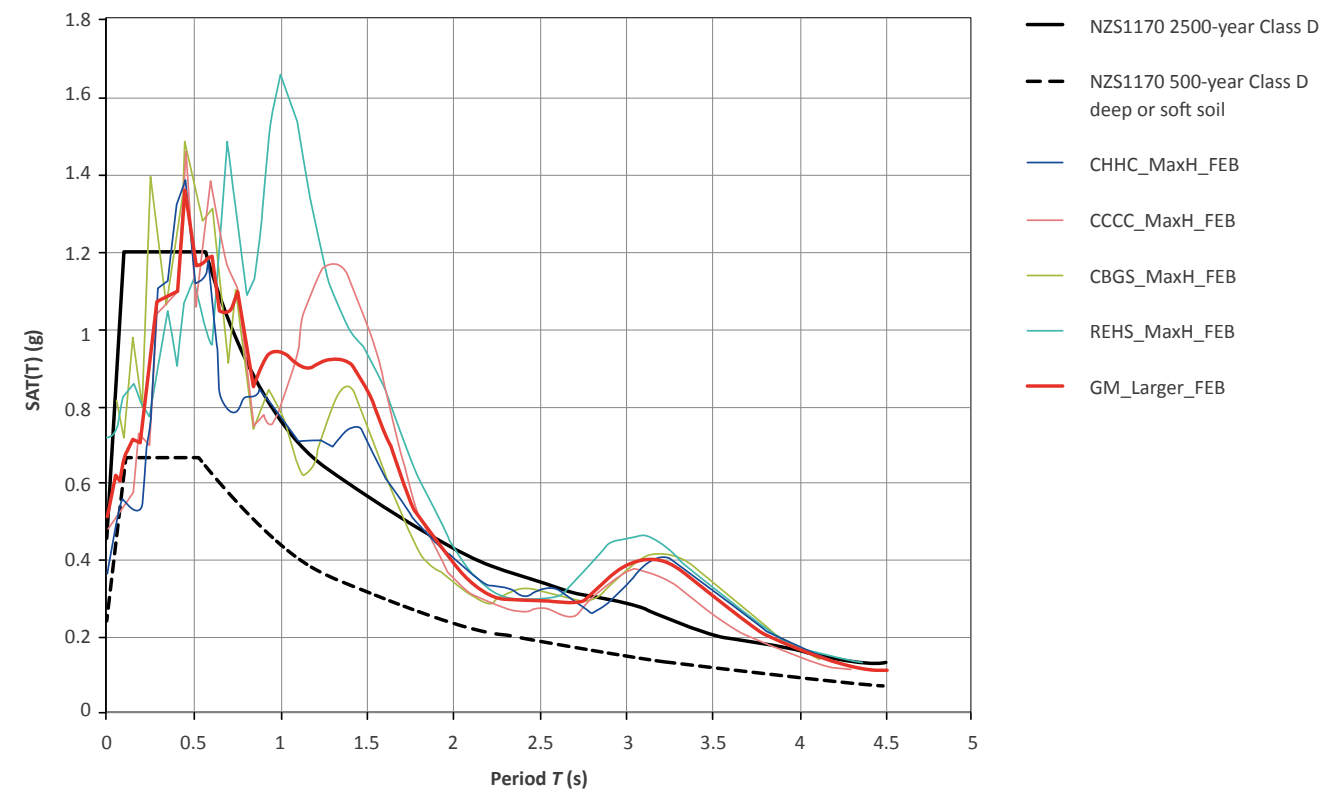

Figure 99. Response spectra for various cases in Christchurch, New Zealand Source: adapted from McVerry et al. (2012).

\section{Ejemplo 19: presentación de figuras con varios componentes}

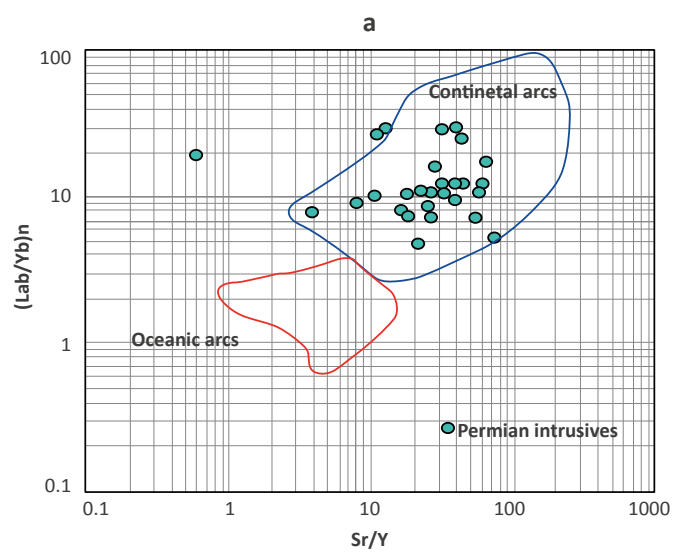

口 Nechí Gneiss

๑ Ortega Granite

口 La Plata Granite

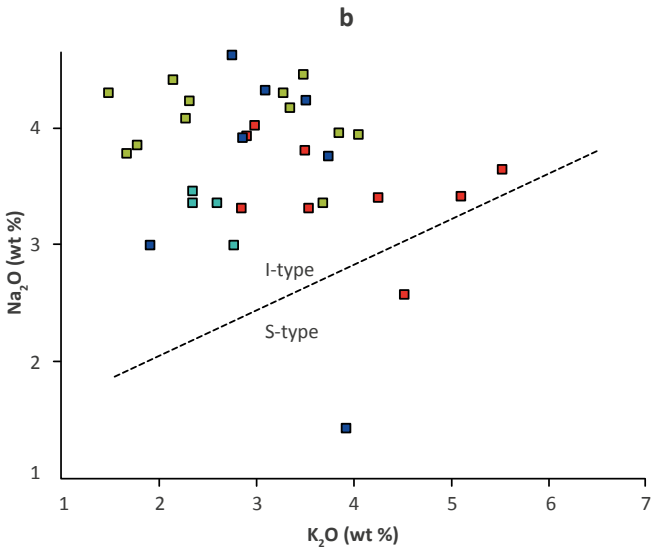

口 El Encanto Orthogneiss

Figure 99. Tectonic environment discrimination diagrams for permian units

a) Condie y Kröner (2013) diagram; b) Chappell y White (1974) diagram. Source: adapted from Rodríguez et al. (2020). 


\subsection{Ecuaciones}

En algunos textos es necesario formar ecuaciones o expresiones matemáticas. El autor puede usar las funciones integradas de su procesador de textos, observando algunos elementos del proceso que requieren su atención.

De acuerdo con Mills y Metanomski (1999), la regla general es que los símbolos que representan cantidades físicas (o variables) se escriben en cursiva, pero los símbolos que representan unidades, o etiquetas, se escriben en romanas (redondas). Algunas veces puede haber dudas sobre si un símbolo representa una cantidad o tiene algún otro significado (como una etiqueta): para estos casos se verifica que a las cantidades, o variables, se les puede dar un valor, pero a las etiquetas no. Los vectores, tensores y matrices generalmente se denotan usando una fuente en negritas, pero aún deben estar en cursiva ya que siguen siendo cantidades.

\section{Ejemplo:}

la masa de la pluma $m=24 \mathrm{~g}=0,024 \mathrm{~kg}$. La intensidad del campo eléctrico $E$ tiene componentes Ex, Ey y Ez. La constante de Planck $h=6,62606876(52) \times 10^{-34} \mathrm{~J} \mathrm{~s}$.

La regla anterior se aplica igualmente a los símbolos de letras del alfabeto griego y latino.

Ejemplo:

cuando el símbolo $\mu$ se usa para denotar una cantidad física (como masa o masa reducida), debe estar en cursiva, pero cuando se usa en una unidad como el microgramo, $\mu \mathrm{g}$, o cuando se usa como símbolo del muón, $\mu$, debe ser romano (Bureau International des Poids et Mesures [BIPM], 2019).

Los números y las etiquetas son generalmente romanos, ya que no son cantidades físicas.

Los símbolos de los elementos de la tabla periódica deben ser romanos, ya que no son cantidades físicas. De manera similar, los símbolos utilizados para representar partículas elementales son siempre romanos.

Ejemplos:

$\mathrm{H}, \mathrm{He}, \mathrm{Li}, \mathrm{Be}, \mathrm{B}, \mathrm{C}, \mathrm{N}, \mathrm{O}, \mathrm{F}, \mathrm{Ne} . .$. para átomos; e para el electrón, p para el protón, n para el neutrón, $\mu$ para el muón, a para la partícula alfa, etc.

\subsubsection{Ecuaciones en la línea del texto}

Cuando las ecuaciones sean cortas y sencillas, como $x=[(7+y) / z)] \frac{1}{2}$, puede escribirlas en la misma línea de texto.

Para las ecuaciones escritas en línea con el texto, utilice la barra diagonal (/) para representar la división. Los paréntesis, corchetes y llaves deben ser usados en este orden, para evitar la ambigüedad: primero ( ), después [ ] y por último \{\}, de adentro hacia afuera. 
En otras palabras, el orden es como sigue: $\{[$ (Expresión) ] \}.

Entre signos de suma, resta, multiplicación, división, mayor que, menor que, la igualdad, use un espacio antes y después del símbolo. Si quiere evitar que un espacio envíe lo que sigue al próximo renglón, use espacio duro o de no separación (en el teclado completo en su parte numérica: $\mathrm{Ctrl}+\mathrm{May}+$ espacio). No olvide que el signo menos no se representa con un guion corto (-), sino con uno mediano $(-)$, que se consigue oprimiendo al tiempo las teclas Ctrl y - del teclado numérico, o con el comando Alt +0150 .

Tenga en cuenta que estas ecuaciones deben estar estrictamente en la misma línea del texto. De lo contrario deberán seguirse las normas de ecuaciones desplegadas del texto.

Ejemplo 20: ecuaciones en la misma línea del texto

El teorema de Pitágoras puede resumirse como $H=\left(A^{2}+B^{2}\right)^{1 / 2}$, donde $H$ es la longitud de la hipotenusa, $A$ es un cateto y $B$ es el otro cateto del triángulo recto.

\subsubsection{Ecuaciones desplegadas del texto}

Las ecuaciones más complejas, que no puedan escribirse en una línea, se deben mostrar desplegadas del texto que las anuncia. Las ecuaciones se centran en la página y, cuando se requiera dar referencia de ellas en el texto, se etiquetan con números arábigos alineados a la derecha, entre paréntesis. Para referirse a ellas, solo se requiere usar en el texto esos números entre paréntesis. Por ejemplo, siempre debe decir "como se ve en (3)" en lugar de "como se ve en la ecuación (3)". La única excepción admitida ocurre si el número de ecuación comienza una oración, en cuyo caso puede decir "La ecuación (3) muestra...", para evitar el inicio de una oración con un número.

Ejemplo 21: ecuaciones desplegadas del texto y su referencia

Dada una función $f: \mathbb{R} \rightarrow \mathbb{C}$, se define formalmente su transformada de Fourier como la función de variable real $f: \mathbb{R} \rightarrow \mathbb{C}$, definida como

$$
f(\varepsilon)=\frac{1}{2 \pi} \int_{-\infty}^{\infty} e^{-i \varepsilon x} f(x) d x, \varepsilon \in \mathbb{R} .
$$

Como se aprecia en (3), la función de la transformada de Fourier corresponde a una integral infinita de la función original por un operador $e^{-i \varepsilon x}$.

\subsection{Unidades de medida del Sistema Internacional}

Con el fin de facilitar el correcto uso de las unidades de medidas y su simbología, en la tabla 23 se presentan las unidades básicas y en la tabla 24, las unidades derivadas, según las recomendaciones documentadas en BIPM (2019). 
Tabla 23. Unidades básicas del Sistema Internacional

\begin{tabular}{ll}
\hline Cantidad & Unidad \\
\hline Tiempo & segundo, símbolo s \\
Longitud & $\begin{array}{l}\text { metro, símbolo m } \\
\text { kilogramo, símbolo kg } \\
\text { Masa }\end{array}$ \\
$\begin{array}{l}\text { Corriente eléctrica } \\
\text { Temperatura }\end{array}$ & kelvin, símbolo K \\
termodinámica & \\
Cantidad de sustancia & mol, símbolo mol \\
Intensidad luminosa & candela, symbol cd \\
\hline
\end{tabular}

Fuente: traducido de BIPM (2019).

Tabla 24. Unidades derivadas con los nombres en el Sistema Internacional

\begin{tabular}{|c|c|c|c|}
\hline Cantidad & $\begin{array}{c}\text { Nombre de la unidad } \\
\text { derivada }\end{array}$ & $\begin{array}{l}\text { Símbolo por } \\
\text { unidad }\end{array}$ & $\begin{array}{c}\text { Expresión en términos de otras } \\
\text { unidades }\end{array}$ \\
\hline Ángulo plano & Radián & $\mathrm{rad}$ & $\mathrm{m} / \mathrm{m}$ \\
\hline Ángulo sólido & Estereorradián & $\mathrm{sr}$ & $\mathrm{m}^{2} / \mathrm{m}^{2}$ \\
\hline Frecuencia & Hercio & $\mathrm{Hz}$ & $\mathrm{s}^{-1}$ \\
\hline Fuerza & Newton & $\mathrm{N}$ & $\mathrm{kg} \mathrm{m} \mathrm{s}^{-2}$ \\
\hline Presión, esfuerzo & Pascal & $\mathrm{Pa}$ & $\mathrm{N} / \mathrm{m}^{2}=\mathrm{kg} \mathrm{m}^{-1} \mathrm{~s}^{-2}$ \\
\hline Energía, trabajo, cantidad de calor & Julio & J & $\mathrm{Nm}=\mathrm{kg} \mathrm{m}^{2} \mathrm{~s}^{-2}$ \\
\hline Potencia, flujo radiante & Vatio & w & $\mathrm{J} / \mathrm{s}=\mathrm{kg} \mathrm{m}^{2} \mathrm{~s}^{-3}$ \\
\hline Carga eléctrica & Culombio & C & As \\
\hline Diferencia de potencial eléctrico & Voltio & $\mathrm{v}$ & $W / A=k g m^{2} s^{-3} A^{-1}$ \\
\hline Capacitancia & Faradio & $\mathrm{F}$ & $C / V=k^{-1} m^{-2} s^{4} A^{2}$ \\
\hline Resistencia eléctrica & Ohmio & $\Omega$ & $V / A=k g m^{2} s^{-3} A^{-2}$ \\
\hline Conductividad eléctrica & Siemens & S & $A / V=k g^{-1} m^{-2} s^{3} A^{2}$ \\
\hline Flujo magnético & Weber & $\mathrm{Wb}$ & $V s=k g m^{2} s^{-2} A^{-1}$ \\
\hline Densidad de flujo magnético & Tesla & $\mathrm{T}$ & $\mathrm{Wb} / \mathrm{m} 2=\mathrm{kg} \mathrm{s}^{-2} \mathrm{~A}^{-1}$ \\
\hline Inductancia & Henry & $\mathrm{H}$ & $W b / A=k g m^{2} s^{-2} A^{-2}$ \\
\hline Temperatura Celsius & Grado Celsius & ${ }^{\circ} \mathrm{C}$ & K \\
\hline Flujo luminoso & Lumen & $\mathrm{Im}=\mathrm{cd} \mathrm{sr}$ & $\mathrm{cd} \mathrm{sr}$ \\
\hline Iluminancia & Lux & $\mathrm{l} x=\mathrm{cd} s \mathrm{r} \mathrm{m}-2$ & $\mathrm{Im} / \mathrm{m}^{2}$ \\
\hline Actividad referida a radionúcleos & Becquerel & $\mathrm{Bq}$ & $\mathrm{s}^{-1}$ \\
\hline Dosis absorbida, kerma & Gray & Gy & $\mathrm{J} / \mathrm{kg}=\mathrm{m}^{2} \mathrm{~s}^{-2}$ \\
\hline Dosis equivalente & Sievert & Sv & $\mathrm{J} / \mathrm{kg}=\mathrm{m}^{2} \mathrm{~s}^{-2}$ \\
\hline Actividad catalítica & Katal & kat & $\mathrm{mols}$ \\
\hline
\end{tabular}

Fuente: traducido de BIPM (2019).

\subsection{Sobre la escritura de números}

Cuando se requiera informar cantidades o resultados cuantitativos de trabajos y análisis es indispensable el uso de números en los textos. A continuación, se presentan algunas recomendaciones para el uso de números, con el fin de que los textos se vuelvan más consistentes y legibles (BIPM, 2019).

\subsubsection{Reglas generales}

La tabla 25 resume las principales reglas relacionadas con la escritura de números (RAE, 2020c). 
Tabla 25. Reglas para la escritura de números

\begin{tabular}{|c|c|}
\hline \multicolumn{2}{|c|}{ Regla general de números expresados en palabras } \\
\hline Descripción del caso & Ejemplos \\
\hline Números expresados en palabras & $\begin{array}{l}\text { De cada cien muestras se encontró que ocho eran completas, } \\
\text { veintiséis eran parcialmente completas y las restantes estaban } \\
\text { incompletas. }\end{array}$ \\
\hline \multicolumn{2}{|l|}{$\begin{array}{l}\text { Como regla general, use palabras para cantidades inferiores } \\
\text { a cien, para números que se escriben en una sola palabra } \\
\text { (veintinueve, setenta, quinientos, mil) y para cifras redondas que } \\
\text { se pueden escribir en dos palabras (dos mil, cinco millones). }\end{array}$} \\
\hline $\begin{array}{l}\text { Si en un párrafo abundan los números expresados con cifras, para } \\
\text { uniformar puede hacer una excepción a la regla precedente. }\end{array}$ & $\begin{array}{l}\text { Se han identificado } 47 \text { elementos incompletos de los } 256 \\
\text { muestreados, dado que } 18 \text { de los empaques en que estaban } \\
\text { contenidos tenían deficiencias apreciables y no permitieron el } \\
\text { aval de } 12 \text { testigos. }\end{array}$ \\
\hline \multicolumn{2}{|c|}{ Casos en los que siempre debe usar números como palabras } \\
\hline Descripción del caso & Ejemplo \\
\hline
\end{tabular}

\section{Cuando comienza con un número}

Una oración o título que comienza con un número debe escribirse

en palabras. Sin embargo, en lo posible, evite iniciar frases con un número. Una excepción es cuando se trata de titulares.

\section{Fracciones comunes}

Aquellas fracciones de uso muy repetido y cotidiano.

Frase universalmente reconocida

Cuando el número pertenece a una frase universalmente reconocida.
Ciento cincuenta y ocho de las muestras tenían su documentación completa, mientras que las 223 restantes no cumplieron con el estándar.

Un quinto de los encuestados no está dispuesto a aportar los datos recolectados. Un tercio de las muestras presenta alguna anomalía.

Los diez mandamientos establecieron los modelos de comportamiento de muchas culturas.

Casos en los que se debe usar siempre números para cantidades

Descripción del caso

Ejemplos

\section{Número con decimales}

En números que tengan decimales, siempre deben escribirse con El valor aproximado del número PI es 3,1416.

números. El signo de separación de decimales es la coma.

Antes de una unidad de medida
Números que preceden inmediatamente a una unidad de medida.

(Las unidades de medida siempre van separadas de las cifras que les anteceden).

\section{Funciones estadísticas o matemáticas}

Fracciones o decimales (excepto fracciones comunes)

Porcentajes.

(El símbolo de porcentaje siempre va separado del número que le La eficiencia del procesamiento global es del $7 \%$. antecede).

\section{Proporciones}

\section{Horas y fechas (incluidas aproximaciones de tiempo)}

Para fechas, use la convención DD/MM/AAAA, sin embargo, en algunos casos podrá usarse AAAA-MM-DD, cuando se aplique una convención internacional que requiere este tipo de homologación Se utilizan monitores de alta resolución con una proporción de pantalla de 16:9.

El evento ocurrió el 16/08/2019 a las 12:05:35 UT.

Cada tres meses se reportan casos de incidentes operacionales.

temporal. 


\begin{tabular}{|c|c|}
\hline \multicolumn{2}{|c|}{ Casos en los que se debe usar siempre números para cantidades } \\
\hline Descripción del caso & Ejemplos \\
\hline \multirow{7}{*}{\multicolumn{2}{|c|}{ 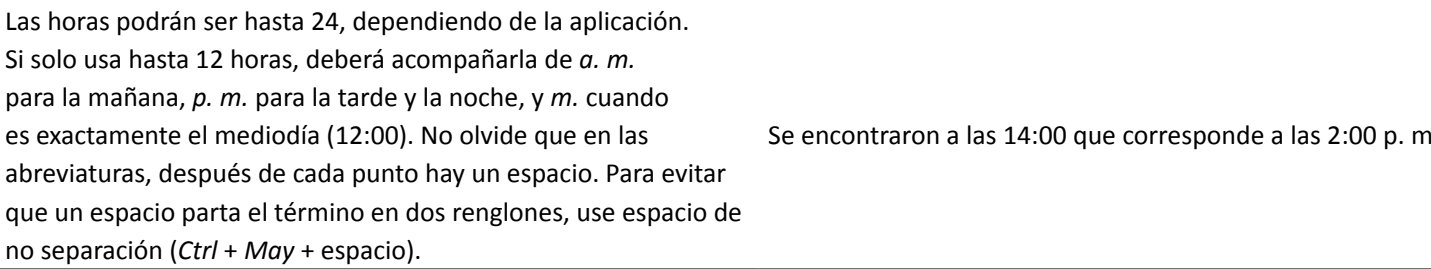 }} \\
\hline & \\
\hline & \\
\hline & \\
\hline & \\
\hline & \\
\hline & \\
\hline Edades & El equipo disponible tiene entre 8 y 12 años de uso. \\
\hline \multirow{2}{*}{ Sumas exactas de dinero } & El proyecto contempló un total de $\$ 14560000$ para \\
\hline & el primer año. \\
\hline
\end{tabular}

Los siglos siempre deberán escribirse en números romanos. Por ejemplo, "El siglo XXI ha representado un gran avance en el derecho de las minorías". Debe recordarse aquí que la palabra siglo siempre se escribe en minúscula.

\subsubsection{Sobre la escritura de números generados estadísticamente}

Cuando se manejan números que han sido generados por paquetes estadísticos, con el fin de utilizar el número de decimales apropiado, conviene adoptar las recomendaciones de Frías-Navarro (2020) y que están resumidas en la tabla 26.

Tabla 26. Uso de los decimales en los números generados mediante paquetes estadísticos

\begin{tabular}{|c|c|}
\hline Descripción del caso & Ejemplos \\
\hline Dato estadístico que no puede exceder de 1 & Para los valores $p$ de probabilidad: escribir \\
\hline $\begin{array}{l}\text { Cuando el valor no puede ser superior a } 1 \text {, debe omitirse el } \\
\text { cero antes del separador decimal (coma para español y punto }\end{array}$ & $p=, 051$ y no escribir como $p=0,051$ \\
\hline \multirow{2}{*}{$\begin{array}{l}\text { para inglés). Por ejemplo, en los coeficientes de correlación, o } \\
\text { similares, o un valor } p \text { de probabilidad. }\end{array}$} & Para coeficientes de correlación: escribir \\
\hline & $r=, 36$ y no escribir $r=0,36$ \\
\hline \multirow{7}{*}{$\begin{array}{l}\text { Dato estadístico que puede exceder de } 1 \\
\text { Si se trata de un valor estadístico que pueda exceder de 1, } \\
\text { entonces debe ponerse un cero antes del separador decimal. Por } \\
\text { ejemplo, si se utiliza un estadístico que puede alcanzar valores } \\
\text { superiores a 1, entonces se pondrá el cero delante del separador } \\
\text { decimal. }\end{array}$} & $d=0,35 ; d=1,1$ (no se debe escribir $d=, 35$ ). \\
\hline & Valores con decimales de las medias, las desviaciones típicas o \\
\hline & cualquier dato estadístico que pueda superar a uno, situando \\
\hline & siempre un cero antes del separador decimal. \\
\hline & $t(20)=0,86$ \\
\hline & $d=0,56$ \\
\hline & $F(1,27)=0,89$ \\
\hline
\end{tabular}

\section{Consideraciones de redondeo}

En lo posible, es conveniente redondear los decimales, ya que con ello la lectura del número decimal es más sencilla y se mejora Si tiene un número como 0,999, podría redondearse a 1,00. su comprensión. No obstante, esta decisión es responsabilidad Si tiene 0,5045, podría redondear a 0,50. del autor, en consideración de la conveniencia matemática o estadística del caso.

\section{Dos decimales}

Para la mayoría de los datos estadísticos es recomendable utilizar El experimento muestra un coeficiente de correlación $r=0,89$. dos decimales. Por ejemplo, los valores estadísticos de correlación El estadístico chi cuadrado es 0,18, lo cual indica una buena y proporción, y los utilizados en la inferencia estadística como $t, F$, concordancia entre las frecuencias observadas y las esperadas. chi cuadrado, se deben presentar con dos decimales. 


\begin{tabular}{|c|c|}
\hline Descripción del caso & Ejemplos \\
\hline $\begin{array}{l}\text { Informar el valor } \mathbf{p} \text { de probabilidad } \\
\text { Informar siempre de los valores } p \text { de probabilidad exactos } \\
\text { con } 2 \text { o } 3 \text { decimales, tanto en los resultados estadísticamente } \\
\text { significativos como en los que no son estadísticamente } \\
\text { significativos. }\end{array}$ & La probabilidad de éxito es, entonces, p = ,032. \\
\hline Valores de $\mathbf{p}$ menores de, 001 , escribirlos como $p<, 001$ & $\begin{array}{l}\text { Si el programa estadístico (SPSS o algún otro) informa que } p= \\
, 000, \text { se debe escribir } p<, 001 \text {. El programa estadístico señala que } \\
\text { el nivel de significación es ,000 porque su valor real es menor de } \\
, 001 \text {. En tal caso, escribir siempre } p<, 001 \text {. }\end{array}$ \\
\hline $\begin{array}{l}\text { Número de decimales por escribir dependiendo de los rangos } \\
\text { del número }\end{array}$ & $\begin{array}{l}\text { Cuando se trata de números mayores que } 100 \text {, escribir el } \\
\text { número entero más próximo. } \\
\text { Si el número se encuentra entre } 10 \text { y } 100 \text {, escribir el número } \\
\text { con un decimal. } \\
\text { Si el número se encuentra entre } 0,10 \text { y } 10 \text {, escribir el número } \\
\text { con dos decimales } \\
\text { Si el número es menor de } 0,10 \text { y se encuentra entre } 0,001 \text { y } \\
0,01 \text {, escribir el número con tres decimales. } \\
\text { Si el número es menor de } 0,001 \text {, escribir el número con cuatro } \\
\text { decimales. } \\
\text { Si el número que se obtiene es menor a } 0,0001 \text {, escribir el } \\
\text { número utilizando la expresión }<0,001 \text {. }\end{array}$ \\
\hline
\end{tabular}

Fuente: adaptado de Frías-Navarro (2020).

La tabla 27 ilustra el número de decimales recomendado tras un procedimiento estadístico o matemático típico.

Tabla 27. Ejemplo de uso de los decimales para números generados por paquetes estadísticos

\begin{tabular}{llll}
\hline \multicolumn{1}{c}{ Rango de números } & \multicolumn{1}{c}{ Redondeo recomendado } & \multicolumn{1}{c}{ Datos del paquete estadístico } & Escribir \\
\hline Mayor que 100 & Número entero & 5088,59 & 18,6 \\
\hline $10-100$ & 1 decimal & 18,63 & 7,99 \\
\hline $0,10-10$ & 2 decimales & 7,987 & 0,006 \\
\hline $0,001-0,10$ & 3 decimales & 0,0057 & 0,0005 \\
\hline $\begin{array}{l}\text { Menor que } 0,001 \\
\text { Menor que } 0,0001 \text { y expresiones }\end{array}$ & 4 decimales & 0,000476 & $<0,001$ \\
\hline
\end{tabular}

\subsubsection{Formatos para los valores de una cantidad}

De acuerdo con el National Institute of Standards and Technology (NIST, 2019), el valor numérico siempre precede a la unidad de medida, y se usa un espacio para separar la unidad de medida del número. Así, el valor de la cantidad es el producto del número y la unidad de medida. El espacio entre el número y la unidad se considera un signo de multiplicación (tal como un espacio entre unidades implica multiplicación). Las únicas excepciones a esta regla son símbolos de unidad para grados, minutos y segundos para ángulo de plano, ${ }^{\circ}, y^{\prime}$ ", respectivamente, para que no quede espacio entre el valor numérico y el símbolo de la unidad.

Esta regla significa que el símbolo ${ }^{\circ} \mathrm{C}$ para el grado Celsius está precedido por un espacio cuando se expresan valores de temperatura en grados Celsius. 
En cualquier expresión, solo se usa una unidad. Una excepción a esta regla ocurre al expresar el valor de tiempo y de ángulos planos usando unidades que no pertenecen al Sistema Internacional (SI). Sin embargo, en ángulos planos generalmente es preferible dividir el grado de forma decimal. Por lo tanto, es preferible escribir $22,20^{\circ}$ en lugar de $22^{\circ} 12^{\prime}$, excepto en campos como navegación, cartografía, astronomía y medición de ángulos muy pequeños. Estas reglas se ilustran en la tabla 28.

Tabla 28. Ejemplo de aplicación de formatos de números para cantidades

\begin{tabular}{|c|c|}
\hline Caso de aplicación & Ejemplos \\
\hline Números sencillos & Escriba $I=10,234 \mathrm{~m}$, pero no $I=10 \mathrm{~m} \mathrm{23,4} \mathrm{cm}$ \\
\hline Espacio entre números y sus unidades & Escriba $t=30,2^{\circ} \mathrm{C}$, pero no $t=30,2^{\circ} \mathrm{C}$ ni $t=30,2^{\circ} \mathrm{C}$ \\
\hline $\begin{array}{l}\text { Formatos de ángulos planos } \\
\text { (a no ser que sea estrictamente necesario) }\end{array}$ & $\begin{array}{l}\text { Prefiera escribir un ángulo como } 32,4^{\circ} \text {, en vez de } 32^{\circ} 24^{\prime} \text { (a pesar } \\
\text { de que son exactamente lo mismo) }\end{array}$ \\
\hline $\begin{array}{l}\text { Si tiene que incluir letras de orientación, sepárelas con un } \\
\text { espacio del número y del símbolo }\end{array}$ & La falla tiene un rumbo $\mathrm{N} 50^{\circ} \mathrm{E}$ \\
\hline
\end{tabular}

\subsubsection{Formato de números, separador de millares y marcador decimal}

En vista de que, dependiendo de la ubicación geográfica de los países o de las reglas del idioma que allí imperen, se acostumbraba separar los millares con punto o con coma, y con los mismos signos se dividían los decimales, y de que el cruce de estos dos sistemas implicaba graves ambigüedades, la Oficina Internacional de Pesos y Medidas y la International Organization for Standardization acordaron reservar dichos signos exclusivamente a la separación de decimales, y adoptaron el espacio fino para separar los millares, decisión adoptada en el 2010 por la RAE. (El espacio fino se consigue digitando Alt +08201 o AltGr + espacio, si usa la plantilla que se detalla en el capítulo 11).

Hay que tener presente que la separación con espacio de los millares solo tiene por objeto facilitar la lectura de números de muchas cifras. Por ello, si el número solo contiene cuatro cifras, una cuantía que es fácil de leer, no se incluye el espacio de separación: 1198 (no 1 198).

Al escribir números sin decimales de más de cuatro cifras, se agruparán estas de tres en tres, empezando por la derecha, y separando los grupos por espacios en blanco: 8327451 (y no por puntos o comas).

En ningún caso deben repartirse en líneas diferentes las cifras que componen un número: 8327 / 451. Para evitar estas rupturas indeseables que realizan los procesadores de palabras, puede usar un espacio duro (Alt + May + espacio).

Por otra parte, hay números que, por muchas cifras que contengan, no se separan, como los números de páginas de un documento o publicación, los números de leyes, decretos u otras normas, los números de los años en fechas, los códigos postales o apartados de correo, códigos, números de registro, o en general, "cuando el número no expresa cantidad, sino que sirve para identificar un elemento en una serie" (RAE, 2010, p. 664). 
El símbolo utilizado para separar la parte integral de un número de su parte decimal se llama marcador decimal. De acuerdo con BIPM (2019), el marcador decimal "será el punto o la coma", y debe ser el habitual en el idioma y el contexto. Para el caso de Colombia, es la coma (,).

Si el número está entre +1 y -1 , el marcador decimal siempre está precedido por un cero.

Con el objeto de facilitar la lectura, en números con muchos dígitos, a partir del marcador decimal se recomienda, igual que se hace con los millares, dividir los dígitos en grupos de tres con un espacio fino ( AltGr + espacio). No se insertan puntos ni comas en los espacios entre grupos de tres.

La práctica de agrupar los dígitos de esta manera es una cuestión opcional; no siempre se sigue en ciertas aplicaciones, como Excel, o en tablas que puedan ser leídas por un computador.

Para los números que figuren en una tabla, el formato utilizado no debe variar dentro de una columna.

Los ejemplos que ilustran la regla se muestran en la tabla 29. Puesto que es muy frecuente importar datos numéricos de aplicaciones como Excel, en la tercera columna se indica el formato personalizado que se usaría en Excel para producir los números con este formato.

Tabla 29. Ejemplos de escritura de números

\begin{tabular}{|c|c|c|}
\hline Casos & Ejemplos & $\begin{array}{l}\text { Formato personalizado } \\
\text { en Excel para generar el número }\end{array}$ \\
\hline \multirow{2}{*}{ Si el número está entre 0 y 1} & Escriba, 118 & \multirow{2}{*}{, \#\#\# } \\
\hline & No escriba 0,118 & \\
\hline \multirow{2}{*}{ Si el número está entre +1 y -1} & Escriba $-0,234$ & \multirow{2}{*}{$\#$ \#\#\# } \\
\hline & No escriba,- 234 & \\
\hline \multirow{8}{*}{ Para números con muchos dígitos } & Escriba 234587 218,324 & \multirow{2}{*}{ \#\#\# \#\#\# \#\#\#,\#\#\# } \\
\hline & No escriba $234.587 .218,324$ & \\
\hline & Escriba 2,3456 & \multirow{2}{*}{ \#,\#\#\#\# } \\
\hline & No escriba 2,345 6 & \\
\hline & Escriba 1892,345 & \multirow{2}{*}{ \#\#\#\#,\#\#\# } \\
\hline & No escriba 1892,345 & \\
\hline & Escriba 3,141 592653589 & \multirow{2}{*}{ \#,\#\#\# \#\#\# \#\#\# \#\#\# } \\
\hline & No escriba 3.141592653589 & \\
\hline
\end{tabular}

En la tabla 30 se ilustra el formato de número obtenido para varios casos con muchos dígitos. Teniendo los valores de prueba del lado izquierdo, se pretende asignarles un formato para que luzcan de la forma que se muestra en la columna de la derecha.

Tabla 30. Ejemplo de aplicación de formato de número en el caso de tener varias cifras

\begin{tabular}{ll}
\hline \multicolumn{1}{c}{ Valores de prueba (sin formato) } & \multicolumn{1}{c}{ Valores de prueba (con formato) } \\
\hline 1967830557823,02 & 1967830557823,0200 \\
7213089968259,10 & 7213089968259,1000 \\
3215918404357,38 & 3215918404357,3800 \\
6219906586716,95 & 6219906586716,9500 \\
328922926736,67 & 328922926736,6700 \\
6221709542683,81 & 6221709542683,8100
\end{tabular}




\begin{tabular}{ll}
\hline \multicolumn{1}{c}{ Valores de prueba (sin formato) } & Valores de prueba (con formato) \\
\hline 7667879522287,26 & 7667879522287,2600 \\
9292306450590,49 & 9292306450590,4900 \\
7444877851877,38 & 7444877851877,3800 \\
696263992308,08 & 696263992308,0800 \\
2129164437131,65 & 2129164437131,6500 \\
2911747590262,20 & 2911747590262,2000 \\
\hline
\end{tabular}

Para la conversión del formato de esta tabla se requirió aplicar un formato con cuatro decimales y separación con un espacio cada tres cifras (el formato sería “\#\#\# \#\#\#\#\#\#\#\#\#\#,0000"). En Excel lo puede aplicar seleccionando los números a los que desea aplicarles el formato, y en el menú Inicio seleccione Número/Personalizada como se muestra en la figura 28. Digite en el espacio debajo de Tipo el texto \#\#\# \#\#\# \#\#\# \#\#\# \#\#\#,0000 y de clic en Aceptar.

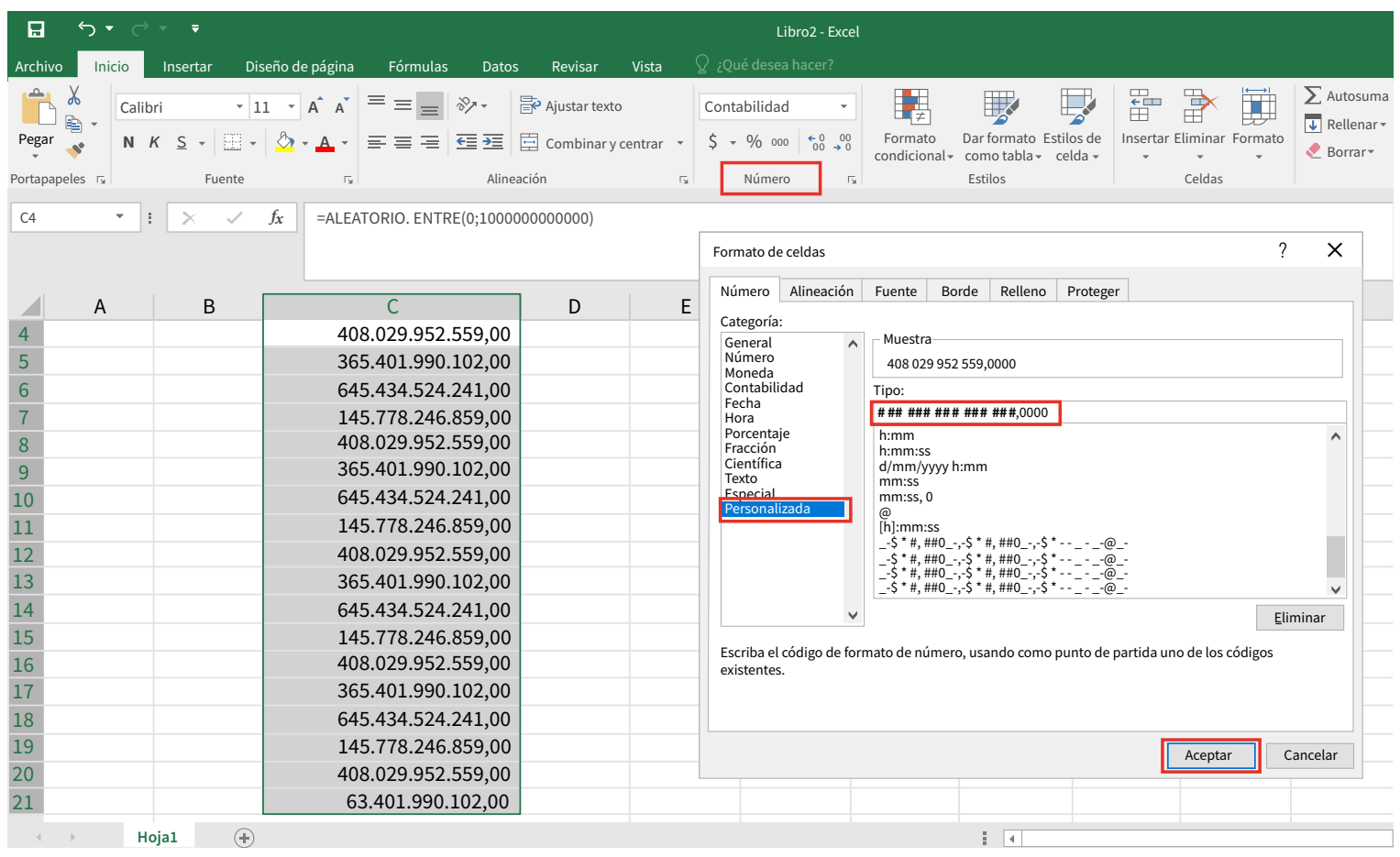

Figura 28. Configuración de formatos de número en Excel

Los números así formateados pueden ser llevados a su procesador de palabras de manera directa con las funciones de copiar y pegar.

\subsection{El nombre de algunos números}

El nombre de algunos números puede tener significados diferentes dependiendo del idioma en que se manejan. En la tabla 31 se aprecian las diferencias de significado entre el idioma inglés y el español. 
Tabla 31. Significado de números con nombres iguales en español y en inglés

\begin{tabular}{llll}
\hline & Nombre & \multicolumn{1}{c}{ Inglés } & Español \\
\hline Million & \multicolumn{1}{c}{ Significado real } & Nombre & Significado real \\
Billion & $10^{6}$ & Millón & $10^{6}$ \\
Trillion & $10^{9}$ (mil millones o millardo) & Billón & $10^{12}$ (un millón de millones) \\
Quadrillion & $10^{12}$ (un millón de millones) & Trillón & $10^{24}$ (un billón de billones) \\
Quintillion & $10^{15}$ (mil billones) & Cuadrillón & $10^{48}$ (un trillón de trillones) \\
\hline
\end{tabular}

Fuente: adaptado de RAE (2020c).

\subsection{Prefijos}

Según la RAE, los prefijos son elementos afijos, carentes de autonomía, que se anteponen a una base léxica (una palabra o una expresión pluriverbal) a la que aportan diversos valores semánticos. Se resumen a continuación las normas que deben seguirse para la correcta escritura de los prefijos en español:

Hay dos casos en que los prefijos se escriben separados: 1) Si la palabra que sigue a un prefijo comienza con mayúscula, el prefijo va separado con un guion de dicha palabra (época pre-Trump, periodo pos-Mioceno, posición anti-España). 2) Si el prefijo afecta a una expresión pluriverbal, irá separado de ella sin guion (ex primer ministro). 3) Si el prefijo modifica números (sub-20) (RAE, 2010).

En términos de unidades de medida, existen también prefijos para el SI como se aprecian en la tabla 32.

Tabla 32. Prefijos de las unidades del SI

\begin{tabular}{llllll}
\hline Factor & Nombre & Símbolo & Factor & Nombre & Símbolo \\
\hline $10^{1}$ & deca & $\mathrm{da}$ & $10^{-1}$ & deci & $\mathrm{d}$ \\
$10^{2}$ & hecto & $\mathrm{h}$ & $10^{-2}$ & centi & $\mathrm{c}$ \\
$10^{3}$ & kilo & $\mathrm{k}$ & $10^{-3}$ & mili & $\mathrm{m}$ \\
$10^{6}$ & mega & $\mathrm{M}$ & $10^{-6}$ & micro & $\mathrm{\mu}$ \\
$10^{9}$ & giga & $\mathrm{G}$ & $10^{-9}$ & nano & $\mathrm{n}$ \\
$10^{12}$ & tera & $\mathrm{T}$ & $10^{-12}$ & pico & $\mathrm{p}$ \\
$10^{15}$ & peta & $\mathrm{P}$ & $10^{-15}$ & femto & $\mathrm{f}$ \\
$10^{18}$ & exa & $\mathrm{E}$ & $10^{-18}$ & atto & $\mathrm{a}$ \\
$10^{21}$ & zetta & $\mathrm{Z}$ & $10^{-21}$ & zepto & $\mathrm{Z}$ \\
$10^{24}$ & yotta & $\mathrm{Y}$ & $10^{-24}$ & yocto & $\mathrm{y}$ \\
\hline
\end{tabular}

Fuente: adaptado de BIPM (2019).

La agrupación formada por un símbolo de prefijo adjunto a un símbolo de unidad constituye un nuevo símbolo de unidad inseparable, que forma un múltiplo o submúltiplo de la unidad en cuestión, que puede ser elevado a una potencia positiva o negativa y que se puede combinar con otros símbolos de unidad para formar símbolos de unidad compuesta.

Ejemplos: pm (picómetro), mmol (milimoles), $\mathrm{G} \Omega$ (gigaohmios), $\mathrm{THz}$ (terahercios)

$2,3 \mathrm{~cm}^{3}=2,3(\mathrm{~cm})^{3}=2,3\left(10^{-2} \mathrm{~m}\right)^{3}=2,3 \times 10^{-6} \mathrm{~m}^{3}$

$1 \mathrm{~cm}^{-1}=1(\mathrm{~cm})^{-1}=1\left(10^{-2} \mathrm{~m}\right)^{-1}=10^{2} \mathrm{~m}^{-1}=100 \mathrm{~m}^{-1}$ 
De manera similar, los nombres de prefijos también son inseparables de los nombres de las unidades a las que están asociados. Así, por ejemplo, milímetro, micropascal y meganewton son palabras únicas.

Existen cuatro formas de escribir los prefijos: con espacio, con guion, unidos sin simplificación y unidos con simplificación. Fundéu BBVA (2016) propone un diagrama para abordar de manera correcta todos estos casos, como puede verse en la figura 29.

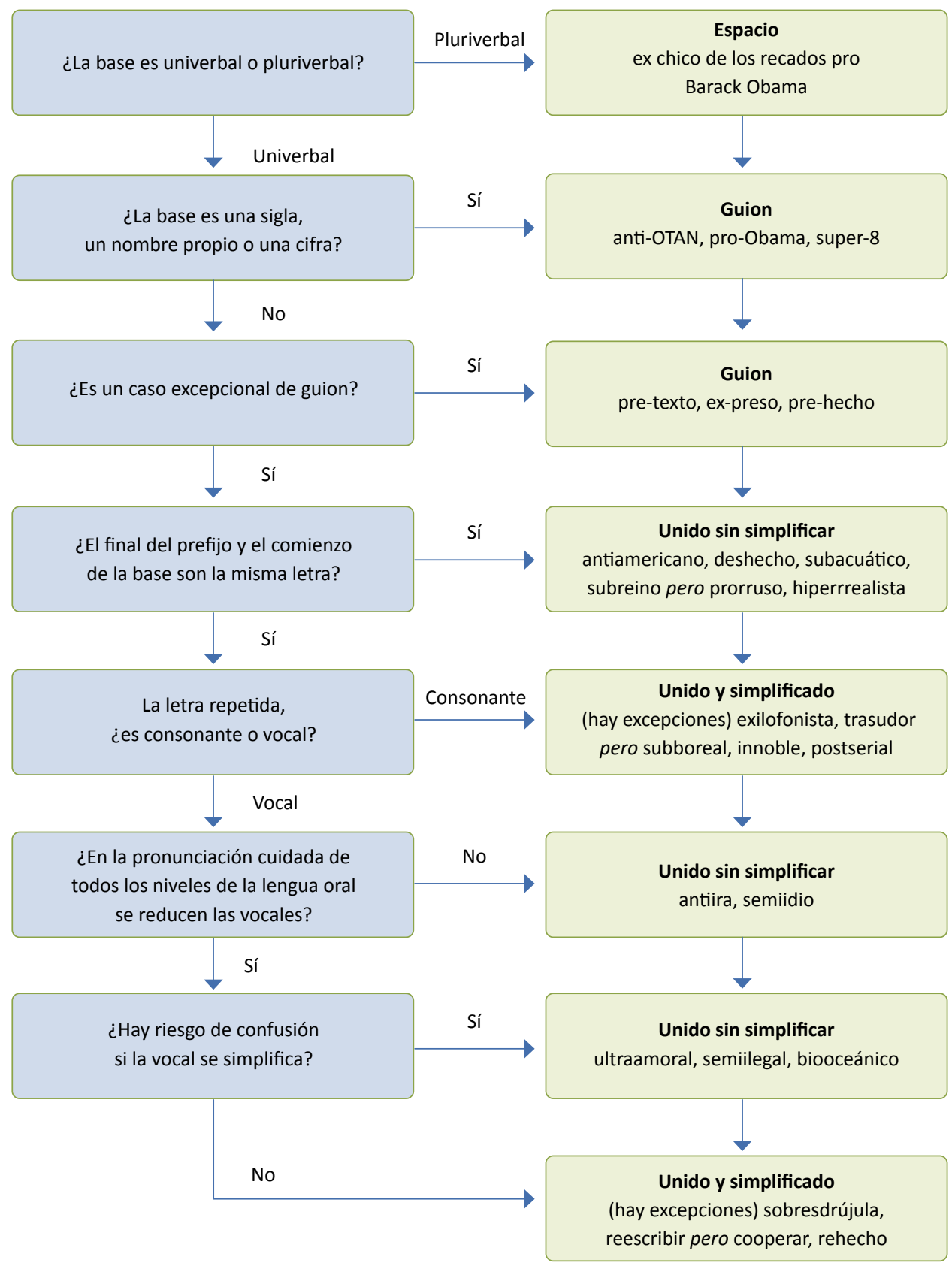

Figura 29. Diagrama para la aplicación de las formas de escribir prefijos Fuente: adaptado de Fundéu BBVA (2016, p. 9). 


\subsection{Citas bibliográficas}

La norma de citación de las publicaciones del SGC es APA, séptima edición (APA, 2020); sin embargo, algunas publicaciones específicas, por uniformidad con otras instituciones o conveniencia del sistema de citación, dada el área temática, podrán utilizar otra norma, siempre que se haga de manera consistente y completa.

\section{Reglas básicas de citación en APA 7}

- En el texto, las citas deben corresponder con la información del autor y fecha de la obra referenciada en la sección de referencias.

- Cuando se citen varias obras de un mismo autor, se organizarán de forma cronológica y se expondrán separadas por coma.

- Cuando un trabajo referenciado sea de dos autores, se citarán los apellidos de los dos autores separados por la conjunción y, no and ni \&. Nota: dado que el documento o publicación donde se incluyen las referencias está en español, se debe preservar la lectura en este idioma, de forma que sea coherente durante todo el texto. Por lo anterior, se usa y en lugar de $\&$ o de and, independientemente del idioma en que esté escrito el artículo o publicación que se está referenciando.

- Si la obra tiene más de dos autores, desde la primera vez se citará solo al primer autor, seguido por la abreviación "et al." en cursiva, una coma (,) y el año.

- Si se trata de un autor corporativo, la primera vez se escribirá el nombre de la organización, y entre paréntesis la sigla, seguida del año; posteriormente se citará solamente la sigla.

- Al citar varios autores, se ordenarán de forma cronológica y separados por punto y coma.

- Si se cita la página específica de una obra, se incluirá luego del año con la abreviatura $p$., o $p p$. si corresponde a varias páginas.

- Cuando múltiples referencias se acorten a la misma abreviatura et al., desambígüelas deletreando tantos apellidos de otros autores como sea necesario para diferenciar las citas y relacionarlas unívocamente con su entrada en la lista de referencias.

- La cita puede ser narrativa, cuando se incluye al autor o autores con el año entre paréntesis afirmando o comunicando alguna idea.

- Por otra parte, la cita puede ser parentética, cuando al concluir la cita se incluye entre paréntesis el autor o autores, el año y opcionalmente la página o páginas.

Estas reglas generales se pueden ilustrar con los siguientes ejemplos:

\section{Ejemplo 22: citando varias obras del mismo autor}

Puede utilizarse las dos siguientes variantes:

- Como se puede observar en Pérez (2010), Pérez (2011) y Pérez (2019), los principios han sido ampliamente aceptados para este tipo de experimentos.

- Los principios se han establecido de manera detallada en varias publicaciones (Pérez, 2010, 2011 y 2019). 
Ejemplo 23: citando un trabajo de dos autores

Esta aproximación ha sido documentada por Raigosa y Londoño (2018).

Ejemplo 24: citando un trabajo de tres autores o más (para todas las veces que se cite, incluyendo la primera)

El método se ha expuesto de manera detallada en Van der Lelij et al. (2016).

Ejemplo 25: citando un autor corporativo la primera vez

Los detalles de la base de datos de sismos pueden verse en Servicio Geológico Colombiano (SGC, 2017).

Ejemplo 26: citando un autor corporativo después de la primera vez Los detalles de la base de datos de sismos pueden verse en SGC (2017).

Ejemplo 27: citando varios autores que se ordenan cronológicamente Varios autores concuerdan en las complejidades del sistema dinámico de la región (Mantilla et al., 2013; Van der Kerkoff et al., 2016; Domínguez et al., 2017).

\section{Ejemplo 28: citando una referencia con página específica o rango de página}

Se ha demostrado que el clima no tiene ninguna influencia relevante en la ocurrencia de terremotos (Marinho et al., 1987, p. 51).

Por otra parte, tampoco tiene sustento que los terremotos respondan a alguna secuencia matemática independiente de la física del fenómeno (Kensington et al., 1997, pp. 58-63).

Ejemplo 29: citando unas referencias que tengan una forma resumida igual (desambiguadas citando más apellidos de autores) El trabajo de varios autores ha dado resultados positivos (Pérez et al., 2018); (Pérez, Méndez et al., 2018) y (Pérez, Salinas et al., 2018).

\subsubsection{Citas indirectas o paráfrasis}

Es una forma muy común de cita indirecta que reproduce la información extractada de alguna fuente, pero en palabras de quien escribe (Sánchez, 2011, p. 63). Busca crear un texto paralelo que continúa el estilo o línea discursiva del autor del texto y evita el exceso de citas directas.

\section{Reglas para citas indirectas}

- Debe anunciarse para saber su inicio.

- Debe cerrarse con la referencia.

- Debe reproducir fielmente el contenido (no las palabras) que se cita.

- Debe caracterizarse por su autonomía expresiva (unidad de comunicación). 


\subsubsection{Citas textuales}

Se reproduce de manera literal un fragmento de otro autor, pero se indica claramente su procedencia.

\section{Reglas para citas textuales}

- Cuando la cita textual sea menor de cuarenta palabras se reproducirá dentro del párrafo, entre comillas y sin cursiva. Al final de la cita deberá aparecer su respectiva referencia con punto final.

- Cuando la cita textual supere cuarenta palabras, se escribirá en párrafo aparte, con sangría izquierda de $2,5 \mathrm{~cm}$, sin comillas y sin cursiva, y se usará la misma tipografía de todo ese párrafo. Al final de la cita deberá aparecer su respectiva referencia sin punto final.

- Tanto en citas dentro de párrafo como en párrafo aparte, si se elimina una palabra o frase de la cita, se pondrán puntos suspensivos entre corchetes en el lugar donde se hace la modificación.

- En citas entrecomilladas dentro de párrafo, si se comienza la cita eliminando las primeras palabras de la oración, la primera palabra de la cita irá con minúscula después de las comillas de apertura, sin necesidad de anunciar el corte de la frase con puntos suspensivos, pues la minúscula da suficiente indicio de que se ha practicado una elisión; y si se eliminan palabras del final de la oración con que termina la cita, no hace falta advertirlo con puntos suspensivos.

Ejemplo 30: citando un párrafo de menos de cuarenta palabras (en la citación, después del paréntesis debe ir un punto, coma o punto y coma)

En The Shawshank redemption puede leerse lo siguiente: "Andy loved geology. I imagine it appealed to his meticulous nature. An ice age here, a million years of mountain building there, plates of bedrock grinding against each other over a span of millennia..." (Narración por Red [Morgan Freeman] en la película The Shawshank redemption, 1994).

Ejemplo 31: citando un párrafo de más de cuarenta palabras (en la citación, después del paréntesis no debe ir punto)

En La peste de Albert Camus, respecto al sentido repetitivo de la enfermedad, puede leerse lo siguiente:

[...] él sabía que esta muchedumbre dichosa ignoraba lo que se puede leer en los libros, que el bacilo de la peste no muere ni desaparece jamás, que puede permanecer durante decenios dormido en los muebles, en la ropa, que espera pacientemente en las alcobas, en las bodegas, en las maletas, los pañuelos y los papeles, y que puede llegar un día en que la peste, para desgracia y enseñanza de los hombres, despierte a sus ratas y las mande a morir en una ciudad dichosa. (Camus, 1947) 


\subsection{Referencias}

\section{Regla general para la lista de referencias}

- La lista de referencias se incluye en la parte final del escrito, en una sección cuyo título es Referencias.

- En las normas APA, de los nombres de pila de los autores solo se aporta la inicial. En caso de que se anoten los dos apellidos, no deben separarse por guion. Las referencias deben ir a espacio sencillo y con sangría francesa de $0,85 \mathrm{~cm}$ (en la sangría francesa, el primer renglón no lleva sangría, y los que le siguen están sangrados, en este caso, a 0,85 cm).

- Si los documentos cuentan con DOI, este código se debe incluir al final de la referencia en forma de URL. Los DOI deben comenzar con el prefijo https://doi.org/ o similar. No se usa la palabra $D O I$ antes de la dirección.

- Proporcione apellidos e iniciales de hasta veinte autores incluidos. Cuando haya entre dos y veinte autores, use la letra y antes del nombre del autor final: Autor, A. A., Autor, B. B. y Autor, M. M.

- Nota: cuando el documento o publicación donde se incluyen las referencias esté en español, se debe preservar la lectura en este idioma de forma que sea coherente durante todo el texto. Por lo anterior, se usa y en lugar de $\&$ o de and, independientemente del idioma en que esté escrito el artículo o publicación que se está referenciando.

- Cuando hay veintiún o más autores, incluya los nombres de los primeros diecinueve, inserte unos puntos suspensivos (pero no la letra $y$ ), y luego agregue el nombre del autor final: Autor, A. A., Autor, B. B. ... Autor, N. N.

- Cuando el autor sea una organización que tiene una sigla, en primer lugar estará la sigla, y, entre paréntesis, el nombre de la institución.

\subsubsection{Libros}

Los títulos de los libros llevan mayúscula únicamente en la inicial de la primera palabra y en la inicial de los nombres propios, si los tiene. Los títulos se escriben en cursiva, y el subtítulo va separado del título por dos puntos, no por punto ni por guion. En español, después de los dos puntos sigue minúscula; en inglés, sigue mayúscula. No se incluye en la citación la ciudad de la editorial.

Para el idioma inglés sí se usan las mayúsculas iniciales en cada palabra.

En la figura 30 puede apreciarse el esquema de citación de libros. 


\section{Autor, A. A., Autor, B. B. y Autor, C. C (Año del copyright). Título del libro (4.a ed.). Editorial. DOI o URL}

Autor, A. A., Autor, B. B. y Autor, C. C.
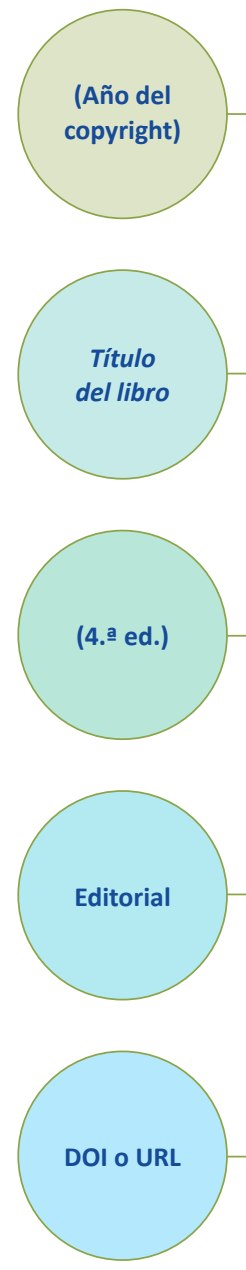

Si el libro tiene DOI, inclúyalo. No incluya una URL o información de la base de datos para trabajos de bases de datos de investigación académica. Incluya una URL para libros electrónicos. No escriba un punto después del DOI o URL.

Los autores se citan por su apellido o apellidos (si firman con los dos), seguido de una coma y las iniciales de los nombres. Deje un espacio entre las iniciales. Se debe conservar el orden de los nombres de los autores. Antes de la conjunción " $y$ " no debe ir coma. Si como autor figura una institución, después de su nombre va un punto.

Escriba el año del copyright entre paréntesis. Termine con un punto.

Escriba con mayúscula solo la primera letra de la primera palabra. Para un título de dos partes, escriba en mayúscula la primera palabra de la segunda parte del título. Título y subtítulo van separados con dos puntos (no use punto ni guion). También escriba con mayúscula los nombres propios. Utilice cursiva. Termine con un punto.

Si el libro tiene una edición o un número de volumen, incluya el número entre paréntesis después del título, pero antes del punto. Si tiene ambos, muestre la edición primero y el volumen después, separados por una coma. No escriba un punto entre el título y la información entre paréntesis. No utilice cursiva para esta información.

Escriba el nombre de la editorial, seguido de un punto. No incluya la ubicación de la editorial. En caso de tener múltiples editoriales, sepárelas con punto y coma.

Figura 30. Esquema para citar libros Fuente: adaptado de APA (2020). 
La información consignada para libros debe corresponder estrictamente a la incluida en los siguientes ejemplos, y seguir las mismas normas de puntuación entre cada elemento de la referencia:

Ejemplo 32: referencia de un libro en idioma inglés con DOI

Maynard, J. (1983). Geochemistry of Sedimentary Ore Deposits. Springer-Verlag. https://doi. org/10.1007/978-1-4613-9493-8

Ejemplo 33: referencia de un libro en español sin DOI

Gaviria, S. (2016). Química para geología: aplicación en laboratorio y campo. Universidad Nacional de Colombia.

Ejemplo 34: referencia de un libro con autor corporativo y sigla

BIPM (Bureau International des Poids et Mesures). (2019). The International System of Units $(S I), 9^{\text {th }}$ edition.

\subsubsection{Capítulos de libros}

Para los capítulos rigen las mismas reglas que para los títulos de libros, con la diferencia de que los títulos de capítulos no llevan cursiva. Debe señalarse en cursiva el título del libro de donde procede el capítulo, introducido por la preposición En, sin mediación de dos puntos.

En la figura 31 puede apreciarse el esquema de citación para capítulos de libros. 


\section{Autor, A. A., Autor, B. B. y Autor, C. C. (Año del copyright). Título del capítulo de libro. \\ En A. A. Editor y B. B. Editor, Título del libro (2.a ed., pp. \#\#-\#\#). Editorial. DOI o URL}

Autor, A. A Autor, B. B. y Autor, C. C.
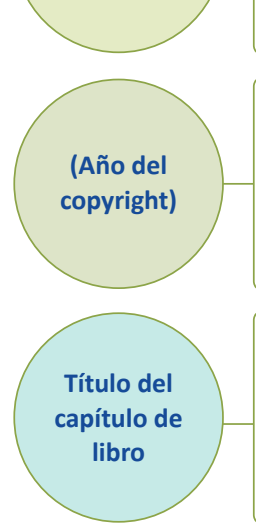

Escriba con mayúscula solo la primera letra de la primera palabra. Para un título de dos partes, escriba en mayúscula la primera palabra de la segunda parte del título. Título y subtítulo van separados con dos puntos (no use punto ni guion). También escriba con mayúscula los nombres propios. No utilice cursiva. Termine con un punto.

En A. A.

Editor y B. B. Editor

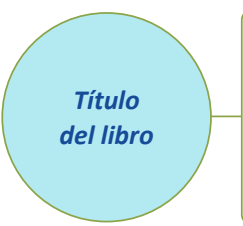

Proporcione el título del libro en el que aparece el capítulo. Use mayúsculas solo en la primera letra de la primera palabra. Para título de dos partes, escriba con mayúscula la primera palabra de la segunda parte del título. Título y subtítulo van separados con dos puntos (no use punto ni guion). Escriba los nombres propios con inicial mayúscula. Utilice cursiva.

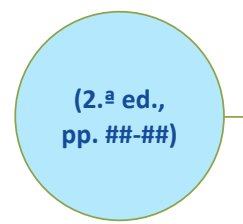

Incluya entre paréntesis el rango de páginas del capítulo. Termine con un punto. Si el libro tiene una edición o número de volumen, incluya el número entre paréntesis antes del rango de páginas. Si tiene ambos, se debe mostrar la edición primero y el volumen después, separados por una coma, antes del rango de página. No escriba punto entre el título y la información entre paréntesis.

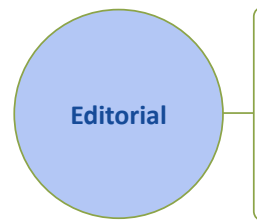

Incluya el nombre de la editorial seguido por un punto. No incluya la ubicación del editor. Si hay varios editores, debe separarlos con un punto y coma.

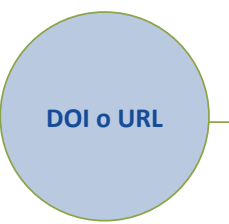

Si el libro tiene DOI, inclúyalo. No suministre una URL o información de la base de datos para trabajos de bases de datos de investigación académica. Incluya una URL para libros electrónicos. No escriba un punto después del DOI o URL.

Figura 31. Esquema para citar capítulos de libros Fuente: adaptado de APA (2020). 
La información consignada debe corresponder estrictamente a la incluida en los siguientes ejemplos, y seguir las mismas normas de puntuación entre cada elemento de la referencia:

\section{Ejemplo 35: referencia a capítulos de libros}

Horstwood, M. (2008). Data reduction strategies, uncertainty assessment and resolution of LA-(MC-) ICP-MS isotope data. En P. Sylvester (ed.), Laser ablation-ICP-MS in the Earth Sciences: Current practices and outstanding issues. Mineralogical Association of Canada. Reimann, C., Birke, M., Demetriades, A., Filzmoser, P. y O'Connor, P. (2014). The Gemas project: Concept and background. En C. Reimann, A. Demetriades, M. Birke e I. Schoeters (eds.). Chemistry of Europe's agricultural soils, Part A. BundesanstAlt fur Geowissenschaften und Rohstoffe.

\subsubsection{Reseñas de libro}

Para las reseñas de libro aparece en primer lugar el nombre de quien hace la respectiva reseña, luego el año entre paréntesis, el título de la reseña, el título del libro reseñado del autor, la publicación con volumen y número, el rango de páginas y el DOI.

En la figura 32 puede apreciarse el esquema de citación para reseñas de libros. 


\section{Reseñista, A. A. (Año del copyright). Título de la reseña \\ de N. Apellido, Título de la publicación. (pp. \#\#-\#\#). DOI o URL}

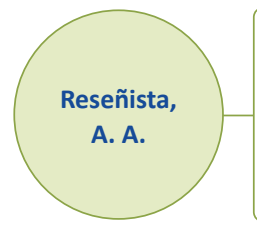

El reseñista se cita por su apellido, seguido de una coma y las iniciales de los nombres. Deje un espacio entre las iniciales.

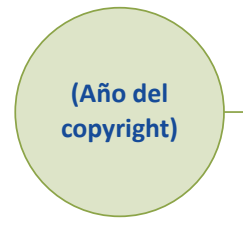

Escriba el año del copyright entre paréntesis. Termine con un punto.

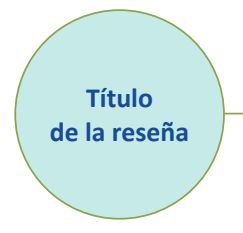

Escriba con mayúscula solo la primera letra de la primera palabra. Para un título de dos partes, escriba en mayúscula la primera palabra de la segunda parte del título. Título y subtítulo van separados con dos puntos (no use punto ni guion). También escriba con mayúscula los nombres propios. No utilice cursiva. Termine con un punto.

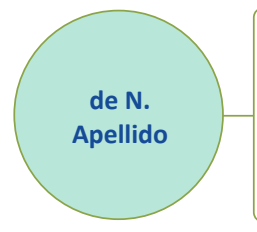

Escriba la palabra "de" (sin dos puntos) y las iniciales de los nombres, seguidas del apellido de cada autor (no invierta el orden de los nombres). Termine con una coma.

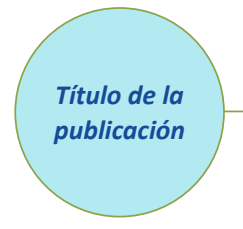

Proporcione el título del libro sobre el que se hace la reseña. Use mayúsculas solo en la primera letra de la primera palabra. Para título de dos partes, escriba con mayúscula la primera palabra de la segunda parte del título. Título y subtítulo van separados con dos puntos (no use punto ni guion). Escriba los nombres propios con inicial mayúscula. Utilice cursiva.

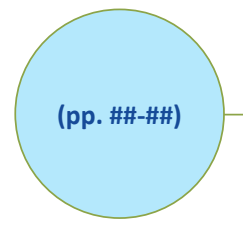

Incluya entre paréntesis el rango de páginas del libro reseñado. Termine con un punto. Si el libro tiene una edición o número de volumen, incluya el número entre paréntesis antes del rango de páginas. Si tiene ambos, se debe mostrar la edición primero y el volumen después, separados por una coma, antes del rango de página. No escriba punto entre el título y la información entre paréntesis.

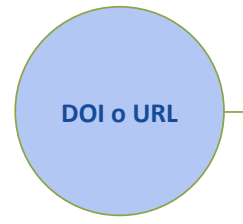

Si el libro tiene DOI, inclúyalo. No suministre una URL o información de la base de datos para trabajos de bases de datos de investigación académica. Incluya una URL para libros electrónicos. No escriba un punto después del DOI o URL.

Figura 32. Esquema para citar reseñas de libros Fuente: adaptado de APA (2020). 
Ejemplo 36: referencia a reseñas de libro

Sandino, J. J. (1997). Reseña de Herramientas metodológicas para el levantamiento de columnas estratigráficas, de F. De Lesseps. Ideas Geológicas, 6(11-13), 185-148.

\subsubsection{Artículos de revista}

Para los títulos de artículos de revista rigen las mismas reglas que para los títulos de capítulos de libro, con la salvedad de que en los títulos de las publicaciones periódicas todas las palabras significativas se escriben con la inicial mayúscula.

En la figura 33 puede apreciarse el esquema de citación para artículos de revista. 


\section{Autor, A. A., Autor, B. B. y Autor, C. C. (Año). Título del artículo. Nombre de la Revista, volumen (número), \#-\#. http://doi.org/ddd}

Autor, A. A., Autor, B. B. y Autor, C. C.
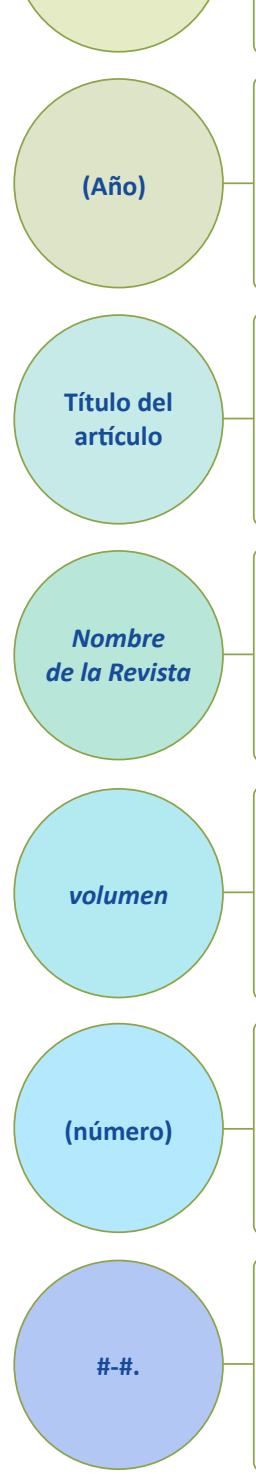

Incluya el rango de página Termine con un punto.

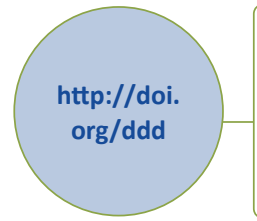
punto después del DOI.
Los autores se citan por su apellido o apellidos (si firman con los dos), seguido de una coma y las iniciales de los nombres. Deje un espacio entre las iniciales. Se debe conservar el orden de los nombres de los autores. Antes de la conjunción " $y$ " no debe ir coma.

Escriba el año entre paréntesis. Termine con un punto.

Escriba con mayúscula solo la primera letra de la primera palabra. Para un título de dos partes, escriba en mayúscula la primera palabra de la segunda parte del título. Ambas partes se separan con dos puntos. También escriba con mayúscula los nombres propios. No use cursiva. Termine con punto.

Escriba en mayúscula todas las palabras significativas en el nombre de la revista, seguido con una coma. Escriba en cursiva el nombre de la publicación periódica (pero no la coma que sigue).

Escriba en cursiva el número del volumen. No incluya espacio entre el número del volumen y los paréntesis alrededor del número de la publicación. Termine con una coma.

Escriba el número en caso de que haya más de una publicación en el volumen. No ponga en cursiva el número o los paréntesis. Escriba una coma a continuación de los paréntesis. Si no hay un número en el volumen, escriba una coma a continuación del número de volumen.

Si el artículo tiene un DOI, inclúyalo para todos los trabajos que tienen uno en forma de URL. No escriba un

Figura 33. Esquema para citar artículos de revista Fuente: adaptado de APA (2020). 
La información consignada debe corresponder estrictamente a la incluida en los siguientes ejemplos, y seguir las mismas normas de puntuación entre cada elemento de la referencia:

\section{Ejemplo 37: referencia a artículos de revista}

Bürgl, H. (1959). Sedimentación cíclica en el geosinclinal cretáceo de la cordillera Oriental de Colombia. Boletín Geológico, 7(1-3), 85-118.

Domeier, M. y Torsvik, T. (2014). Plate tectonics in the late Paleozoic. Geoscience Frontiers, 5(3), 303-350. https://doi.org/10.1016/j.gsf.2014.01.00249

Ejemplo 38: referencia con más de veinte autores

Kalnay, E., Kanamitsu, M., Kistler, R., Collins, W., Deaven, D., Gandin, L., Iredell, M., Saha, S., White, G., Woollen, J., Zhu, Y., Chelliah, M., Ebisuzaki, W., Higgins, W., Janowiak, J., Mo, K. C., Ropelewski, C., Wang, J., Leetmaa, A., ... Joseph, D. (1996). The NCEP/NCAR 40year reanalysis project. Bulletin of the American Meteorological Society, 77(3), 437-471. https://doi.org/10.1175/1520-0477(1996)077\%3C0437:TNYRP\%3E2.0.CO;2

\subsubsection{Informes y literatura gris}

Para citar un informe en una entrada de referencia, incluya el autor, el año, el título del informe, el número del informe (si lo hay), la ubicación del editor y el nombre de editorial. Las citas en el texto siguen el formato de incluir al autor (u organización de autor) y el año de publicación.

En la figura 34 puede apreciarse el esquema de citación para informes y literatura gris. 


\section{Autor, A. A., Autor, B. B. y Autor, C. C. (Año del informe). \\ Título del informe. Ciudad de la editorial: Editorial. DOI o URL}

Autor, A. A., Autor, B. B. y Autor, C. C.
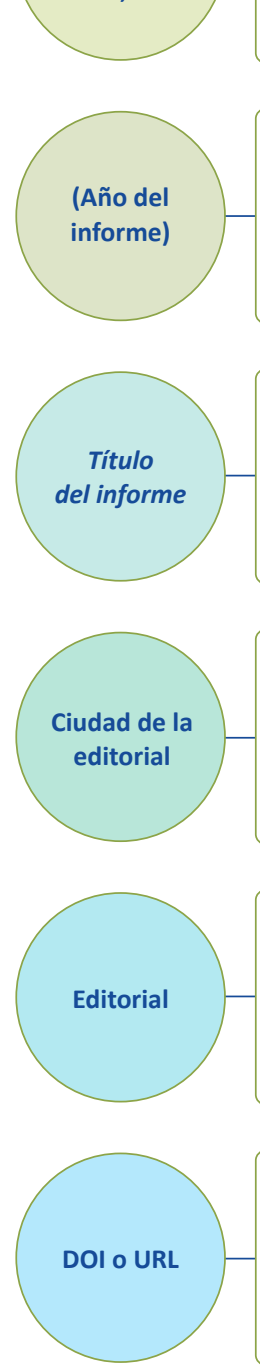

Si el informe tiene DOI, inclúyalo. No incluya una URL o información de la base de datos para trabajos de bases de datos de investigación académica. Incluya una URL para documentos electrónicos. No escriba un punto después del DOI o URL.

Los autores se citan por su apellido o apellidos (si firman con los dos), seguido de una coma y las iniciales de los nombres. Deje un espacio entre las iniciales. Se debe conservar el orden de los nombres de los autores. Antes de la conjunción " $y$ " no debe ir coma.

Escriba el año del informe entre paréntesis. Termine con un punto.

Escriba con mayúscula solo la primera letra de la primera palabra. Para un título de dos partes, escriba en mayúscula la primera palabra de la segunda parte del título. También escriba con mayúscula los nombres propios. Utilice cursiva. Termine con un punto.

Escriba la ciudad de la editorial. Para informes del SGC, la ciudad es Bogotá. Termine con dos puntos.

Escriba el nombre de la editorial, seguido de un punto. En caso de tener múltiples editoriales, sepárelas con un punto y coma.

Figura 34. Esquema para citar informes y literatura gris 
Ejemplo 39: referencia a informes y literatura gris

Correa Martínez, A. M., Ramírez, D., Rodríguez, G., Zapata, J. P., Obando, G., Muñoz, J. A., Rayo, L. del P. y Ureña, C. I. (2020). Batolito central de la Sierra Nevada, Magdalena, La Guajira y Cesar. Bogotá: Servicio Geológico Colombiano.

Castro Marín, E., Rangel, M., Ocampo, E. y Medina Ávila, D. (2020). Avenida Torrencial del 28 de enero de 2020 en la cuenca del río Frío del Municipio de Floridablanca. Departamento de Santander. Versión año 2020. Bogotá: Servicio Geológico Colombiano.

\section{Ejemplo 40: referencia a tesis}

Van der Lelij, R. (2013). Reconstructing north-western Gondwana with implications for the evolution of the lapetus and Rheic Oceans: A geochronological, thermochronological and geochemical study (tesis de doctorado). Université de Genève, Ginebra, Suiza.

\subsubsection{Congresos, seminarios y otros}

Los títulos de las ponencias presentadas en eventos se escriben en cursiva y llevan mayúscula únicamente en la inicial de la primera palabra y en los sustantivos propios, si los tienen. Los nombres de los eventos llevan mayúscula en todas las palabras significativas y no se escriben en cursiva.

En la figura 35 puede apreciarse el esquema de citación para congresos, seminarios y otros. 


\section{Autor, A. A., Autor, B. B. y Autor, C. C. (Año del evento, mes día 1-día 2). Título del trabajo [Formato]. Nombre del Evento, Lugar del evento. DOI o URL}

Autor, A. A., Autor, B. B. y Autor, C. C.
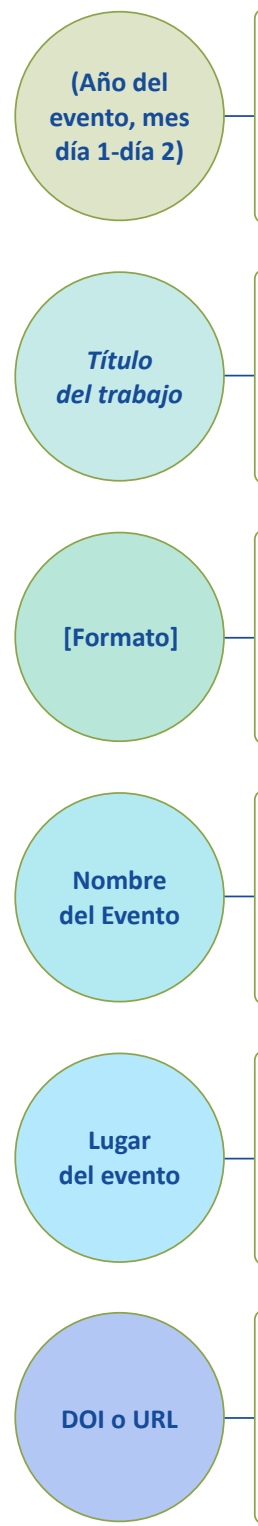

Los autores se citan por su apellido o apellidos (si firman con los dos), seguido de una coma y las iniciales de los nombres. Deje un espacio entre las iniciales. Se debe conservar el orden de los nombres de los autores. Antes de la conjunción " $y$ " no debe ir coma.

Escriba entre paréntesis el año del evento, seguido de coma, el mes del evento y el rango de días de todo el evento, separados por un guion sin espacios. Termine con un punto.

Escriba con mayúscula solo la primera letra de la primera palabra. Para un título de dos partes, escriba en mayúscula la primera palabra de la segunda parte del título, y entre ambas, dos puntos. También escriba con mayúscula los nombres propios. Utilice cursiva. Termine con un punto.

Entre corchetes escriba el tipo de trabajo. Escoja entre las siguientes posibilidades o similares: "Presentación de artículo", "Sesión de conferencia", "Simposio", "Presentación de póster".

Escriba el nombre del evento en el que se hizo la presentación, con inicial mayúscula en todas las palabras significativas. Finalice con coma.

Escriba el lugar donde se realizó el evento. Termine con un punto.

Escriba con mayúscula solo la primera letra de la primera palabra. Para un título de dos partes, escriba en mayúscula la primera palabra de la segunda parte del título, y entre ambas, dos puntos. También escriba con mayúscula los nombres propios. Utilice cursiva. Termine con un punto.

Figura 35. Esquema para citar congresos, seminarios y otros 
La información consignada debe corresponder estrictamente a la incluida en el siguiente ejemplo, y seguir las mismas normas de puntuación entre cada elemento de la referencia:

Ejemplo 41: referencia a congresos, seminarios y otros

Duque Caro, H. (1972). The geology of Monteria area. $14^{\text {th }}$ Annual Conference. Colombian Society of Petroleum Geologists and Geophysicists, Bogotá.

Pearson, J. (2018, septiembre 27-30). Fat talk and its effects on state-based body image in women [Presentación de póster]. Australian Psychological Society Congress, Sydney, NSW, Australia. http://bit.ly/2XGSThP

\subsubsection{Páginas web}

\section{Sitio web completo}

De acuerdo con el manual de APA (2020), no se necesita citar sitios web completos en la lista de referencias. En el cuerpo del documento, proporcione el nombre del sitio y la URL.

La cita textual de un contenido en la web puede hacerse de esta manera:

El Servicio Geológico Colombiano acaba de lanzar un nuevo portal, Libros del SGC, en https://libros.sgc.gov.co, en el que se ofrece cualquier libro publicado por el SGC desde 2010.

\section{Página web/documento}

Si requiere citar una página o documento de un sitio web, el tipo de contenido determina cómo debe citar la fuente (por ejemplo, artículo de revista, publicación de blog, wiki, video de YouTube, etc.).

En la figura 36 puede apreciarse el esquema de citación de documentos de páginas web. 


\section{Autor, A. A. y Autor, B. B. (Fecha). Título de la página web/documento. Institución responsable. Recuperado, fecha de Sitio web}

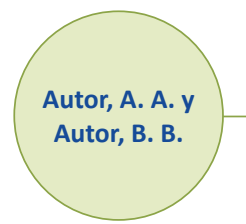

Los autores se citan por su apellido o apellidos (si firman con los dos), seguido de una coma y las iniciales de los nombres. Deje un espacio entre las iniciales. Se debe conservar el orden de los nombres de los autores. Antes de la conjunción " $y$ " no debe ir coma.

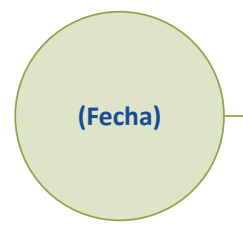

Escriba la fecha del sitio web (DD/MM/AAAA) y termine con un punto. En caso de que no se pueda determinar la fecha, se debe escribir "s. f.", con un espacio de separación entre las letras.

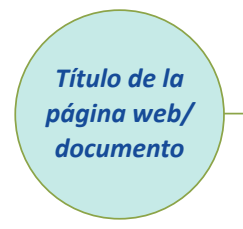

Escriba con mayúscula solo la primera letra de la primera palabra. Para un título de dos partes, escriba en mayúscula la primera palabra de la segunda parte del título, ambas separadas por dos puntos. También escriba con mayúscula los nombres propios. Utilice cursiva. Termine con un punto.

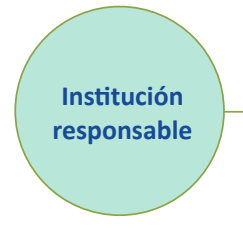

Escriba el nombre de la institución responsable de la página web o del contenido publicado. Termine con un punto. No utilice cursiva. En caso de que el autor coincida con la institución responsable, omita este campo.

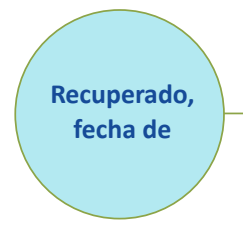

En caso de que se requiera la fecha de recuperación del contenido de la web, escriba la palabra "Recuperado" con la fecha de consulta (DD/MM/AAAA) y la palabra "de" antes de la dirección del sitio web.

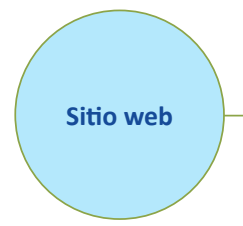

Escriba la dirección (URL) del sitio web citado, sin punto al final. No utilice cursiva.

Figura 36. Esquema para citar documentos de páginas web 
Ejemplo 42: referencia a contenido de un solo autor en la web

Barasch, A. (2/04/2018). Yes, Africa is splitting in two, and it's extremely slow and extremely fast. Pizarra. https://slate.com/technology/2018/04/yes-africa-is-splitting-in-two-andits-extremely-slow-and-extremely-fast.html

Ejemplo 43: referencia a contenido de autores múltiples en la web

Harel, D., Katz, G., Marelly, R. y Marronn, A. (23/01/2015). Wise computing: Towards endowing system development with true wisdom. University of Cornell. https://arxiv.org/ abs/1501.05924

\section{Autores corporativos, formato general}

Cuando el autor de la página web y el editor del sitio web son los mismos, omita el nombre del editor para evitar la repetición.

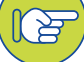

Ejemplo 44: referencia a contenido en la web cuando el autor de la página web y el editor del sitio web son los mismos

Clínica CROW (2016). Found an Animal? Here's what to do... http://www.crowclinic.org/ found-animal

\section{Página web sin fecha}

Cuando se tenga una página web de la que no se puede determinar una fecha, en lugar de la fecha requerida, use la abreviatura s. $f$. entre paréntesis.

Ejemplo 45: referencia a contenido en la web cuando no se puede determinar la fecha United Nations (s. f.). Water Action Decade. https://www.un.org/sustainabledevelopment/ water-action-decade/

Las citas correspondientes en el texto para los ejemplos de sitios web se realizan de la siguiente manera:

(Barasch, 2018)

(Harel et al., 2015)

(Clínica CROW, 2016)

(United Nations, s. f.)

Cuando se necesita una fecha de consulta de contenidos que provienen de páginas web, se deben usar las palabras "Leído Fecha de" antes de una URL. Si no se requiere fecha exacta, las URL se presentan sin una etiqueta, tal como se muestra en los siguientes ejemplos: 
Ejemplo 46: referencia a contenido en la web en que no se requiere la fecha exacta de lectura

University of Innsbruck. (2018). Giant earthquakes: Not as random as thought. ScienceDaily. http://www.sciencedaily.com/releases/2018/01/180130091241.htm

Ejemplo 47: referencia a contenido en la web en que sí se requiere la fecha exacta de lectura

Geobulletin. (2020). New papers on paleoseismology, earthquakes, and active tectonics. Leído 06/08/2020 de http://www.geobulletin.org/

\subsubsection{Mapas}

La información consignada debe corresponder estrictamente a la incluida en el siguiente ejemplo y seguir las mismas normas de puntuación entre cada elemento de la referencia:

Ejemplo 48: referencias de mapas

Behrendt, J. y Bajwa, L. (1972). Bouguer gravity map of Colorado. Scale 1:500 000. U.S. Geological Survey.

\section{Múltiples mapas de Google Maps}

Si requiere citar más de un mapa de Google en su texto, deberá distinguirlos en sus citas y referencias en el texto con una letra minúscula después del año, de la siguiente manera:

Ejemplo 49: referencias de varios mapas de Google Maps

Google (s. f.-a). [Google Maps directions to drive from Colwood City Hall to Royal Roads University]. Recuperado 4/12/2019, de https://goo.gl/maps/BXdsUNzwHnzzeEes9

Google (s. f.-b). [Google Maps Royal Roads University, Colwood, BC]. Recuperado 19/12/2019, de https://goo.gl/maps/WA4S6snveYWy36mj6

En el texto se citaría así:

(Google, s. f.-a)

(Google, s. f.-b).

\subsection{Epílogo}

Esta sección es escrita por el autor, el editor o el prologuista de un libro una vez se ha concluido el trabajo de redacción o compilación de la obra. Su objetivo es manifestar ajustes o modificaciones en el punto de vista sobre toda la obra o parte de ella (Beltrán, 2017, p. 183). Estos ajustes pudieron surgir durante la revisión y edición. Las interpretaciones o revelaciones contenidas en esta parte no son incluidas en otros 
textos de preámbulo para no anticipar elementos nuevos y expectativas de la obra, y permitir que los lectores formen su propio concepto sin esta información.

\subsection{Glosario}

El glosario, a pesar de que es opcional, podría ser importante cuando el contenido se refiere a varios términos que requieren aclaración o definición precisa en el contexto del trabajo.

La ubicación del glosario en el documento depende de la necesidad de recurrir a las definiciones. Si es muy frecuente su consulta, puede estar antes del contenido. Si no, puede ubicarse al final, antes de las referencias.

Escriba la palabra Glosario, centrada, en negritas y en tipografía 14 puntos. En caso de informes, escríbalo con mayúscula sostenida.

Use un interlineado sencillo para cada término. La lista debe ordenarse alfabéticamente. Escriba el término con mayúscula en la primera letra y minúscula en las restantes, en negritas, seguido de un punto; a continuación, el texto explicativo. Si lo considera, puede citar la fuente entre paréntesis al final del texto explicativo. Use sangría francesa de $1 \mathrm{~cm}$.

Un ejemplo de glosario para un libro es el siguiente:

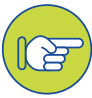

\section{Glosario}

Amenaza. Peligro latente de que un evento físico de origen natural, o causado, o inducido por la acción humana de manera accidental, se presenta con una severidad suficiente para causar pérdida de vidas, lesiones u otros impactos en la salud, así como también daños y pérdidas en los bienes, la infraestructura, los medios de sustento, la prestación de servicios y los recursos ambientales. (https://www.idiger.gov.co/glosario)

Terciario. Dicho de un periodo: primero de la era cenozoica, que abarca desde hace 65 millones de años hasta hace dos millones de años, caracterizado por la aparición y diversificación de los mamíferos. (RAE, https://dle.rae.es)

\subsection{Anexos}

Los contenidos relevantes relacionados con el texto, que tengan gran extensión o que se encuentren en un formato distinto al texto pueden incluirse como anexos. Estos pueden ir integrados o como documentos aparte.

Los anexos deben ir en hoja aparte (salto de página), el título en mayúscula (la primera letra), negritas y en fuente Calibri, 11 puntos. 
La escritura debe darse en párrafo aparte del título de primer nivel, en fuente Calibri 11 puntos.

En el caso de los libros y los informes, cada anexo debe llevar su propia portadilla.

En caso de que se tenga un solo anexo, no se requiere numerarlo, basta con llamarlo Anexo; en la referencia puede utilizarse véase el anexo.

Los anexos podrán ser numerados de manera consecutiva. Con el fin de evitar confusiones con los elementos del texto principal, los anexos podrán utilizar sistemas de numeración de figuras y tablas que se enumeren utilizando como prefijo el número del anexo y un guion.

Así, para el anexo 2, la numeración de figuras y tablas se haría de la siguiente manera:

Figura 2-1, Figura 2-2, Figura 2-3...

Tabla 2-1, Tabla 2-2, Tabla 2-3...

\subsection{Referencias cruzadas}

Una referencia cruzada permite dirigir al lector a otras partes del mismo documento. Por ejemplo, puede usar una referencia cruzada para crear un vínculo a una figura que aparece en otra parte del documento.

Las referencias cruzadas solo se hacen a contenidos que realmente existen, por esta razón, deben señalarse al final, cuando los contenidos del documento estén completos.

A pesar de que son muy funcionales, conviene no excederse en su uso para no generar confusión en el lector, por tanto, deberían reservarse para los casos más importantes o relevantes.

Para insertar una referencia cruzada en Word, puede seguir los siguientes pasos:

1) Escriba el texto que comienza la referencia cruzada, por ejemplo, "Véase la tabla 3 para revisar los datos de origen". Mantenga el punto de inserción justo después de este texto.

2) En el menú Insertar, seleccione el botón Referencia cruzada del grupo Vínculos.

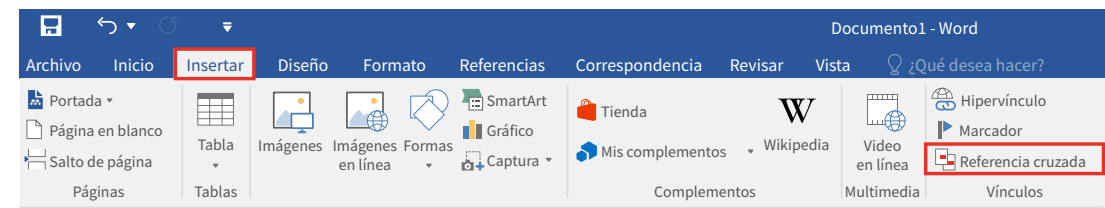

3) En la lista Tipo, haga clic en el tipo de elemento que quiere hacer referencia: Título, Marcador, Nota al pie, Tabla, Figura, etc.

4) En la lista Para qué "elemento" seleccione el elemento al que desea realizar la referencia cruzada.

5) Active la opción Insertar como hipervínculo, si desea ir al elemento de referencia haciendo clic en la referencia cruzada. 


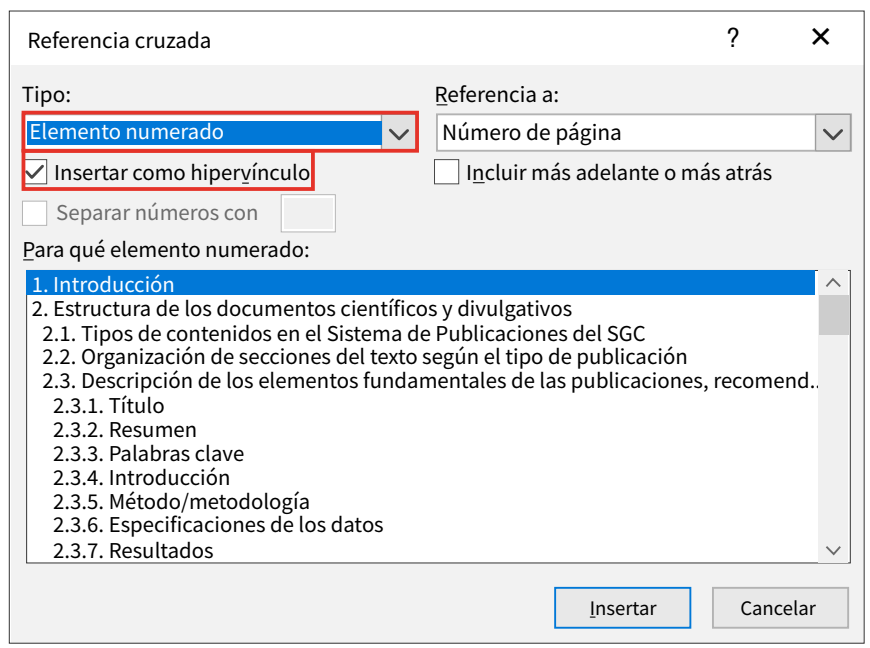

6) Puede activar la opción Incluir más adelante o más atrás, si desea agregar a la referencia cruzada las palabras Más adelante o Más atrás en función de la posición del elemento referenciado.

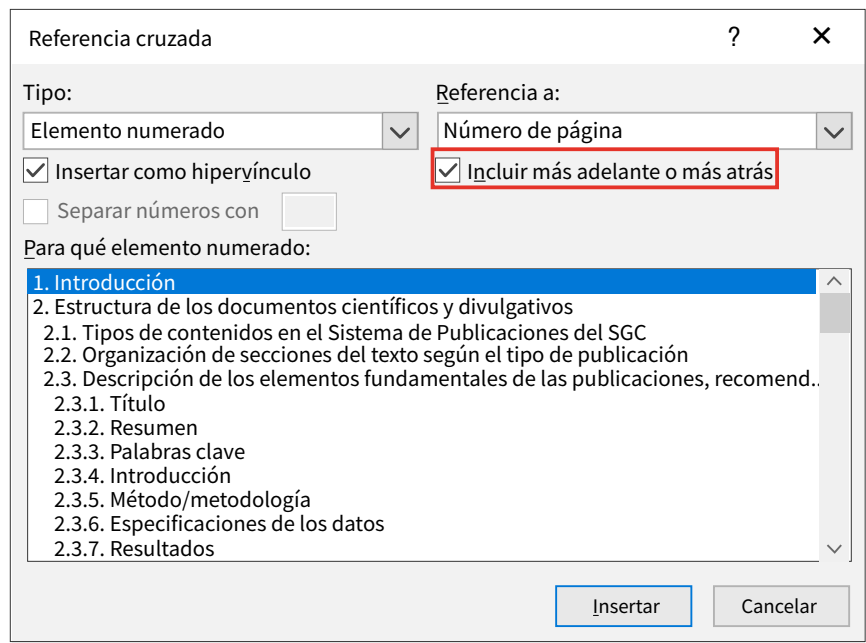

7) Pulse el botón Insertar.

Nota: con estas opciones el programa Word automáticamente inserta la referencia cruzada con la letra inicial en mayúscula. Puede hacer el ajuste para dejar toda la palabra en minúsculas desde la edición del campo respectivo.

\subsection{7. Índice de figuras}

En informes, es obligatorio generar un índice de figuras. Escriba "Índice de figuras" centrado, en negritas, en fuente de 14 puntos. 
Liste en orden el número de cada figura en Calibri de 10 puntos, seguida de un punto. A continuación, el título de la figura sin negritas y el número de página al lado derecho. Utilice sangría francesa de $1 \mathrm{~cm}$.

Un ejemplo del índice de figuras se muestra a continuación:

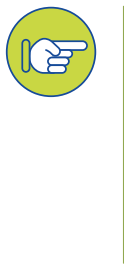

\section{Índice de figuras}

Figura 1. Mapa geológico del Valle del Cauca, Colombia, con detalles de vías de comunicación

Figura 2. Esquema de las curvas Hipsométricas de las cuencas de drenaje (IH)

\subsection{8. Índice de tablas}

En informes es obligatorio generar un índice de tablas. Escriba "Índice de tablas" centrado, en negritas y en fuente de 14 puntos.

Liste en orden de aparición las tablas con su numeración en Calibri 10 puntos, seguida de un punto. A continuación, se escribe el título de la tabla, sin negritas, y el número de página al lado derecho. Utilice sangría francesa de $1 \mathrm{~cm}$.

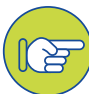

\section{Índice de tablas}

Tabla 1. Resumen de edades U-Pb en circón de monzogranitos, granodioritas, cuerpos menores y diques del Batolito de Mogotes

Tabla 2. Resultados de elementos traza en los circones de la muestra MIA-638

\subsection{9. Índice de mapas}

En informes que cuenten con una cantidad considerable de mapas de gran formato (no como figuras) es recomendable generar un índice de mapas ordenado según su aparición en el informe. Escriba "Índice de mapas" centrado, en negritas y fuente de 14 puntos.

Liste según el orden de aparición de los mapas en Calibri de 10 puntos, seguida de un punto. A continuación, se escribe el título del mapa sin negritas y el número de página al lado derecho. Utilice sangría francesa de $1 \mathrm{~cm}$.

Un ejemplo del índice de mapas se muestra a continuación: 


\section{Índice de mapas}

Mapa 1. Mapa geológico del Valle del Cauca, Colombia. Escala 1:250 000

con detalles de vías de comunicación

8

Mapa 2. Mapa de isosistas para el evento principal y sus réplicas

\subsection{0. Índice de anexos}

Para facilitar la referencia a los contenidos en anexos, es recomendable generar un índice. Escriba "Índice de anexos" centrado, en negritas y en fuente de 14 puntos. Utilice sangría francesa de $1 \mathrm{~cm}$.

Liste los anexos de manera ordenada en Calibri 10 puntos, con su respectiva numeración, seguida de un punto. A continuación, escriba el título del anexo sin negritas, y el número de página, al lado derecho.

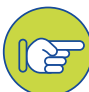

\section{Índice de anexos}

Anexo 1. Datos de muestras recogidas en campo

Anexo 2. Análisis de confiabilidad del muestreo y medición de certidumbre de los datos de la región Caribe

\subsection{Colofón}

Es el espacio reservado para la información sobre la realización física del libro: impresor, taller o empresa de producción del libro. Los datos que se suelen incluir son: título de la obra, nombre de la editorial, nombres de la colección y la serie a las que pertenece el libro, nombre de la tipografía y del papel utilizado para su impresión, nombre de la empresa impresora y año de impresión (Beltrán, 2017, pp. 195-196). 


\section{6.}

Recomendaciones para la elaboración de figuras
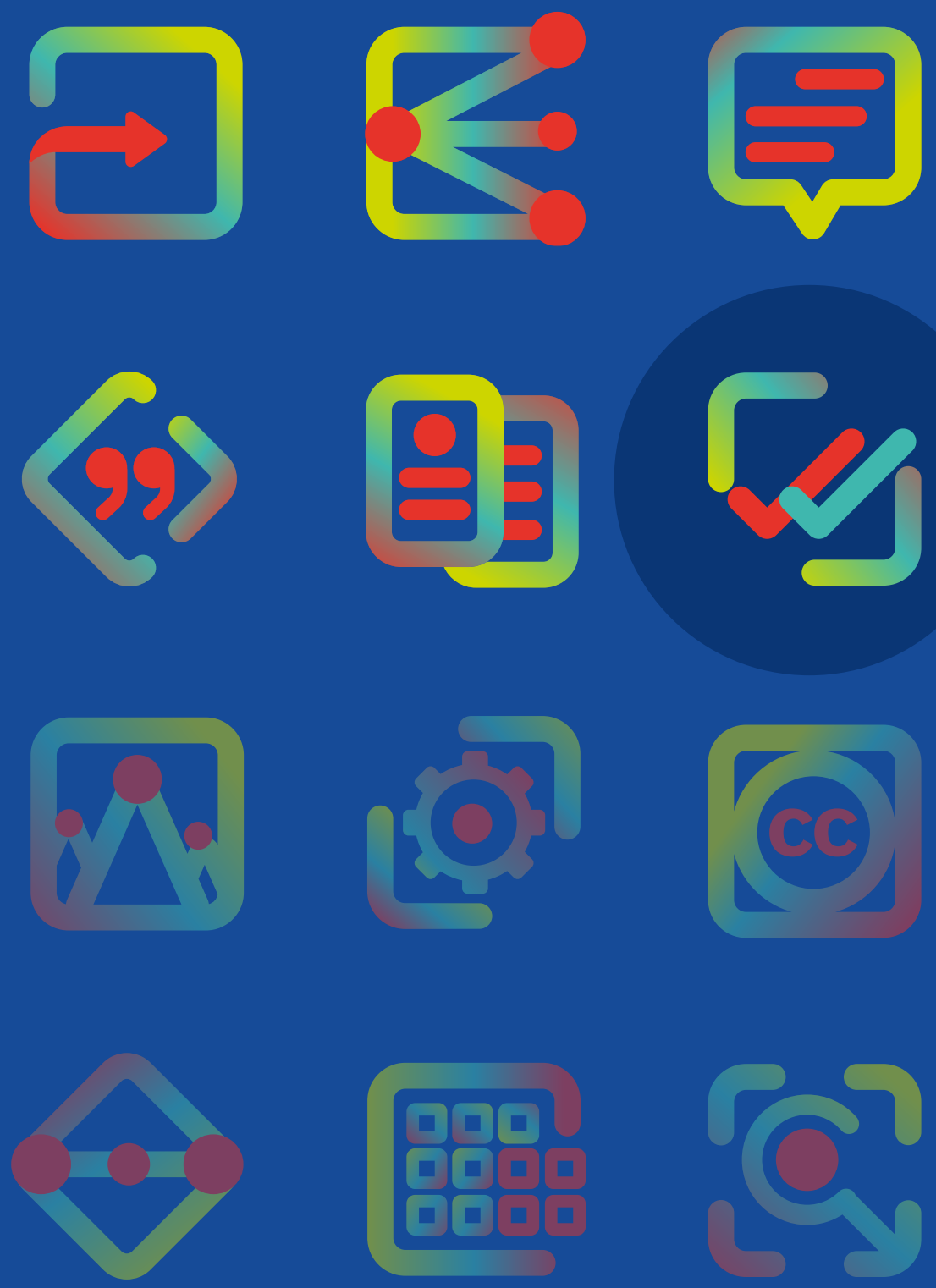


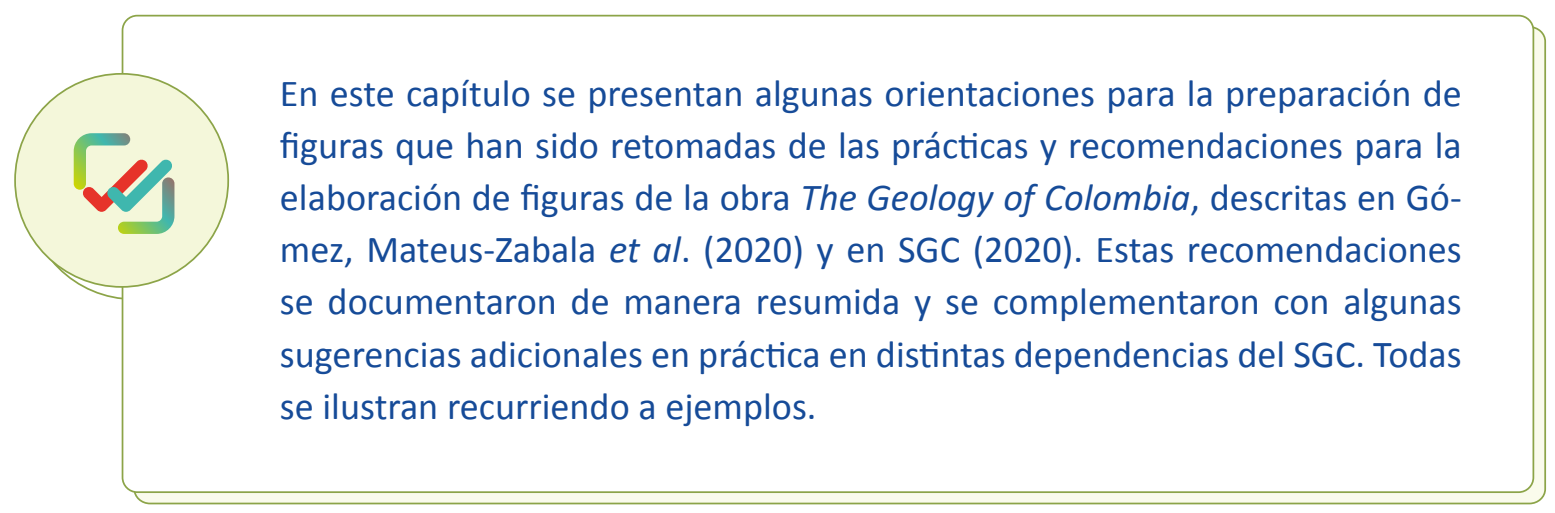

\subsection{Recomendaciones básicas de diseño}

\subsubsection{Uso de técnicas de jerarquía visual}

La elaboración de figuras y material gráfico en las publicaciones del SGC deberá, en lo posible, observar criterios de jerarquía visual. Este es el principio de diseño utilizado para organizar los elementos según su importancia. En una figura se estructuran las características visuales más importantes para que los usuarios puedan entender la información fácilmente (Tait, 2018). Al diseñar los elementos de manera lógica y estratégica, los diseñadores influyen en las percepciones de los lectores y los guían a reconocer los elementos más importantes.

La jerarquía visual se soporta en los criterios descritos en la tabla 33.

Tabla 33. Criterios básicos de la jerarquía visual

\begin{tabular}{ll}
\hline \multicolumn{1}{c}{ Nombre del criterio } & \multicolumn{1}{c}{ Descripción } \\
\hline Color & Los colores brillantes suelen atraer más atención que los opacos. \\
Tamaño & Los lectores notan los elementos más grandes con mayor facilidad. \\
Contraste & Los colores que se presentan con más contrate son más llamativos. \\
Alineación & Los elementos fuera de alineación se destacan sobre los alineados. \\
Repetición & Estilos con repetición pueden sugerir que el contenido está relacionado entre sí. \\
Proximidad & Los elementos colocados cerca unos de otros parecen estar relacionados. \\
Espacio en blanco & Más espacio alrededor de los elementos atrae la atención hacia ellos. \\
Textura y estilo & Las texturas más ricas se destacan sobre las planas. \\
\hline
\end{tabular}

En las figuras que maneja el SGC se recomienda la técnica de jerarquía visual para resaltar las principales características mediante atributos, como el grosor de línea, el color, el contraste, el tamaño y la alineación de los elementos de la figura compuestos por puntos, líneas, polígonos y textos (Gómez, Mateus-Zabala et al., 2020).

Para los mapas geocientíficos y otras figuras, a continuación se describe cómo se implementan algunos de los criterios mencionados. 


\subsubsection{Sobre el color}

Cada color tendrá una aplicación específica. Por ejemplo, las unidades de un mapa geológico tendrán unos tonos de relleno de acuerdo con los estándares geológicos, los drenajes tendrán un color azul para que quien lea la figura pueda asociarlo con agua; las fallas geológicas podrían estar en negro para que resalte de los demás elementos del mapa; las fallas inactivas podrían representarse con gris claro, dado que no representan la característica principal del mapa; para el elemento principal, por ejemplo fallas activas, puede trabajarse el rojo, que llama la atención del lector hacia ese objeto.

Los colores de los textos también pueden llevar una jerarquía; por ejemplo los nombres de los drenajes y cuerpos de agua pueden seguir con colores azules (asociados con agua); los textos del elemento principal, con el mismo color del elemento gráfico, en el caso del ejemplo, en rojo. Para los textos de localización y de poblaciones se pueden utilizar blancos o grises muy sutiles para que no sea lo primero que atraiga la atención del lector, y los demás elementos de texto pueden ir en negro.

\subsubsection{Sobre el tamaño de textos y objetos}

De manera similar a los colores, pueden utilizarse tamaños de texto o de elementos para que los más importantes tengan los mayores tamaños (11 puntos máximo) y los de menor relevancia tengan un tamaño menor (6 puntos mínimo). Así, los textos para poblaciones o elementos geográficos pueden tener un tamaño de 6 puntos, mientras que los tamaños de texto de los elementos principales pueden estar en tamaño de 8 puntos, o más.

De la misma manera, cuando se trata de objetos que representan puntos, los elementos más importantes podrán tener un mayor tamaño, respecto a los elementos que son secundarios.

\subsubsection{Sobre el grosor de líneas}

El grosor de las líneas puede usarse como criterio de jerarquía para resaltar los elementos más importantes. En un mapa geológico, el grosor de los límites de las unidades geológicas es muy fino (del orden de 0,25 puntos), dado que el elemento importante en las unidades son los colores de relleno de los polígonos; para las fallas geológicas se usa uno de 0,5 puntos $(0,2 \mathrm{~mm})$, mayor que el de los límites de las unidades; los drenajes, las vías y la grilla de coordenadas pueden tener un grosor muy fino $(0,25$ puntos) para no saturar el mapa con elementos secundarios.

\subsubsection{Sobre el contraste}

Mediante el contraste es posible resaltar algunos elementos de manera deliberada con el fin de mejorar su legibilidad. En un mapa geológico se pueden trabajar patrones para destacar las unidades sobre las que se quiere hacer énfasis. Si se tiene una unidad de fondo oscuro, puede usarse un patrón de fondo claro para mejorar el contraste; si, por lo contrario, se tiene un fondo claro, es viable recurrir a un patrón de fondo oscuro para lograr el mismo efecto de contraste. Similarmente, cuando hay fondos claros, de- 
ben usarse textos de tonos oscuros, y viceversa, cuando se tiene un fondo oscuro, es adecuado un color claro en el texto.

Cuando se tienen textos sobre gráficas con muchos detalles, es posible utilizar unos halos de color para estos, así se evita que queden enmascarados en los detalles de la figura. Cuando los textos están sobre fondos de colores uniformes, para el color del halo es procedente el mismo color de estos fondos para no introducir elementos extraños. Cuando hay un texto sobre varios polígonos de diferentes tonos, se usa el halo blanco.

\subsubsection{Sobre la alineación}

La alineación de los elementos de una figura ordena la composición y permite que exista armonía. Por el contrario, un elemento desalineado del resto resaltará por encima de los demás, lo que resultaría en un efecto indeseable. Para las figuras compuestas de diferentes elementos, debe tenerse un criterio consistente de alineación vertical y horizontal.

En caso de que existan elementos de diferente tamaño, podrán alinearse por el borde superior y por el borde izquierdo.

Para textos que describan polígonos, es recomendable que estén centrados respecto al polígono para que no haya duda sobre a qué se refiere este.

En textos que nombren o describan elementos lineales - ya sea horizontales o inclinados-, aquellos deberán colocarse, con la misma inclinación, sobre el elemento, de izquierda a derecha. Cuando se trate de objetos lineales verticales, se escribirá el texto rotado $90^{\circ}$ y escrito de abajo hacia arriba. Dependiendo de los espacios disponibles en el dibujo, podrán colocarse a la izquierda o a la derecha del elemento.

Cuando se trate de drenajes, el texto deberá seguir la curvatura del drenaje y marcarse con la fuente Book Antiqua.

Los detalles de ubicación y dirección de los textos en elementos lineales pueden apreciarse en la figura 37. 


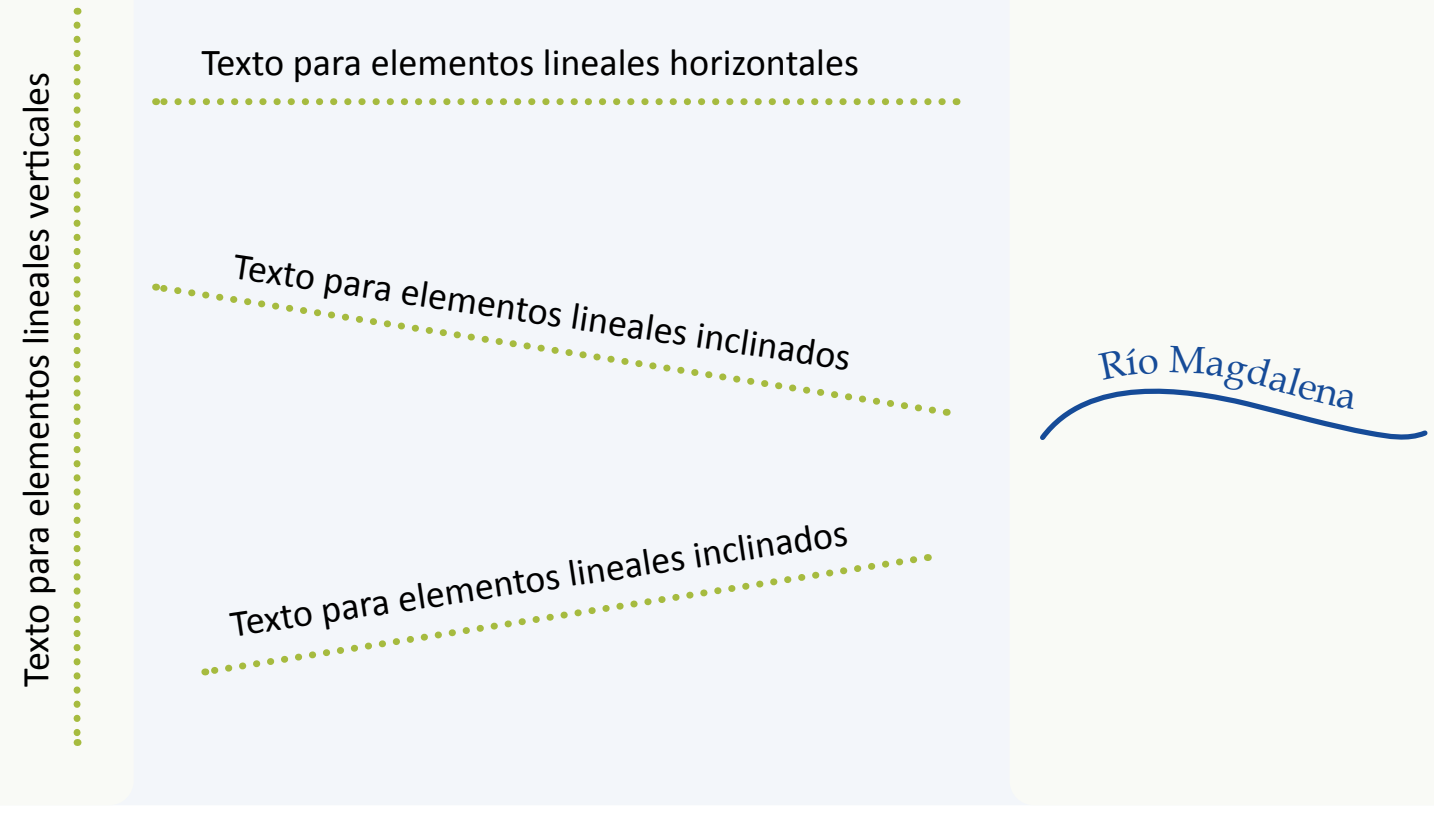

Figura 37. Ubicación de textos en elementos lineales Fuente: adaptado de SGC (2020).

\subsubsection{Manejo de color}

El perfil de color a utilizar debe ser CMYK (cian, magenta, amarillo, negro). Este perfil es adecuado para versiones impresas y digitales en formato PDF.

En los mapas geocientíficos es importante el uso del color para mostrar, de manera más efectiva, los elementos sobre los que se desea hacer énfasis. Con la presencia masiva de las publicaciones del SGC en mecanismos digitales, no hay límites por impresión o por tipo de papel, por esta razón, deberá estimularse el uso generalizado de colores para la presentación de figuras.

\subsubsection{Consideraciones sobre el tamaño de las figuras}

Para las publicaciones de libros, artículos e informes del SGC debe seleccionarse el tamaño ideal para la figura y elaborarse con base en ese tamaño desde el principio. Se recomiendan cuatro tamaños estandarizados para artículos y libros, y dos para informes, como se muestra en la tabla 34 . 
Tabla 34. Características de los tamaños de figuras para artículos y libros e informes

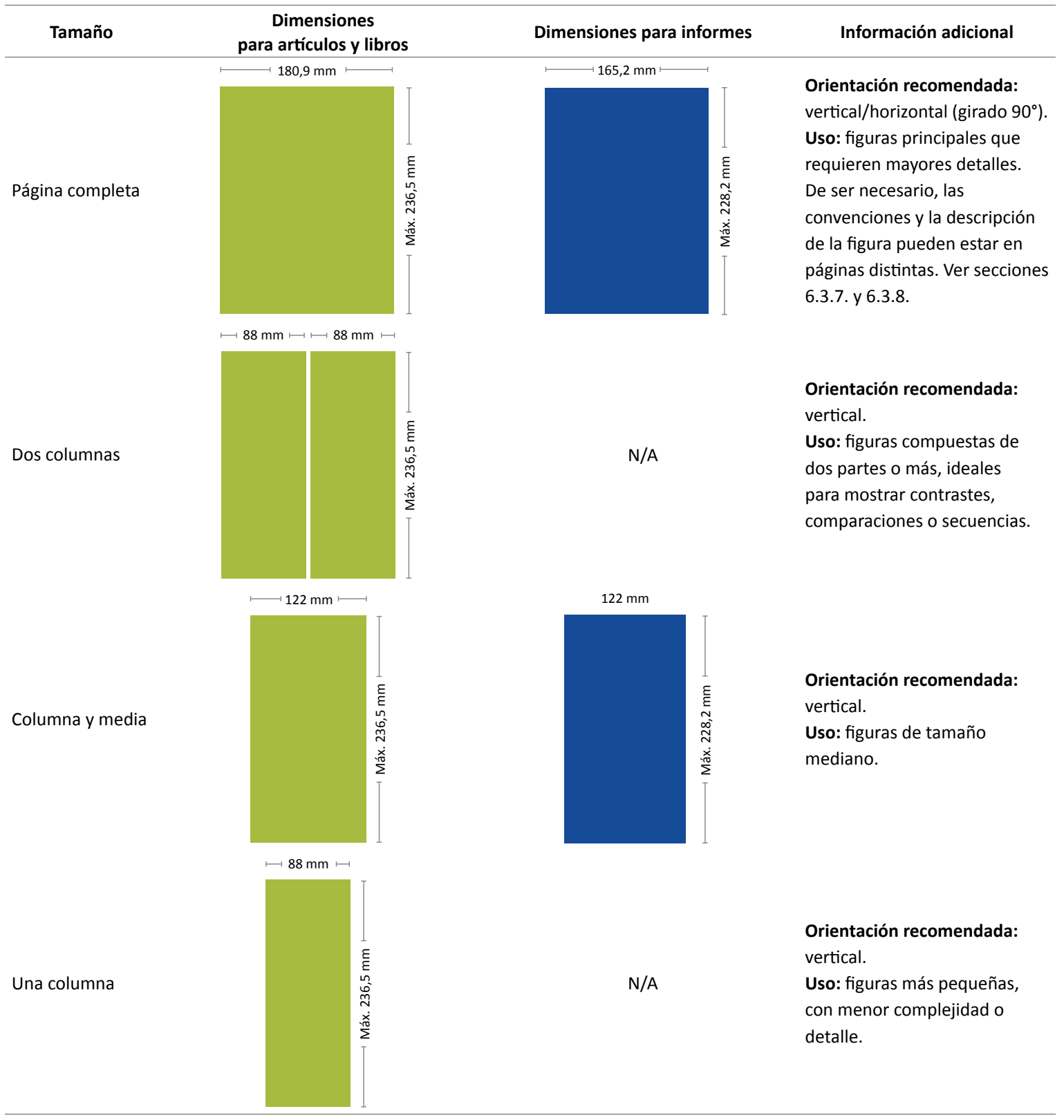

\subsubsection{Consideraciones sobre la tipografía para las figuras}

Mantenga los textos de la figura con la misma fuente y con un tamaño uniforme. Las variaciones del tamaño deberán ser mínimas.

Evite efectos en los textos como sombreados, negritas y subrayados, a menos que se requiera para contrastar algún elemento que necesite una mejor visualización. 
No incluya títulos o textos explicativos dentro de las figuras. Si precisa de ellos, recurra a las notas debajo del título para suplir esta necesidad.

Para textos se recomienda una orientación horizontal, excepto para estructuras lineales (ríos, fallas o vectores) que pueden seguir la orientación de la estructura lineal.

Las fuentes recomendadas para los textos de las figuras son del tipo SanSerif (sin serifas) e incluyen las siguientes:

- Calibri

- Helvética LT Std

- Helvética LT Std Cond

- Arial

Para cuerpos de agua (ríos, lagos, mares):

- Book Antiqua

Para la orientación de los nombres de estructuras como fallas, pliegues, drenajes y flechas indicativas se siguen las recomendaciones de Gómez, Mateus-Zabala et al. (2020) en donde, para las estructuras con inclinaciones NE a SO, la dirección del etiquetado es en dirección sur-norte, y para aquellas inclinadas NW a SE, la dirección del etiquetado es norte-sur. El texto es recto o curvo dependiendo de la forma de la estructura.

Los textos relacionados con un punto exacto se colocan a la derecha de este, preferiblemente en la parte de arriba. Cuando ninguna de estas dos posiciones es posible, se sugieren las ubicaciones a la izquierda, preferiblemente arriba. La última opción es colocar el texto inmediatamente encima o debajo del punto.

El tamaño de texto para las figuras debe estar entre 6 y 11 puntos, con 8 puntos como el más apropiado (Gómez, Mateus-Zabala et al., 2020). Se deben evitar las mayúsculas sostenidas para no desviar la atención del lector.

Las muestras del texto con las distintas fuentes mencionadas para varios tamaños se pueden observar en la tabla 35. 
Tabla 35. Comparación de las fuentes recomendadas en diferentes tamaños para las figuras

\begin{tabular}{|c|c|c|c|c|c|}
\hline $\begin{array}{l}\text { Tamaño/ } \\
\text { Fuente } \\
\text { (puntos) }\end{array}$ & Helvética LT Std & $\begin{array}{l}\text { Helvética LT Std } \\
\text { Cond }\end{array}$ & Calibri & Arial & $\begin{array}{l}\text { Book Antiqua } \\
\text { (solo en drenajes y } \\
\text { cuerpos de agua) }\end{array}$ \\
\hline 6 & $\begin{array}{l}\text { El video proporciona } \\
\text { una manera eficaz para } \\
\text { ayudarle a demostrar } \\
\text { el punto. }\end{array}$ & $\begin{array}{l}\text { El video proporciona una } \\
\text { manera eficaz para ayudarle } \\
\text { a demostrar el punto. }\end{array}$ & $\begin{array}{l}\text { El video proporciona } \\
\text { una manera eficaz para } \\
\text { ayudarle a demostrar el } \\
\text { punto. }\end{array}$ & $\begin{array}{l}\text { El video proporciona } \\
\text { una manera eficaz para } \\
\text { ayudarle a demostrar } \\
\text { el punto. }\end{array}$ & \\
\hline 8 & $\begin{array}{l}\text { El video } \\
\text { proporciona una } \\
\text { manera eficaz } \\
\text { para ayudarle } \\
\text { a demostrar el } \\
\text { punto. }\end{array}$ & $\begin{array}{l}\text { El video proporciona } \\
\text { una manera eficaz } \\
\text { para ayudarle a } \\
\text { demostrar el punto. }\end{array}$ & $\begin{array}{l}\text { El video proporciona } \\
\text { una manera eficaz } \\
\text { para ayudarle a } \\
\text { demostrar el punto. }\end{array}$ & $\begin{array}{l}\text { El video } \\
\text { proporciona una } \\
\text { manera eficaz } \\
\text { para ayudarle } \\
\text { a demostrar el } \\
\text { punto. }\end{array}$ & Río M \\
\hline 10 & $\begin{array}{l}\text { El video } \\
\text { proporciona } \\
\text { una manera } \\
\text { eficaz para } \\
\text { ayudarle a } \\
\text { demostrar el } \\
\text { punto. }\end{array}$ & $\begin{array}{l}\text { El video } \\
\text { proporciona una } \\
\text { manera eficaz } \\
\text { para ayudarle } \\
\text { a demostrar el } \\
\text { punto. }\end{array}$ & $\begin{array}{l}\text { El video } \\
\text { proporciona una } \\
\text { manera eficaz } \\
\text { para ayudarle } \\
\text { a demostrar el } \\
\text { punto. }\end{array}$ & $\begin{array}{l}\text { El video } \\
\text { proporciona } \\
\text { una manera } \\
\text { eficaz para } \\
\text { ayudarle a } \\
\text { demostrar el } \\
\text { punto. }\end{array}$ & Rín Ma \\
\hline 11 & $\begin{array}{l}\text { El video } \\
\text { proporciona } \\
\text { una manera } \\
\text { eficaz para } \\
\text { ayudarle a } \\
\text { demostrar el } \\
\text { punto. }\end{array}$ & $\begin{array}{l}\text { El video } \\
\text { proporciona } \\
\text { una manera } \\
\text { eficaz para } \\
\text { ayudarle a } \\
\text { demostrar el } \\
\text { punto. }\end{array}$ & $\begin{array}{l}\text { El video } \\
\text { proporciona } \\
\text { una manera } \\
\text { eficaz para } \\
\text { ayudarle a } \\
\text { demostrar el } \\
\text { punto. }\end{array}$ & $\begin{array}{l}\text { El video } \\
\text { proporciona } \\
\text { una manera } \\
\text { eficaz para } \\
\text { ayudarle a } \\
\text { demostrar el } \\
\text { punto. }\end{array}$ & Magd \\
\hline
\end{tabular}

\subsection{Uso de herramientas y formatos}

\subsubsection{Software recomendado}

Las figuras de las publicaciones del SGC deben elaborarse con herramientas adecuadas de diseño gráfico. Existen varias herramientas, sin embargo, las más recomendables son las siguientes:

Sketch: manejo vectorial (disponible para Mac).

Adobe Photoshop CC: tratamiento de fotografías.

Adobe Illustrator: creación de dibujos, tipografías e ilustraciones (principalmente vectorial).

Adobe InDesign: trabajos editoriales digitales. Usado para maquetación.

PicMonkey: manejo de fotografías y diseño.

Canva: manejo de imágenes rápidas y de calidad.

En lo posible, las herramientas deben manejar formatos vectoriales para permitir los cambios de escala sin pérdida de resolución y para el posterior mejoramiento de las figuras y de los textos. 


\subsubsection{Uso de formatos apropiados para cada caso}

\subsubsection{Formatos vectoriales}

Un archivo de formato vectorial está formado por objetos geométricos independientes (puntos, líneas, polígonos y arcos), cada uno de ellos definido por distintos atributos matemáticos de forma, posición, color, etc.

El formato vectorial es completamente opuesto al de las imágenes de mapa de bits o ráster, también llamadas imágenes matriciales, que están formados por píxeles.

La ventaja principal de los gráficos vectoriales es que puede ampliarse el tamaño de una imagen sin sufrir la pérdida de calidad que afectan a los mapas de bits. En imágenes matriciales, se alcanza un punto en su tamaño en el que es evidente que la imagen está compuesta por píxeles. Por encima de este punto, en diseño se dice que las imágenes aparecen pixeladas.

De igual manera, un formato vectorial permite mover, estirar y ajustar imágenes de forma relativamente sencilla. Los objetos definidos por vectores pueden ser guardados y modificados en el futuro.

Los formatos vectoriales recomendados para las figuras incluyen los siguientes:

\subsubsection{EPS (PostScript encapsulado)}

Es el formato de imágenes vectoriales más usado y constituye el estándar de intercambio en la industria de impresión. Es un formato de exportación ampliamente compatible, pero debido a la complejidad de la especificación del formato completo, no todos los programas que dicen ser compatibles con EPS pueden importar todas sus variantes. Adobe Illustrator tiene buena compatibilidad con la lectura y escritura de EPS.

\subsection{SVG (Scalable Vector Graphics)}

El formato vectorial estándar W3C se llama SVG. Inkscape y las versiones recientes de Adobe Illustrator tienen buena compatibilidad de escritura y lectura del formato SVG. Su extensión es .svg.

\subsection{PDF (Portable Document File)}

El formato PDF se usa ampliamente como formato de documento independiente de la plataforma para uso general. Aunque no se usa exclusivamente para eso, también es un formato de imagen vectorial muy versátil. Debe tener en cuenta que el PDF se debe haber generado a partir de una fuente vectorial para que herede esta condición (también hay archivos PDF con imágenes ráster, que no son las recomendadas para las figuras). La extensión de estos archivos es .pdf. 


\subsection{Al (Adobe Illustrator)}

Esta es una versión modificada del formato EPS más antigua. El formato Al tiene bastante compatibilidad, pero es menos común que el EPS. La mayoría de los programas que pueden leer el formato Al también pueden leer el EPS. Su extensión es .ai.

\subsubsection{DXF (Drawing eXchange Format)}

Es un formato CAD (computer aided design) de Autodesk, que usa las herramientas CAD de muchos proveedores. Su extensión es .dxf.

\subsection{XAR (Xara Xtrem)}

El formato XAR es nativo de Xara Xtrem. Su extensión es .xar.

\subsubsection{Formatos ráster}

Para fotografías e imágenes son aceptables los formatos ráster o matriciales. En los archivos tipo ráster, cada celda (píxel) posee un valor. Los valores de celda representan el fenómeno descrito por el archivo ráster, como, por ejemplo, una categoría de color, magnitud, altura o valor espectral.

Los formatos ráster más recomendados son Geotiff para mapas y Tiff para fotografías, sin embargo, a continuación se muestra un panorama de las distintas opciones con sus características y usos preferidos.

\subsection{GeoTIFF}

Es el formato estándar para imágenes más usado en la industria de los SIG y en las aplicaciones de teledetección, y fue desarrollado por el Jet Propulsion Laboratory de la NASA. Por lo general, este archivo viene acompañado de archivos de geolocalización (TFW), XML de metadatos y un archivo AUX en el que se almacenan las proyecciones geográficas y otra información. Su extensión es .tif.

\subsection{MrSID (Multi-resolution Seamless Image Database)}

Es un estándar abierto de compresión de imágenes ráster, de amplia penetración en la industria de los SIG por la facilidad de manejo de imágenes de gran tamaño. Las imágenes MrSID tienen una extensión .sid y se acompañan de un archivo con extensión .sdw.

\subsection{Erdas Imagine (IMG)}

Es un formato de almacenamiento propietario de ERDAS que admite multicapa de imágenes georreferenciadas. Es ampliamente trabajado por los usuarios de ERDAS para el procesamiento de imágenes satelitales. Su extensión es .img. 


\subsection{2. .4 . TIFF (Tagged Image File Format)}

Es un formato ampliamente utilizado por fotógrafos profesionales y diseñadores, debido a su versatilidad ya que sus técnicas de compresión son tanto de tipo lossy (con pérdida de calidad) como lossless (sin pérdida de calidad). Es ideal para el procesamiento e impresión de fotografías ya que permite el reconocimiento de capas y puede editarse sin que se pierda calidad. Su extensión es .tif.

\subsection{JPEG (Joint Photographic Experts Group)}

También se le conoce como JPG y es uno de los formatos de imagen más populares en medios digitales para fotografías e imágenes de documentos.

\section{También se le} conoce como JPG y es uno de los formatos de imagen más populares en medios digitales para fotografías e imágenes de documentos

Cada píxel se almacena con 24 bits de resolución. Se usa ampliamente en la web por ser un formato que comprime gran cantidad de información de cualquier imagen o fotografía. Esto implica que, aunque se pueden obtener archivos pequeños y ligeros, la imagen pierde gran cantidad de información y su calidad se ve afectada. Su extensión es .jpg.

\subsection{GIF (Graphics Interchange Format)}

Este formato admite animaciones. A diferencia de JPEG, posee solo 256 colores ( 8 bits), de esta manera se crean archivos aptos para la web, pero con una paleta de colores limitada. Los GIFs también permiten la transparencia, característica que los JPEG no poseen.

Otra de sus ventajas respecto al formato JPEG es que realiza compresiones sin perder la calidad. A pesar de esto, la calidad de un JPEG puede opacar la calidad de un archivo GIF, en parte debido al limitado número de colores que posee este formato. Su extensión es .gif.

\subsection{PNG (Portable Network Graphics)}

Al igual que el formato GIF, posee transparencia, de modo que se suele emplear cuando se requiere que la imagen tenga esta característica. A pesar de que el GIF también posee transparencia, el PNG suele ser el formato estándar que muchos diseñadores trabajan para transparencias en una imagen.

PNG también recurre a un sistema de compresión en el que no se pierde calidad. Esta es una de las ventajas que presenta frente al formato JPEG, sin embargo, esto implica que también crea un archivo de mayor tamaño.

Al igual que los JPEG, los PNG no admiten animaciones de ningún tipo y solo sirven para imágenes estáticas. Su extensión es .png. 


\subsection{BMP (Bits Map Protocole)}

También se le conoce como mapa de bits y es un formato propio del sistema operativo Windows.

Los archivos BMP suelen ocupar un gran tamaño, pues la compresión se realiza sin pérdida de calidad. Por estas características, las imágenes en formato BMP suelen tener colores vibrantes y en general de una gran calidad.

BMP combina ciertas características de los formatos JPEG y GIF, pues permite guardar imágenes en 24 bits (JPEG) con una mayor cantidad de colores, o solo de 8 bit ( 256 colores empleados en el formato GIF). También puede guardar imágenes en 16 bits. Su extensión es .bmp.

\subsection{Recomendaciones específicas para la construcción de mapas}

Muchas de las figuras que se trabajan en las publicaciones del SGC corresponden a mapas, que es donde se plasman los datos, las interpretaciones y los resultados de las investigaciones ligadas al territorio. Dado que los mapas tienen unas exigencias específicas, a continuación se abordan algunas recomendaciones para mejorar su presentación y optimizar sus efectos comunicativos.

\subsubsection{Jerarquía visual en los mapas}

Aplicado a un mapa, la jerarquía visual es la implementación gráfica de un orden de los elementos de manera que los más importantes tengan una mayor prominencia visual. La jerarquía visual funciona acercando visualmente al lector a elementos específicos del mapa (más alto en un orden vertical) y alejando a otros del lector (más bajo en una jerarquía vertical) (Tait, 2018).

\subsubsection{Disposición de elementos de un mapa}

La disposición es la organización primaria de los elementos sobre el espacio del mapa (o pantalla). Esta tiene una influencia sobre la prominencia visual de los elementos del mapa (Tait, 2018). La disposición del mapa debe ser coherente con su propósito (Brewer, 2015).

Los elementos del mapa se clasifican en los seis niveles mostrados en la tabla 36.

Tabla 36. Niveles de elementos de un mapa

\begin{tabular}{ll}
\hline \multicolumn{1}{c}{ Nivel } & \multicolumn{1}{c}{ Elementos del mapa } \\
\hline 1 & Símbolos temáticos \\
2 & Título / Leyenda / Símbolos de mapa / Etiquetas \\
3 & Mapa base: áreas terrestres, límites políticos, características físicas \\
4 & Materiales explicativos: fuentes, créditos \\
5 & Mapa base: drenajes y cuerpos de agua \\
6 & Otros elementos del mapa base: etiquetas, cuadrículas, escalas \\
\hline
\end{tabular}

Se pueden tener dos formas de disposición de elementos en un mapa: compartimentalizada y fluida. 


\subsubsection{Disposición compartimentalizada}

Organiza cada uno de los elementos del mapa en un compartimiento separado, por lo general en forma de caja. Esta disposición es a menudo rígida, rectilínea, con una aproximación más institucional. En los mapas del SGC, es la más utilizada en informes y cartografía temática.

Es de anotar, que se debe usar línea de borde de $1 / 2$ punto en los siguientes casos: zona de información geográfica del mapa principal y del mapa de ubicación, secciones de texto especial y compartimentos de leyendas, cuando sus elementos puedan confundirse con otros. Para la escala gráfica, puede usarse un reborde cuando se encuentre dentro de la zona del mapa. No obstante, no debe abusarse de los bordes para no recargar innecesariamente las figuras.

De la misma manera, no es aconsejable usar líneas de borde en los siguientes casos: fotografías de cualquier tipo, infografías, figuras de modelos en dos o tres dimensiones, dibujos o esquemas, diagramas de distintos tipos, histogramas, flujogramas y cronogramas. Tampoco son necesarias las líneas de borde alrededor de toda la composición de una figura.

En la figura 38 se aprecian los elementos de un ejemplo de un mapa compartimentalizado.

\subsubsection{Disposición fluida}

La disposición fluida, según Tait (2018), evita las divisiones marcadas entre los elementos del mapa. Esta aproximación permite utilizar un mapa extendido hasta los bordes del campo visual con los otros elementos, superpuestos en áreas de la geografía cartografiada que no son importantes para su propósito. Los mapas fluidos suelen tener una mejor estética y una escala del mapa principal más grande. Un ejemplo de un mapa fluido puede verse en la figura 39. 


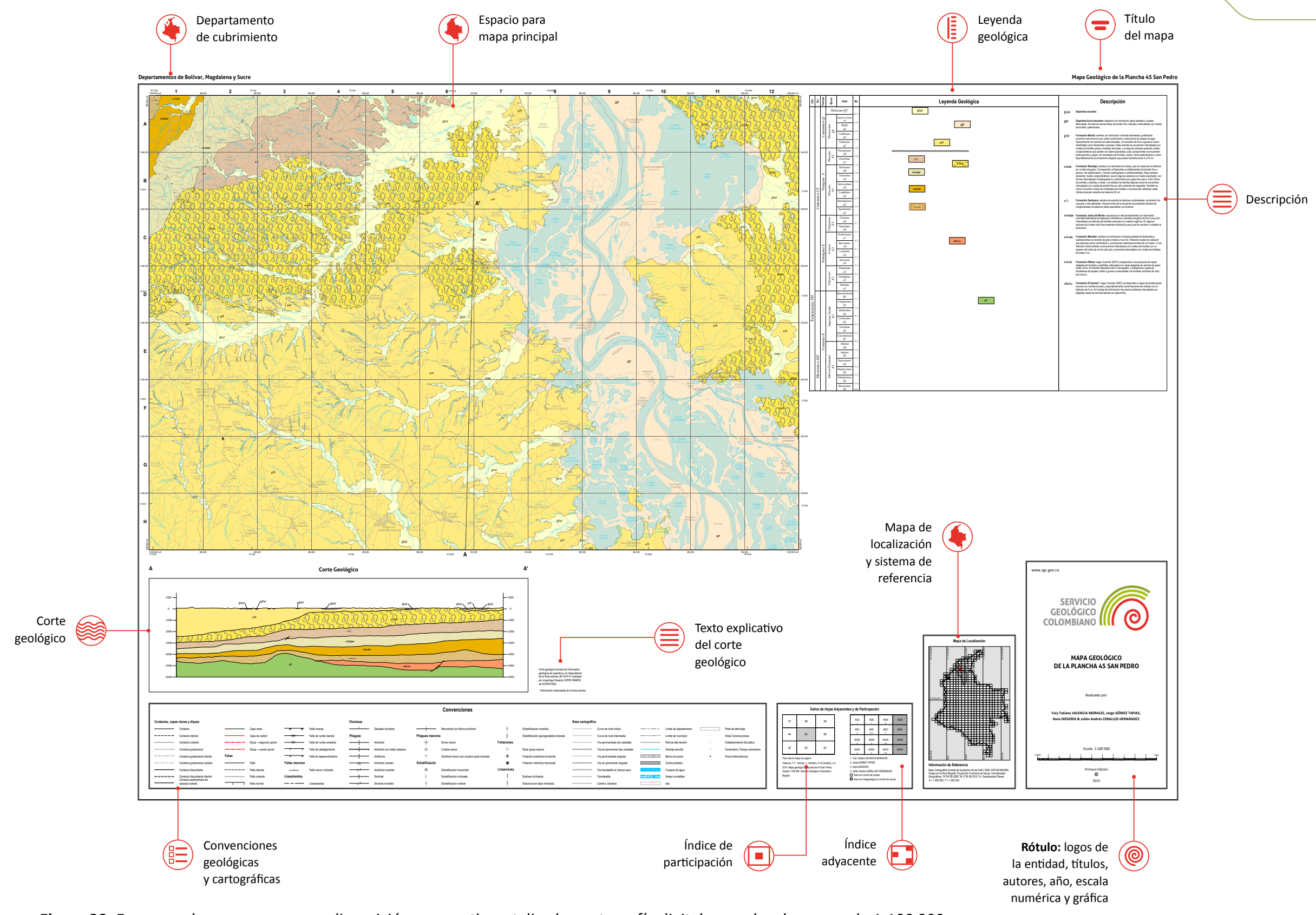

Figura 38. Esquema de un mapa en una disposición compartimentalizada: cartografía digital para planchas a escala 1:100 000 Fuente: adaptado de la disposición de mapas de cartografía geológica a escala 1:100 000 en práctica en el SGC. 


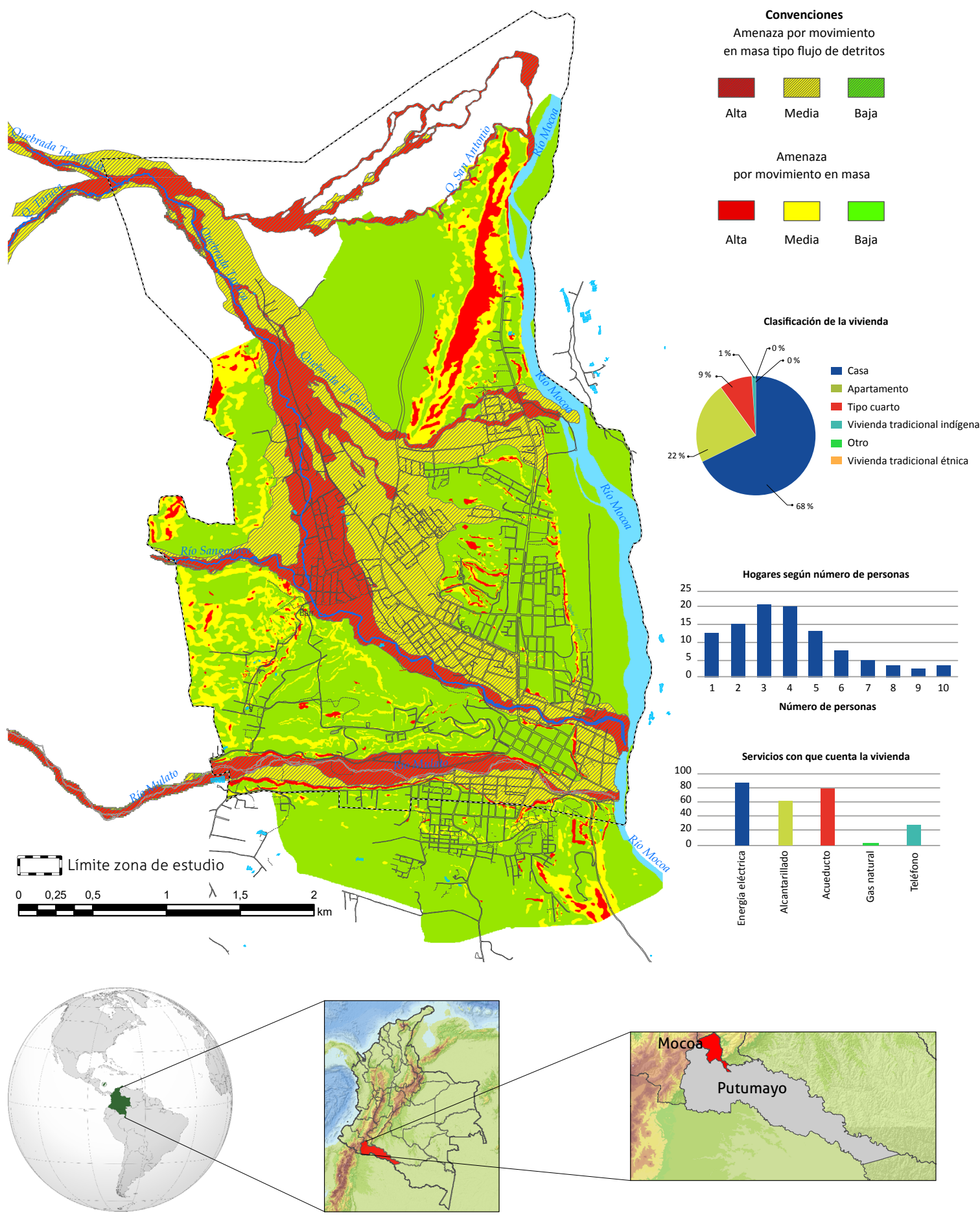

Figura 39. Mapa fluido: mapa integrado de amenaza por movimientos en masa y avenidas torrenciales del área urbana, periurbana y de expansión del municipio de Mocoa, Putumayo

Fuente: adaptado de SGC (2017). 


\subsubsection{Manejo de coordenadas y escalas}

Las coordenadas podrán expresarse geográficamente (latitud y longitud en grados, minutos y segundos) o en una proyección específica, la cual deberá indicarse completamente en la información complementaria de la respectiva figura. Dependiendo de la publicación, podrá optarse por un sistema de coordenadas geográficas (sobre el elipsoide WGS84) o en el sistema de proyección escogido.

Para los trabajos de cartografía podrá considerarse la Resolución 471 de 2020 del Instituto Geográfico Agustín Codazzi que promueve el uso de un único origen para Colombia con el fin de garantizar la homogeneidad y continuidad en la representación de los elementos del territorio, así como facilitar los trabajos relacionados con la gestión de coordenadas en el país.

En los mapas de las publicaciones, con el fin mostrar de manera más efectiva los elementos que se desean resaltar, es recomendable incluir, cuando sea posible, las coordenadas hacia el interior del mapa, de manera que no se utilicen espacios de la página de manera inoficiosa. No obstante, varios de los mapas de formato grande que se manejan en el Servicio Geológico Colombiano manejan coordenadas por la parte exterior, dado que no tienen las restricciones de espacio que se encuentran en una publicación y al mismo tiempo pueden ser más sencillos de construir.

Adicionalmente, es importante utilizar escalas gráficas (y numéricas cuando la escala sea estandarizada, por ejemplo 1:5000, 1:50 000, etc.), de manera que el lector reconozca la relación entre las proporciones de la representación y las de la realidad de forma más sencilla.

\subsubsection{Mapas de ubicación}

Con el fin de tener un contexto geográfico claro, es conveniente contar con un mapa de ubicación a una escala más pequeña de una porción del territorio reconocido y con un recuadro al interior que delimite la zona del mapa principal. Este recuadro debe elaborarse con un borde en color rojo, con mínimo 1 punto de grosor y sin relleno. Como mapa de ubicación puede utilizarse un mapa sencillo con la división político-administrativa sobre un mapa de relieve.

Para construir un mapa base con el relieve, puede seguirse la recomendación de Gómez, Mateus-Zabala et al. (2020) mediante el uso del modelo digital de elevación (DEM) con 30 m de resolución de la Shuttle Radar Topography Mission (SRTM) de la Administración Nacional de Aeronáutica y del Espacio (NASA). Las imágenes se pueden realizar con la herramienta Hillshade del software ArcMap mediante procesamiento de imágenes.

La construcción de la imagen en relieve, sombreada con características geomorfológicas bien definidas se realiza mediante la producción de dos imágenes, con un ángulo de altitud solar de $45^{\circ}$, diferenciadas por el azimut: la primera con la sombra generada por un ángulo de azimut solar de $315^{\circ}$ y la segunda por un ángulo de azimut solar de $45^{\circ}$. A esta segunda imagen se le asigna una transparencia del $50 \%$ y se superpone a la primera imagen generada. La imagen resultante puede exportarse en formato PNG a 300 DPI y ser usada en el software de construcción de mapas que esté trabajando. La figura 40 fue construida mediante esta técnica. 
El mapa de ubicación puede completarse con temas de referencia geográfica como la división político-administrativa, drenajes principales, ciudades, vías de acceso, etc. Como se trata de un mapa de ubicación, puede incluirse un rectángulo o un polígono en un color que resalte para informarle al usuario la posición exacta del mapa principal.

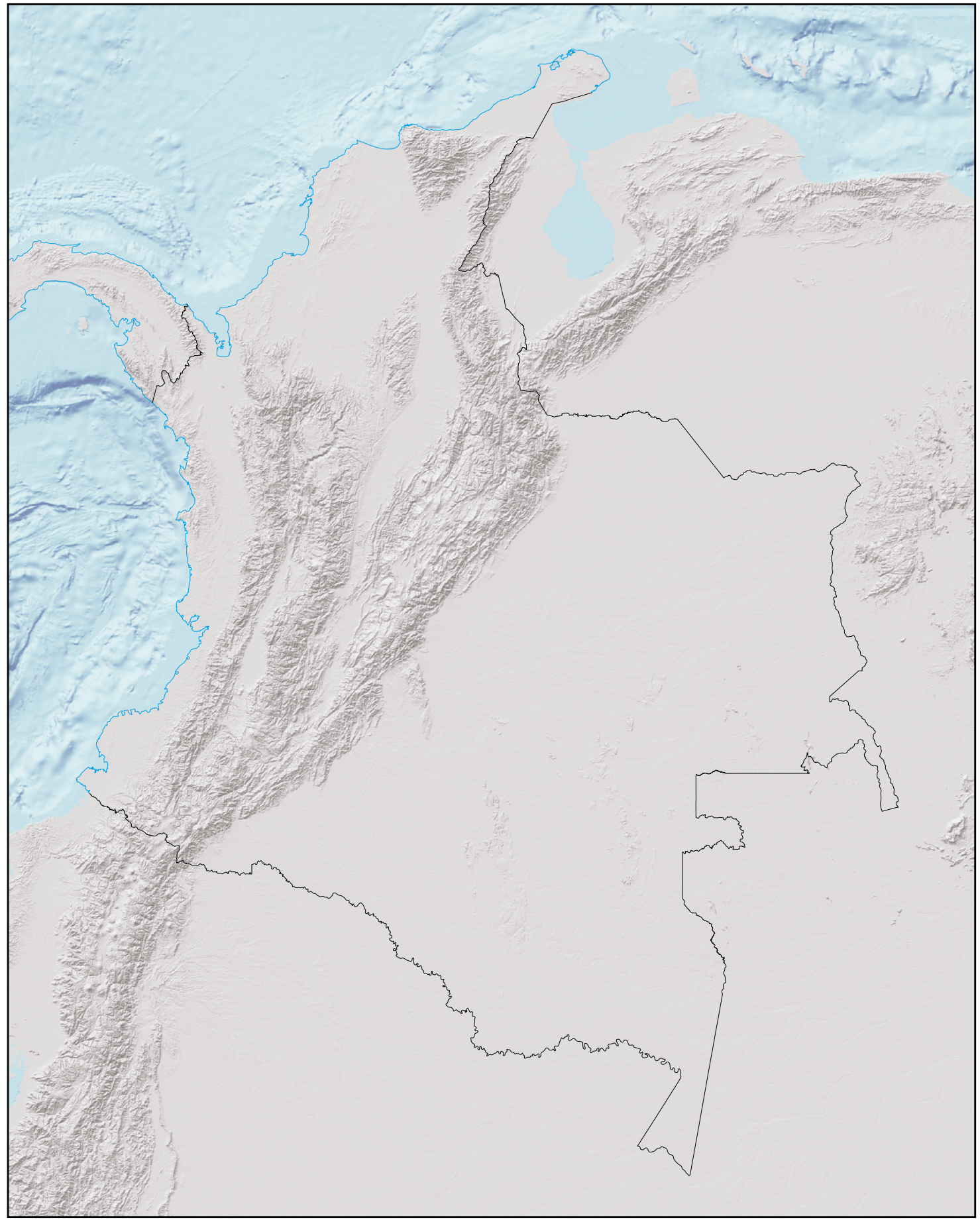

Figura 40. Imagen de relieve de la esquina noroccidental de Suramérica construida con las recomendaciones Fuente: tomado de Gómez, Mateus-Zabala et al. (2020). 


\subsubsection{Perfiles en los mapas}

Un perfil presenta los elementos de un mapa en un plano vertical orientado con un acimut determinado. Los perfiles deben estar referidos a un mapa principal donde se muestran su ubicación y orientación. Si se trata de un perfil geológico del subsuelo, deben indicarse las unidades litoestratigráficas regionales y demás estructuras geológicas siguiendo los colores y texturas asignadas a dichas unidades.

La escala horizontal del perfil debe ser la misma que la del mapa principal, por tanto, la distancia para el segmento ( $B-B^{\prime}$ en la figura 41 ) en el mapa es igual a la distancia para el mismo segmento en el perfil.

Una parte importante del perfil es la escala vertical, la cual suele tener una exageración considerable con respecto a la escala horizontal con el fin de identificar de mejor manera las diferencias en altura de cada elemento relevante. En el costado izquierdo del perfil se muestra una escala de altura en metros, como se ilustra en la figura 41.

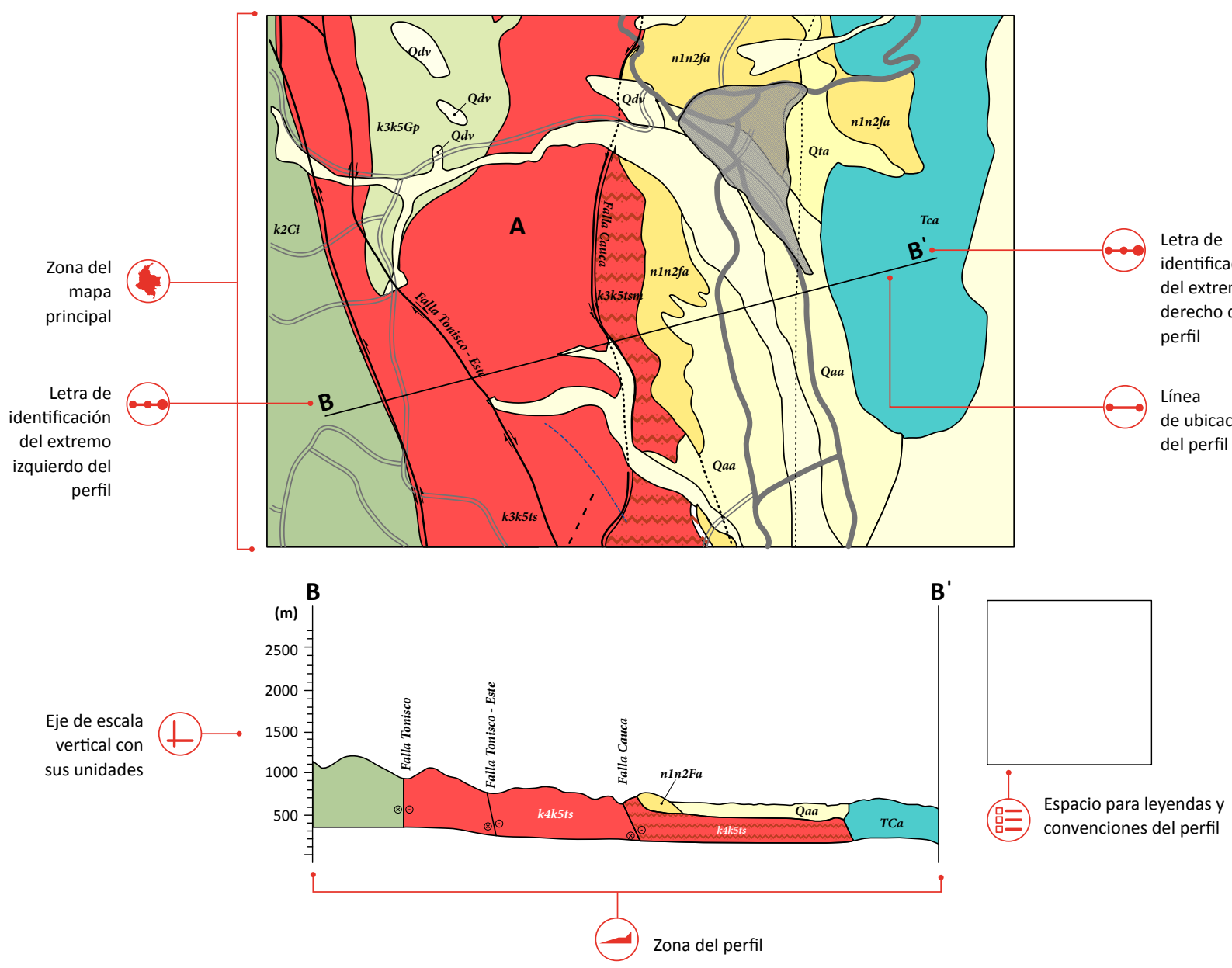

Figura 41. Esquema de un perfil de un mapa geológico El perfil muestra una imagen transversal de un mapa geológico donde se identifican las unidades geológicas y fallas, con los mismos colores que están referidos en el mapa principal. Fuente: adaptado de Correa et al. (2015). 


\subsubsection{Nomenclatura de figuras con diferentes partes}

Cuando se tengan figuras compuestas de varias partes, deberá darse un identificador a cada una con una letra minúscula en Calibri, con un tamaño entre 6 y 10 puntos, y en negritas.

Cuando todas las partes se ordenen de manera horizontal, la posición de la letra podrá estar encima de cada parte, como se ilustra en la figura 42.
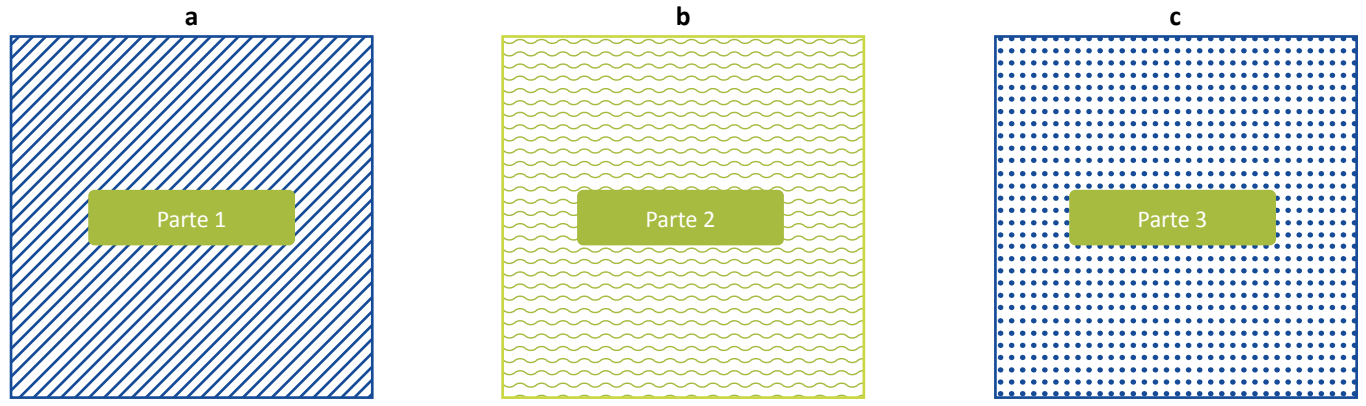

Figura 42. Nomenclatura de las partes de una figura con una sola fila

Cuando las partes se expongan en dos filas o más, la posición de la letra podrá estar en el costado izquierdo de cada parte.

Para referirse a cada parte en las notas de la figura podrá usarse la letra seguida del paréntesis de cierre y su correspondiente descripción. Cada parte deberá separarse por coma (,), punto y coma (;) o punto (.), según el contexto de la descripción. En la misma nota de figura debe usarse el mismo tipo de puntuación, como se ilustra en la figura 43.

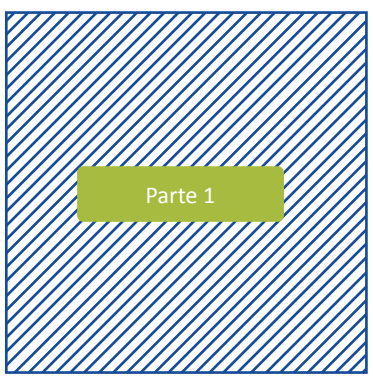

C

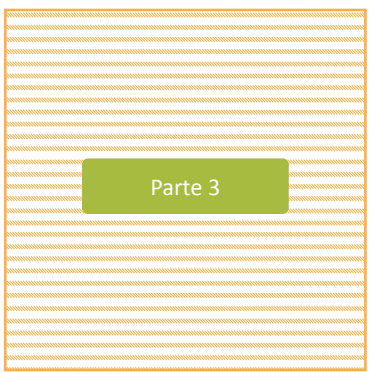

b

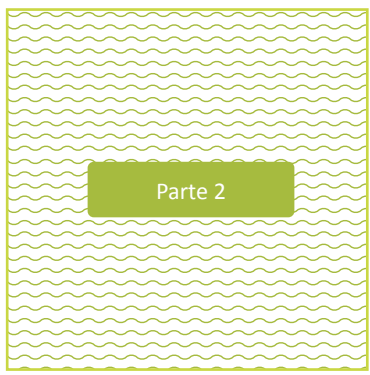

d

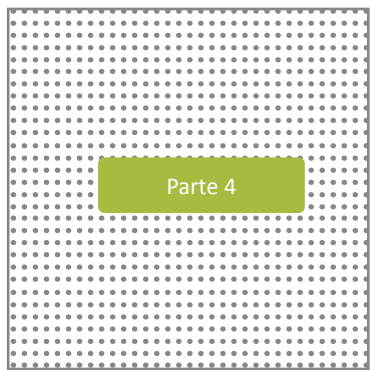

Figura 43. Nomenclatura de las partes de una figura con más de una fila

a) muestra el color azul, b) muestra el color verde, c) muestra el color naranja y d) muestra el color gris. 
En caso de que haya poco espacio para las letras, podrá incluirse la letra con un recuadro en color blanco de un tamaño máximo de $0,5 \mathrm{~cm}$ de lado y sin ningún borde, con una posición consistente con la siguiente prioridad: 1) en la esquina superior izquierda, 2 en la esquina superior derecha, 3) en la esquina inferior izquierda y 4) en la esquina inferior derecha, como se muestra en la figura 44.
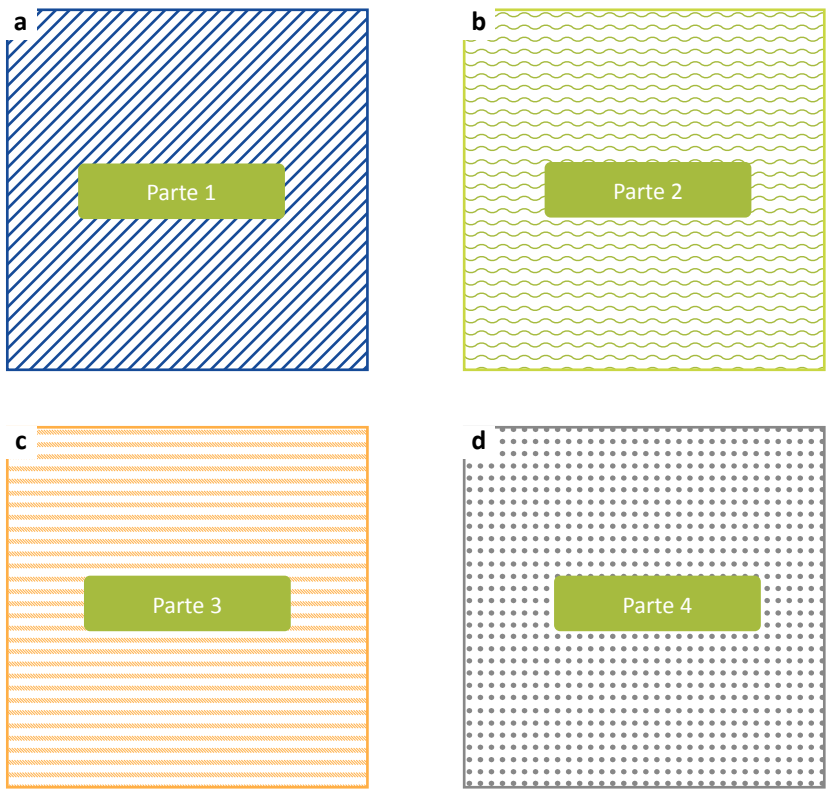

Figura 44. Nomenclatura de las partes de una figura que cuenta con poco espacio para las letras de identificación Se incluyen las letras en un recuadro blanco a un costado fijo de cada parte de la figura con un tamaño entre 6 y 10 puntos.

\subsubsection{Textos de descripción de las figuras cuando no hay espacio en la misma página}

Para el caso de las publicaciones de libros, cuando se manejan figuras que ocupan toda la página, el título y las notas pueden incluirse en una página anterior o posterior, indicando con una flecha simple en qué posición se encuentra la figura a la cual hace referencia. Debe incluirse una flecha de color negro, de $1,0 \mathrm{~cm}$ de longitud, $3 / 4$ de punto de grosor, $0,5 \mathrm{~cm}$ por encima del texto de la figura.

La flecha debe apuntar a la izquierda, alineada con el margen izquierdo cuando la figura se encuentra en una página anterior; y debe apuntar a la derecha alineada con el margen derecho de la página cuando la figura se encuentre en una página posterior.

Debe procurarse que el texto en esta página esté lo más cercano posible de la figura para evitar confusiones del lector. Esto se logra colocando el texto y su flecha en la parte superior de la hoja, cuando la figura está en la página anterior; y colocando el texto y su flecha en la parte inferior de la página si la figura está ubicada en la página siguiente, como se indica en la figura 45.

Es de anotar que, para los informes en esta situación, debe optarse por la generación de una figura de un formato en mayor tamaño que puede incluirse en los anexos del documento. 

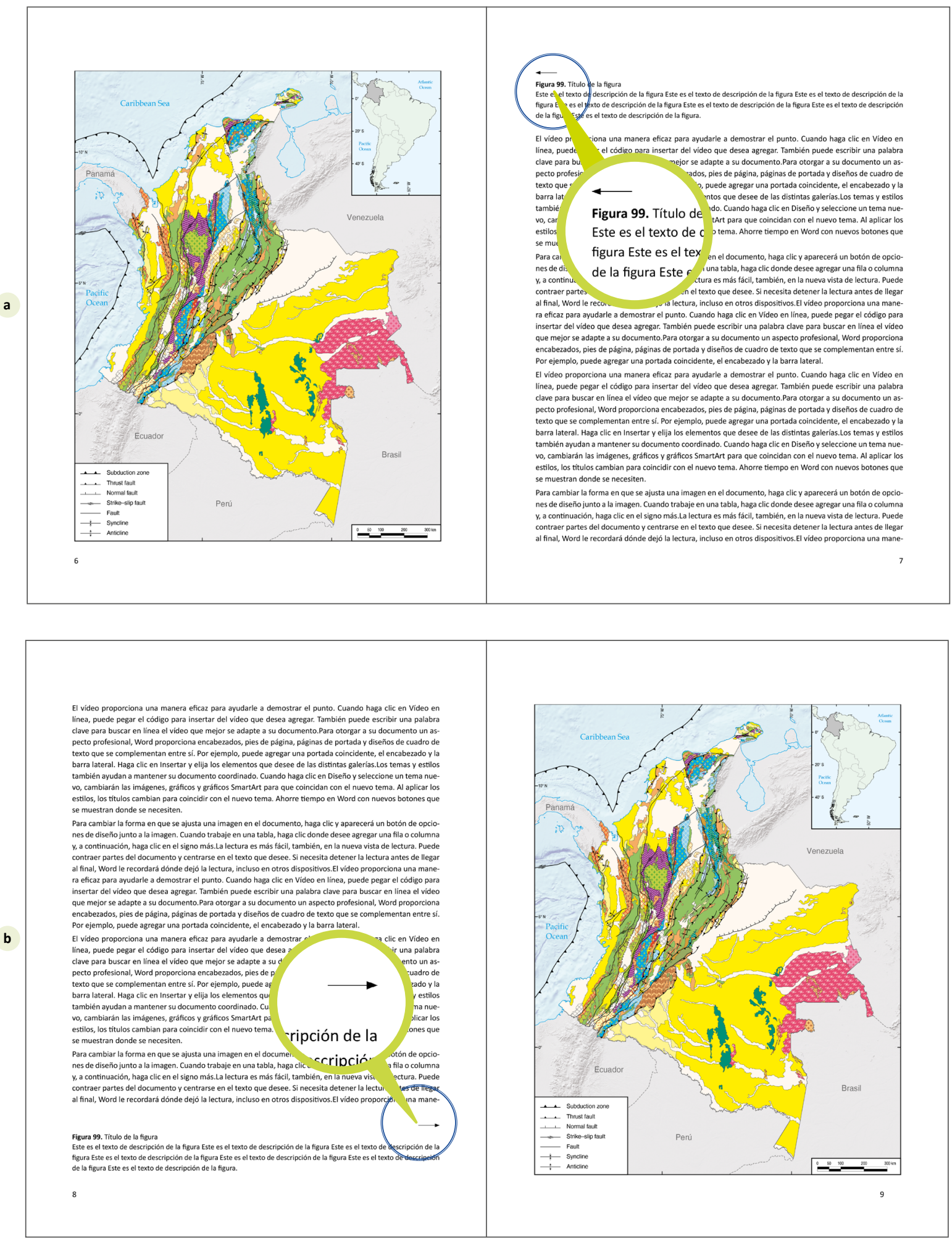

Figura 45. Títulos e información de una figura que ocupa una página completa

a) Figura en la página anterior: el texto se coloca en la parte superior de la página siguiente a la figura, con la flecha apuntando a la izquierda; b) figura en la página siguiente: el texto se coloca en la parte inferior de la página anterior a la figura, con la flecha apuntando a la derecha. Fuente: mapa y criterios adaptados de Gómez, Núñez-Tello et al. (2020) 


\subsubsection{Textos y convenciones de las figuras cuando no hay espacio en la misma página}

En mapas que no tienen suficiente espacio para sus convenciones o leyendas, dichos elementos junto con el título y las notas pueden aparecer en una página posterior. Para las convenciones debe incluirse en la página siguiente una flecha negra que apunta a la izquierda, de $1,0 \mathrm{~cm}$ de longitud, $3 / 4$ de punto de grosor. Debajo de esta, debe escribirse el texto "Convenciones" justificado a la izquierda, en 11 puntos y en negritas. Inmediatamente deben colocarse las convenciones requeridas.

Debajo de las convenciones, para relacionar el título y las notas de la figura, debe incluirse otra flecha de $1,0 \mathrm{~cm}$ de longitud, $3 / 4$ de punto de grosor que apunte también a la izquierda, alineada con el margen izquierdo de la página, debajo de la cual deben transcribirse el número y el título de la figura, seguidos en los renglones siguientes de las notas de la figura.

Similar al caso de la sección anterior, debe procurarse que las convenciones y los títulos y notas de la figura estén lo más cercanos posible a la figura principal para evitar confusiones del lector. Esto se logra colocando la flecha y las convenciones en la parte superior de la hoja, seguidas de la flecha, el título y las notas de la figura, como se muestra en la figura 46.

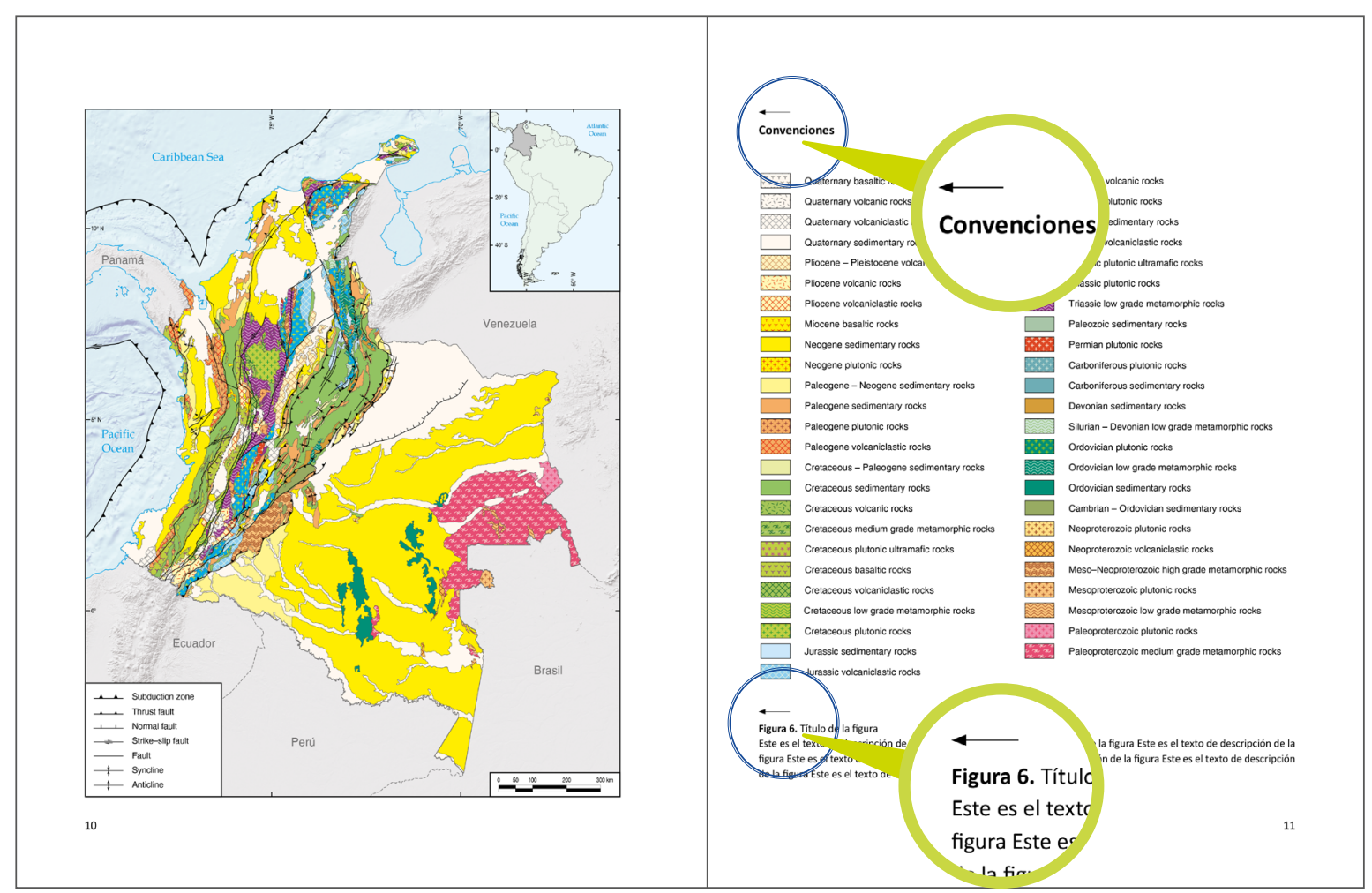

Figura 46. Manejo de convenciones, títulos y notas de una figura en una página distinta a la figura principal En la página posterior a la figura, en la parte superior se coloca una flecha que apunta a la izquierda, debajo de la cual se escribe el texto "Convenciones". Debajo de este texto se colocan las convenciones. Debajo de estos elementos se incrusta otra flecha apuntando a la izquierda, y debajo el título y las notas de la figura. Fuente: adaptado de Gómez, Núñez-Tello et al. (2020). 
Para el caso de los informes, en esta situación debe optarse por la generación de un mapa de un formato en mayor tamaño que pueda incluirse en los anexos del documento en donde puedan ubicarse de manera adecuada todas las convenciones necesarias.

\subsubsection{Consideraciones sobre la posición de los textos descriptivos en los mapas}

Los textos descriptivos de un mapa pueden ubicarse con la siguiente prioridad:

1) Parte superior derecha

2) Parte inferior izquierda

3) Parte superior izquierda

4) Parte inferior izquierda

5) Parte superior centrada

6) Parte inferior centrada

La ubicación definitiva depende de la forma del mapa y sus contenidos, así se logra mostrar de la manera más limpia y completa posible los elementos importantes. La figura 47 indica las seis posibilidades mencionadas.

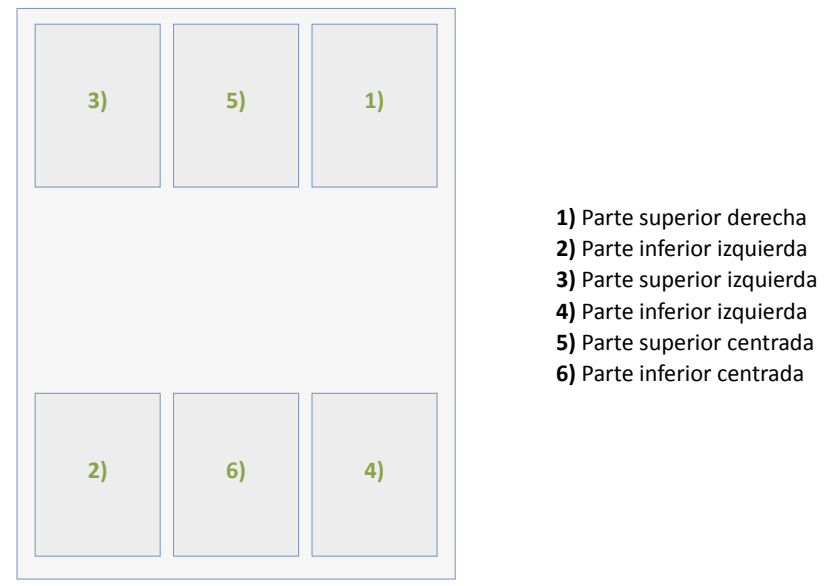

Figura 47. Prioridad en la ubicación de los textos descriptivos en un mapa

\subsubsection{Aplicación de estas recomendaciones en un mapa geológico}

El ejemplo 50 muestra un mapa geológico en el que se siguieron las recomendaciones de este capítulo que incluye las siguientes características:

1) Se utilizó un mapa de relieve para demarcar el área de estudio, el cual se complementó con una capa de división política y los nombres de los países y los océanos. En esta figura se utiliza un recuadro en color rojo que demarca el área de interés del mapa principal.

2) En cuanto al mapa principal, se aplicaron los conceptos de manejo de jerarquía visual y la disposición proporcionada y organizada de los distintos elementos del mapa, así como las recomenda- 
ciones sobre color, contrastes, texturas, grosor de líneas, tamaños y tipo de textos, y orientación de los textos para los elementos lineales.

3) Se incluyeron la escala gráfica, las coordenadas con la posición recomendada y leyendas de los temas del mapa.

4) La descripción del mapa se hace debajo de la figura con su título y las notas complementarias.

\section{Ejemplo 50: mapa geológico observando las recomendaciones de diseño}
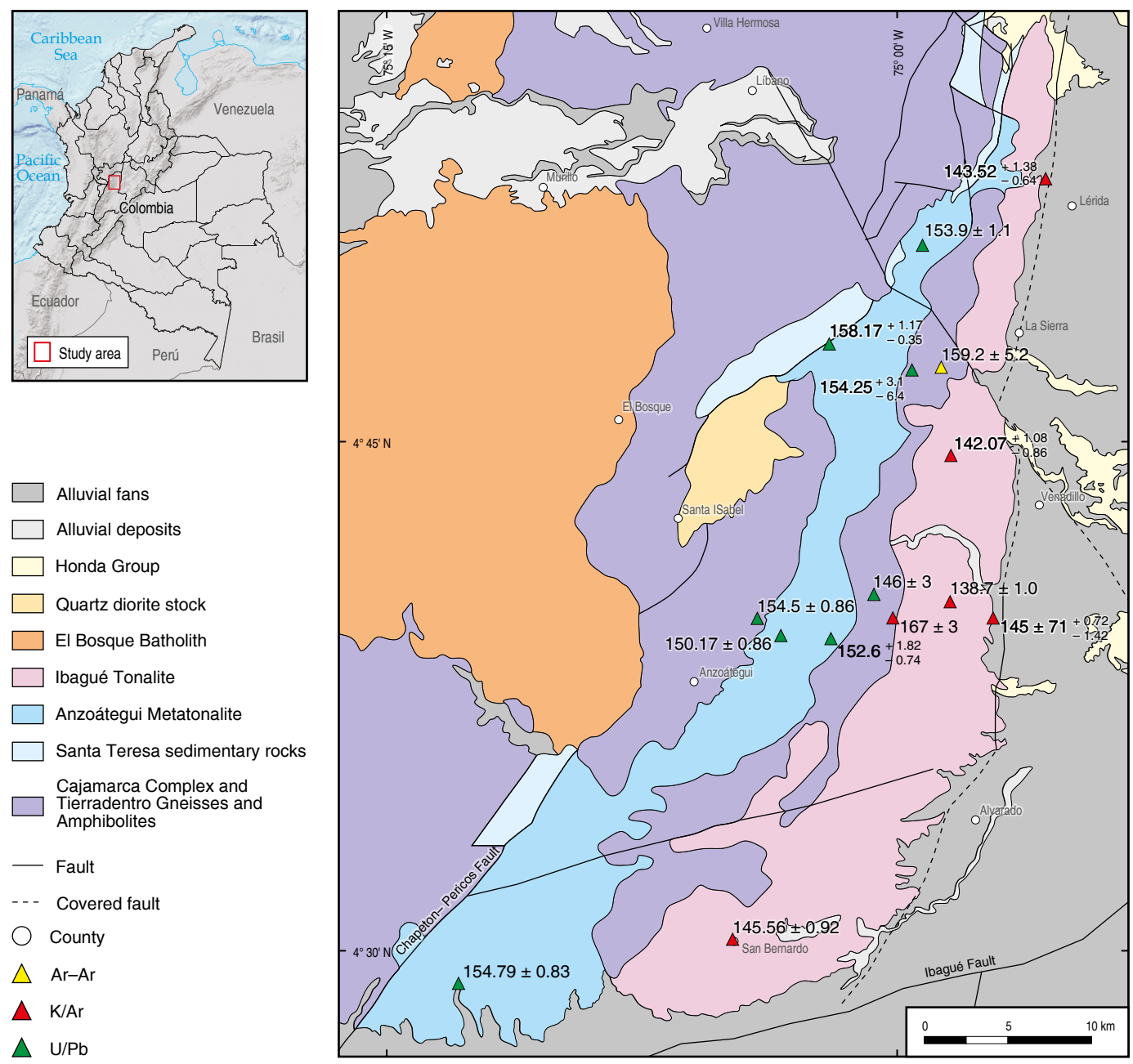

Figure 99. Geological map and U-Pb zircon ages of the Anzoátegui Metatonalite and Ibagué Tonalite. Source: adapted from Rodríguez-García et al. (2020). 


\subsection{Tratamiento de fotografías de campo}

Las fotografías de campo constituyen un elemento fundamental de los trabajos de geociencias ya que ilustran de manera comprensiva un conjunto de características físicas, una ubicación o una disposición particular de una estructura, un evento o un fenómeno. Por lo anterior, es importante que dichas fotografías cuenten con unos elementos mínimos, como los que se muestran en la tabla 37.

Tabla 37. Requisitos mínimos de presentación para fotografías de campo (afloramientos o panorámicas)

\begin{tabular}{ll}
\hline \multicolumn{1}{c}{ Elemento } & \multicolumn{1}{c}{ Requisito de presentación } \\
\hline Resolución mínima aceptable & $300 \mathrm{DPI}$ \\
\hline & Este parámetro es de gran importancia ya que aporta información relevante (estructural, \\
& estratigráfica y geomorfológica, entre otras). Debe indicarse la orientación sobre la misma \\
& fotografía (mínimo el norte). \\
& Para dar una correcta orientación existen muchas variantes en diferentes sistemas de información \\
& geográfica. Para el caso de las publicaciones del SGC se prefieren símbolos minimalistas como las \\
& opciones siguientes:
\end{tabular}

Flecha indicando el norte, disponibles en la plataforma de ESRI y algunas variaciones con rellenos en amarillo

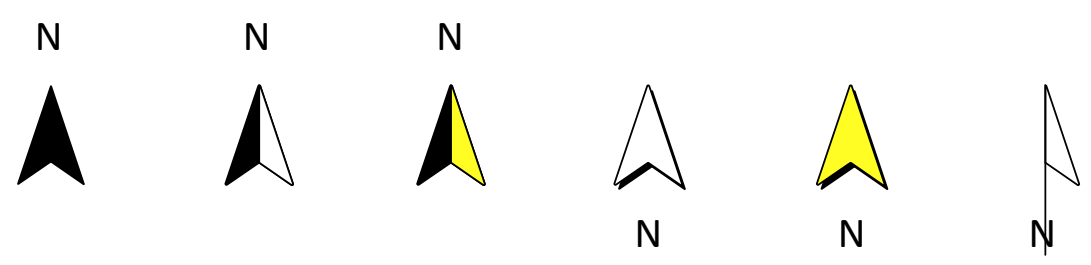

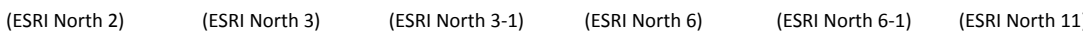

Orientación de la fotografía

En caso de que no exista un buen contraste, puede utilizarse un rectángulo blanco debajo del símbolo con una transparencia entre el $40 \%$ y el $60 \%$. Para los informes del SGC se prefiere la flecha del norte con fondo blanco (ESRI North 6).

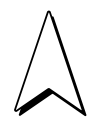

$\mathrm{N}$

Símbolo de los puntos cardinales, disponible en la plataforma de ESRI

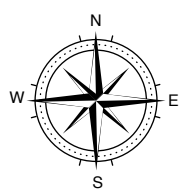

(ESRI North 7)

En caso de que no exista un buen contraste, puede utilizarse un rectángulo blanco debajo del símbolo con una transparencia entre el $40 \%$ y el $60 \%$.

Letras indicando los puntos cardinales. Preferiblemente en las esquinas superiores de la foto, y si no es posible, en las esquinas inferiores de la foto, en mayúsculas, en color negro y negritas, con un tamaño máximo de 14 puntos. Las orientaciones posibles son las siguientes: N S, NE SW, E W, SE NW, S N, SW NE, W E, NW SE. En caso de que no exista un buen contraste, puede utilizarse un rectángulo blanco debajo del símbolo con una transparencia entre el $40 \%$ y el $60 \%$. Para los informes del SGC se prefiere la flecha del norte con fondo blanco (ESRI North 6). 


\begin{tabular}{ll}
\hline \multicolumn{1}{c}{ Elemento } & \multicolumn{1}{c}{ Requisito de presentación } \\
\hline Georreferenciación y escala & $\begin{array}{l}\text { Dependiendo del tipo de fotografía, podrá usarse una figura humana (o una silueta), una regla o } \\
\text { un artículo de dimensiones conocidas. Los datos de referencia espacial podrán especificarse en la } \\
\text { descripción de la fotografía como coordenadas norte, este, en este orden. }\end{array}$ \\
\hline $\begin{array}{l}\text { Convenciones sugeridas } \\
\text { para rasgos estructurales o } \\
\text { estratigráficos }\end{array}$ & $\begin{array}{l}\text { Fallas: línea continua roja } \\
\text { Lineamiento: línea punteada roja }\end{array}$ \\
\hline \multirow{3}{*}{ Contacto o estratificaciones: línea continua amarilla } \\
\hline Identificación de fotografías & $\begin{array}{l}\text { En caso de tener varias fotografías, deberá tenerse un solo número de figura y sus partes se } \\
\text { identifican con una letra minúscula en color negro que deberá estar en un recuadro con fondo } \\
\text { blanco y sin borde, con un tamaño entre } 6 \text { y } 10 \text { puntos y en negritas. El recuadro se ubicará en } \\
\text { el vértice superior izquierdo y no podrá tener más de 0,5 cm de lado. En caso de que oculte } \\
\text { información relevante, se cambiará la posición a un sitio más conveniente. }\end{array}$ \\
& $\begin{array}{l}\text { Podrán usarse algunos símbolos que identifiquen aspectos específicos y fotografías en recuadros a } \\
\text { escalas mayores para la visualización de detalles. }\end{array}$ \\
\hline Títulos & $\begin{array}{l}\text { Título breve y explicativo para la fotografía en Calibri 10 puntos, debajo de la imagen y justificado. } \\
\text { En lo posible, organice el texto de manera que no sobrepase el ancho de los márgenes del texto. }\end{array}$ \\
\hline \multirow{2}{*}{ Explicación de las fotografías } & $\begin{array}{l}\text { La explicación se hará en las notas debajo del título. En caso de múltiples fotografías, se hará } \\
\text { referencia a cada una mediante letras minúsculas seguidas de un paréntesis, sin negritas. Las } \\
\text { diferentes descripciones se separarán por un punto y coma (;). }\end{array}$ \\
\hline Contenidos de la descripción & $\begin{array}{l}\text { La descripción debe contener como mínimo la georreferenciación del punto donde se tomó } \\
\text { la fotografía y la localidad donde se encuentra. A continuación se debe realizar una pequeña } \\
\text { descripción de la fotografía resaltando la característica por la cual se tomó la misma. }\end{array}$
\end{tabular}

\section{Ejemplo 51: fotografía panorámica}

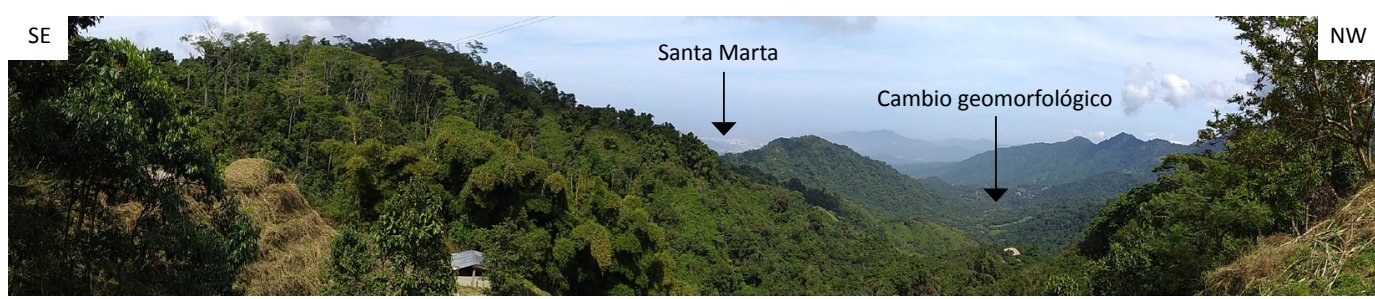

Figura 99. Panorámica en la vía Casa Elemento-El Campano

Estación PAR0019/ECC0010. Tomada desde la vía que del sector Casa Elemento conduce a la vereda El Campano (Minca). Se observa en la parte media de la foto un cambio geomorfológico a una zona más baja topográficamente, sobre la cual está construido el corregimiento de Minca, además dentro del mapa geomorfológico se observaron unas zonas bajas las cuales asocian suelos arcillosos de color rojizo (PAR0014). Fuente: cortesía de Elizabeth Cortés Castillo. 
Ejemplo 52: fotografía de campo de un afloramiento
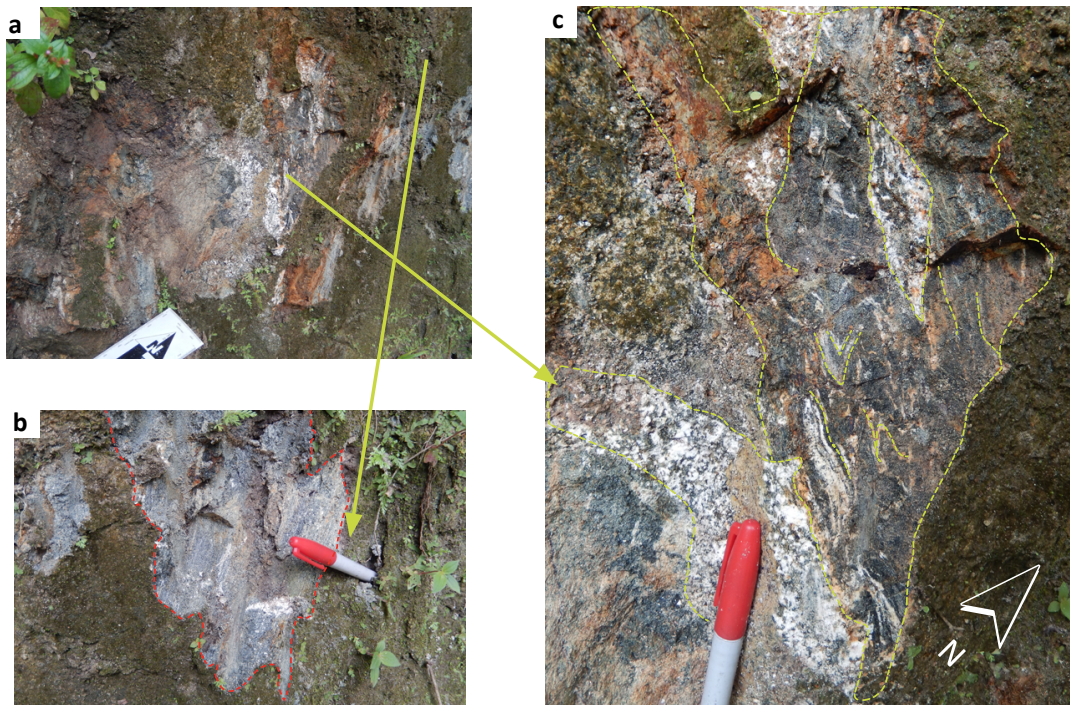

Figura 99. Afloramiento en carreteable hacia las Cascadas de Marinca

Estación ECC0004/PAR 0012. Zona muy deformada y triturada. a) Vista del afloramiento completo; b) y c) zoom que resalta material triturado, de textura muy fina, milonitizada y deformada. Las rocas leucocráticas corresponden a una cuarzodiorita y las rocas melanocráticas corresponden a una anfibolita con foliación interna. Fuente: cortesía de Elizabeth Cortés Castillo.

\section{Ejemplo 53: fotografía de campo de un saprolito con zoom en la imagen}

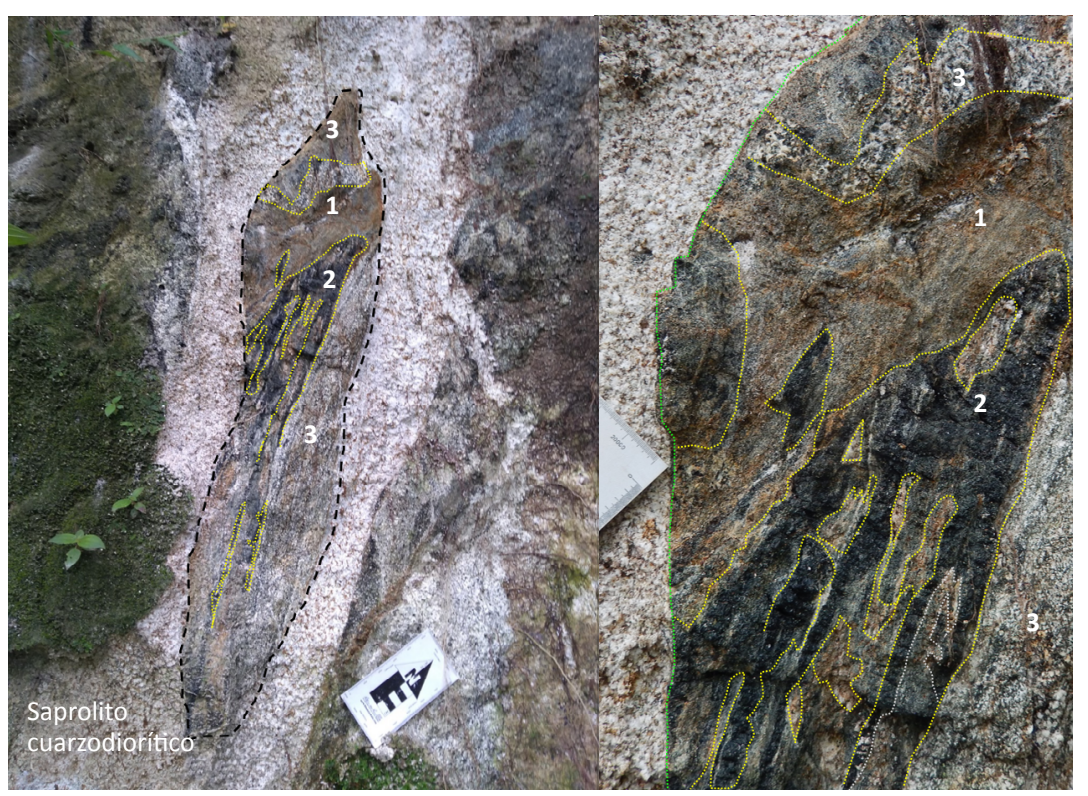

Figura 99. Estación PAR 12 /ECC0004. Xenolitos ígneos en fusión granítica

1-Zona de color pardo amarillento, muy oxidada, alterada, en la cual no preserva textura de la roca original.

2-Zona de color negro, compuesta por anfíboles, finogranular, foliada y plegada.

3-Zona externa de color gris claro, textura media, de composición diorítica, con cristales de anfíbol de tamaños mayores al milímetro. Fuente: cortesía de Elizabeth Cortés Castillo. 


\subsection{Tratamiento de imágenes de petrografía}

En un estudio petrográfico se utilizan fotografías para caracterizar una roca en dos escalas distintas. Por un lado, se realiza un examen físico macroscópico de la roca sobre el aspecto, textura, color, dureza, tamaño de grano o granularidad. De manera complementaria, se realiza una descripción microscópica para determinar la composición mineralógica y los rasgos texturales, así como la forma y el color de los cristales, tipo u origen de cada mineral, la textura, la relación mutua entre los minerales o asociaciones minerales, así como la matriz o cementante en caso de que esté presente.

Las fotografías utilizadas en estos estudios deben seguir las recomendaciones de esta sección.

\subsubsection{Imágenes macroscópicas}

Los requisitos de presentación se resumen en la tabla 38.

Tabla 38. Requisitos mínimos para fotografías macroscópicas de petrografía

\begin{tabular}{|c|c|}
\hline Elemento & Requisito de presentación \\
\hline Resolución mínima aceptable & 300 DPI \\
\hline Referencia de escala & $\begin{array}{l}\text { Uso de martillo geológico, regla, lápiz, lapicero, tapa de lente de cámara o monedas reconocidas, } \\
\text { según el tamaño de la muestra original. }\end{array}$ \\
\hline Identificación de fotografías & $\begin{array}{l}\text { En caso de tener varias fotografías, deberá tenerse un solo número de figura y sus partes se } \\
\text { identifican con una letra minúscula en color negro que deberá estar en un recuadro con fondo } \\
\text { blanco y sin borde, con un tamaño entre } 6 \text { y } 10 \text { puntos y en negritas. El recuadro y la letra se } \\
\text { ubicarán en el vértice superior izquierdo y no podrá tener más de } 0,5 \mathrm{~cm} \text { de ancho. En caso de que } \\
\text { oculte información relevante, se cambiará la posición a otro vértice más conveniente. }\end{array}$ \\
\hline Títulos & $\begin{array}{l}\text { Título breve y explicativo para la figura en Calibri } 10 \text { puntos, debajo de la imagen y justificado. } \\
\text { En lo posible, organice el texto de manera que no sobrepase el ancho de los márgenes del } \\
\text { documento. }\end{array}$ \\
\hline Explicación de las fotografías & $\begin{array}{l}\text { La explicación se hará en las notas debajo del título. Realizar una pequeña descripción resaltando } \\
\text { la característica por la cual se tomó la fotografía. En caso de múltiples figuras, se hará referencia } \\
\text { a cada una mediante letras minúsculas seguidas de un paréntesis sin negritas. Las diferentes } \\
\text { descripciones se separarán por un punto y coma (;). }\end{array}$ \\
\hline Contenidos de la descripción & $\begin{array}{l}\text { La descripción debe contener como mínimo la georreferenciación del punto donde se tomó la } \\
\text { muestra (estación en caso de que exista mapa de estaciones y/o libro índice, o coordenadas } \\
\text { geográficas). Adicionalmente, cuando la fotografía sea de un tercero, deberá darse los créditos } \\
\text { respectivos iniciando con la palabra Fuente:. }\end{array}$ \\
\hline
\end{tabular}




\section{Ejemplo 54: fotografías con descripción macroscópica para petrografía}
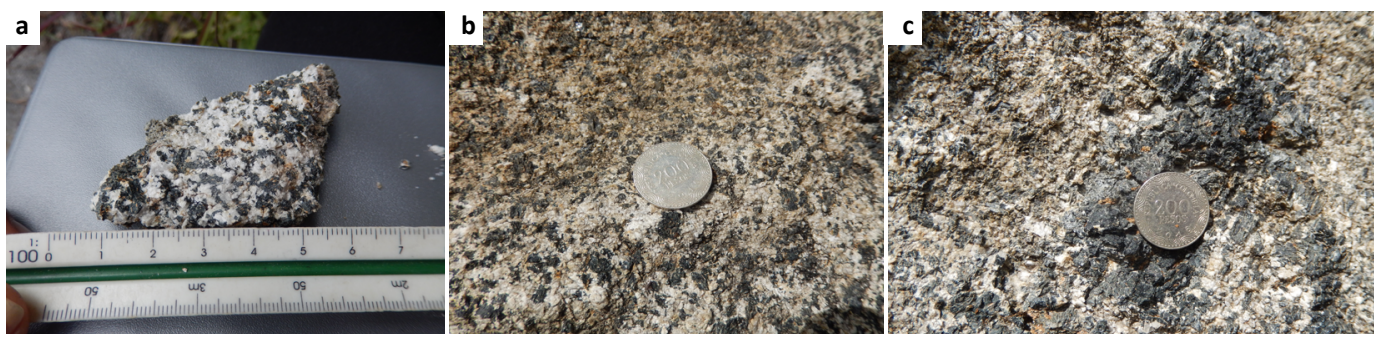

Figura 99. Estación: ECC0007/PAR0015

a) Muestra completa; b) clústeres de anfíbol, con cristales de tamaño entre $3 \mathrm{~mm}$ y $1 \mathrm{~cm}$; c) detalle de la cuarzodiorita, nótese el tamaño de los cristales oscuros de anfíbol. Fuente: cortesía de Elizabeth Cortés Castillo.

\subsubsection{Imágenes microscópicas}

Para el caso de secciones delgadas, los requisitos de presentación se resumen en la tabla 39.

Tabla 39. Requisitos mínimos para fotografías microscópicas de petrografía

\begin{tabular}{|c|c|}
\hline Elemento & Requisito de presentación \\
\hline Resolución mínima aceptable & $300 \mathrm{DPI}$ \\
\hline Referencia de escala & $\begin{array}{l}\text { Barra de escala micrómetro (generada automáticamente por el software de toma de fotos del } \\
\text { microscopio), ubicada en el costado inferior derecho. Como alternativa, puede utilizar una raya } \\
\text { negra o blanca de 1,5 puntos de espesor y las unidades encima de la raya en el mismo color. Otra } \\
\text { variante aceptable es utilizar un recuadro gris con el texto de la escala en la parte interior. }\end{array}$ \\
\hline Identificación de fotografías & $\begin{array}{l}\text { En caso de tener varias fotografías, deberá tenerse un solo número de figura y sus partes se } \\
\text { identifican con una letra minúscula en color negro, en negritas, que deberá estar en un recuadro } \\
\text { con fondo blanco y sin borde, con un tamaño entre } 6 \text { y } 10 \text { puntos. El recuadro se ubicará en } \\
\text { el vértice superior izquierdo y no podrá tener más de } 0,5 \mathrm{~cm} \text { de ancho. En caso de que oculte } \\
\text { información relevante, se cambiará la posición de esta identificación a un sitio más conveniente. }\end{array}$ \\
\hline Títulos & $\begin{array}{l}\text { Título breve y explicativo para la figura en Calibri } 10 \text { puntos, debajo de la imagen y justificado. En lo } \\
\text { posible, organice el texto de manera que no sobrepase el ancho de los márgenes del documento. }\end{array}$ \\
\hline Colores de los textos & $\begin{array}{l}\text { Se deben usar según el contraste de la figura, con el siguiente orden de prioridad: 1) color } \\
\text { amarillo, 2) color blanco y 3) color negro. En lo posible, solo se debe usar un color para toda la } \\
\text { microfotografía y no se debe trabajar el color rojo. Para mejorar el contraste, incluya un recuadro } \\
\text { blanco sin borde alrededor del texto, con una transparencia entre } 40 \% \text { y } 60 \% \text {. Si las herramientas } \\
\text { a su disposición lo posibilitan, también puede usarse un efecto de halo en el texto para mejorar su } \\
\text { contraste. En caso de que el recuadro o la abreviatura tape lo que se quiere mostrar, se aconseja } \\
\text { colocarlo a un lado y señalarlo con una flecha en el mismo color de las letras. }\end{array}$ \\
\hline $\begin{array}{l}\text { Abreviaturas o nomenclaturas } \\
\text { de los minerales. }\end{array}$ & $\begin{array}{l}\text { Utilizar las abreviaturas de Whitney y Evans (2010), las del International Union of Geological } \\
\text { Sciences (IUGS) (Fettes y Desmons, 2011) o las de la Subcomisión sobre Sistemática de Rocas } \\
\text { Metamórficas de la IUGS (SCMR). }\end{array}$ \\
\hline Explicación de las fotografías & $\begin{array}{l}\text { La explicación se hará en las notas debajo del título. Para múltiples figuras, se hará referencia } \\
\text { a cada una mediante letras minúsculas seguidas de un paréntesis sin negritas. Las diferentes } \\
\text { descripciones se separarán por un punto y coma (;). }\end{array}$ \\
\hline Contenidos de la descripción & $\begin{array}{l}\text { Se debe empezar describiendo la imagen, luego entre paréntesis la identificación de la muestra } \\
\text { IGM, los parámetros de la toma de la muestra (nícoles: paralelos o cruzados, magnificación). } \\
\text { En informes, en formatos de análisis se utiliza la convención IGM XXX, clasificación de la roca y una } \\
\text { breve descripción de lo que se quiere resaltar en la fotografía. Magnificación 4X (la magnificación } \\
\text { corresponde al objetivo que se utilizó para la toma de la fotografía). Nicoles XPL o PPL. }\end{array}$ \\
\hline
\end{tabular}


Ejemplo 55: fotografías con descripción microscópica para petrografía
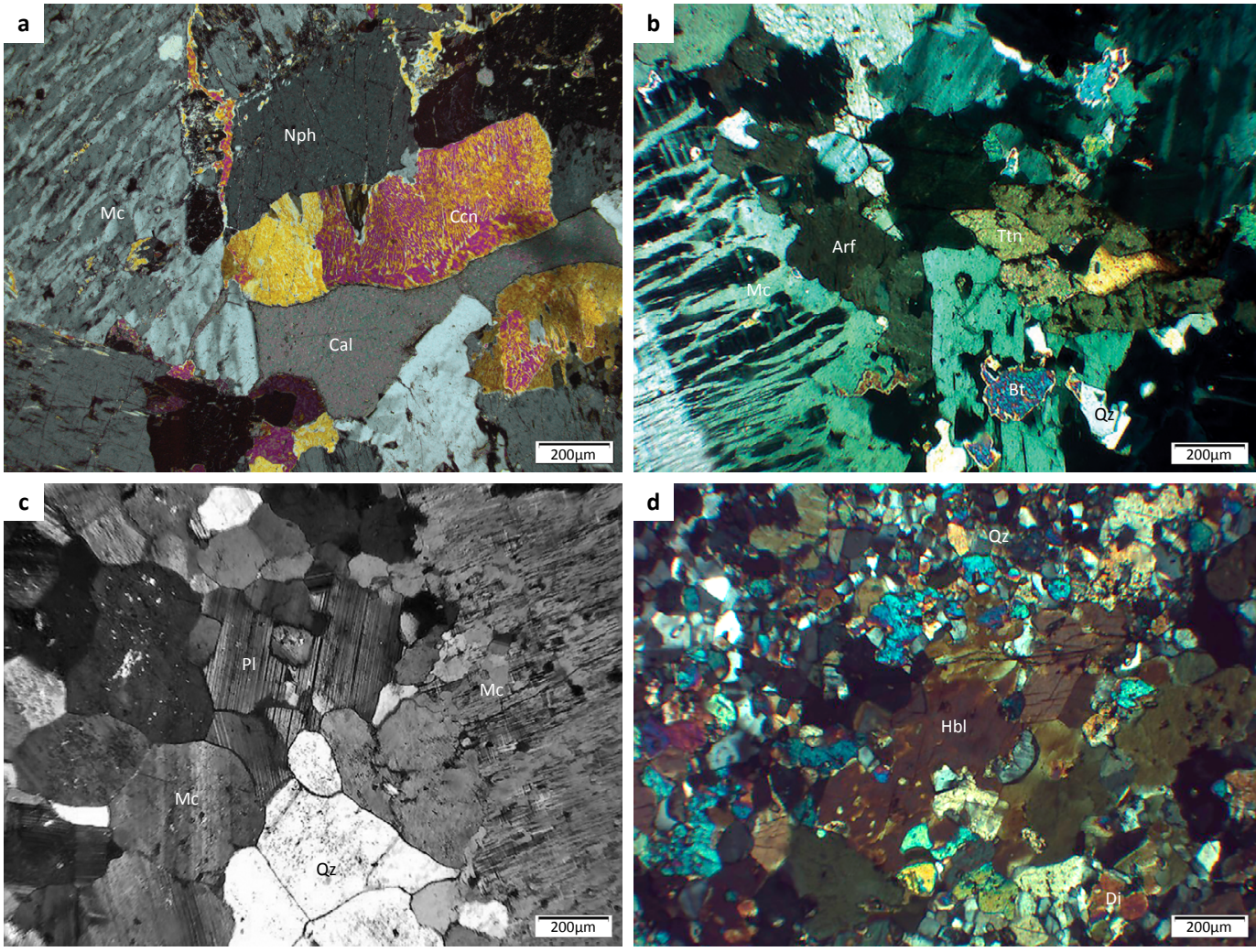

Figure 99. Mineralogy and textures of SJGS rocks

a) Nepheline (Nph)-, microcline (Mc)-, cancrinite ( $\mathrm{Ccn}$ )-, and calcite (Cal)-bearing, hypidiomorphic, holocrystalline nepheline syenite; b) Syenite with aggregates of arfvedsonite (Arf), titanite (Ttn), and biotite $(\mathrm{Bt}) ; \mathrm{c})$ Syenite with recrystallized zone in polygonal granoblastic mosaics with straight edges of plagioclase (PI), quartz (Qz), and microcline (Mc); d) Mafic hornfels with quartz-feldspathic domains and mafic domains (Di: diopside; Hbl: hornblende). Source: adapted from Amaya et al. (2021).

\subsection{Construcción de figuras mixtas}

Algunas figuras pueden tener una naturaleza mixta, esto es, que sean la combinación de diferentes tipos de figuras, incluyendo diagramas, mapas 2D, modelos 3D, fotografías, secciones delgadas, histogramas y otros elementos.

Estas construcciones normalmente cuentan con una figura de referencia geográfica o de posición, por lo general una fotografía, o un mapa en dos o tres dimensiones, sobre los que se indican los demás elementos.

Una composición mixta deberá presentar los detalles solo en su justa medida, evitando proveer información excesiva o ilegible. Las recomendaciones para los demás tipos de figuras aplican a cada componente, sin perder de vista que ahora los elementos de cada parte podrían no ser los más importantes de la composición y, por tanto, no contar con la misma jerarquía visual en cuanto a color, tamaño, contraste, alineación, repetición, proximidad, uso de espacios en blanco, textura o estilo. 
A continuación, se presenta un ejemplo de figura mixta que usa una microfotografía de una muestra como base y seis recuadros a mayor detalle de partes de la muestra. Se usan colores para facilitar la identificación de las referencias de mayor detalle. Se hace un montaje de tal forma que la fotografía base se encuentre el centro y de allí se deriven los recuadros de mayor detalle en diferentes direcciones. Cada parte puede estar marcada con una letra minúscula en negritas y tamaño entre 7 y 10 puntos, para que al momento de la descripción se identifique fácilmente a cuál fotografía se está refiriendo.

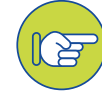

Ejemplo 56: composición de microfotografías de distintas escalas para mostrar detalles de una misma muestra

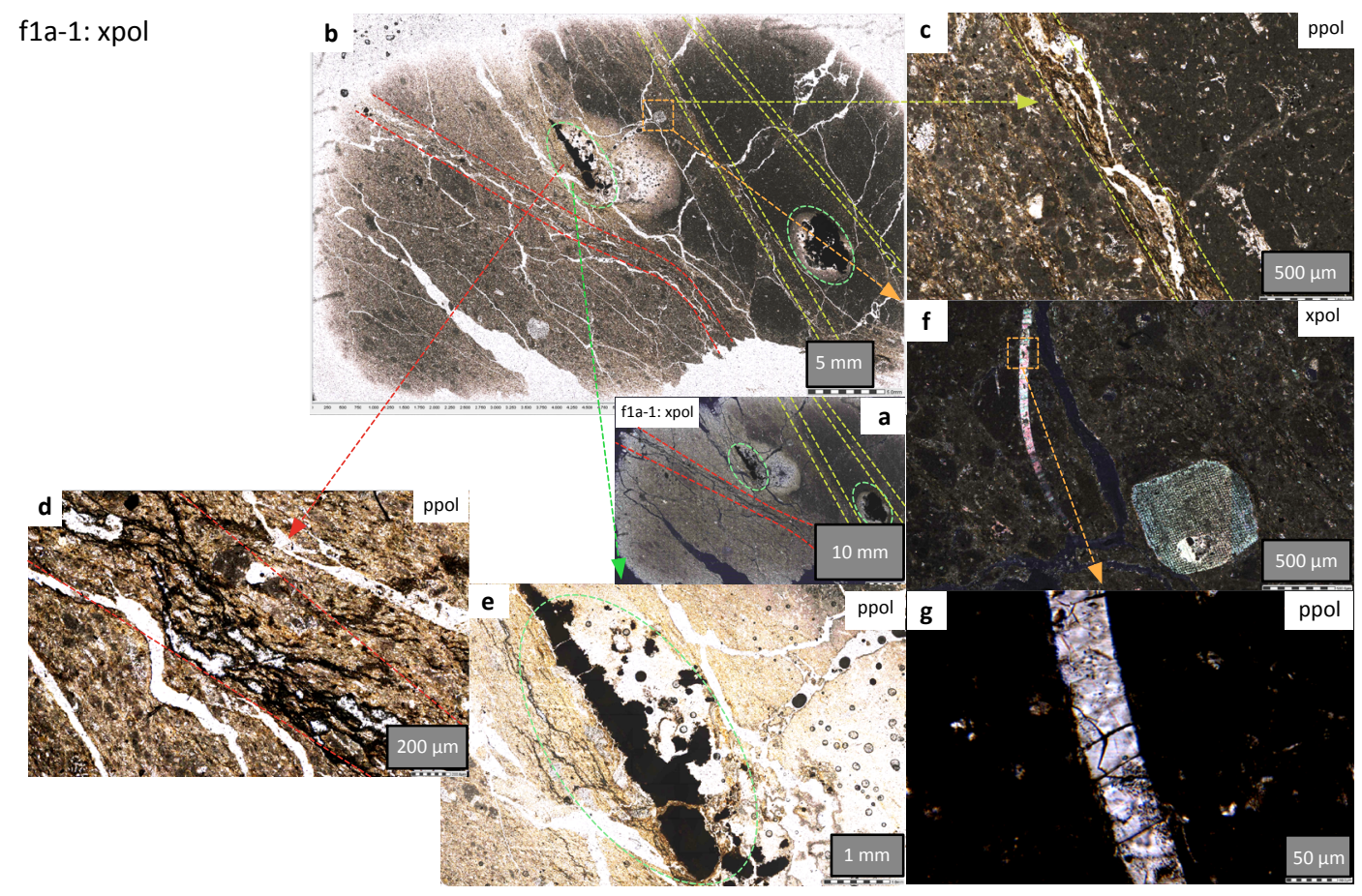

Figure 99. Overview on the most important features

a) Complete sample; b) zone of interest; c) yellow: pure clay layers; d) red: anastomosing pressure solution bands; e) green: precipitations of magnetite; f) blue: larger bioclasts; g) zoom of f). Source: adapted from Hoffmann (2021).

Otra forma de figura mixta consiste en una composición que muestre dos o más temas complementarios en donde además pueda incorporarse otra información de tipo texto o de histogramas, como se muestra en la figura 48. 


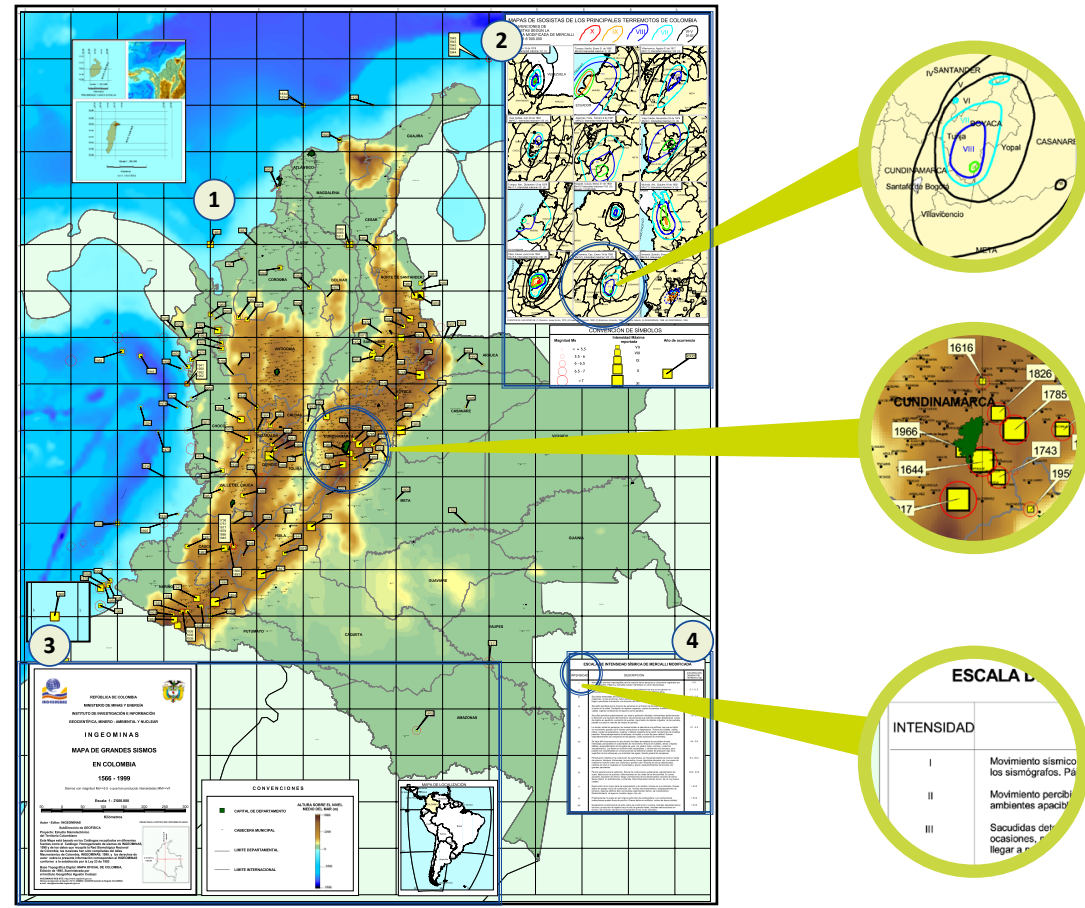
1 Tema principal
2 Tema complementario
3 Rótulo y leyendas del mapa
4 Información adicional

Figura 48. Esquema de mapas que presenta varios temas relacionados Un mismo mapa puede presentar dos o más temas con espacios para rótulos, leyendas e información adicional. La complementariedad entre los temas es lo más importante en este tipo de mapa mixto. Fuente: adaptado de Servicio Geológico Colombiano (1999).

\subsection{Infografías en temas de geociencias}

Las infografías son recursos para transmitir conocimiento o para informar temas generales o específicos en geociencias, con aplicación tanto en publicaciones como en pósteres. Una infografía es una colección de imágenes, gráficos y texto simple (minimalista) que resume un tema para que se pueda entender fácilmente, además, pueden ser muy útiles para ofrecer un rápido compendio sobre un tema, explicar un proceso complejo, presentar los resultados de una investigación, simplificar una publicación larga o un informe y comparar diferentes opciones (Nediger, 2020).

Para crear una infografía, es importante que el autor diseñe una historia con un punto de vista interesante que pueda ser transmitido en la infografía.

Las sugerencias para la creación de infografías son las siguientes:

- Prefiera en lo posible una orientación vertical.

- Utilice un esquema de color definido.

- Incluya un título sugestivo.

- Desarrolle una secuencia cohesiva y un punto de vista interesante.

- Balancee de manera apropiada las figuras y los textos. 
Establezca un flujo definido que guíe al lector a través de la información.

- Siga las mejores prácticas de diseño referidas en este capítulo.

El ejemplo 57 ilustra una infografía para un tema geocientífico.

\section{Ejemplo 57: infografías en geociencias}

Capas de la estructura interna de la Tierra

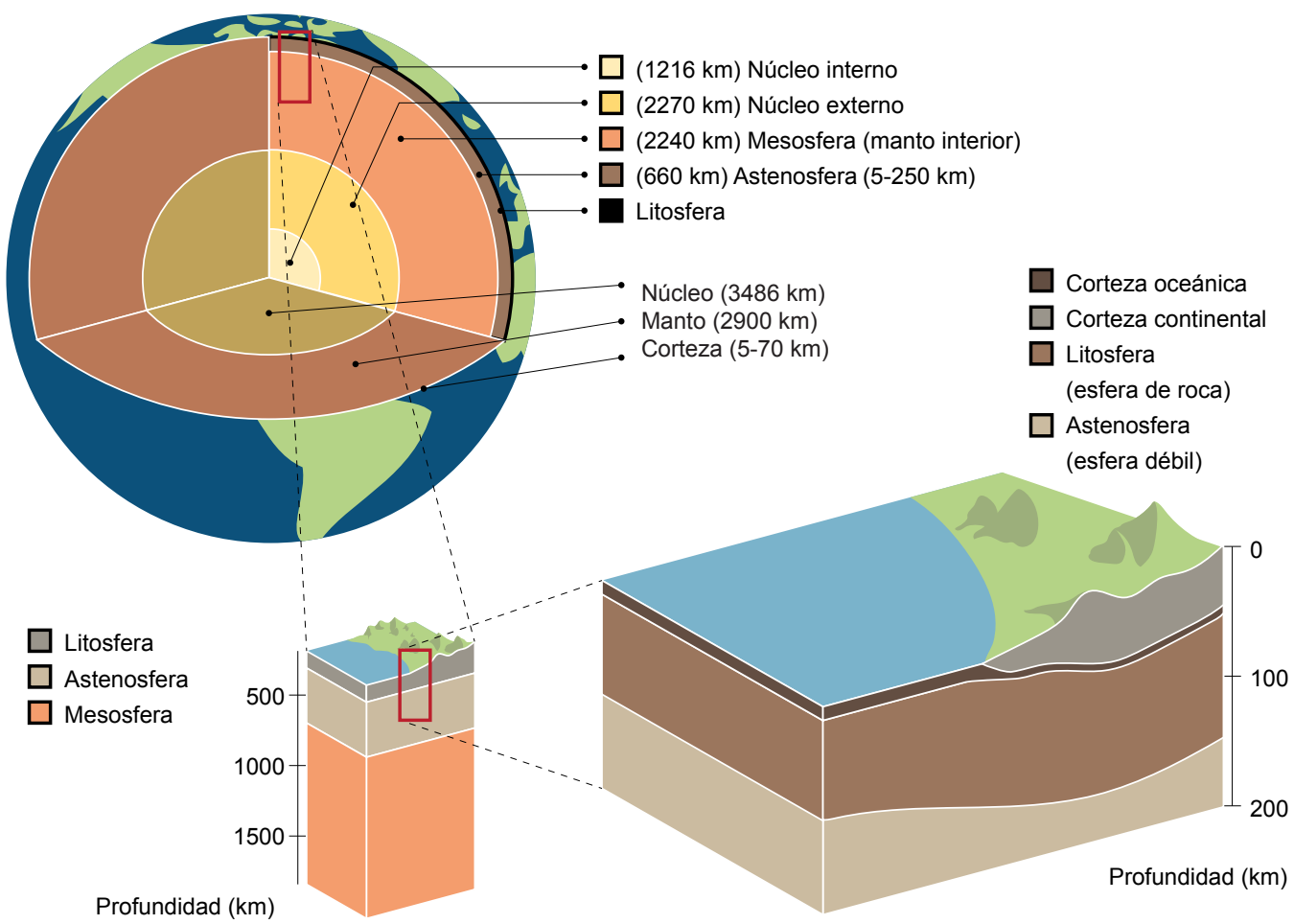

Figura 99. Capas de la estructura interna de la Tierra

La parte central ilustra la división según propiedades químicas y la parte superior derecha, la división según propiedades físicas. Fuente: tomado y adaptado de González Oviedo (2019). 


\section{Lista de chequeo de revisión final de los textos}
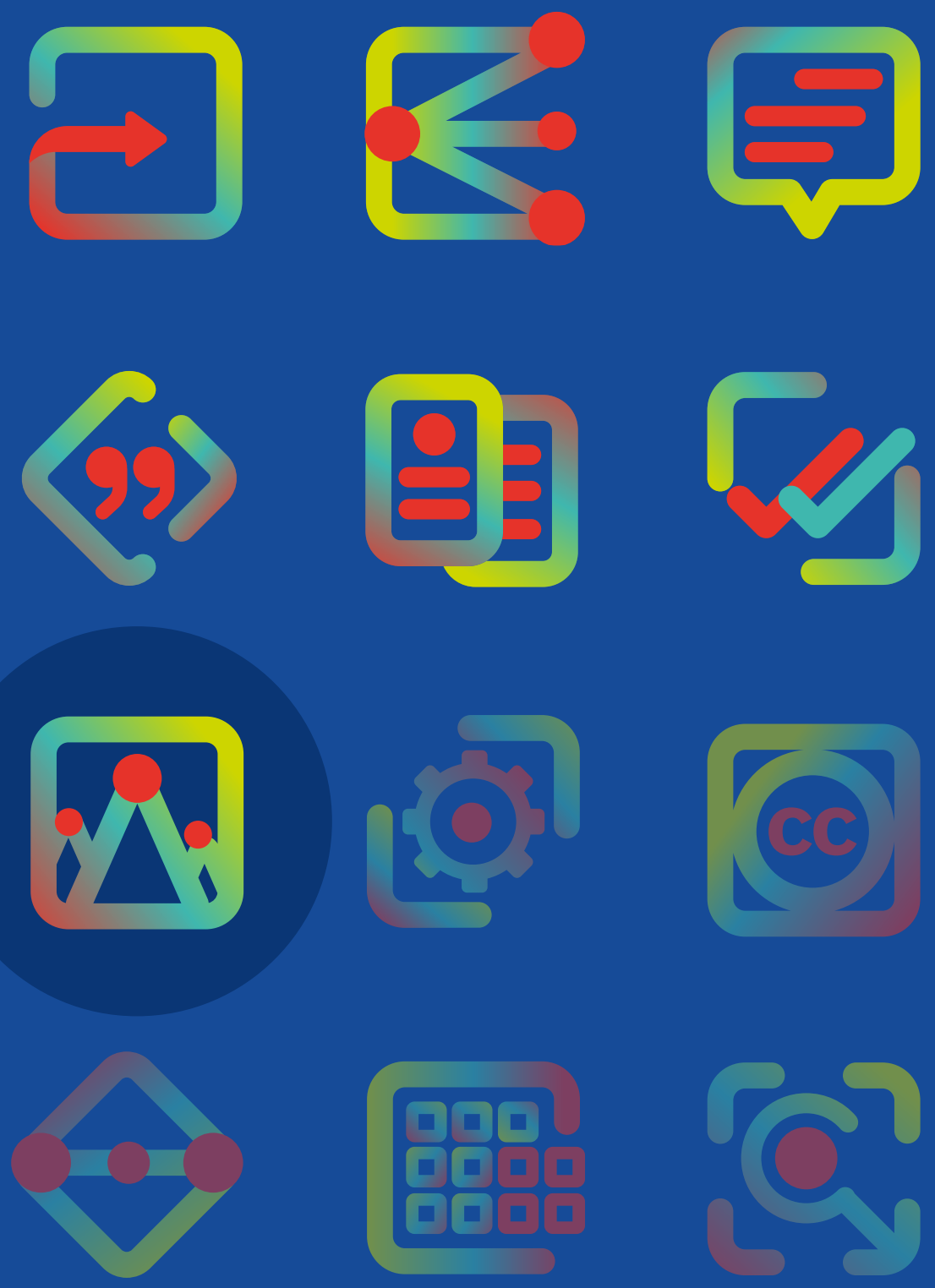


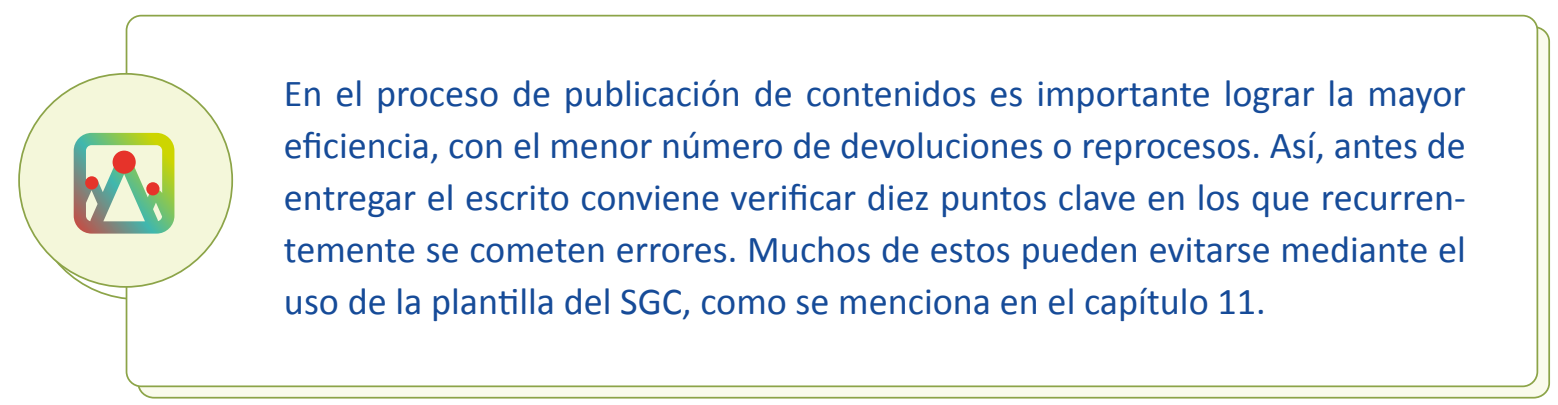

\subsection{Numeración de páginas y pie de página}

Incluya la numeración de páginas iniciando en 1 en la página del título, en la esquina inferior derecha de la hoja, en Calibri tamaño 10. Los folios, o números de página, deben continuar en esa posición hasta la última página del documento.

En libros y en revistas, la numeración definitiva será asignada después de la fase de diseño y diagramación.

En informes, también deberá incluirse como pie de página justificado a la izquierda el texto Servicio Geológico Colombiano, en Calibri tamaño 10 puntos. Si hay informes en convenio, deberá atenderse la instrucción de la sección 4.1. Esta numeración y el pie de página deben estar visibles a partir de la página de la tabla de contenido.

\subsection{El título del trabajo}

Asegúrese de que el título sea conciso, corto (idealmente, debe tener menos de 12 palabras) y que en lo posible, junto con las palabras clave, contenga los elementos suficientes para su búsqueda. Debe aparecer en la página de título y en la parte superior de la primera página del texto; debe estar centrado, en mayúscula la primera letra y los nombres propios, y en negritas.

En informes, el título también deberá aparecer como encabezado en cada página a partir de la tabla de contenido, como se ilustra en la figura 49. 


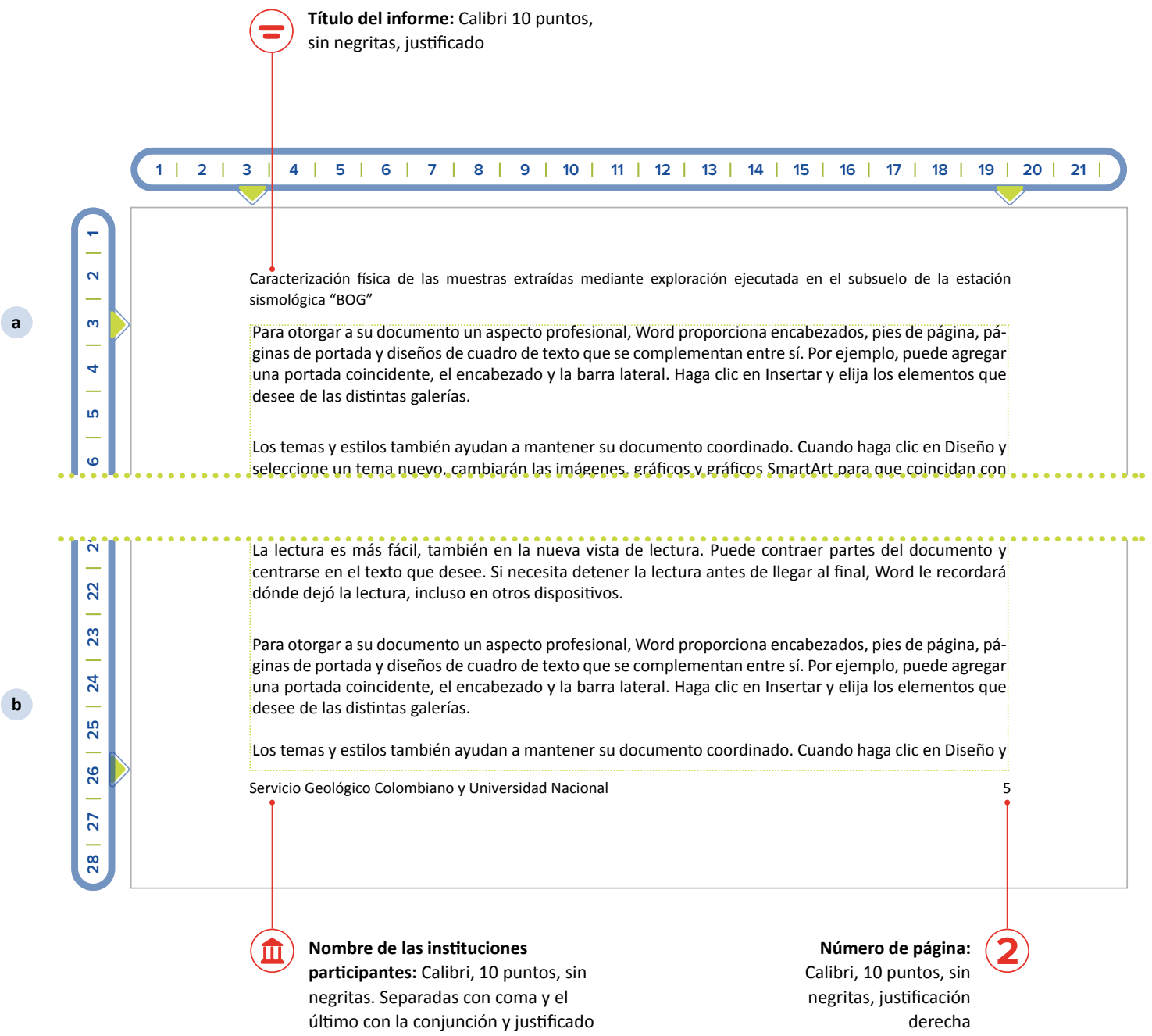

Figura 49. Esquema de encabezado y pie de página para informes

a) Encabezado en la parte superior con el título del informe; b) pie de página con los nombres de las instituciones participantes y el número de página.

\subsection{Use espaciado sencillo en todo el texto}

Utilice espaciado sencillo en todo el texto, incluyendo la página de título, resumen, texto, títulos, citaciones, lista de referencias, notas de tablas y figuras y anexos. Para facilitar la lectura, se deben insertar saltos de línea adicionales antes o después de los títulos de sección y entre párrafos. Verifique la configuración de espaciado en su programa de procesamiento de texto para establecer el espaciado de línea a espacio sencillo sin espacios adicionales antes o después de cada párrafo, como se muestra en la figura 50 para la configuración de estilo de párrafo. 


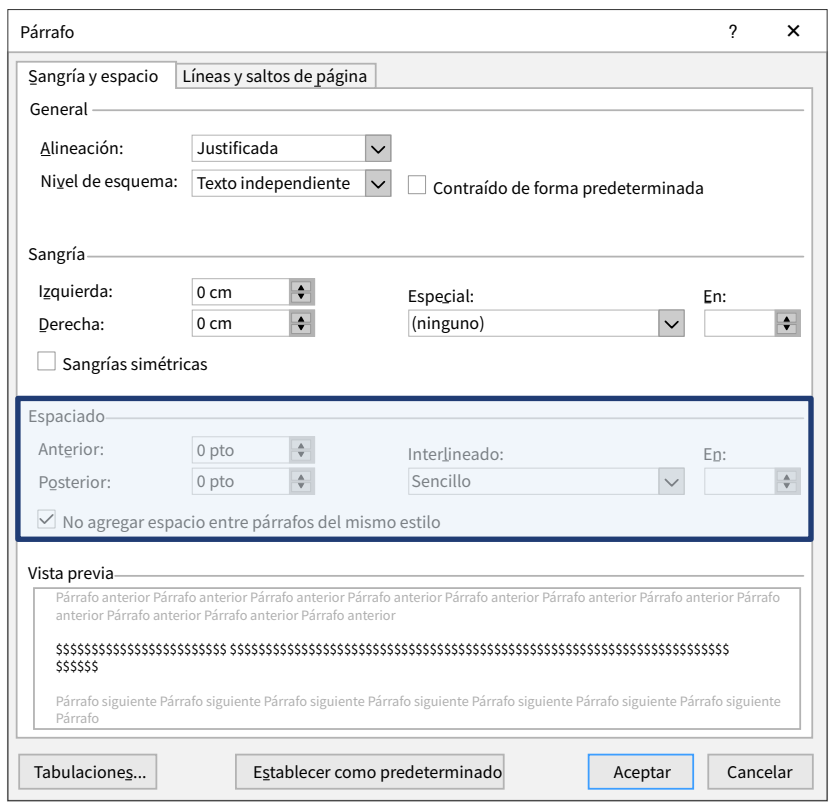

Figura 50. Configuración de los espacios en párrafos en Word

\subsection{Formato de párrafo}

Los párrafos deben tener justificación izquierda y derecha. Si está trabajando en Word, use la configuración de párrafo para configurar la alineación justificada sin sangría automática, como se muestra en la figura 51.

\begin{tabular}{|c|c|c|c|c|c|c|}
\hline \multicolumn{5}{|l|}{ Párrafo } & \multirow[t]{2}{*}{$?$} & \multirow[t]{2}{*}{$\times$} \\
\hline Sangría y espacio & \multicolumn{4}{|c|}{ Líneas y saltos de página } & & \\
\hline \multicolumn{7}{|l|}{ General } \\
\hline Alineación: & \multicolumn{6}{|c|}{ Justificada } \\
\hline Nivel de esquema: & \multicolumn{2}{|c|}{ Texto independiente $\checkmark$} & \multicolumn{4}{|c|}{$\square$ Contraído de forma predeterminada } \\
\hline \multicolumn{7}{|l|}{ Sangría- } \\
\hline Izquierda: & $0 \mathrm{~cm}$ & $\because$ & Especial: & & \multicolumn{2}{|l|}{ En: } \\
\hline Derecha: & $0 \mathrm{~cm}$ & 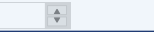 & (ninguno) & $v$ & & $\div$ \\
\hline \multicolumn{7}{|c|}{$\square$ Sangrías simétricas } \\
\hline \multicolumn{7}{|l|}{ Espaciado } \\
\hline Anterior: & 0 pto & 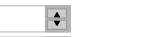 & \multicolumn{2}{|l|}{ Interlineado: } & \multicolumn{2}{|l|}{ En: } \\
\hline Posterior: & 0 pto & $:$ & Sencillo & $\checkmark$ & & 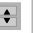 \\
\hline \multicolumn{7}{|c|}{$\checkmark$ No agregar espacio entre párrafos del mismo estilo } \\
\hline \multicolumn{7}{|l|}{ Vista previa } \\
\hline \multirow{3}{*}{\multicolumn{7}{|c|}{ 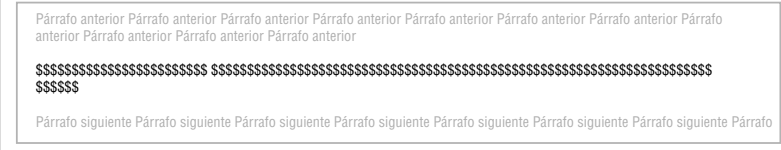 }} \\
\hline & & & & & & \\
\hline & & & & & & \\
\hline Tabulaciones... & \multicolumn{3}{|c|}{ Establecer como predeterminado } & Aceptar & \multicolumn{2}{|c|}{ Cancelar } \\
\hline
\end{tabular}

Figura 51. Configuración de alineación y sangrías en Word 


\subsection{Márgenes}

Establezca todos los márgenes en $2,54 \mathrm{~cm}$, como se muestra en la figura 52 . Si se requieren diferentes márgenes, debido a los requisitos de publicación, siga los lineamientos del editor.

\begin{tabular}{|c|c|c|c|c|c|c|}
\hline \multicolumn{5}{|c|}{ Configurar página } & \multirow[t]{2}{*}{ ? } & \multirow[t]{2}{*}{$x$} \\
\hline Márgenes & Papel & Diseño & & & & \\
\hline \multicolumn{7}{|l|}{ Márgenes } \\
\hline Superior & & $2,54 \mathrm{~cm}$ & $:$ & Inferior: & $2,54 \mathrm{~cm}$ & $\div$ \\
\hline Izquierd & & $2,54 \mathrm{~cm}$ & $\div$ & Derecho: & $2,54 \mathrm{~cm}$ & $\div$ \\
\hline Encuade & ación: & $0 \mathrm{~cm}$ & 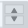 & Posición del margen interno: & Izquierda & 2 \\
\hline \multicolumn{7}{|c|}{ Orientación- } \\
\hline $\mathrm{A}^{\mathrm{A}}$ & $\mathrm{A}$ & & & & & \\
\hline Vertica & Horizo & & & & & \\
\hline
\end{tabular}

Figura 52. Configuración de los márgenes en Word

\subsection{Puntuación después de las citas}

Cuando una cita de treinta y nueve palabras o menos termina una oración, el punto aparece después de la cita. El punto después de una cita en texto de cuarenta palabras o más aparece antes de la cita. Para ilustrar este tema, revise los ejemplos 30 y 31.

\subsection{Títulos de sección}

Verifique el cumplimiento de la estructura de títulos y subtítulos de las secciones 4.1.1. o 4.1.2.

Si está utilizando la función de tabla de contenido automática de Word, use Estilos para formatear títulos de sección, para que los mismos aparezcan en la tabla de contenido. Consulte personalizar o crear nuevos estilos e insertar una tabla de contenido, como se ilustra en la figura 53.

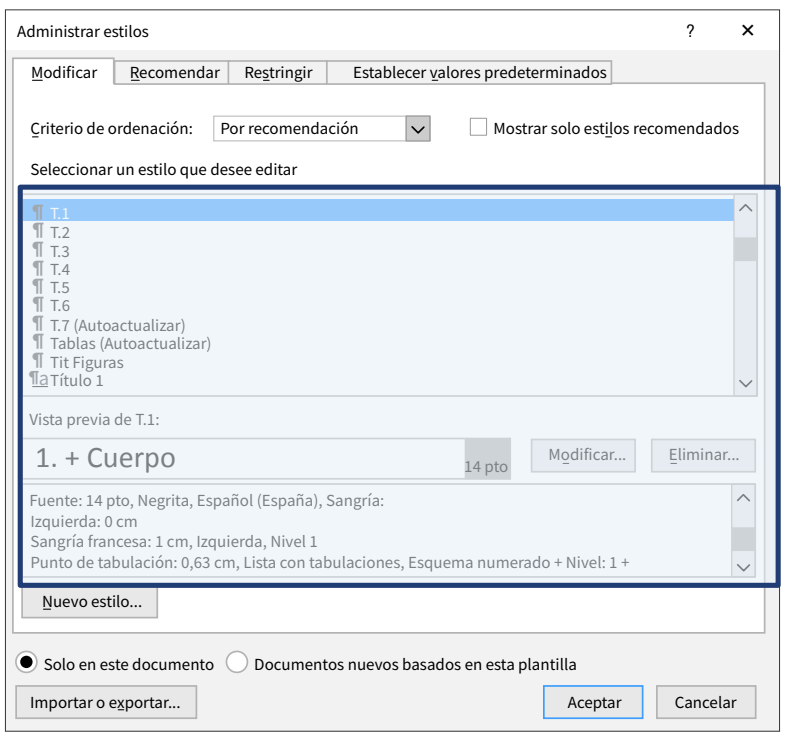

Figura 53. Administración de los estilos en Word 


\subsection{Referencias}

La lista de referencias debe comenzar en una nueva página. La página debe titularse "Referencias", y el título, que es una etiqueta de sección, debe estar centrado y en negritas, no necesariamente requiere un numeral. Todas las referencias deben presentarse a espacio sencillo con una sangría francesa de 0,85 cm.

Debe estar organizada por orden alfabético y cronológico, siguiendo las recomendaciones del estilo seleccionado. Para el caso del SGC, se utilizarán las normas APA, séptima edición (APA, 2020).

Recuerde que no debe incluir referencias que no hayan sido citadas en el texto, y que no debe haber citaciones que no tengan una entrada en la sección de referencias.

Para ver ejemplos de referencias de diversos documentos con este formato, consulte los ejemplos 32 a 49.

Los gestores de referencias constituyen una herramienta muy valiosa para facilitar el trabajo. En el capítulo 8 puede encontrar varios elementos de guía que le permitirán trabajar dichas ayudas de manera eficiente.

\subsection{Verificación del uso de cursivas en la expresión "et al."}

Es común olvidar el uso de las cursivas en la expresión "et al.". Más aún, algunos gestores de citaciones como Mendeley (ver capítulo 8) generan las citaciones utilizando las palabras "et al." en redondas (o Normal) y no en cursivas. Por lo anterior, si su texto es en español, puede reemplazar en todo el documento el texto "et al." en redondas por el mismo texto con el estilo de la fuente en cursiva.

\subsection{Numeración de figuras y tablas}

Todas las figuras y todas las tablas deben estar numeradas en orden de aparición en el texto. Cada uno de estos elementos debe citarse en el trabajo, para que tenga sentido en la secuencia de ideas del documento.

\subsection{Consistencia y actualidad de las URL}

Todas las URL que se mencionen en el texto, y que se usen como referencia o como DOI, deben ser funcionales; esto quiere decir que deben desembocar en la fuente mencionada.

Cuando se tengan URL demasiado largas (de más de un renglón), se recomienda utilizar herramientas como los acortadores de URL. Un ejemplo de estos acortadores es Cuttly (https://cutt.ly/es). Es de anotar que los URL de los números DOI no deben acortarse, estos se representan en direcciones relativamente cortas. En caso de que sea necesario partir una URL al final de una línea, puede hacerse en los siguientes casos (University of Chicago, 2010, p. 7.42): 
1) Después de dos puntos (:) o de doble barra inclinada, o slash (//);

2) Antes de barra inclinada sencilla (/), de un punto (.), de una coma (,), un guion (-), una raya al piso (_), un signo de interrogación (?), un signo de número (\#) o de porcentaje (\%);

3) Antes o después de un signo igual (=) o un et (\&). Nunca debe añadir un guion para generar partición de línea ni debe aparecer un guion al final de la línea del URL.

Debe verificarse que las URL del cuerpo del documento que no figuren en la lista de referencias no estén activas en la versión final, para evitar inconvenientes en la navegación del lector en su versión digital. Esto se logra situándose en Word sobre cada una de las URL y haciendo clic con el botón derecho del ratón (Ctrl + clic en un computador Mac) y finalmente seleccionando la opción Quitar hipervículo. Alternativamente, para eliminar todos los hipervínculos en una sola operación, puede seleccionar el texto sobre el cual desea su eliminación y utilizar el comando AltGr + K, como puede verse en la sección 11.2.4. 
0

Gestores

de referencias
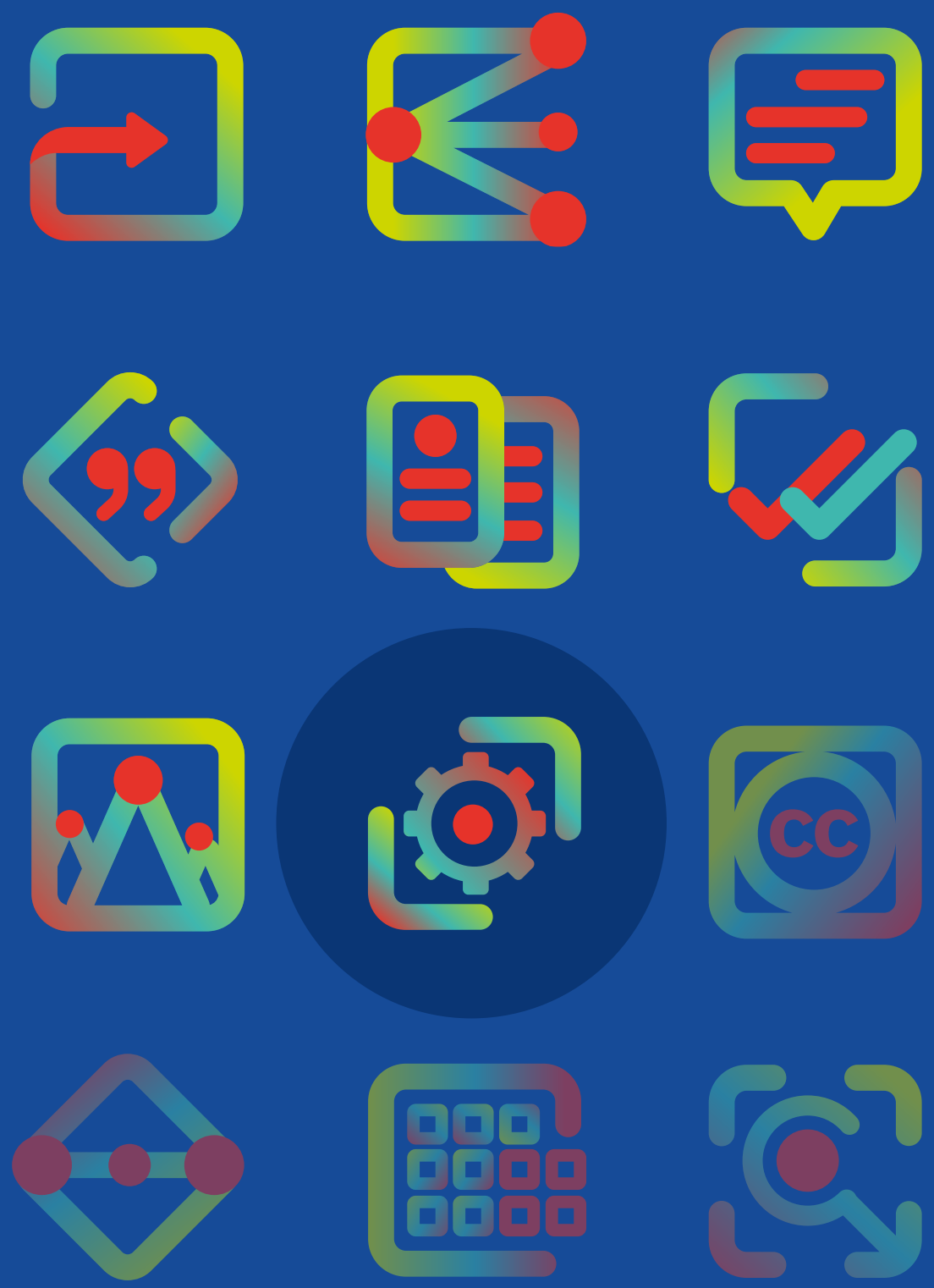


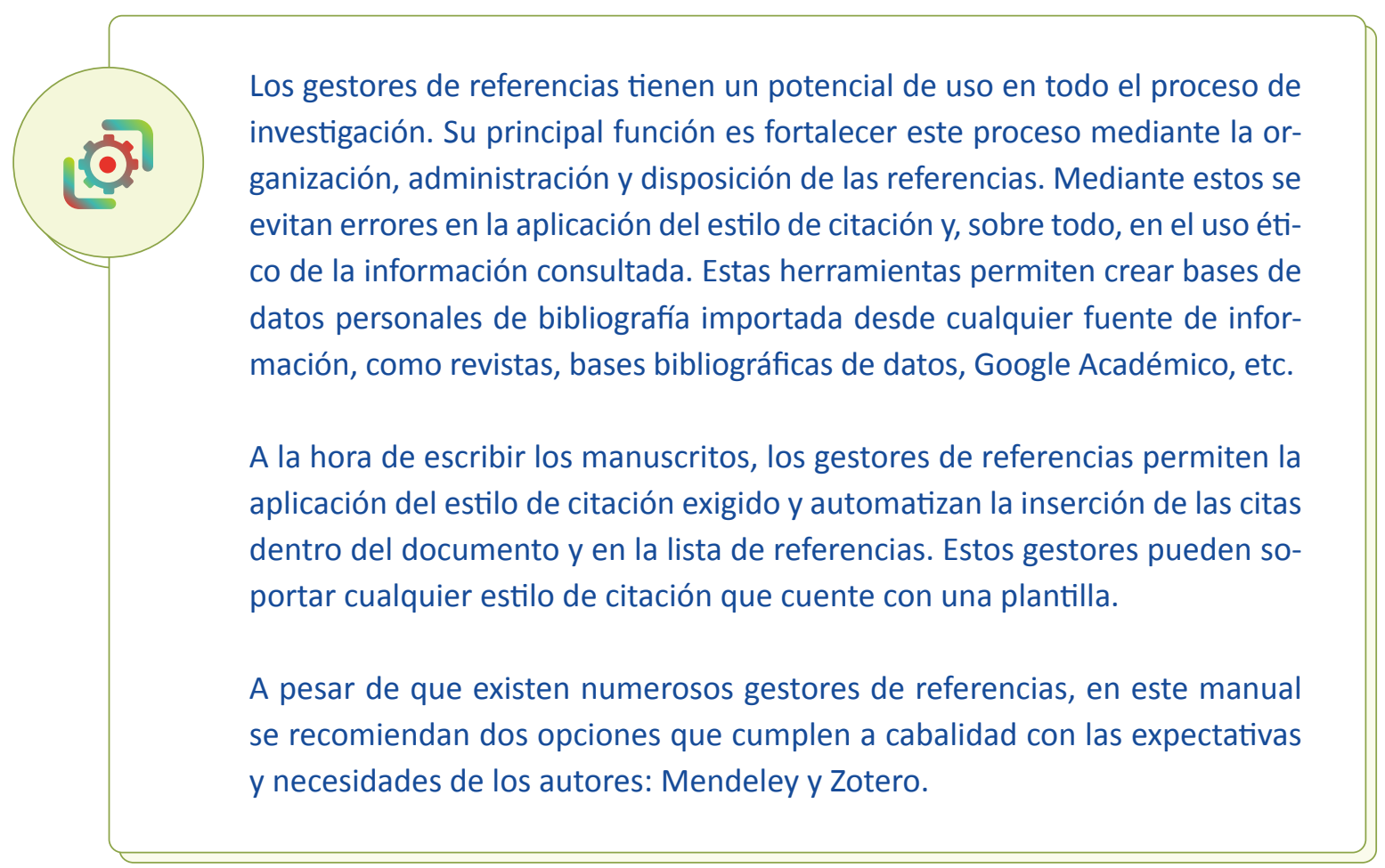

\subsection{Uso de plantillas para el gestor de referencias}

Los gestores, en su mayoría, utilizan el mismo tipo de archivo de configuración de estilos para interpretar las citas (APA, IEEE, Vancouver, etc.). Estas se basan en el lenguaje de estilos de citación Citation Style Language (CSL) de código abierto en XML. Cada estándar de citación tiene una plantilla CSL asociada en la que están consignadas de manera completa todas las reglas, particularidades y formatos establecidos para dicho estándar. La plantilla seleccionada puede ser aplicada en cualquier gestor de referencias, y su resultado, en cuanto a las citaciones y referencias, será el mismo, independientemente de cuál gestor se haya utilizado.

Para el caso de las publicaciones del SGC, se recomienda utilizar la plantilla de APA en la versión 7, que utiliza la conjunción y o and en lugar del signo \&. La configuración de su gestor de referencias, con la plantilla recomendada, soportando la norma APA, 7. ${ }^{\text {a }}$ edición, puede realizarse siguiendo las instrucciones de las secciones 8.2. y 8.3. de este manual.

\subsection{Gestor de referencias Mendeley}

Mendeley es un gestor de referencias libre soportado por Elsevier. Este gestor combina las versiones web y de escritorio, que se sincronizan automáticamente, y que están disponibles para Mac, Windows y Linux. Este gestor incorpora funcionalidades para compartir las referencias con otros contactos y navegar en los contenidos subidos por diferentes usuarios. 
Mendeley dispone de una versión gratuita y versiones de pago (institucionales), con más funcionalidades.

Las principales características del gestor Mendeley son las siguientes:

- Extrae de manera automática los metadatos y las referencias de los diferentes artículos o fuentes desde archivos PDF. También puede recuperar información adicional desde Crossref, PubMed, ArXiv y otros.

- Sincroniza la base de datos bibliográfica de varios computadores, permite compartir con otros autores y administra, o integra, las referencias en blogs y sitios web.

- Soporta estándares de estilo de citación mediante plantillas CSL, incluidas APA, MLA, Chicago, IEEE, etc.

- Crea la sección de referencias en el estilo de citación e idioma seleccionados, de manera automática, a partir de los datos capturados.

- Se integra con editores de texto como Word u OpenOffice Writer, mediante un plugin descargable de manera gratuita.

- Captura referencias de sitios web usando la herramienta web importer para instalar en diferentes navegadores o sincronizarse con Citeulike y Zotero.

- Almacena hasta 2 GB en la nube y 100 GB en la versión institucional. Es obligatorio el almacenamiento en la nube.

- Permite crear grupos para compartir documentos y etiquetas con otros colegas.

- Permite la creación de notas para las distintas entradas, en caso de que el autor necesite anotaciones adicionales.

- Dispone de un lector de PDF que permite agregar notas y resaltar contenido de interés.

Para instalar Mendeley, siga las instrucciones del Manual para el uso de Mendeley (Laiton, 2021), que puede consultar en https://libros.sgc.gov.co.

Si ya tiene instalado y en funcionamiento el gestor de referencias Mendeley, es posible que no tenga disponibles las plantillas de APA en la versión 7. Para actualizar dicha plantilla a esta versión, siga estos pasos:

1) Abra Mendeley Desktop con el botón Open Mendeley en el menú Referencias de Word.

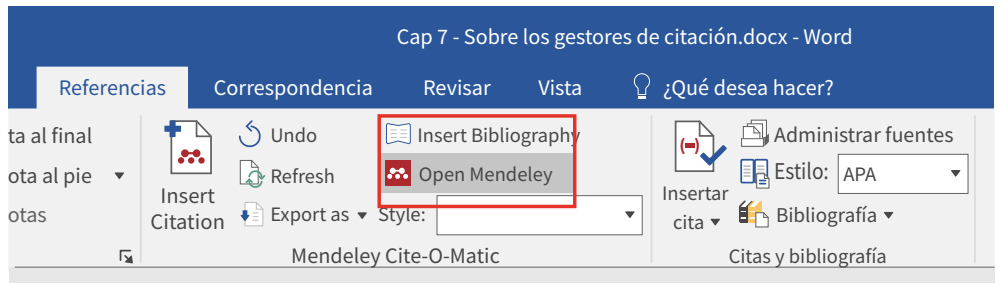

Figura 54. Opción de abrir Mendeley 
2) Vaya al programa Mendeley Desktop y entre a la opción More Styles... siguiendo la ruta View / Citation Style / More Styles...

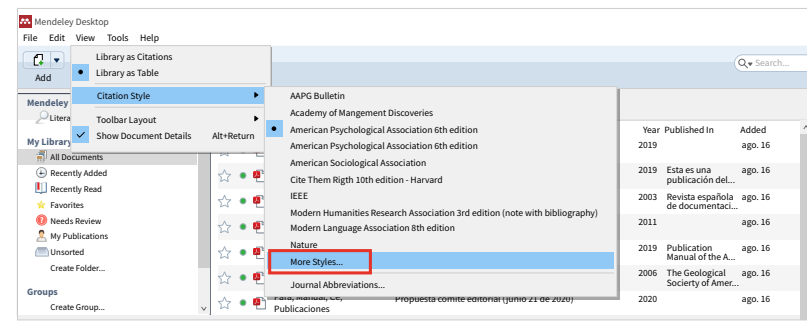

Figura 55. Configuración de estilos de citación

3) Vaya a la pestaña Get More Styles y configure el idioma español en Citation and Bibliography Language en la parte inferior.

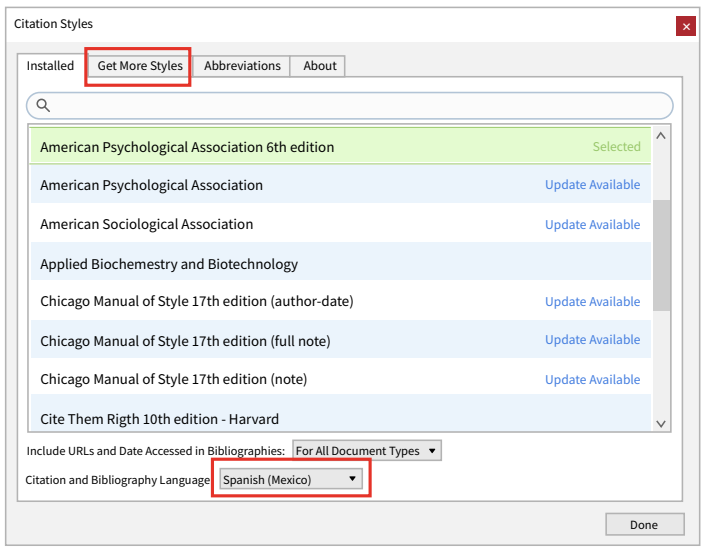

Figura 56. Selección de estilo de citación en Mendeley

4) Si en los estilos no figura la plantilla American Psychological Association 7th edition, dé clic sobre la plantilla American Psychological Association 6th edition, dé clic con el botón derecho del ratón (Ctrl + clic en un computador Mac) y seleccione Update style.

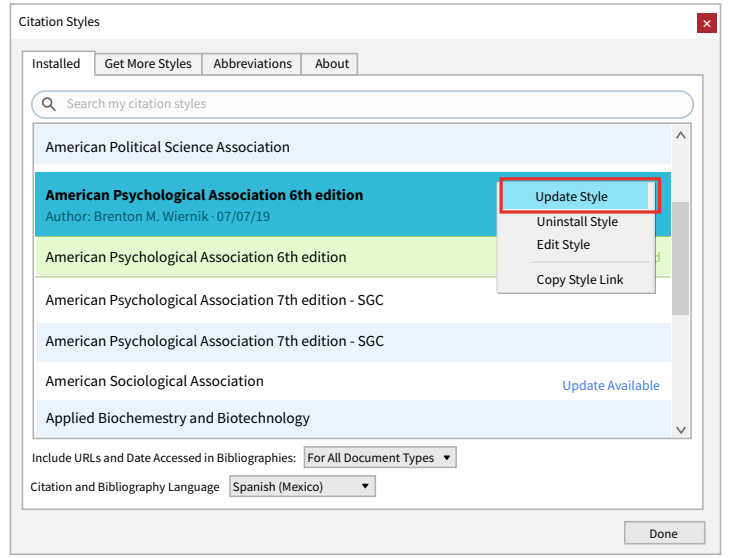

Figura 57. Actualización de la plantilla de citación en Mendeley 
La plantilla de APA que viene por defecto en Mendeley utiliza el signo et (\&) en vez de la conjunción y, en español, o and, en inglés. Dado que en español no se usa el símbolo et, se deberá configurar el gestor para hacer el cambio a la palabra $y$, en español, o and, en inglés, siguiendo estos pasos:

1) Vaya nuevamente a la pestaña Get more styles y digite en la parte superior la palabra ampersand" y seleccione la plantilla American Psychological Association 7th edition (no ampersand). Haga clic en el botón Install.

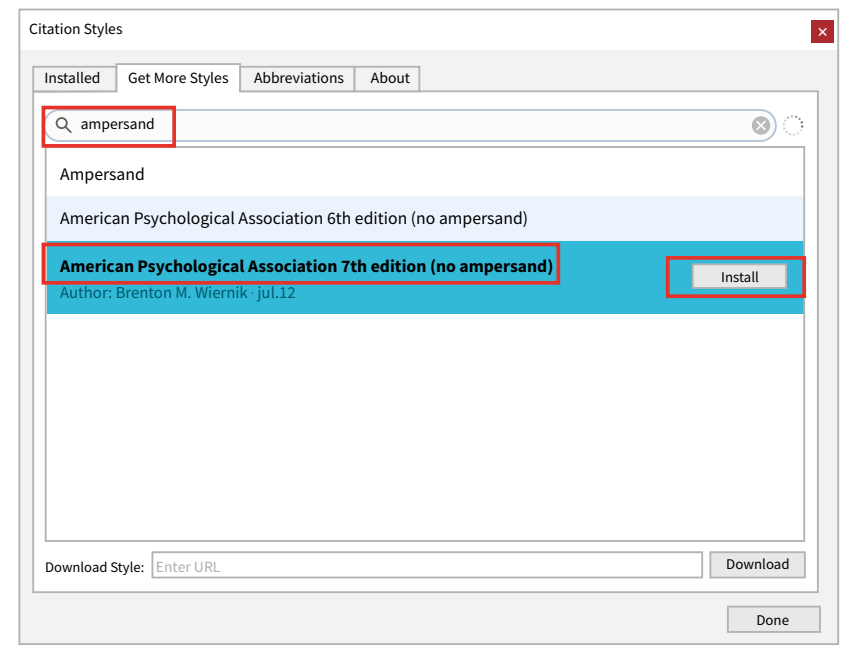

Figura 58. Instalación de la plantilla de citación en Mendeley

2) Una vez se ha cargado la plantilla, puede verificar que está disponible en la pestaña Installed. Selecciónela para que pueda utilizarla en el futuro.

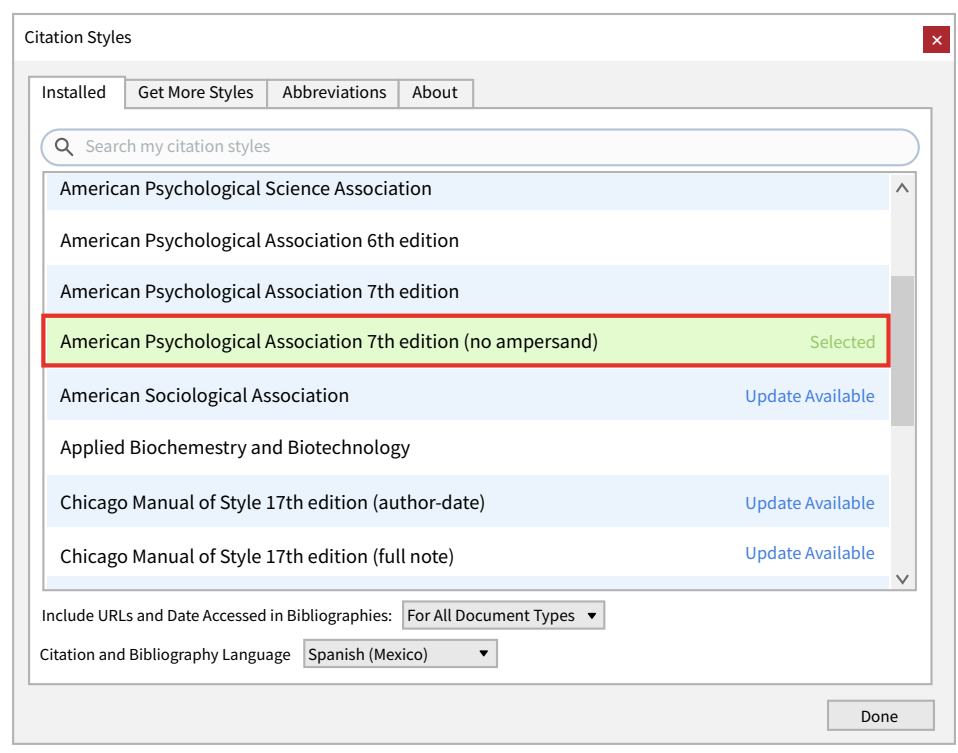

Figura 59. Verificación de instalación de plantilla de citación en Mendeley 


\subsection{Gestor de referencias Zotero}

Zotero es un gestor de referencias de acceso libre que trabaja como una extensión del navegador Firefox. Permite a los usuarios crear su propia base de datos (biblioteca) donde guardar, manejar, buscar, organizar y citar fuentes de todo tipo. Zotero reside en el navegador Firefox, aunque la versión Standalone Alpha (desktop) funciona con los navegadores Safari y Chrome, mediante un plugin disponible para Mac, Windows y Linux, y que se puede descargar desde la página http://www.zotero.org/.

Las principales características del gestor Zotero son las siguientes:

- Extrae de manera automática los metadatos y las referencias de diferentes artículos o fuentes desde archivos PDF. También recupera información adicional desde Crossref, PubMed, ArXiv y otros.

- Importa y exporta referencias en formatos interoperables con otros gestores.

- Permite la conformación de una biblioteca (base de datos) personalizada.

- Guarda la biblioteca en un disco o recurso externo.

- Almacena hasta $300 \mathrm{MB}$ b en la nube (opcional).

- Se integra con editores de texto como Word u OpenOffice Writer.

- Soporta estándares de estilo de citación mediante plantillas CSL, incluidas APA, MLA, Chicago, IEEE, etc.

- De manera automática, crea la sección de referencias en el estilo de citación e idioma seleccionados, a partir de los datos capturados.

Soporta más de cincuenta manuales de estilo.

- Su interfaz está en treinta idiomas, incluido el español.

- Soporta etiquetas (tags) para facilitar el manejo de las referencias.

- Captura citas automáticamente para distintos tipos de archivos y páginas web.

- Permite la creación de notas para las distintas entradas, en caso de que el autor necesite anotaciones adicionales.

El manual de instalación de Zotero puede ser consultado en https://www.zotero.org/support/es/installation, y la configuración para soportar la norma APA 7. ${ }^{a}$ edición se puede consultar en https://www.zotero. org/support/preferences/cite.

Si ya tiene instalado y en funcionamiento el gestor Zotero, es posible que no tenga disponible la versión adecuada de la plantilla de APA en la versión 7.

La plantilla de la 7. ${ }^{a}$ edición de APA viene por defecto con el gestor de referencias Zotero, que utiliza el signo et, o ampersand ( \&), en vez de la conjunción $y$, en español, o and, en inglés. Dado que en español no se usa el símbolo et, se deberá configurar el gestor para hacer el cambio a la palabra y en español, o and en inglés, siguiendo los siguientes pasos: 
1) Abra Zotero y vaya al menú Editar / Preferencias.

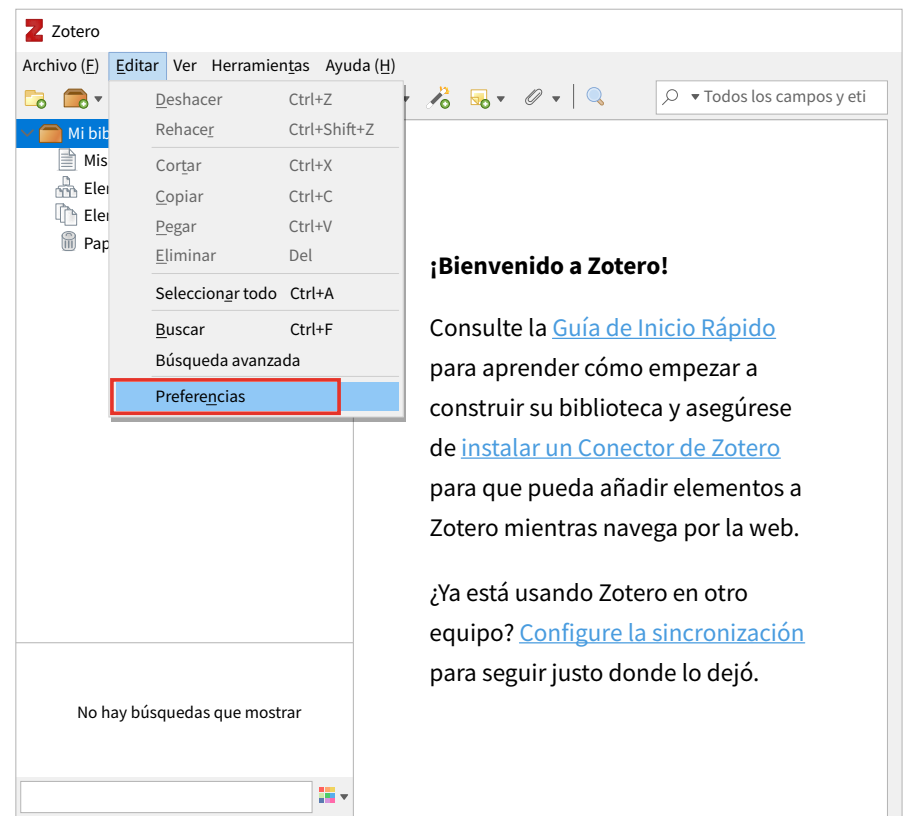

Figura 60. Edición de las preferencias de Zotero

2) Revise los estilos disponibles. Si no encuentra la plantilla American Psychological Association 7th edition (no ampersand), seleccione Obtener estilos adicionales.

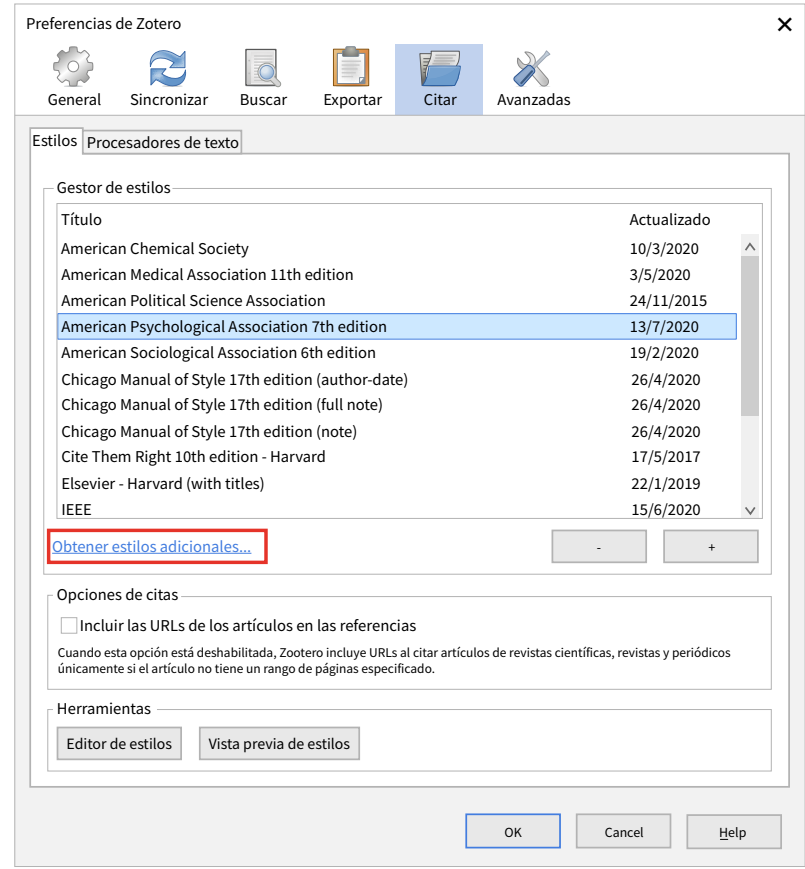

Figura 61. Selección de estilos adicionales en Zotero 
3) En el espacio de la parte superior digite la palabra apa y busque la plantilla American Psychological Association 7th edition (no ampersand). Selecciónela para que quede disponible.

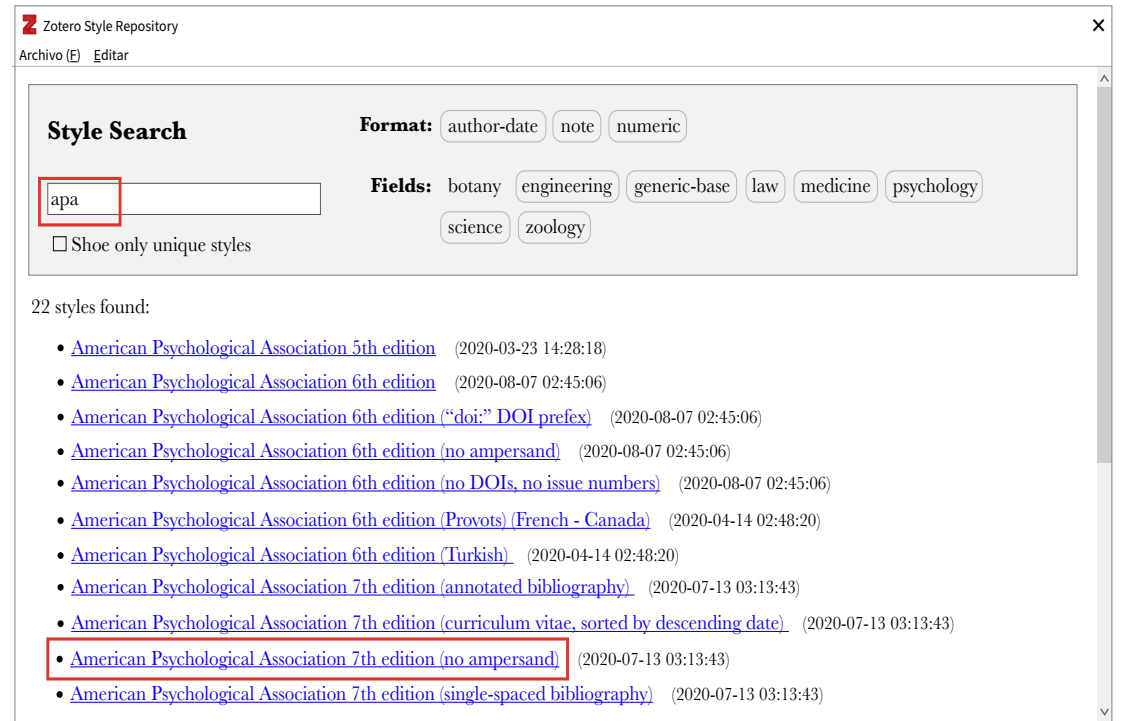

Figura 62. Selección de plantilla APA en Zotero

4) Una vez se ha cargado la plantilla, puede verificar que está disponible en la pestaña Estilos. Selecciónela para poder utilizarla en el futuro.

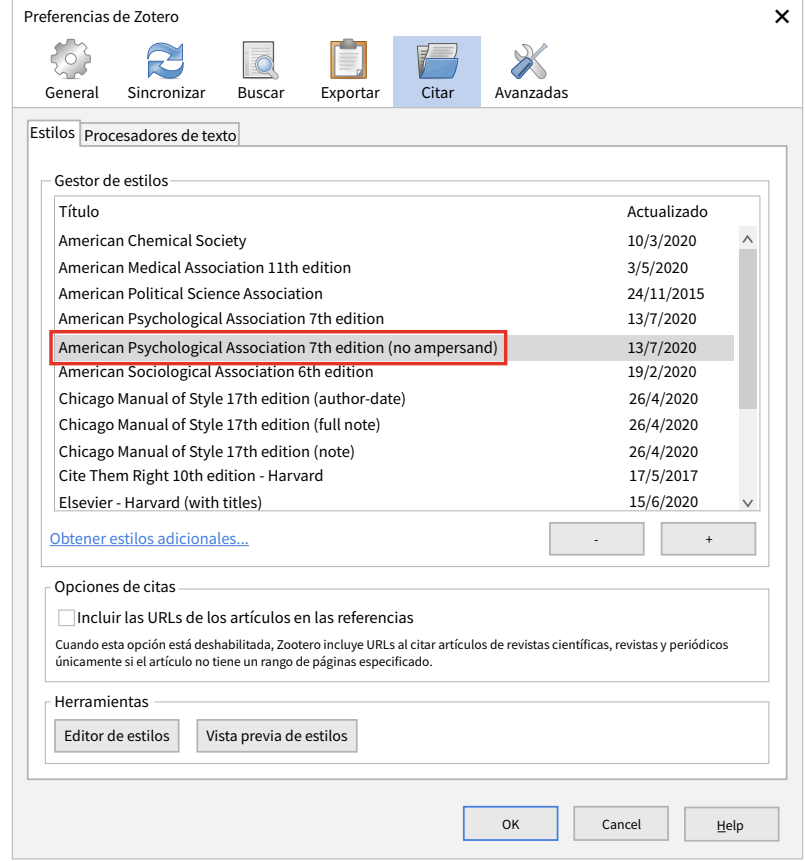

Figura 63. Verificación de plantilla en Zotero 
9.

Licencias de uso de las publicaciones
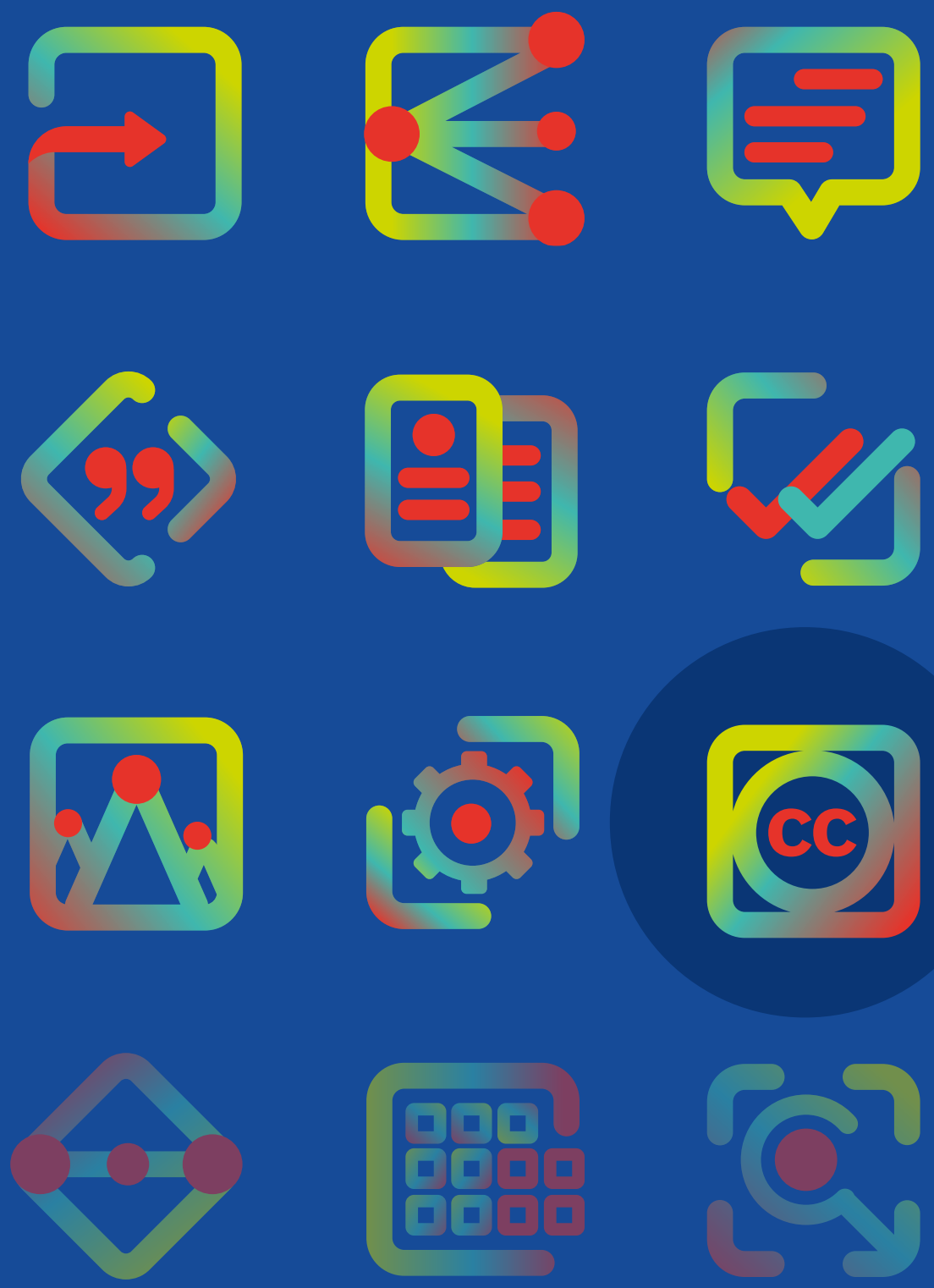
Los derechos de autor nacen desde el momento de la creación de la obra, es decir, desde que se expresa la idea del autor, aun si esta no ha sido publicada. Así, no es necesario cumplir con requisitos formales como registrar la obra, ni solicitar autorización alguna, ni agregar el símbolo de copyright, ni tener ISBN para que la obra tenga protección legal (Cerda Silva y Lara Gálvez, 2011, p. 12).

EI SGC promulga el acceso abierto como estrategia para la máxima difusión y el adecuado uso de su información. Al aceptar la descarga de contenidos, los lectores adquieren algunos compromisos que están ligados al uso del producto o publicación y que están enunciados en la licencia.

Con el fin de comunicar de manera clara qué puede y qué no puede hacer un lector con el contenido, se utilizan las licencias y herramientas Creative Commons (CC) que pueden verse en Creative Commons (s. f.).

\subsection{Características de la licencia de uso de las publicaciones e informes técnicos y científicos del Servicio Geológico Colombiano}

El contenido de las publicaciones del SGC y sus informes técnicos se distribuyen bajo una licencia internacional Creative Commons - atribución/reconocimiento (CC BY). Esta permite que la obra sea distribuida, reproducida, adaptada, transformada y utilizada para crear nuevas obras a partir de su contenido, con cualquier finalidad (incluso comercial). Quien ejerza cualquiera de los derechos anteriormente mencionados, deberá reconocer adecuadamente los derechos de autor sobre la obra original, e indicar si la misma fue modificada.

El SGC no se hace responsable por ningún daño o perjuicio derivado del ejercicio de los derechos otorgados bajo la licencia Creative Commons - Atribución/Reconocimiento, ni ofrece garantías de ningún tipo en relación con el material licenciado.

La licencia de uso que se otorga a los usuarios debe indicarse de manera clara en la página legal o en el caso de artículos, donde figuren los autores, como se puede ver en la sección 5.4.

Los detalles de la licencia seleccionada para las publicaciones e informes del SGC se muestran en la tabla 40. 
Tabla 40. Detalles de la licencia de Creative Commons utilizada en el SGC para sus publicaciones e informes

\begin{tabular}{lll}
\hline $\begin{array}{c}\text { Nombre de la licencia, } \\
\text { logo y texto descriptivo }\end{array}$ & Descripción & Publicación donde se aplica \\
& &
\end{tabular}

Los siguientes textos podrán incluirse en el metadato o en un lugar específico del portal donde se encuentre publicado el contenido para darle al usuario una clara descripción de la licencia otorgada.

\section{Licencia CC BY (atribución/reconocimiento)}

- Sujeto a los términos y condiciones de esta licencia pública, el Servicio Geológico Colombiano otorga una licencia de carácter global, gratuita, no transferible a terceros, no exclusiva e irrevocable para ejercer los derechos licenciados sobre el material licenciado, para reproducir y compartir el material, en su totalidad o en parte, y producir, reproducir y compartir material adaptado.

- La licencia Creative Commons atribución/reconocimiento 4.0 Internacional permite el uso, el intercambio, la adaptación, la distribución y la reproducción en cualquier medio o formato, siempre que otorgue el crédito apropiado al autor o autores originales y a la fuente, proporcione un enlace a la licencia de Creative Commons e indique si se realizaron cambios. Las imágenes u otro material de terceros en este contenido están incluidos en la licencia, a menos que se indique lo contrario en una línea de crédito del material. Si el material no está incluido en la licencia Creative Commons del contenido y su uso previsto no está permitido por la normativa legal o excede el uso permitido, deberá obtener el permiso directamente del titular de los derechos de autor.

- El usuario puede remitirse a las condiciones legales completas de esta licencia en https://creativecommons.org/licenses/by/4.0/legalcode.es

\subsection{Forma de incluir los elementos de la licencia de uso en las publicaciones e informes técnicos y científicos}

La licencia que cubre los contenidos debe ser informada de manera visible con la inclusión del respectivo logo, en la página legal o, para el caso de artículos, en la primera página donde se haga alusión a los autores, debajo del URL del DOI de la publicación. En los informes que no tengan DOI, la información de la licencia debe incluirse debajo de la citación sugerida. 
El logo utilizado debe tener al menos $2 \mathrm{~cm}$ de ancho y puede ser obtenido en la página https://creativecommons.org/about/downloads/. El texto de la licencia debe ir debajo del logo, en fuente Calibri 8 puntos.

Para las publicaciones en español, debajo del logo debe incluirse el texto: "Esta obra es distribuida bajo licencia internacional Creative Commons atribución/reconocimiento 4.0".

Para las publicaciones en inglés, el texto de la licencia debajo del logo debe ser:

"This work is distributed under a Creative Commons Attribution 4.0 International license".

Ejemplo 58: ubicación de la información de la licencia de una publicación especial

$\begin{array}{ll}\text { Instituto Nacional de Salud } & \text { Imagen de carátula } \\ \text { Bogotá - Colombia } & \text { Adobe Stock } \\ & \text { Esta obra está bajo licencia internacional } \\ \text { Patricia Bedregal } & \text { Creative Commons Reconocimiento } 4.0 \\ \text { Instituto Peruano de Energía Nuclear } & \text { cc) } \\ \text { Lima - Perú } & \text { (c) }\end{array}$

Mauricio Bermúdez

Universidad Pedagógica y Tecnológica de Colombia @ Servicio Geológico Colombiano

Sogamoso - Colombia

Diciembre de 2020

Ejemplo 59: ubicación de la información de la licencia en un informe

Citación: Chamorro, M. E. y Salas, L. E. (2021). Gestión de Oficialización,

primer semestre de 2021. Bogotá: Servicio Geológico Colombiano.

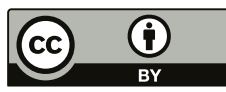

(c) Servicio Geológico Colombiano. (2021). Esta obra es distribuida

bajo licencia internacional Creative Commons Atribución/

Reconocimiento 4.0 
Ejemplo 60: ubicación de la información de la licencia en un artículo de revista en inglés
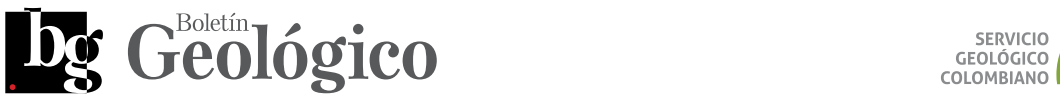

GEOLOÓGICO

Boletín Geológico, 47, 5-34, 2020 https://doi.org/10.32685/0120-1425/ oletingeo.47.2020.502 (c) (1)

This work is distributed under the Creative Commons Attribution 4.0 License. Received: May 17,2020

Revised: July 9, 2020

Accepted: August 20, 2020

Published online: December 28, 2020
The Guaviare Complex: new evidence of Mesoproterozoic (ca. $1.3 \mathrm{Ga}$ ) crust in the Colombian Amazonian Craton

El Complejo Guaviare: nueva evidencia de corteza continental

En las versiones digitales (PDF, HTML y otros) y en contenidos en página web en español, cuando el usuario haga clic sobre el logo de la licencia debe ser dirigido al enlace siguiente:

https://creativecommons.org/licenses/by/4.0/legalcode.es

Cuando se trate de publicaciones en inglés, en estas versiones digitales y contenidos en página web, cuando el usuario haga clic sobre el logo de la licencia debe ser dirigido al siguiente enlace:

https://creativecommons.org/licenses/by/4.0/legalcode 


\section{0.}

Pautas de ética para autores y evaluadores
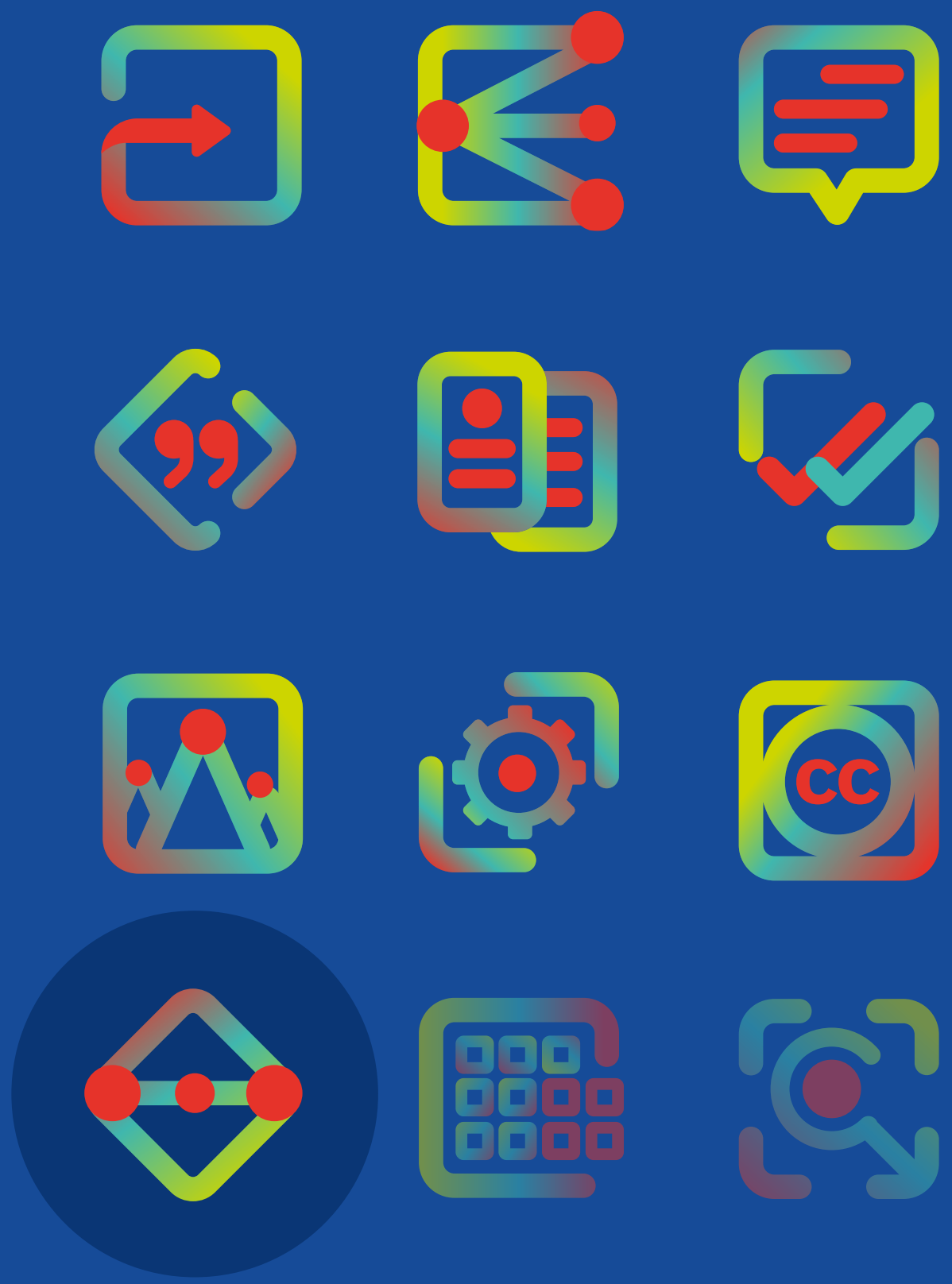


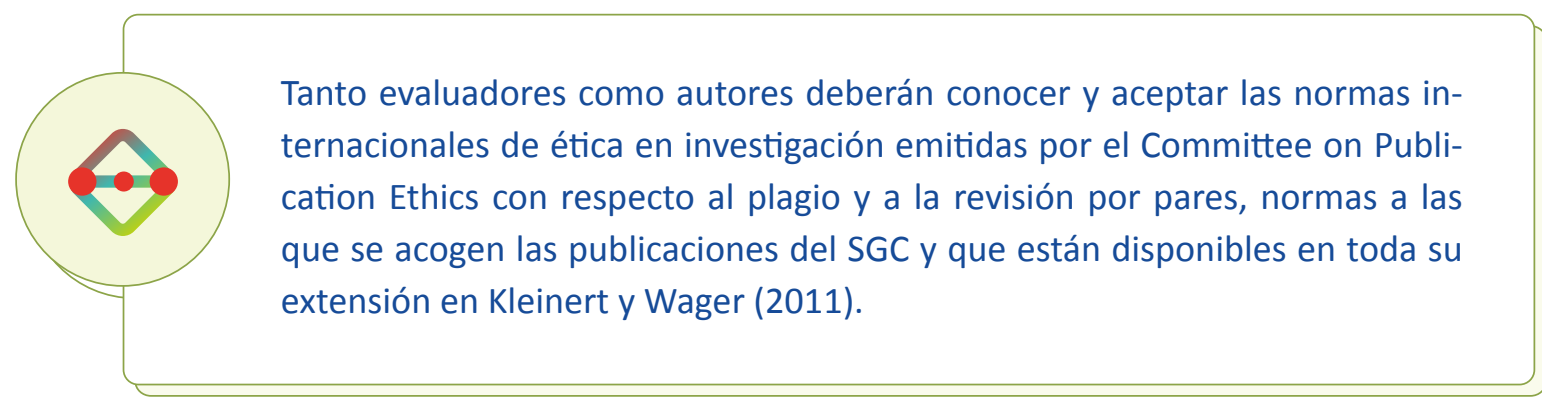

\subsection{Consideraciones sobre la autoría de contenidos}

En las publicaciones del SGC se considera que la autoría debe estar restringida solo a quienes contribuyeron sustancialmente en la elaboración de la obra técnica, científica o divulgativa. El mero aporte de ideas que sirven de antecedente para la creación de la obra, o la contribución puramente física, administrativa, de supervisión o mecánica, no atribuyen la condición de autor a quien las realiza, pero su trabajo debe ser reconocido en los agradecimientos respectivos.

En trabajos de varios autores o en colaboración, se debe incluir la responsabilidad de cada uno y los créditos correspondientes en la extensión posible, incluyendo su filiación. El orden de los autores debe reflejar su grado de participación y responsabilidad en el trabajo. En caso de ser imposible la determinación del grado de participación de los autores, se seguirá un orden alfabético por apellido y se incluirá una nota indicando que el orden de los autores no corresponde a su grado de participación. En trabajos extensos, es posible definir una tabla de autoría particular para cada uno de los capítulos relevantes.

Aparte de la autoría, se deben realizar reconocimientos por contribuciones a quienes aportaron datos, contenidos o trabajos adicionales, pero que no alcanzan la participación como autores del estudio.

Se debe dar crédito de asistencias especiales y cortesías brindadas por otros colaboradores durante los trabajos, sean científicos, técnicos o divulgativos.

De igual manera, debe darse el respectivo reconocimiento cuando se trate de contribuciones de analistas por sus determinaciones químicas o físicas, u otras determinaciones analíticas, e interpretaciones, por sus contribuciones únicas.

En informes internos, debe mencionarse de manera específica a los grupos de trabajo del SGC distintos al que pertenecen los autores que contribuyeron a su elaboración.

\subsection{Comportamientos no éticos relacionados con publicaciones}

A continuación, se enuncian algunos comportamientos que se consideran no éticos y que por tanto no son aceptables en las publicaciones del SGC. 


\subsubsection{Fabricación y falsificación de datos}

La fabricación de datos significa que el investigador en realidad no realizó el estudio, sino que falsificó los datos. La falsificación de datos puede darse cuando el investigador hizo el experimento, pero luego cambió algunos de los datos.

\subsubsection{Plagio}

Tomar las ideas y el trabajo de otros científicos sin darles crédito se considera un comportamiento deshonesto e injusto. Copiar una frase del manuscrito de otra persona, o incluso una propia que se haya publicado previamente, sin una cita adecuada se considera plagio;

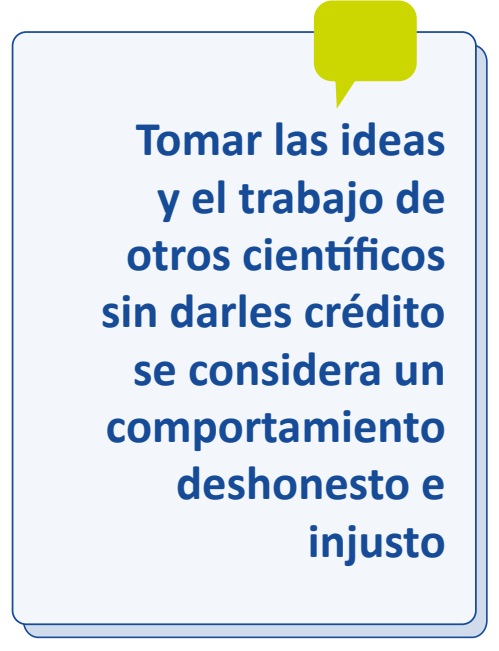
cada autor deberá usar sus propias palabras.

Con el fin de asegurar que los contenidos no han sido publicados anteriormente o que atribuyen de manera completa las contribuciones de terceros, es recomendable utilizar los sistemas antiplagio. Una vez revisado, debe asegurarse de que se cumpla con las normas de intertextualidad y atribución adecuada a las fuentes de donde se toman textos o datos.

\subsubsection{Múltiples presentaciones}

No es ético someter el mismo manuscrito a más de una revista o publicación al mismo tiempo. Hacer esto va en contra del tiempo de los editores y pares revisores, y puede dañar la reputación de los autores y de la revista donde se duplicó, puesto que la publicación tendrá que retirarse.

\subsubsection{Publicaciones redundantes (o publicaciones salami)}

Esto significa publicar muchos manuscritos similares con base en el mismo experimento. La combinación de sus resultados en un documento muy sólido es de mayor interés para una revista selectiva. Es recomendable que el editor rechace un documento débil cuando hay sospecha de su resultado por ser del corte salami.

\subsubsection{Contribución o atribución incorrecta del autor}

Todos los autores enumerados deben haber hecho una contribución científica significativa a la investigación en el manuscrito y deben haber aprobado todas sus afirmaciones. No olvide enumerar a todos los que hicieron una contribución científica importante, incluidos estudiantes y técnicos de laboratorio. No "regale" autoría a aquellos que no contribuyeron significativamente. 


\subsection{Verificación de prácticas no éticas}

Al momento de recibirse contenidos para publicar en el SGC, el Comité Editorial respectivo podrá utilizar programas de software especializados para detectar los artículos y autores que participan en un comportamiento poco ético en cuanto a plagio y otras conductas. Si se confirma al menos una práctica no ética, el manuscrito podrá ser rechazado y la institución o dependencia de origen del autor del documento será informada del incidente. 


\section{1.}

Plantilla del SGC para soportar los estilos del manual
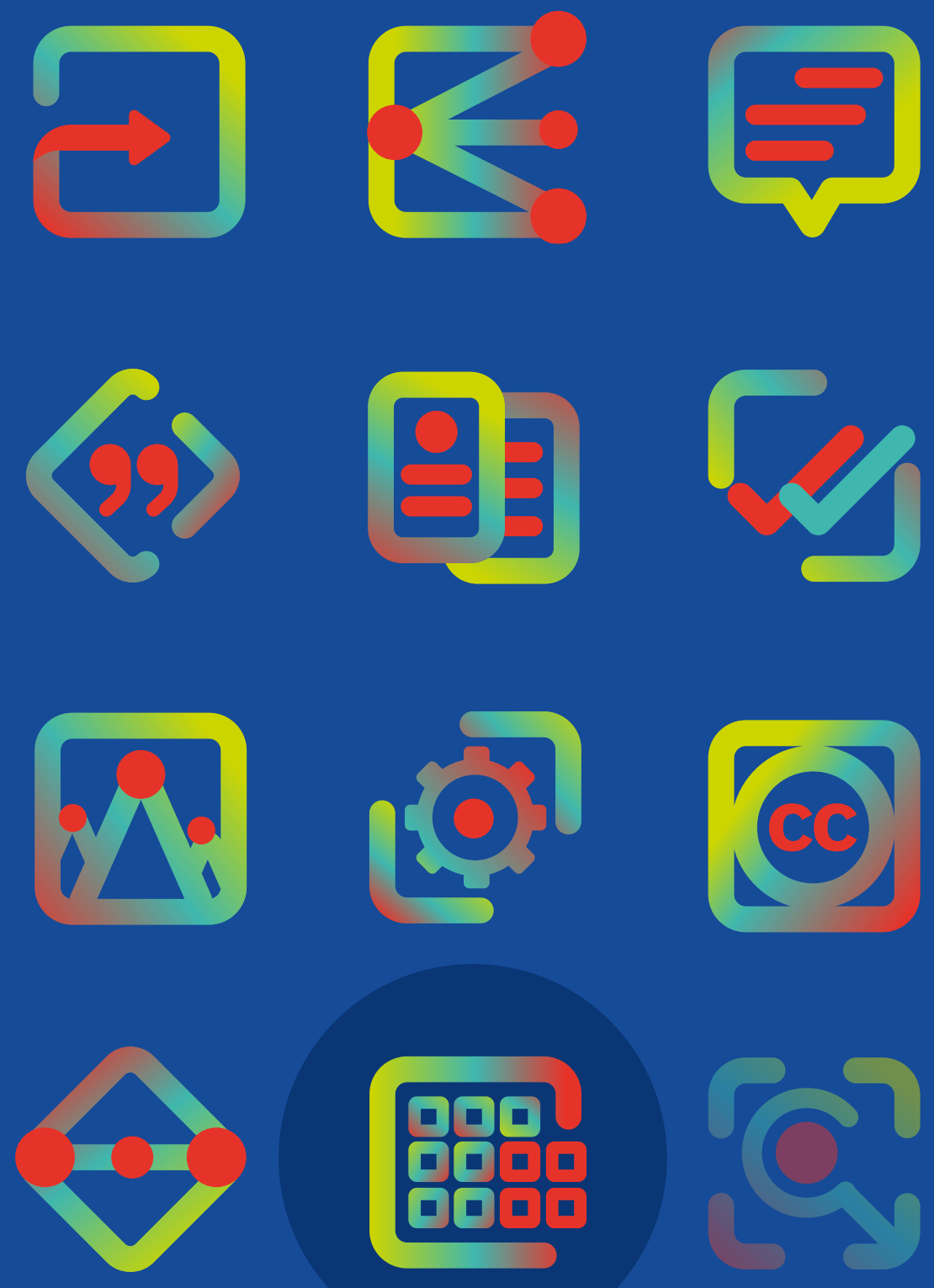


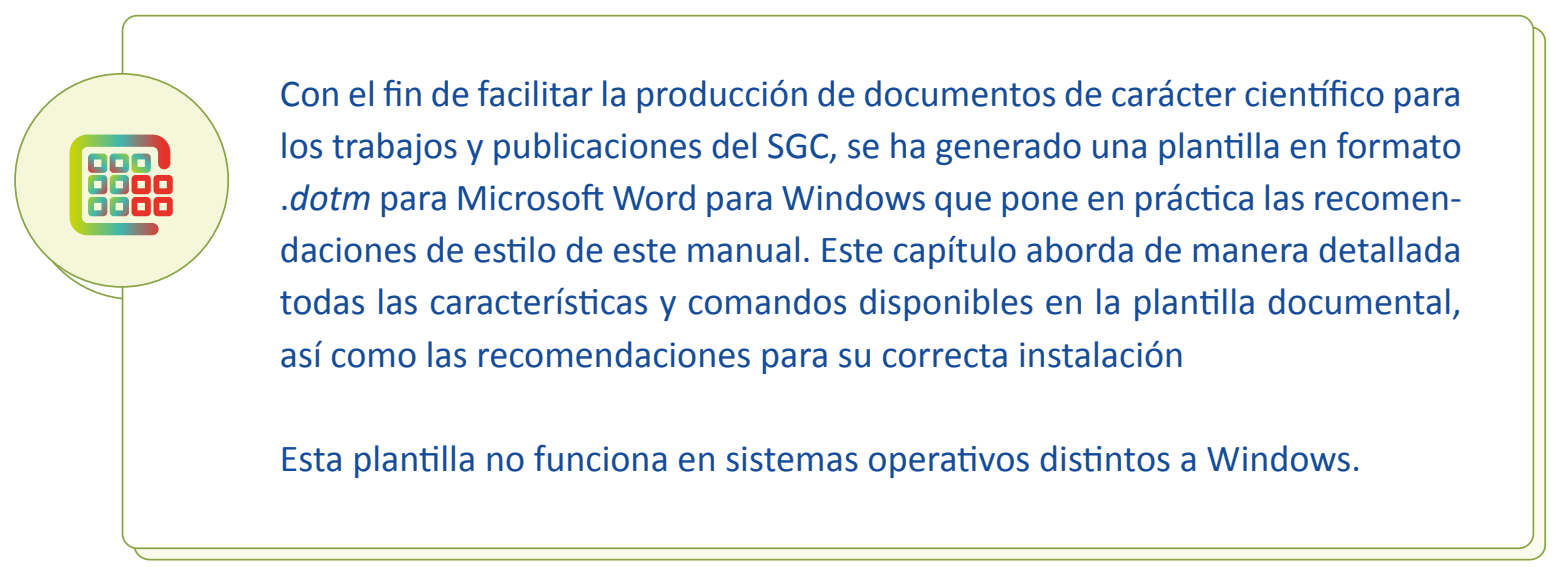

\subsection{Generalidades de la plantilla}

La plantilla del SGC es un documento en blanco, similar a la plantilla Normal.dotm de Word en la que visiblemente solo se tiene una página indicativa de portada y una segunda página de contenidos del texto, sin ningún logo o figura adicional; sin embargo, en el momento de abrirla se genera un archivo que cumple con las indicaciones de formato del Manual de estilo, comenzando por el tamaño del papel, las márgenes y los diversos estilos de texto que se emplean en documentos del SGC. La plantilla incluye también algunas macros programadas que facilitan tareas dispendiosas como dar formato a tablas, estructurar y generar títulos y numerar figuras, tablas, mapas y anexos.

Los estilos de la plantilla están disponibles en la galería de estilos del menú Inicio, que contiene exclusivamente los que se deben usar. Esto facilita su navegación, pues evita la visualización de estilos no necesarios.

No obstante, si se abre un documento realizado con base en otra plantilla, o se pega texto producido en ella, los estilos usados en ese documento aparecerán en la galería de estilos del documento.

Aparte del estilo de texto normal, encontrará los diversos niveles de títulos, que le otorgan a cada uno de ellos sus rasgos de formato particulares y le permiten una numeración automática en secuencia consecutiva a lo largo del texto, así se interpongan títulos de otros niveles o muchas páginas de texto. Esta característica también se aplica para las figuras, las tablas, los mapas y los anexos.

Para aplicar esta plantilla a documentos creados con plantillas distintas, simplemente cree un nuevo documento y copie en él todos los contenidos que provienen de los otros documentos. Inmediatamente podrá utilizar las funcionalidades en el nuevo documento y aplicarlos a los contenidos anteriormente elaborados.

Un ejemplo de aplicación de esta plantilla es justamente el presente manual cuyo manuscrito ha sido preparado mediante su uso en el programa Microsoft Word. 


\subsection{Características principales y comandos para la plantilla}

La plantilla facilita al usuario ciertas tareas que resultan engorrosas por su complejidad o por la cantidad de pasos que se deben ejecutar para obtener los resultados deseados. Estas tareas se realizan mediante una buena cantidad de macros que, con la simple combinación de unas cuantas teclas, reducen a una sola operación las tareas que requerirían múltiples operaciones.

Las macros se han dividido en varios grupos, según su naturaleza:

- Relacionados con estilos de títulos: permite acceder a los estilos de títulos con la combinación de la tecla control más el número del respectivo nivel del título, lo que facilita su memorización.

- Relacionados con los estilos de texto y listas: permiten acceder a los estilos del texto normal y opciones para listas con viñetas.

- Relacionados con signos matemáticos y letras griegas: crea atajos de teclado para poner al alcance de los autores ciertos signos usados en matemáticas y letras griegas de uso corriente en el ámbito científico.

- Relacionados con los tipos de espacios: genera una combinación de teclas para generar los espacios finos, duros, superfinos, etc.

- Relacionados con formatos y acciones que requieren programación más compleja: estas actividades tienen varios pasos que automatizan acciones rutinarias.

En general, para facilitar la memorización, se ha procurado que la distribución de teclas utilizadas en los diversos comandos, sobre todo cuando se trata de obtener símbolos, sea lo más intuitiva posible.

En cuanto a la obtención de signos que no se encuentran en el teclado, pero cuyo uso es frecuente, y que hasta ahora obligaba a los autores a memorizar intrincados códigos numéricos para producirlos o a realizar búsquedas en la red, resulta más fácil aprender a escribirlos mediante combinaciones de dos teclas.

Para entender los comandos disponibles en la plantilla conviene tener presente las siguientes aclaraciones:

1) Todas las funcionalidades de la plantilla estarán vigentes solo si la plantilla Normal.dotm de Word es reemplazada por la nueva plantilla Normal.dotm del SGC, tal como se indica en la sección 11.4. Para ello es imprescindible que el nombre de la plantilla no sea modificado.

2) El signo "+" que participa en casi todos los atajos de teclado no se escribe, salvo que esté repetido, y el segundo signo esté encerrado en un círculo. Si no está encerrado, indica superposición o simultaneidad de teclas.

3) Los números incluidos en los comandos, deben escribirse, en todos los casos, en el teclado alfabético, no en el teclado numérico. Esto quiere decir que los números a que se refieren los comandos son los que se encuentran en la parte superior, debajo de las teclas de funciones F1 a F10.

4) Todos los títulos obtenidos con comandos pueden activarse desde la galería de estilos, en el menú Inicio, salvo los estilos para título de tabla, título de figura, título de mapa y título de anexo, que por ser elementos que se indizan para producir referencias cruzadas, se diseñan de 
modo diferente a un estilo corriente de texto. Esos tres estilos solo se consiguen mediante los comandos que se muestran más adelante.

5) En los comandos en los que participa Alt, esta tecla no es intercambiable por AltGr. En los que participa May (mayúscula) o Shift, esta no es intercambiable por BloqMay.

6) El asterisco entre paréntesis al final de un comentario indica que el comando pertenece a la plantilla Normal.dotm de Word, así que también puede utilizarse en un documento creado con esa plantilla. Los demás comandos solo funcionan en documentos creados con la plantilla del SGC.

\subsubsection{Comandos de la plantilla relacionados con estilos de títulos}

En la figura 64 se muestran las teclas involucradas en los diferentes comandos y la forma de llamarlas en este manual.

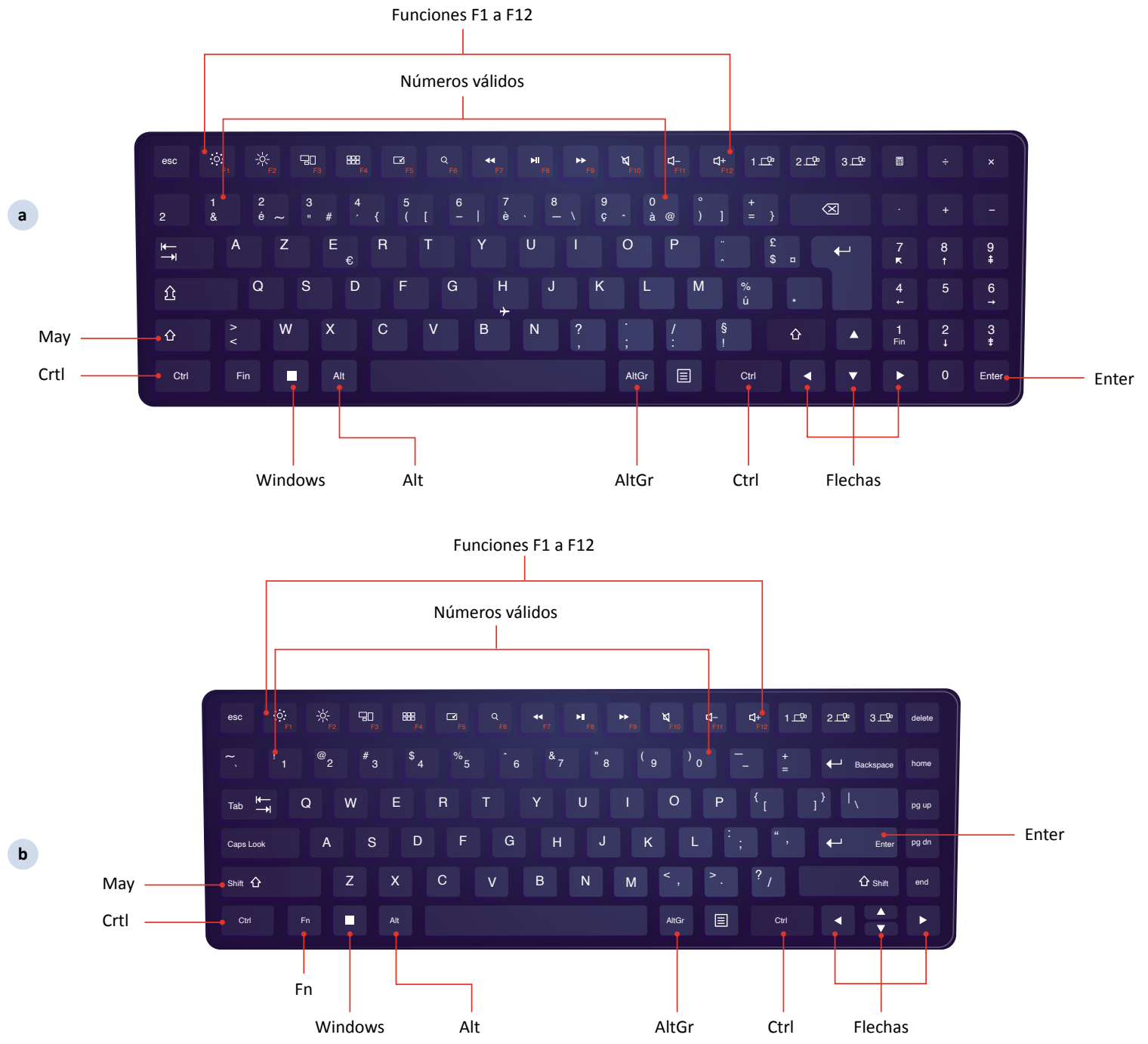

Figura 64. Ubicación de las teclas usadas para los comandos de la plantilla

a) Teclado de computador de escritorio; b) Teclado de computador portátil. 
Para la descripción de los comandos de esta sección, se usarán los nombres de las teclas más comunes en los teclados, incluyendo el uso de las letras en mayúsculas, sin que ello signifique que deban escribirse como mayúsculas. De la misma manera, estos comandos se escribirán sin cursiva para lograr una apariencia más familiar. Es de anotar que el comando AltGr es equivalente a las dos teclas Ctrl + Alt. Por tanto, el comando AltGr + A es equivalente a Ctrl + Alt + A.

En la tabla 41 se muestran los comandos con los que se fijan los distintos niveles de títulos, sus estilos y un comentario explicativo.

Tabla 41. Comandos de estilos de títulos

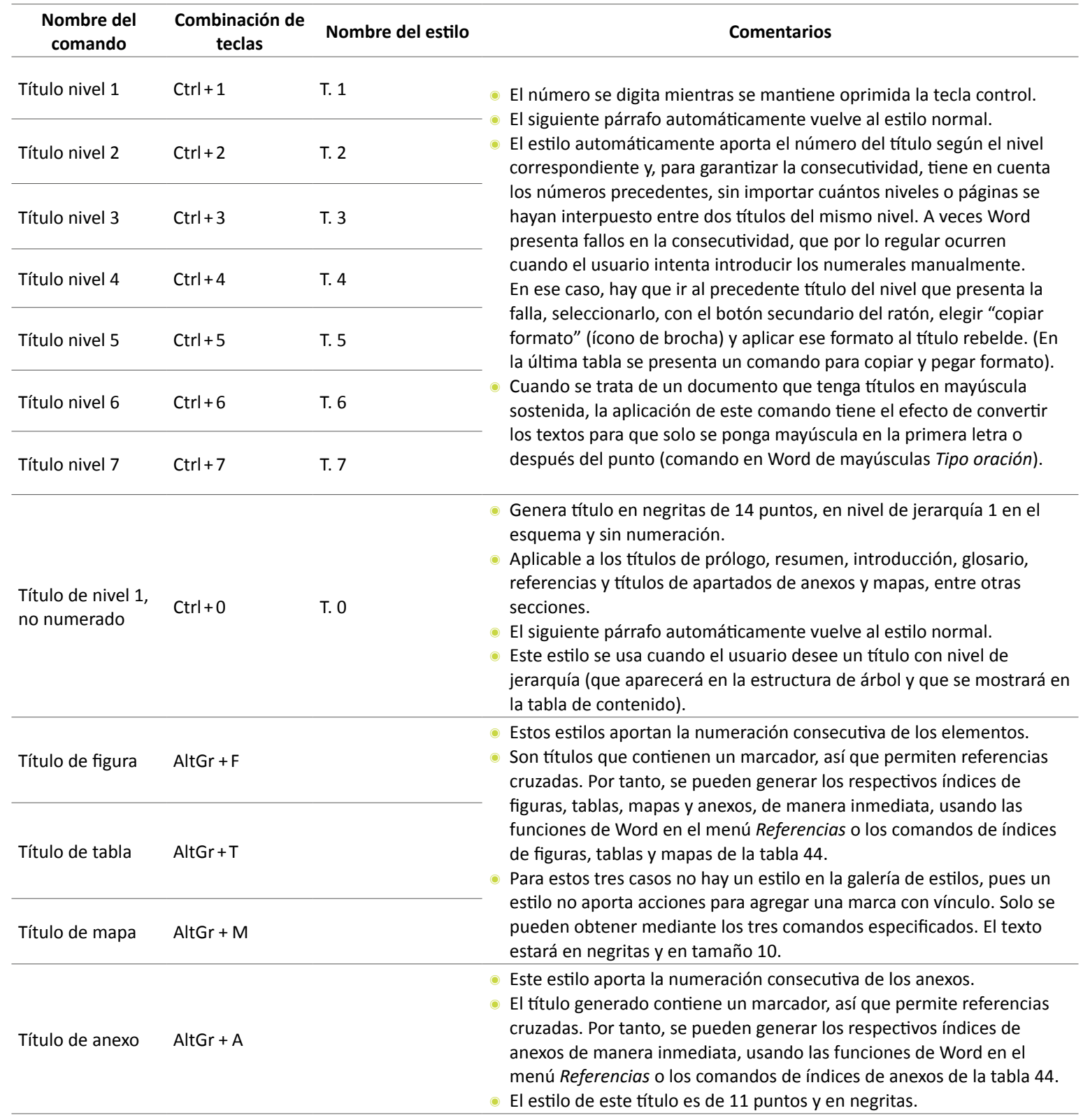




\begin{tabular}{|c|c|c|c|}
\hline $\begin{array}{l}\text { Nombre del } \\
\text { comando }\end{array}$ & $\begin{array}{c}\text { Combinación de } \\
\text { teclas }\end{array}$ & Nombre del estilo & Comentarios \\
\hline $\begin{array}{l}\text { Nota de figura o } \\
\text { tabla }\end{array}$ & AltGr $+\mathrm{N}$ & & $\begin{array}{l}\text { Selecciona el estilo de Notas (Calibri 10, sin negritas y justificado), } \\
\text { utilizado para las notas de tablas y figuras (textos escritos debajo de la } \\
\text { tabla o debajo del título de la figura). }\end{array}$ \\
\hline
\end{tabular}

Es de anotar que los distintos niveles de título generados con la plantilla no solo se asocian con tipos y tamaños de letra y reglas de numeración, sino que también tienen asociada una estructura jerárquica que puede ser apreciada en la vista de esquema del programa Word. Para comprobar esta situación, una vez generados los distintos títulos, puede entrar a Vista/Esquema y aprovechar las ventajas de manejar los contenidos con esquemas estructurados y con el panel de navegación, haciendo uso de la opción de títulos como se observa en la figura 65.

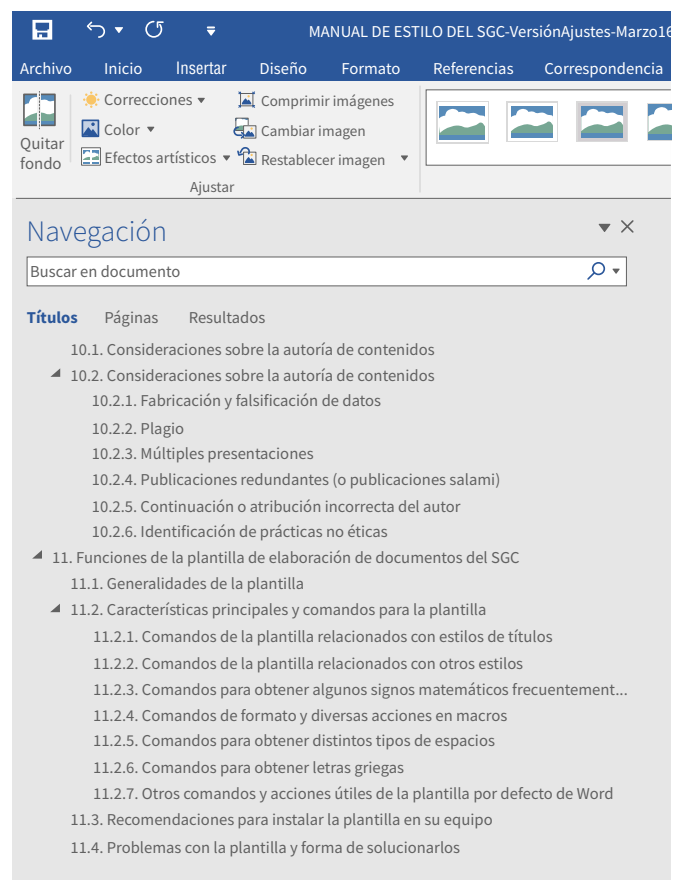

Figura 65. Panel de navegación de Word con visualización de la estructura del documento

\subsubsection{Comandos de la plantilla relacionados con el texto normal y estilos para listas}

La tabla 42 muestra comandos para los estilos del texto normal y opciones para listas mediante viñetas.

Tabla 42. Comandos para el texto normal y estilos de viñetas para listas

\begin{tabular}{|c|c|c|c|}
\hline $\begin{array}{c}\text { Nombre } \\
\text { del comando }\end{array}$ & $\begin{array}{l}\text { Combinación de } \\
\text { teclas }\end{array}$ & $\begin{array}{l}\text { Nombre } \\
\text { del estilo }\end{array}$ & Comentarios \\
\hline Estilo normal & Ctrl +0 & Normal & Estilo de texto corriente. \\
\hline Sangría francesa & $\mathrm{Ctrl}+8$ & SangFrancesa & Produce una sangría francesa de $1 \mathrm{~cm}$. Se puede usar en glosarios. \\
\hline Estilo cita & $\mathrm{Ctrl}+9$ & Citas & $\begin{array}{l}\text { Estilo de cita en párrafo aparte: mayor sangría de todo el párrafo, fuente } 11 \\
\text { puntos, justificación izquierda con sangría de } 2,5 \mathrm{~cm} \text {. }\end{array}$ \\
\hline
\end{tabular}




\begin{tabular}{|c|c|c|c|}
\hline $\begin{array}{c}\text { Nombre } \\
\text { del comando }\end{array}$ & $\begin{array}{l}\text { Combinación de } \\
\text { teclas }\end{array}$ & $\begin{array}{l}\text { Nombre } \\
\text { del estilo }\end{array}$ & Comentarios \\
\hline $\begin{array}{l}\text { Título general } \\
\text { independiente de } \\
\text { esquema }\end{array}$ & $\mathrm{Ctrl}+{ }^{\prime}$ & T. G & $\begin{array}{l}\text { Genera un título en negritas, centrado, } 14 \text { puntos, sin nivel de esquema y } \\
\text { sin numeración. } \\
\text { Apropiado para el título general y cualquier título independiente como } \\
\text { índice de figuras, índice de tablas, índice de anexos e índice de mapas, entre } \\
\text { otros. }\end{array}$ \\
\hline \multirow{2}{*}{$\begin{array}{l}\text { Lista nivel } 1 \text { en } \\
\text { viñetas } \\
\text { Lista nivel } 2 \text { en } \\
\text { viñetas }\end{array}$} & AltGr +1 & Viñ 1 & $\begin{array}{l}\text { En texto normal, las listas con viñetas se han previsto con dos niveles de } \\
\text { subordinación (cambian el topo y la sangría). }\end{array}$ \\
\hline & AltGr +2 & Viñ 2 & El estilo del siguiente párrafo es el mismo del respectivo nivel de la viñeta. \\
\hline $\begin{array}{l}\text { Lista en tabla } \\
\text { nivel } 1 \\
\text { Lista en tabla } \\
\text { nivel } 2\end{array}$ & AltGr + 6 & Viñ 6 & $\begin{array}{l}\text { Son dos niveles de listas, y solo se deben usar en tablas: tienen topos más } \\
\text { pequeños, sangría reducida, cuerpo de letra menor y justificación a la } \\
\text { izquierda. }\end{array}$ \\
\hline
\end{tabular}

\subsubsection{Comandos para obtener signos matemáticos y letras griegas}

Con el fin de evitar la búsqueda repetitiva de signos matemáticos en los menús de Word, en la tabla 43 se muestran los comandos para los signos más utilizados.

Tabla 43. Comandos para obtener algunos signos matemáticos utilizados en documentos del SGC

\begin{tabular}{|c|c|c|c|}
\hline Nombre del comando & Representación & Combinación de teclas & Comentarios \\
\hline & & & El signo menos (-) es diferente del guion (-) \\
\hline Signo menos & - & Alt + May + - & $\begin{array}{l}\text { En un teclado numérico también se puede conseguir con } \\
\operatorname{Ctrl}+-\left({ }^{*}\right)\end{array}$ \\
\hline División & $\div$ & Alt + : & \\
\hline Multiplicación & $x$ & Alt $+x$ & $\begin{array}{l}\text { El signo por es más achatado, pequeño y verticalmente } \\
\text { centrado que una letra } x\end{array}$ \\
\hline Multiplicación & $*$ & Alt + May $+*$ & $\begin{array}{l}\text { El asterisco de multiplicación se sitúa a media altura y es más } \\
\text { grande que el asterisco de texto }\end{array}$ \\
\hline Raíz cuadrada & V & Alt + V & \\
\hline Más/menos & \pm & Alt $+\oplus$ & Alt y el signo más (+) \\
\hline Cantidad aproximada & $\sim$ & Alt $+\tilde{N}$ & $\begin{array}{l}\text { El signo matemático } \sim \text { es diferente de la virgulilla ( ), con la } \\
\text { que suele ser suplantado }\end{array}$ \\
\hline $\begin{array}{l}\text { Aproximadamente } \\
\text { igual a }\end{array}$ & $\approx$ & AltGr $+\tilde{N}$ & \\
\hline Congruente con & $\cong$ & Alt + May + N & \\
\hline Diferente de & $\neq$ & Alt $+=$ & El igual está situado en la misma tecla que el cero \\
\hline Cerillo de grados & $\circ$ & Alt $+\underline{o}$ & $\begin{array}{l}\text { Hay varios tipos de cerillos }\left(0^{\circ},{ }^{\circ},{ }^{\circ}\right) \text {. Esta macro proporciona } \\
\text { el símbolo usado en ciencias para los grados }\end{array}$ \\
\hline Menor o igual & $\leq$ & Alt $+<$ & \\
\hline Mayor o igual & $\geq$ & Alt + May $+<$ & \\
\hline Tanto por mil & $\%$ & Alt $+\%$ & \\
\hline Raya & - & AltGr + - & $\begin{array}{l}\text { Cumple las funciones de los paréntesis en textos y es más } \\
\text { larga que el signo menos }\end{array}$ \\
\hline Flecha izquierda & $\leftarrow$ & Alt $+\leftarrow$ & Genera la flecha hacia la izquierda \\
\hline Flecha derecha & $\rightarrow$ & Alt $+\rightarrow$ & Genera la flecha hacia la derecha \\
\hline Flecha arriba & $\uparrow$ & Alt $+\uparrow$ & Genera la flecha hacia arriba \\
\hline Flecha abajo & $\downarrow$ & Alt $+\downarrow$ & Genera la flecha hacia abajo \\
\hline
\end{tabular}

$(*)$ Disponible en la plantilla de Word por defecto.

Por otra parte, en la tabla 44 se resumen las letras griegas para ecuaciones matemáticas u otros usos. 
Tabla 44. Comandos para obtener las letras griegas más usadas en ciencias

\begin{tabular}{|c|c|c|c|}
\hline Nombre de la letra & Representación & Combinación de teclas & Comentarios \\
\hline Alfa & $\alpha$ & Alt + A & \multirow{6}{*}{$\begin{array}{l}\text { Para facilitar la memorización, se ha procurado que el } \\
\text { comando de cada letra sea la combinación de Alt más la } \\
\text { inicial del nombre de la letra. }\end{array}$} \\
\hline Beta & $\beta$ & Alt $+B$ & \\
\hline Delta & $\delta$ & Alt $+D$ & \\
\hline Épsilon & $\varepsilon$ & Alt $+E$ & \\
\hline Eta & $\eta$ & Alt $+N$ & \\
\hline $\mathrm{Fi}$ & $\varphi$ & Alt $+F$ & \\
\hline Gamma & $\gamma$ & Alt + G & \multirow{3}{*}{$\begin{array}{l}\text { Épsilon }(\varepsilon) \text { y eta }(\eta) \text { comienzan por "e", así que eta se la } \\
\text { ha ubicado en la " } n \text { ", dado su parecido con esta letra. }\end{array}$} \\
\hline Lambda & $\lambda$ & Alt $+\mathrm{L}$ & \\
\hline $\mathrm{Mi}$ & $\mu$ & $A l t+U$ & \\
\hline Sigma & $\Sigma$ & Alt $+S$ & \multirow{5}{*}{$\begin{array}{l}\text { Tau }(\tau) \text { y theta }(\theta) \text { comparten la " } \mathrm{t} \text { ", así que theta se ha } \\
\text { ubicado en la " } \mathrm{O} \text { ", dado su parecido con esta letra. }\end{array}$} \\
\hline Tau & $\tau$ & Alt $+\mathrm{T}$ & \\
\hline Rho & $\rho$ & Alt $+R$ & \\
\hline Theta & $\theta$ & Alt +0 & \\
\hline $\mathrm{Pi}$ & $\pi$ & Alt $+P$ & \\
\hline
\end{tabular}

\subsubsection{Comandos para obtener distintos tipos de espacios}

En la tabla 45 se resumen los distintos tipos de espacios sin recurrir a los códigos ASCII.

Tabla 45. Comandos para obtener distintos tipos de espacios

\begin{tabular}{|c|c|c|}
\hline Nombre del comando & Combinación de teclas & Comentarios \\
\hline $\begin{array}{l}\text { Espacio duro o de no } \\
\text { separación }\end{array}$ & Ctrl + May + espacio & $\begin{array}{l}\text { Espacio de longitud normal que mantiene unidas las palabras entre las } \\
\text { que se interpone. Se usa entre números y sus unidades de medida, en } \\
\text { expresiones matemáticas que deben permanecer como un bloque al tiempo } \\
\text { que sus elementos se mantienen separados, y en las bibliografías, entre } \\
\text { los apellidos de los autores y las iniciales de sus respectivos nombres, para } \\
\text { evitar que un apellido quede en un renglón y las iniciales en otro (*). }\end{array}$ \\
\hline Espacio fino & AltGr + espacio & $\begin{array}{l}\text { Es un espacio duro un poco menor que el espacio corriente. Se usa entre } \\
\text { elementos que no se quiere que se vean muy separados, como entre los } \\
\text { signos de porcentaje y de pesos y los números con ellos relacionados, o } \\
\text { entre las letras separadas por puntos de las siglas. En algunos casos, se } \\
\text { puede usar para separar miles o números muy grandes, de difícil lectura, en } \\
\text { grupos de cifras suficientemente perceptibles por el ojo. (Nota: en números } \\
\text { de cuatro cifras no se usa ninguna separación). }\end{array}$ \\
\hline Espacio superfino & Ctrl + espacio & $\begin{array}{l}\text { Es un espacio duro muy fino. Se usa para separar miles o números muy } \\
\text { grandes, de difícil lectura, en grupos de cifras suficientemente perceptibles } \\
\text { por el ojo. (Nota: en números de cuatro cifras no se usa ninguna separación). }\end{array}$ \\
\hline Guion de no separación & Ctrl + May + - & $\begin{array}{l}\text { Se utiliza cuando al final de un renglón hay dos elementos unidos con guion, } \\
\text { para evitar que queden en dos renglones diferentes }(*) \text {. }\end{array}$ \\
\hline
\end{tabular}

Nota: $\left({ }^{*}\right)$ Disponible en la plantilla de Word por defecto.

\subsubsection{Comandos de formato y diversas acciones en macros}

La tabla 46 muestra las funciones programadas en Visual Basic para Aplicaciones (VBA) para Office que ejecutan varias operaciones, las cuales se utilizan de manera repetida en la edición de textos científicos. 
Tabla 46. Comandos de formato y diversas acciones en macros

\begin{tabular}{|c|c|c|}
\hline Nombre del comando & Combinación de teclas & Comentarios \\
\hline Formato básico de tabla & $\mathrm{F} 2$ & $\begin{array}{l}\text { Una vez seleccionada la tabla, con la tecla F2 (Fn + F2 en algunos portátiles) se } \\
\text { obtiene lo siguiente: } \\
\text { Alineación a la izquierda del texto y centrada en el encabezado; } \\
\text { Tamaño de fuente, distribución de negritas y blancas, líneas básicas (superior } \\
\text { e inferior de la tabla, y bajo la primera fila), centrado vertical del contenido, } \\
\text { repetición del encabezado en nuevas páginas (si la tabla excede de una) y } \\
\text { autoajuste del ancho de las columnas de acuerdo con el texto. Fija el tamaño } \\
\text { de letra en } 10 \text { puntos (pero esto se puede cambiar luego por el usuario). } \\
\text { Para tablas ya elaboradas y que tengan celdas combinadas, distintos colores de } \\
\text { celdas o de texto, al aplicar este comando se respetarán estas condiciones. Por } \\
\text { esta razón, se puede aplicar de manera segura sin afectar los contenidos y los } \\
\text { efectos de visualización que un autor haya concebido con anterioridad. } \\
\text { Se sugiere armar la tabla con los datos o importarla de Excel, inicialmente sin } \\
\text { poner mayor cuidado a detalles de formato o presentación, pues todos serán } \\
\text { ajustados al aplicar la macro. } \\
\text { Para tablas que tengan particularidades como celdas combinadas y subtítulos, } \\
\text { el usuario podrá realizar los ajustes que considere, después de la aplicación del } \\
\text { comando. Sin embargo, la mayoría de los parámetros generales exigidos en el } \\
\text { manual quedarán ajustados con esta macro. } \\
\text { La ejecución de este comando no incluye la asignación de título ni las notas de } \\
\text { la tabla. Estas operaciones se generan con otros comandos que se pueden ver } \\
\text { en la tabla } 41 .\end{array}$ \\
\hline $\begin{array}{l}\text { Cambio de sección de } \\
\text { página vertical a apaisada } \\
\text { y viceversa }\end{array}$ & F3 & $\begin{array}{l}\text { Con la tecla F3 (Fn + F3 en algunos portátiles) se introduce un salto de sección } \\
\text { y se cambia la orientación de la página. Esta función es útil cuando tablas o } \\
\text { figuras muy anchas así lo exigen. }\end{array}$ \\
\hline Duplicar ventana & $\mathrm{F} 4$ & $\begin{array}{l}\text { Con la tecla F4 (Fn + F4 en algunos portátiles) el documento se duplica, así que } \\
\text { se puede navegar en una ventana mientras en la otra se conserva la posición } \\
\text { inicial. }\end{array}$ \\
\hline Dividir ventana & AltGr + V & $\begin{array}{l}\text { La ventana del documento se divide horizontalmente en dos, cada cual con } \\
\text { navegación independiente. Con el mismo comando se restaura una sola } \\
\text { ventana, o corriendo manualmente la línea divisoria hacia arriba o hacia abajo, } \\
\text { o dando doble clic en la línea divisoria }\left({ }^{*}\right) \text {. }\end{array}$ \\
\hline MAYÚSCULAS & F5 & $\begin{array}{l}\text { Con la tecla F5 (Fn + F5 en algunos portátiles) y con un texto seleccionado, } \\
\text { pasa todas las letras a mayúsculas. }\end{array}$ \\
\hline Iniciales mayúsculas & F6 & $\begin{array}{l}\text { Con la tecla F6 (Fn + F6 en algunos portátiles) y con un texto seleccionado, } \\
\text { pasa a mayúsculas las iniciales de todas las palabras. }\end{array}$ \\
\hline Mayúscula inicial & F7 & $\begin{array}{l}\text { Con la tecla F7 (Fn + F7 en algunos portátiles) y con un texto seleccionado, } \\
\text { pasa a mayúscula la primera palabra de una oración (después de punto). }\end{array}$ \\
\hline todo en minúsculas & F8 & $\begin{array}{l}\text { Con la tecla F8 (Fn + F8 en algunos portátiles) y con un texto seleccionado, } \\
\text { pasa todo a minúsculas. }\end{array}$ \\
\hline Rechazar cambios & F9 & $\begin{array}{l}\text { Con la tecla F9 (Fn + F9 en algunos portátiles), en un documento con control de } \\
\text { cambios, rechaza los cambios del fragmento de texto seleccionado. }\end{array}$ \\
\hline Aceptar cambios F10 & F10 & $\begin{array}{l}\text { Con la tecla F10 (Fn + F10 en algunos portátiles), en un documento con control } \\
\text { de cambios, valida los cambios del fragmento de texto seleccionado. }\end{array}$ \\
\hline Mantener juntos & F11 & $\begin{array}{l}\text { Con la tecla F11 (Fn + F11 en algunos portátiles), cuando un título queda al } \\
\text { final de una página, se selecciona ese texto y se activa el comando, que evita } \\
\text { que el título quede "viudo" o desvinculado (si después del título hay un párrafo } \\
\text { en blanco, también hay que seleccionarlo). }\end{array}$ \\
\hline Eliminar comentario & F12 & $\begin{array}{l}\text { Con la tecla F12 (Fn + F12 en algunos portátiles) se elimina un comentario en } \\
\text { nota marginal y pasa al siguiente. }\end{array}$ \\
\hline
\end{tabular}




\begin{tabular}{|c|c|c|}
\hline Nombre del comando & Combinación de teclas & Comentarios \\
\hline Tabla de contenido & $\mathrm{Ctrl}+\mathrm{F} 5$ & $\begin{array}{l}\text { Genera una tabla de contenido con títulos de los niveles } 0,1,2 \text { y } 3 \text {, si se } \\
\text { crearon con los comandos Ctrl + } 0, \text { Ctrl }+1, C \operatorname{trl}+2 \text { y Ctrl + 3. El título de } \\
\text { "Contenido" estará centrado, en negritas, en } 14 \text { puntos, sin generar ningún } \\
\text { nivel de esquema (por lo tanto, esta entrada no se reflejará en la tabla de } \\
\text { contenido del documento). }\end{array}$ \\
\hline Índice de figuras & $\mathrm{Ctrl}+\mathrm{F} 6$ & $\begin{array}{l}\text { Genera un índice de figuras si los títulos se crearon con el comando AltGr + } \\
\text { F. El título "Índice de figuras" estará en negritas, centrado, en } 14 \text { puntos, sin } \\
\text { generar ningún nivel de esquema (por lo tanto, esta entrada no se reflejará en } \\
\text { la tabla de contenido del documento). }\end{array}$ \\
\hline Índice de tablas & $\mathrm{Ctrl}+\mathrm{F} 7$ & $\begin{array}{l}\text { Genera un índice de tablas si los títulos si se crearon con el comando AltGr + } \\
\text { T. El título "Índice de tablas" estará en negritas, centrado, en } 14 \text { puntos, sin } \\
\text { generar ningún nivel de esquema (esta entrada no se reflejará en la tabla de } \\
\text { contenido del documento). }\end{array}$ \\
\hline Índice de anexos & $\mathrm{Ctrl}+\mathrm{F} 8$ & $\begin{array}{l}\text { Genera un índice de anexos si los títulos se crearon con el comando AltGr + } \\
\text { A. El título "Índice de anexos" estará en negritas, centrado, en } 14 \text { puntos, sin } \\
\text { generar ningún nivel de esquema (esta entrada no se reflejará en la tabla de } \\
\text { contenido del documento). }\end{array}$ \\
\hline Índice de mapas & $\mathrm{Ctrl}+\mathrm{F9}$ & $\begin{array}{l}\text { Genera un índice de mapas si los títulos se crearon con el comando AltGr + M. } \\
\text { El título de "Índice de mapas" estará en negritas, centrado, en } 14 \text { puntos, sin } \\
\text { generar ningún nivel de esquema (esta entrada no se reflejará en la tabla de } \\
\text { contenido del documento). }\end{array}$ \\
\hline Insertar hipervínculo & AltGr $+K$ & $\begin{array}{l}\text { Abre el cuadro de diálogo con las distintas opciones para vínculos internos en } \\
\text { el documento, o con elementos externos }\left({ }^{*}\right) \text {. }\end{array}$ \\
\hline $\begin{array}{l}\text { Quitar todos los } \\
\text { hipervínculos del texto } \\
\text { seleccionado }\end{array}$ & $\mathrm{Ctrl}+$ May + F9 & Para el texto seleccionado elimina todos los hipervínculos (no el texto) $\left(^{*}\right)$. \\
\hline Citación en Mendeley & $\begin{array}{l}\text { Alt }+M \\
\text { AltGr }+C\end{array}$ & $\begin{array}{l}\text { Cuando se tenga instalado el gestor de Mendeley, ingresa una citación con } \\
\text { base en el listado previamente preparado con Mendeley. Cada citación se hará } \\
\text { con el estilo que se haya seleccionado en dicha aplicación. }\end{array}$ \\
\hline $\begin{array}{l}\text { Listado de referencias del } \\
\text { documento }\end{array}$ & AltGr + R & $\begin{array}{l}\text { Cuando se tenga instalado el gestor de Mendeley, genera la lista de referencias } \\
\text { con base en las referencias ingresadas con el método del comando anterior } \\
\text { (Alt + M o AltGr }+\mathrm{C} \text { ). El título de "Referencias" estará en negritas, centrado, } \\
\text { en } 14 \text { puntos, generando nivel de esquema } 1 \text { (podrá ser citado en la tabla de } \\
\text { contenido). Cada entrada de referencia usará sangría francesa de } 0,85 \mathrm{~cm} \text { con } \\
\text { el estilo de citación que se haya seleccionado en Mendeley. }\end{array}$ \\
\hline Nota al pie & $\begin{array}{l}\text { AltGr+O } \\
\text { AltGr+P }\end{array}$ & $\begin{array}{l}\text { Inserta un número como superíndice y lo referencia en el pie de página para } \\
\text { insertar la nota que corresponda. }\end{array}$ \\
\hline Nota al final & AltGr $+E$ & $\begin{array}{l}\text { Inserta un número en formato de número romano en minúscula, como } \\
\text { superíndice, y lo referencia en el pie de una página final donde aparece la nota } \\
\text { que corresponda. }\end{array}$ \\
\hline Referencia cruzada & AltGr $+X$ & $\begin{array}{l}\text { Activa el cuadro de diálogo para insertar una referencia cruzada de Word, sin } \\
\text { embargo, los detalles del tipo de referencia y el tipo de elemento al que se } \\
\text { hace la referencia deben ser construidos por el usuario. }\end{array}$ \\
\hline Superíndice & $\mathrm{Ctrl}+\theta$ & $\begin{array}{l}\text { Al seleccionar un elemento, este comando lo convierte en superíndice. Vuelve } \\
\text { a normal con el mismo comando }\left({ }^{*}\right) \text {. }\end{array}$ \\
\hline Subíndice & Ctrl + - & $\begin{array}{l}\text { Al seleccionar un elemento, este comando lo convierte en subíndice. Vuelve a } \\
\text { normal con el mismo comando. }\end{array}$ \\
\hline
\end{tabular}

Nota: $\left({ }^{*}\right)$ Disponible en la plantilla de Word por defecto. 


\subsubsection{Otros comandos y acciones útiles de la plantilla por defecto de Word}

Aunque los comandos de la tabla 47 no son exclusivos de la plantilla del SGC, sí están disponibles en la plantilla por defecto de Word y, por tanto, conviene tenerlos presentes.

Tabla 47. Otros comandos y acciones útiles de la plantilla por defecto de Word

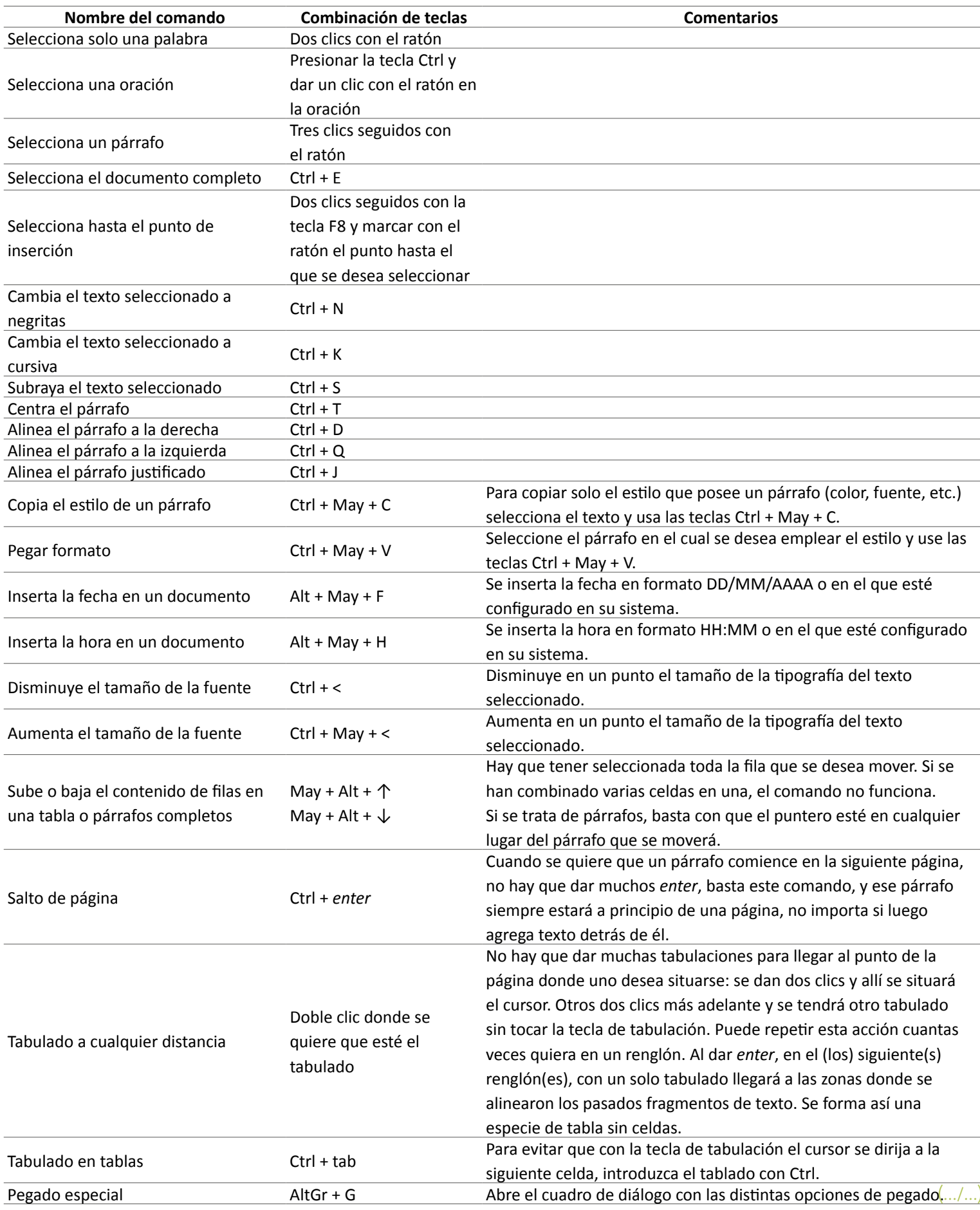




\begin{tabular}{lll}
\hline \multicolumn{1}{c}{ Nombre del comando } & Combinación de teclas & \multicolumn{1}{c}{ Comentarios } \\
$\begin{array}{l}\text { Cambia ancho de columna sin afectar } \\
\text { el ancho de las demás }\end{array}$ & $\begin{array}{l}\text { Clic del ratón sobre la } \\
\text { línea vertical de la tabla } \\
\begin{array}{l}\text { Cambia ancho de columna afectando } \\
\text { el ancho de las demás }\end{array}\end{array}$ & $\begin{array}{l}\text { En las tablas, permite modificar el ancho de una columna sin } \\
\text { cambiar el ancho de las columnas restantes. }\end{array}$ \\
\hline la línea vertical de la tabla la sobre & $\begin{array}{l}\text { En las tablas, permite modificar el ancho de una columna } \\
\text { cambiando el ancho de las columnas restantes de manera } \\
\text { proporcional. }\end{array}$ \\
\hline Control de cambios & Tecla Windows +V & $\begin{array}{l}\text { Útil cuando se quiere pegar algo copiado tiempo atrás, que ha sido } \\
\text { suplantado por otras acciones de copia. }\end{array}$ \\
\hline Salto al escritorio & Ctrl + May + E & Activa o desactiva el control de cambios. \\
\hline Alternancia entre dos aplicaciones & Tecla Windows + D & $\begin{array}{l}\text { Alterna la vista entre el escritorio y la aplicación desde la que se } \\
\text { partió. }\end{array}$ \\
\hline Estadísticas del documento & Ctrl + May + G & $\begin{array}{l}\text { Alterna la vista entre las dos ventanas o vistas más recientemente } \\
\text { frecuentadas. Si continúa presionando, puede alternar con otras } \\
\text { ventanas abiertas. }\end{array}$ \\
\hline
\end{tabular}

Fuente: adaptado de Microsoft (2021).

\subsection{Diccionario de términos especializados en geociencias usados en los últimos años}

En el archivo "LexicoSGC.dic" se incluyen más de tres mil palabras, en su mayoría, de términos especializados de geología y topónimos colombianos usados en documentos del SGC que han sido sometidos a corrección de estilo en los últimos años. Este archivo se encuentra en el archivo PlantillaBase.zip y su instalación se tratará en la sección 11.5. Dicho archivo se puede cargar como diccionario ortográfico personalizado en Word, de manera que, al escribir esos términos, el diccionario ortográfico del programa no los marcará como errores y, si se han escrito mal, sugerirá la ortografía correcta.

De manera complementaria, se invita al lector a consultar, entre otros, los siguientes diccionarios especializados:

- https://pubs.geoscienceworld.org/jgs/article/148/5/825/112311/The-IUGS-systematics-of-igneous-rocks

- https://www.usgs.gov/centers/astrogeology-science-center/glossary-terms

- https://www.nps.gov/parkhistory/online_books/geology/publications/bul/1191/glossary.htm

- https://www.usgs.gov/special-topic/water-science-school/science/dictionary-water-terms

- https://apps.usgs.gov/thesaurus/

- https://www.bgs.ac.uk/technologies/bgs-rock-classification-scheme/

- https://www2.sgc.gov.co/AtencionAlCiudadano/Paginas/Glosario.aspx

\subsection{Recomendaciones para instalar la plantilla en su equipo}

Las plantillas que utiliza Word son instrumentos que hacen la vida más sencilla al usuario; sin embargo, este tipo de archivos están bajo la mira de administradores de sistemas y programas que protegen la seguridad de los recursos informáticos de la institución (antivirus y otros). 
La plantilla del SGC incluye algunos programas que, si no se instala correctamente, pueden ser tomados de manera equivocada por los antivirus como material dañino, pues suponen la inclusión de instrucciones con el potencial de dañar o corromper algunos elementos del sistema.

Los programas de la plantilla constituyen una gran ayuda para simplificar el trabajo de un escritor con elementos que incluyen varias instrucciones. Por lo anterior, es conveniente configurar correctamente su antivirus para evitar que la plantilla sea modificada de manera inconveniente o que sea rechazada por los sistemas antivirus, haciendo que su potencial no pueda ser aprovechado.

Por otra parte, con el fin de que los resultados sean los deseados, es recomendable que cualquiera sea su versión de Office, tenga la última actualización disponible.

\subsubsection{Instalación de la plantilla con antivirus McAfee}

A continuación, se muestra el paso a paso para la instalación de la plantilla, cuando un computador tiene instalado el antivirus McAfee.

1) Cierre su programa de Word.

2) Abra el antivirus y seleccione el botón de Configuración y luego la opción de Análisis en tiempo real.

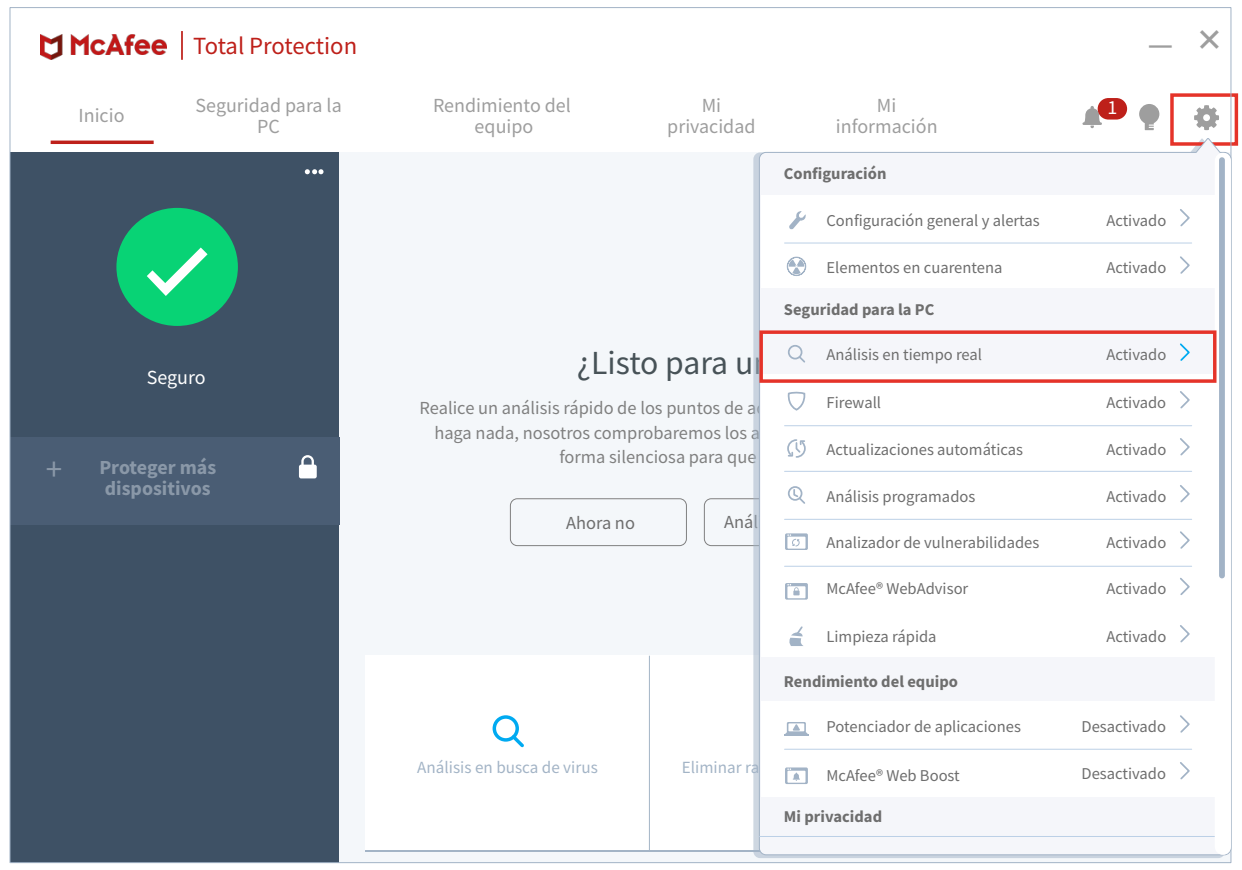

3) Seleccione la opción Desactivar.

4) Confirme la desactivación temporal del análisis del antivirus con la opción Desactivar por 15 minutos para reanudar el análisis en tiempo real. 


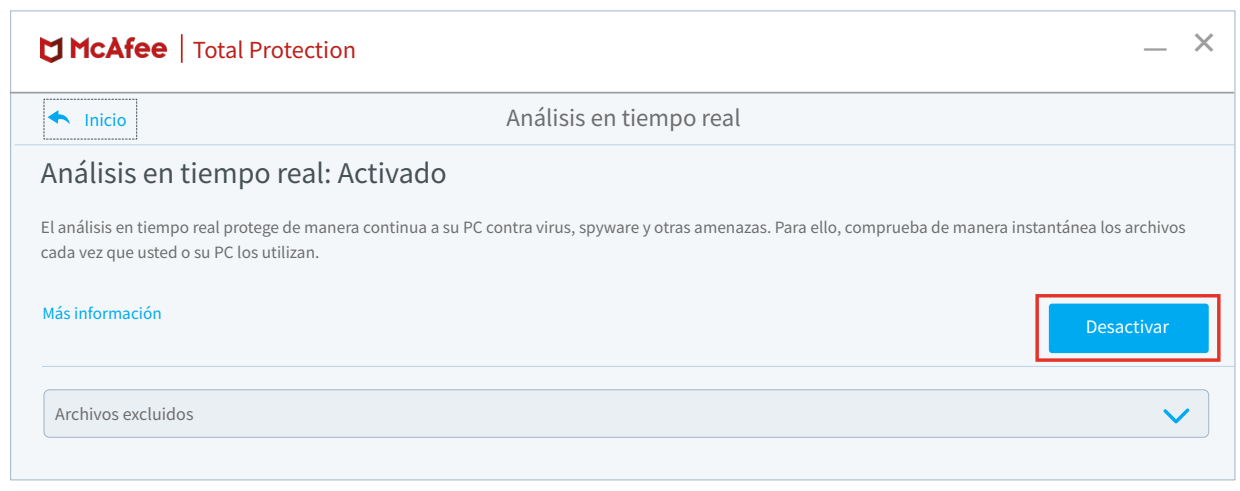

5) Durante el lapso que el antivirus esté desactivado, descargue el archivo PlantillaBase.zip de la dirección https://libros.sgc.gov.co/index.php/editorial/libraryFiles/downloadPublic/1.

6) Cargue el programa Ejecutar con la tecla de Windows + R y escriba appdata, para que abra la ruta donde se reemplazará el archivo. Seleccione Aceptar.

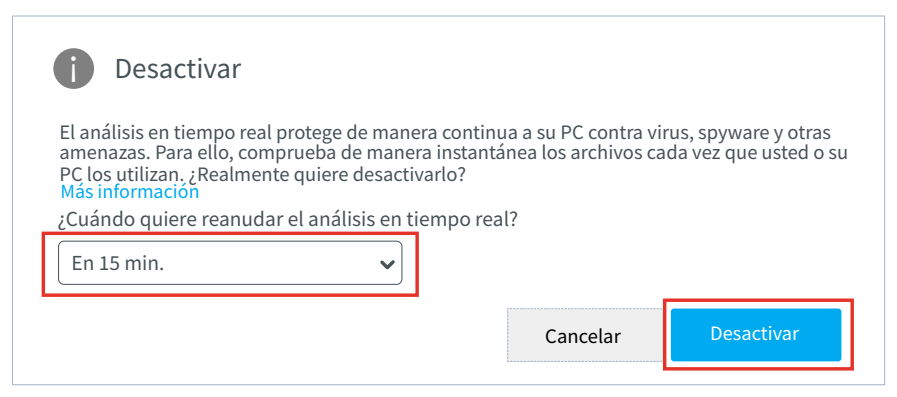

7) Enseguida seleccione el archivo Normal.dotm, que se encuentra dentro del archivo ZIP, e inclú-

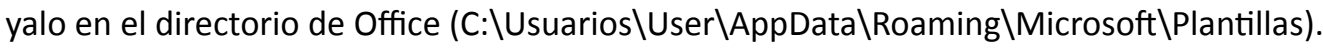

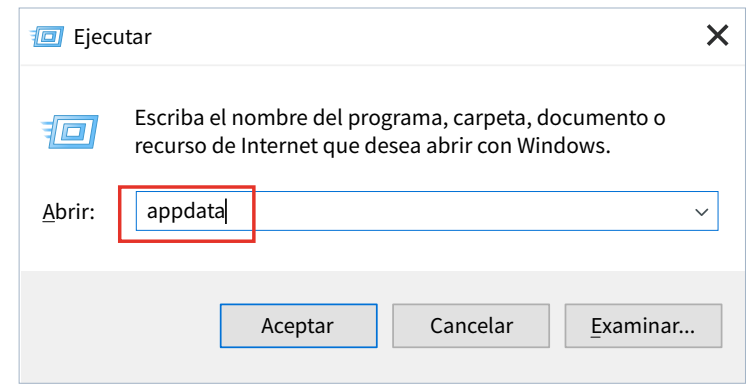

Adicionalmente, si tiene una versión de Office diferente a la de 2016, valide la versión del paquete Office que tiene, ya que para las versiones 2013 y 2019 debe copiar el archivo en la carpeta C:\Usuarios\User\AppData\Roaming\Microsoft \Templates. Esta recomendación también aplica a versiones de Word en idioma inglés.

8) Vaya nuevamente al antivirus y en el mismo menú de Análisis en tiempo real del antivirus, seleccione Archivos excluidos y seleccione Agregar archivo. 


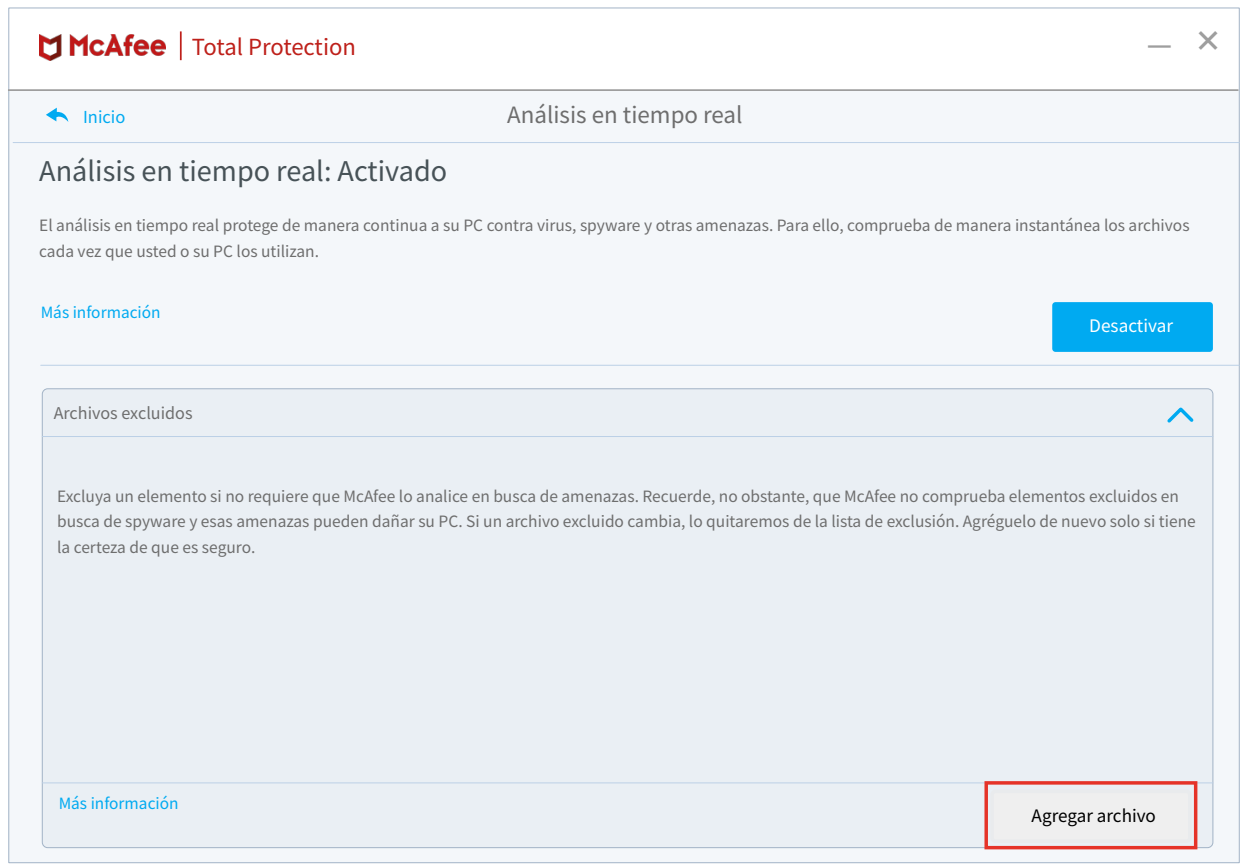

9) Incluya el archivo Normal.dotm en la dirección correspondiente.

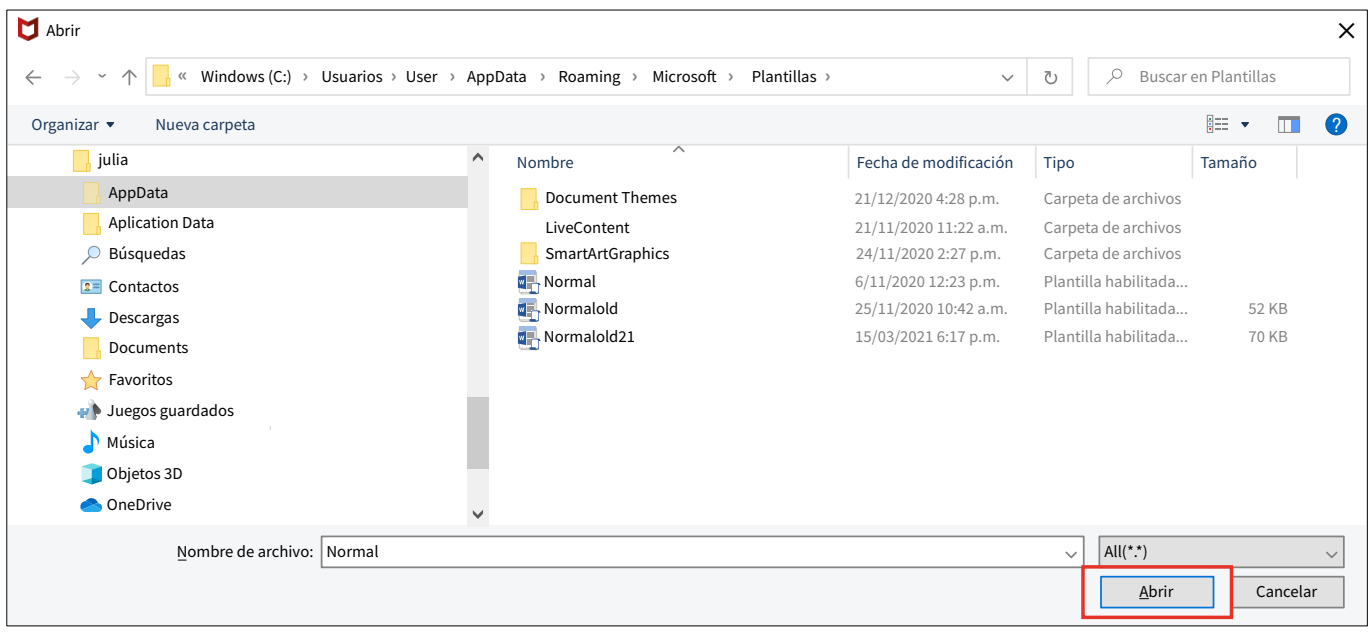

10) Cambie los atributos del archivo Normal.dotm a Solo lectura para evitar cambios indeseados en el futuro. En el explorador de archivos seleccione el archivo Normal.dotm y, con el clic derecho del ratón, cambie el atributo a Solo lectura. 


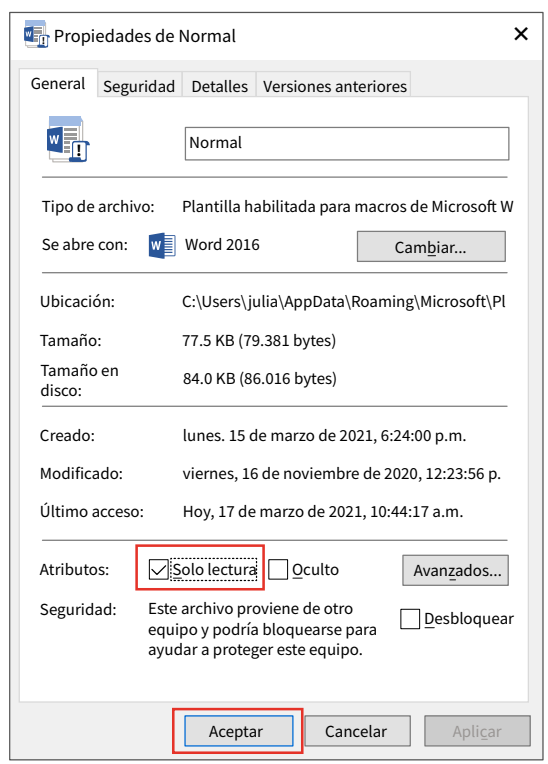

11) Abra el programa Word y asegúrese de que en la opción Archivo/Opciones/Centro de confianza/ Configuración del Centro de Confianza en Configuración de macros esté seleccionada la opción de Habilitar todas las macros. Seleccione el botón Aceptar.

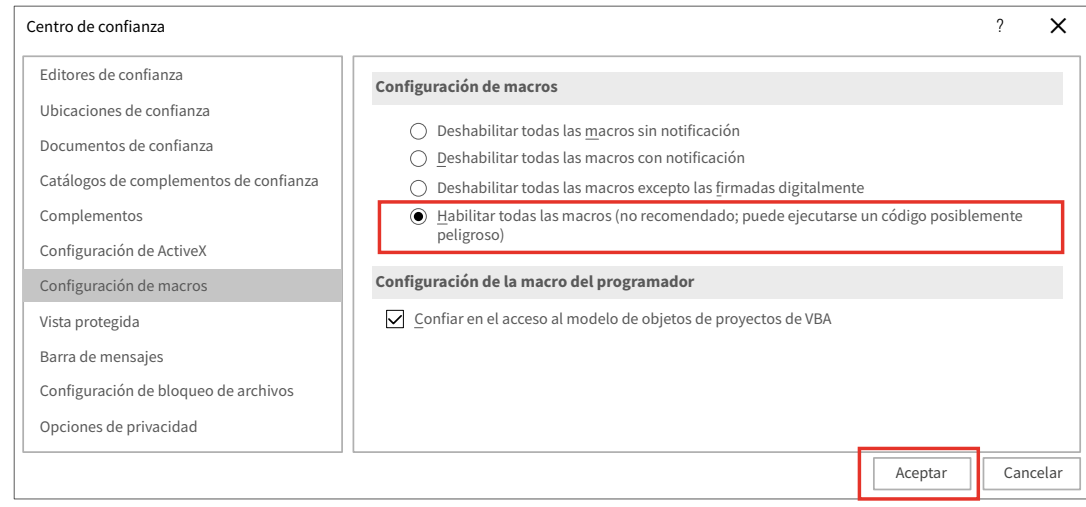

12) Cierre el programa Word y vuelva a abrirlo con un documento nuevo. La plantilla que Word empezará a usar por defecto es la que se ha referido en esta sección. Verifique que los comandos descritos en la sección 11.2. sean funcionales, en particular los que ejecutan programas como F2 (formato básico de tablas) y Ctrl + F5 (tabla de contenido).

\subsubsection{Instalación de la plantilla con antivirus Norton}

A continuación, se muestra el paso a paso para la instalación de la plantilla, cuando un computador tiene instalado el antivirus Norton.

1) Cierre su programa de Word.

2) Abra el antivirus y seleccione Configuración. 


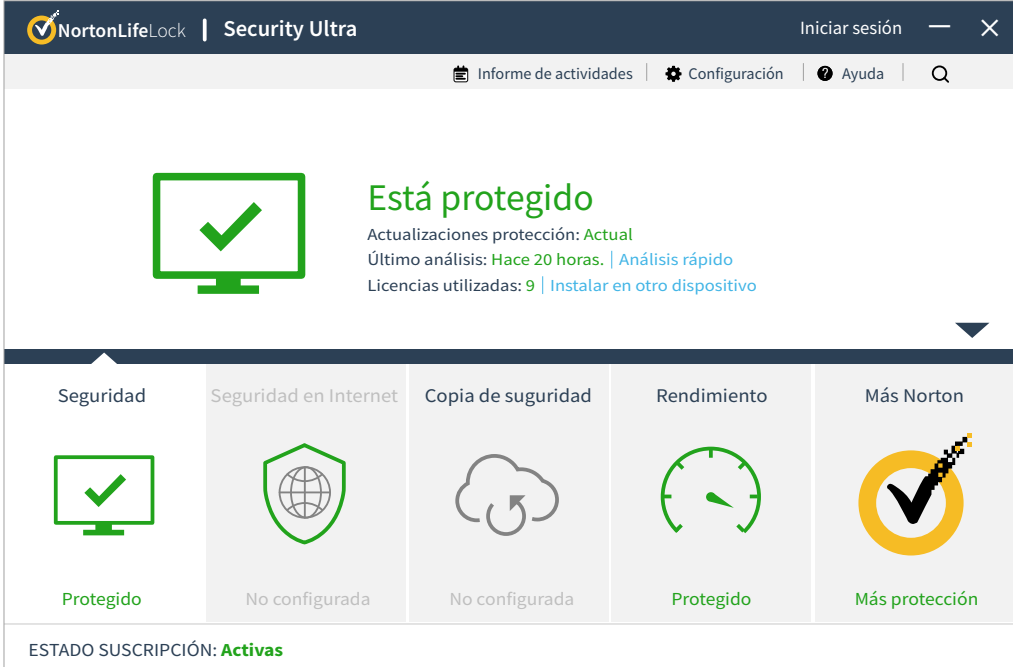

3) Seleccione la opción Antivirus.

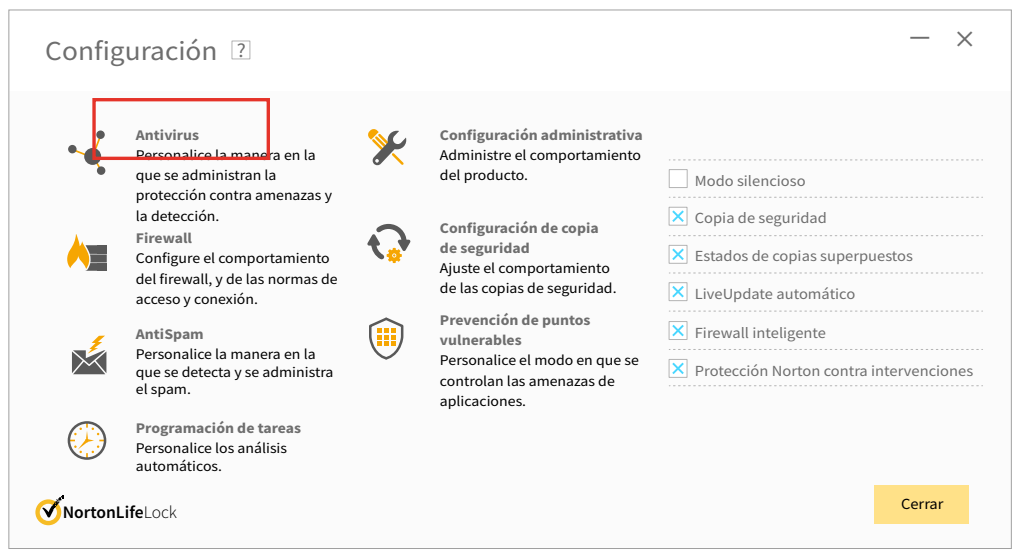

4) Seleccione la pestaña Control de scripts.

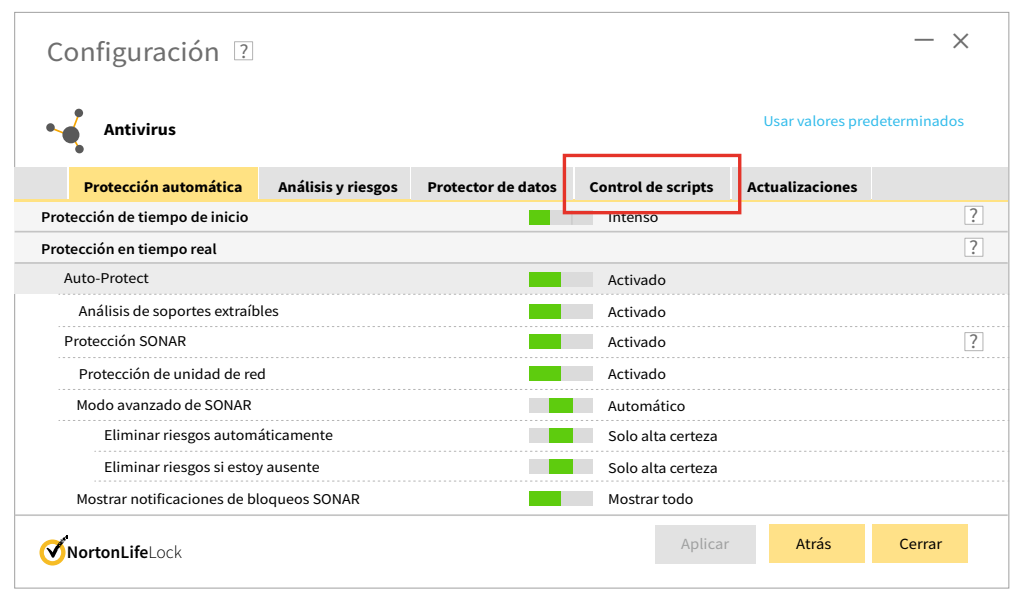

5) Desactive en Control de scripts Eliminar scripts al descargar documentos. El antivirus realiza esta operación de manera temporal (15 minutos o el espacio de tiempo que decida el usuario). 


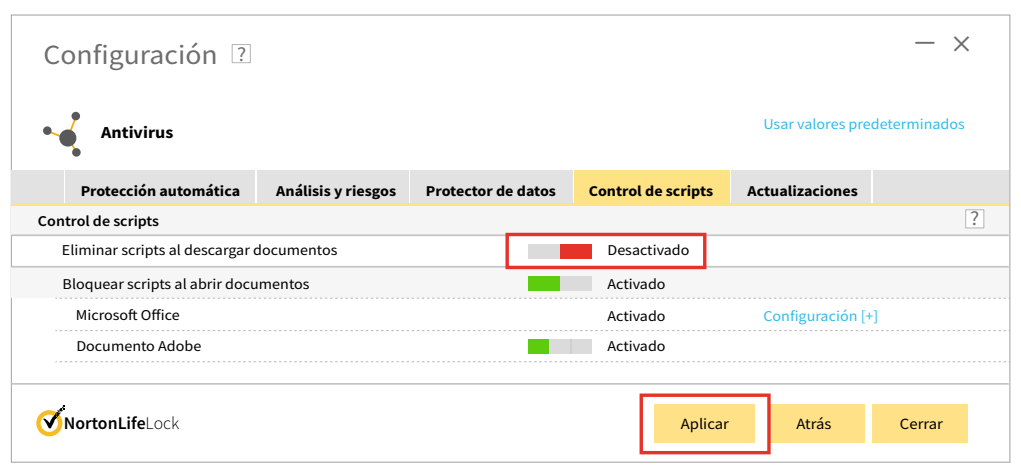

6) Descargue el archivo plantillabase.zip de la dirección https://libros.sgc.gov.co/index.php/editorial/libraryFiles/downloadPublic/1.

7) Inicie la función Ejecutar con la tecla de Windows + R y escribir appdata, para que abra la ruta donde se reemplazará el archivo.

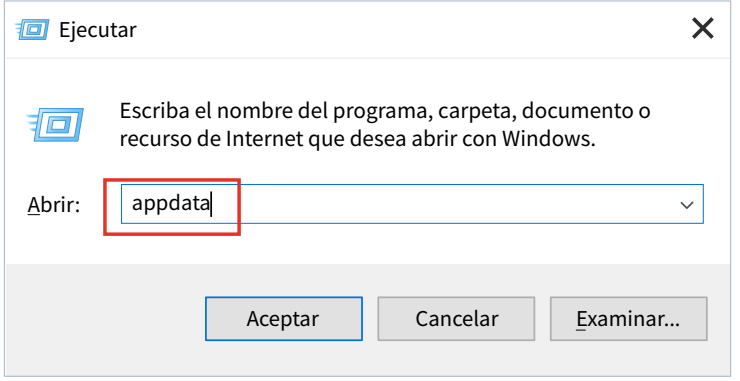

8) Enseguida seleccione el archivo Normal.dotm, que se encuentra dentro del archivo ZIP, y cópielo en el directorio de Office (C:〈Usuarios\User\AppData\Roaming \Microsoft\Plantillas).

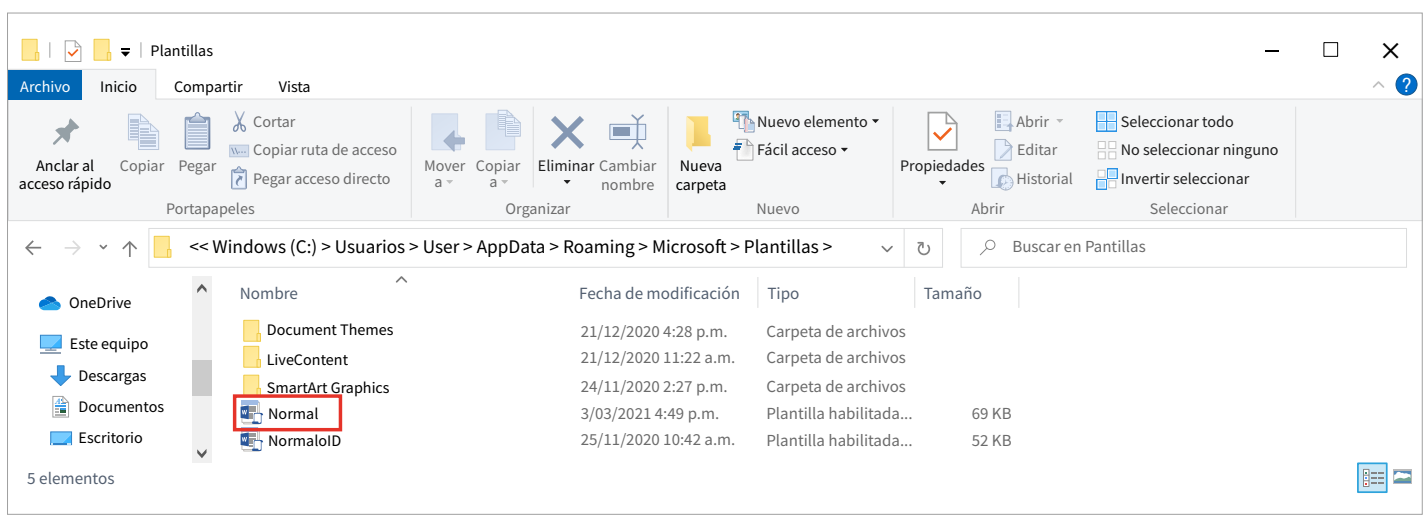

Adicionalmente, si tiene una versión de Office diferente a la de 2016, valide la versión del paquete Office que tiene, ya que para las versiones 2013 y 2019 debe copiar el archivo en la carpeta C:\Usuarios\User\AppData\Roaming\Microsoft \Templates. Esta recomendación también aplica a versiones de Word en idioma inglés.

9) Cambie los atributos del archivo Normal.dotm a Solo lectura para evitar cambios indeseados en el futuro. En el explorador de archivos seleccione el archivo Normal.dotm y, con el clic derecho del ratón, cambie el atributo a Solo lectura. 


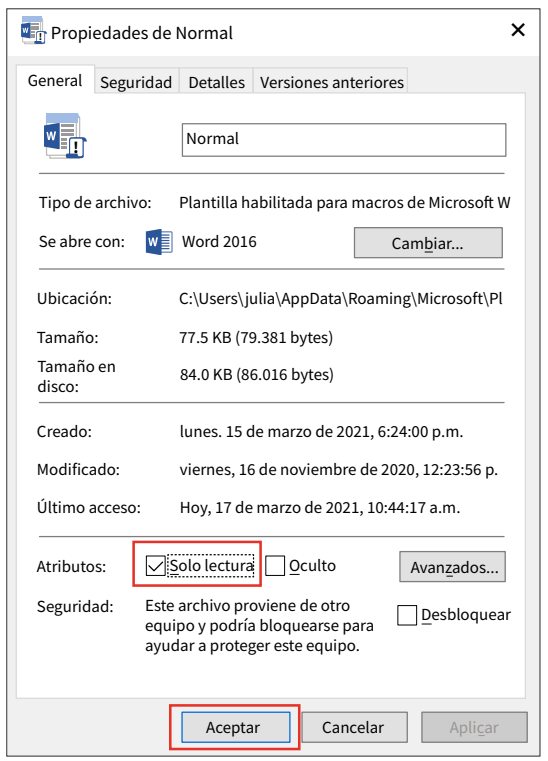

10) Vaya nuevamente al antivirus y seleccione la opción Configurar (+) en Control de scripts.

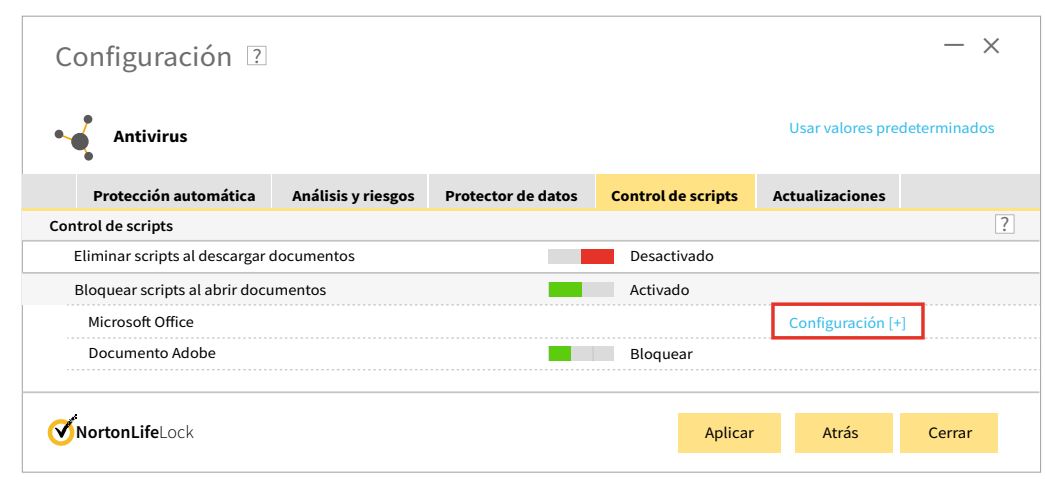

11) Seleccione, en las preferencias de Microsoft Office, el programa Microsoft Word en el que debe dejar la opción Permitir para evitar que se bloquee el script al abrir los documentos. Seleccione el botón Aceptar.

\begin{tabular}{|c|c|c|c|}
\hline \multicolumn{3}{|l|}{ Preferencias de Microsoft Office ? } & $-\times$ \\
\hline \multicolumn{4}{|c|}{ Seleccione su preferencia para bloquear scripts al abrir documentos en programas de Microsoft Office. } \\
\hline Programa & & Acción & \\
\hline Microsoft Word & & Permitir & 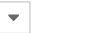 \\
\hline Microsoft Excel & & Bloquear & $\cdot$ \\
\hline Microsoft PowerPoint & & Bloquear & - \\
\hline$\underline{\text { Usar valores predeterminados }}$ & Aceptar & Cancelar & Aplicar \\
\hline
\end{tabular}

12) Abra nuevamente su programa Microsoft Word y asegúrese de que, en la opción Archivo/Opciones/Centro de confianza/Configuración del Centro de Confianza en Configuración de macros, esté seleccionada la opción de Habilitar todas las macros. Seleccione el botón Aceptar. 


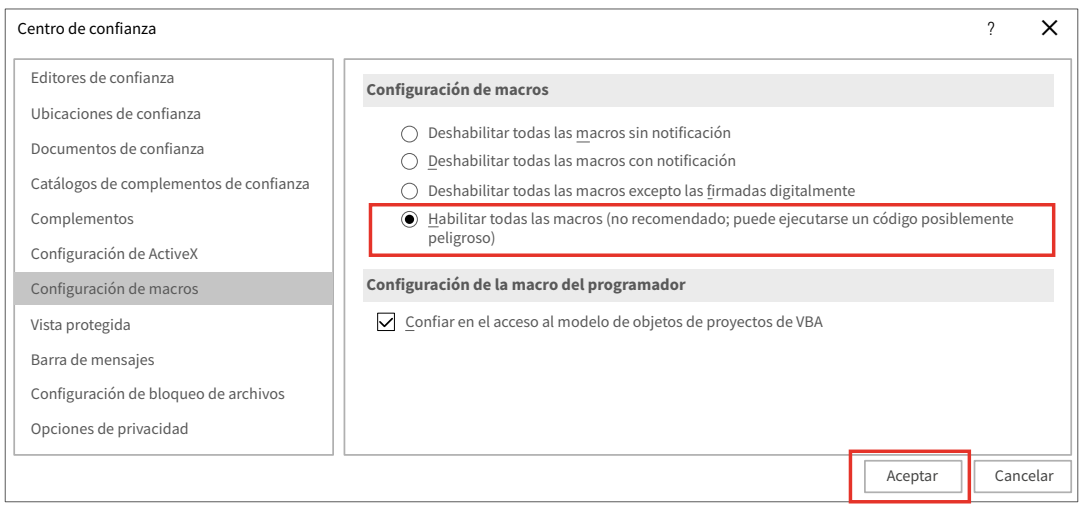

13) Cierre el programa Word y vuelva a abrirlo con un documento nuevo. La plantilla que Word empezará a usar por defecto es la que se ha referido en esta sección. Verifique que los comandos descritos en la sección 11.2. sean funcionales, en particular los que ejecutan programas como F2 (formato básico de tablas) y Ctrl + F5 (tabla de contenido).

\subsubsection{Instalación del diccionario personalizado de términos geológicos}

En el mismo archivo de la plantilla (PlantillaBase.zip) se encuentra el archivo LexicoSGC.dic que se debe extraer del archivo comprimido para que sea cargado como diccionario ortográfico personalizado en Word.

Los pasos para cargar este diccionario son los siguientes:

1) Descomprima el archivo LexicoSGC.dic del archivo PlantillaBase.zip.

2) Vaya al programa Word con el menú Archivo, en Opciones de Word en Revisión, y asegúrese de que esté desactivada la casilla Sugerir solo del diccionario principal.

3) Seleccione Diccionarios personalizados y agregue como diccionario el archivo LexicoSGC.dic.

\subsubsection{Desinstalación de la plantilla}

En el momento que no desee continuar con el uso de esta plantilla, puede simplemente borrarla o renombrarla en esta ubicación (C:\Usuarios\Usuario\AppData\Roaming\Microsoft\Plantillas). La próxima vez que entre a Word, automáticamente se restaurará la plantilla original del programa Microsoft Word, y los estilos, comandos y macros de la plantilla documental ya no estarán disponibles.

\subsection{Problemas con la plantilla y acciones para solucionarlos}

Los problemas que surjan con el uso de la plantilla están relacionados, en gran parte, con una instalación y configuración incompleta o deficiente. En la tabla 48 se indican algunos problemas frecuentes y las acciones para su solución. 
Tabla 48. Problemas, causas y soluciones para el funcionamiento de la plantilla

\begin{tabular}{|c|c|c|}
\hline Problema & Causa probable & Acción sugerida para resolverlo \\
\hline $\begin{array}{l}\text { No se puede acceder al directorio de las } \\
\text { plantillas de Word }\end{array}$ & $\begin{array}{l}\text { El usuario no tiene privilegios de } \\
\text { administrador o el directorio se encuentra } \\
\text { en un directorio escondido. }\end{array}$ & $\begin{array}{l}\text { Contacte a Mesa de Ayuda para que } \\
\text { el administrador de su equipo pueda } \\
\text { acceder a los directorios necesarios y a su } \\
\text { sistema de antivirus, y pídale que realice la } \\
\text { configuración sugerida en este manual. }\end{array}$ \\
\hline $\begin{array}{l}\text { Se instaló la plantilla, pero algunos } \\
\text { comandos no funcionan }\end{array}$ & $\begin{array}{l}\text { No se realizaron adecuadamente los } \\
\text { pasos de configuración del antivirus o } \\
\text { del programa Microsoft Word. Si no se } \\
\text { configuró el antivirus de manera adecuada } \\
\text { y en el orden mencionado, las funciones } \\
\text { de seguridad del antivirus detectaron } \\
\text { los programas dentro del archivo de } \\
\text { la plantilla, y estos fueron borrados. El } \\
\text { resultado es que ningún programa o script } \\
\text { se puede ejecutar. }\end{array}$ & $\begin{array}{l}\text { Repita el proceso completo, incluyendo la } \\
\text { descarga del archivo Plantilla.zip desde el } \\
\text { repositorio indicado. El archivo que tiene } \\
\text { en el directorio de plantillas puede no ser } \\
\text { el adecuado, por lo que es recomendable } \\
\text { que lo descargue nuevamente. } \\
\text { Tenga en cuenta que si descarga y copia el } \\
\text { archivo Normal.dotm antes de configurar } \\
\text { su antivirus, el archivo descargado no } \\
\text { será funcional. Debe hacer la descarga } \\
\text { durante la ventana de desactivación de } \\
\text { la verificación de scripts del antivirus } \\
\text { (usualmente de } 15 \text { minutos). }\end{array}$ \\
\hline $\begin{array}{l}\text { La plantilla se instaló correctamente, pero } \\
\text { algunos de los comandos que requieren } \\
\text { números como combinación de teclas no } \\
\text { funcionan }\end{array}$ & $\begin{array}{l}\text { Puede estar usando los números del } \\
\text { teclado numérico. }\end{array}$ & $\begin{array}{l}\text { Ensaye los comandos con los números del } \\
\text { teclado alfabético (debajo de las teclas de } \\
\text { funciones F1... F10, como se ve en la figura } \\
64 \text { ). }\end{array}$ \\
\hline $\begin{array}{l}\text { La plantilla se instaló correctamente, } \\
\text { pero al aplicar los comandos a un archivo } \\
\text { previamente construido, no funcionan de } \\
\text { manera apropiada o genera un mensaje } \\
\text { de error }\end{array}$ & $\begin{array}{l}\text { La plantilla no está siendo usada por su } \\
\text { procesador de palabras y aún utiliza las } \\
\text { definiciones y comandos que estaban } \\
\text { vigentes en la plantilla original con que } \\
\text { se creó el documento. Word respeta } \\
\text { las definiciones previas de documentos } \\
\text { preexistentes. }\end{array}$ & $\begin{array}{l}\text { Cree un documento en blanco en Word } \\
\text { (esto garantiza que se usará la nueva } \\
\text { plantilla) y, copie sobre este documento los } \\
\text { contenidos del documento existente al que } \\
\text { desea aplicar la nueva plantilla. No olvide } \\
\text { guardar el archivo con otro nombre. Con } \\
\text { este documento ya puede aplicar todos } \\
\text { los comandos de la plantilla sobre los } \\
\text { contenidos anteriores. }\end{array}$ \\
\hline
\end{tabular}




\section{Glosario}
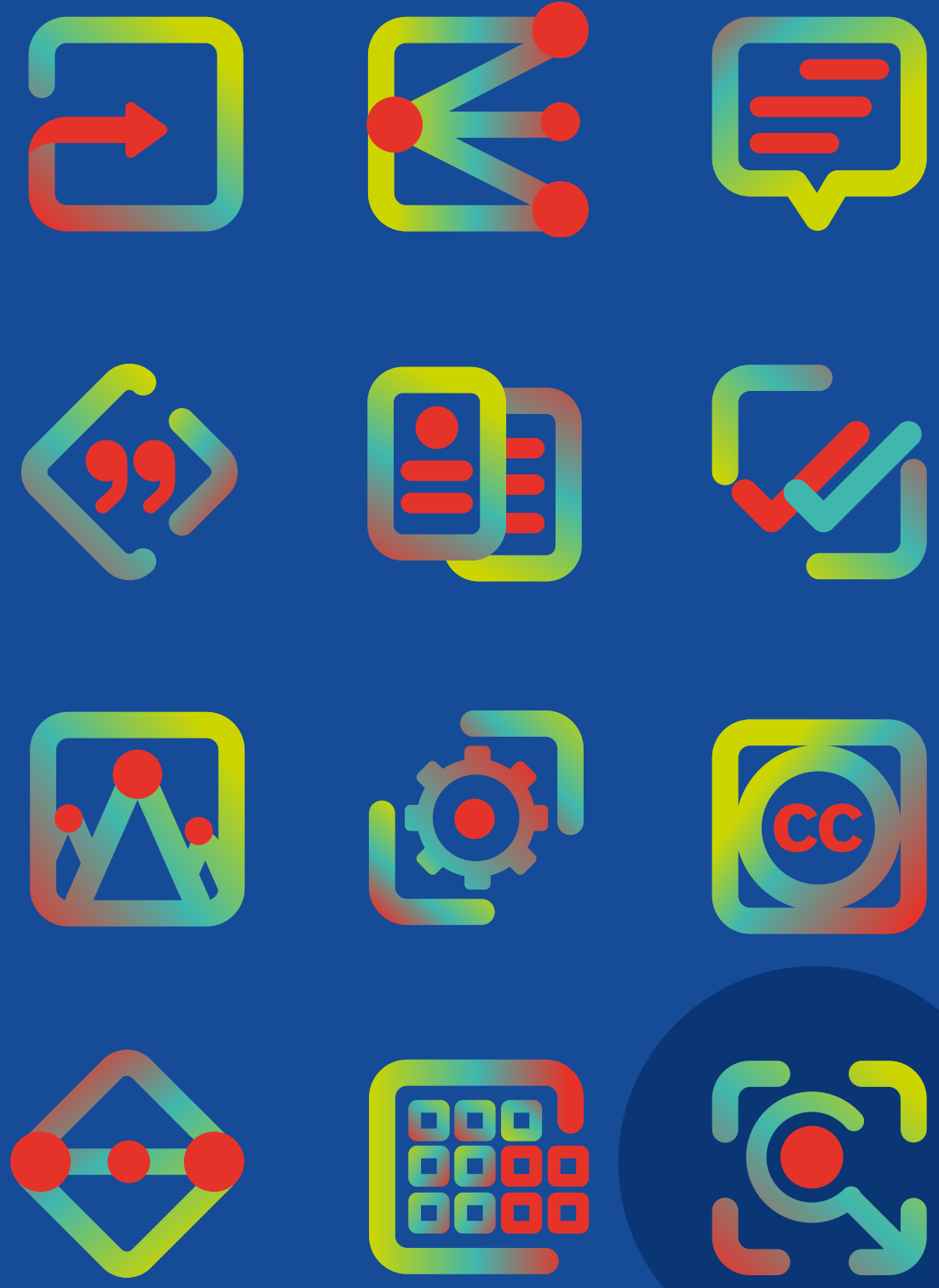


\section{A}

Acrónimo:

Sigla cuya configuración permite su pronunciación como una palabra (RAE, 2020).

Anexo:

Contenidos agregados a un trabajo que usualmente se incluyen al final del documento. Los anexos generalmente son documentos autónomos y ofrecen información adicional al documento principal.

Autor:

Persona que ha producido alguna obra científica, literaria o artística y que puede hacerse públicamente responsable de ella.

Calidad:

Conjunto de características de un producto o servicio que se relacionan con su capacidad de satisfacer necesidades establecidas o implícitas.

\section{Colofón:}

Espacio reservado para incluir información sobre la realización física del libro: impresor, taller o empresa de producción del libro (Beltrán, 2017, p. 195).

Comité Científico:

Órgano asesor permanente de una revista científica del SGC, que tiene como objetivo velar por la calidad científica de dicha revista y promover, coordinar y evaluar los artículos seleccionados para publicación (Creative Commons, s. f.).

Comité Editorial del SGC:

Comité de nivel operativo que tiene por objeto asegurar la calidad de las publicaciones técnicas y científicas institucionales, mediante una acción coordinada entre las direcciones técnicas, para el aprovechamiento de las capacidades institucionales con miras a editar y gestionar contenidos. Este comité orientará la publicación de los contenidos técnicos y científicos en el Sistema de Publicaciones institucional o en una editorial externa.

\section{Cornisa:}

Parte superior e inferior al texto principal que tiene por finalidad ubicar al lector para que pueda identificar el material sin tener que volver a la página inicial del artículo o publicación que esté leyendo. Las siguientes páginas de la publicación no llevan cornisas: tabla de contenido y páginas que las preceden, las subsecciones de una sola página, las portadillas, las páginas en planco (Beltrán, 2017, p. 91).

Creative Commons:

Organización sin fines de lucro que ayuda a superar los obstáculos legales para compartir conocimientos y creatividad, para abordar los desafíos más importantes del mundo.

\section{Dedicatoria:}

Texto en el que se da una dedicatoria del trabajo a personas o grupos de personas.

DOI:

Identificador único y permanente que por medio de metadatos proporciona información descriptiva, como autor, título y datos de publicación, entre otros, de objetos digitales y publicaciones electrónicas (revistas, artículos y otros) localizados en internet. 
Edición:.

Conjunto de una misma obra, reproducida en uno o varios tirajes. Si a la obra inicial se le introducen cambios sustanciales, se la considera una nueva edición, por lo cual debe llevar un nuevo ISBN independiente. Si no hay cambios sustanciales en el contenido, un nuevo tiraje de una publicación se denomina reimpresión.

Editor:

Persona designada por el SGC para coordinar la organización científico-administrativa, la composición y el funcionamiento del Comité Editorial y del Comité Científico de las revistas. Adicionalmente, se encarga de coordinar la gestión editorial de las publicaciones seriadas y no seriadas del SGC.

Epígrafe:

Frase o sentencia de un autor destacado que se antepone a la obra (Beltrán, 2017, p. 168).

Epílogo:

Sección escrita por los autores, el editor o el prologuista para expresar ligeros ajustes o modificaciones en el punto de vista sobre toda la obra o parte de ella, que haya surgido en el proceso de revisión y edición (Beltrán, 2017, p. 183).

Espacio duro:

Espacio del mismo tamaño que el espacio normal que no separa palabras y no es roto en una línea de texto por el procesador de palabras. (Comando: Ctrl + May + espacio).

\section{Espacio fino:}

Espacio más estrecho o más angosto que el espacio normal que no separa palabras y no es roto en una línea de texto por el procesador de palabras. (Comando en teclados completos: $A / t+08201$. Para el caso de portátiles, usar Insertar $\rightarrow$ Símbolo $\rightarrow$ Thin Space (que está en el subconjunto Puntuación general).

\section{Espacio súperfino:}

Espacio más estrecho o más angosto que el espacio fino que no separa palabras y no es roto en una línea de texto por el procesador de palabras. (Comando en teclados completos: Alt + 08202. Para el caso de portátiles usar Insertar $\rightarrow$ Símbolo $\rightarrow$ Hair Space (que está en el subconjunto Puntuación general).

Filiación institucional:

Dependencia, pertenencia o vinculación de una persona a una institución.

Hipótesis:

Propuesta teórica para explicar ciertos hechos; una explicación tentativa de una observación, fenómeno o ciencia o problema que puede probarse mediante una investigación adicional (McLelland, 2020).

Índices bibliográficos:

Bases de datos constituidas con criterios de selección de alta exigencia científica y editorial. Tienen comités que evalúan el análisis catalográfico de la publicación (comité editorial), y la calidad científica, la originalidad y la pertinencia de los documentos publicados (comité cien- 
tífico). Estos índices son construidos por asociaciones científicas, universidades, instituciones académicas, institutos especializados en el análisis de la información científica o agencias que apoyan la actividad científica.

Información geocientífica:

Toda aquella información relacionada con las ciencias de la Tierra, con las actividades de licenciamiento y control de fuentes radiactivas, con la operación del reactor nuclear o con las aplicaciones radiactivas y nucleares.

Jerarquía visual:

Principio de diseño utilizado para organizar los elementos basados en su orden de importancia. Este principio es recomendado para la creación de figuras de las publicaciones del SGC.

Libro:

Publicación impresa no periódica que consta como mínimo de 49 páginas, sin contar la cubierta, de acuerdo con el criterio de la Unesco. La palabra libro es usada por la Agencia Internacional del ISBN con el sentido de publicación.

Licencias de Creative Commons:

Proporcionan una forma simple y estandarizada de otorgar permisos legales a las obras creativas, en los límites de la ley de propiedad intelectual.

Literatura gris:

Cualquier tipo de documento que no se difunde por los canales ordinarios de publicación comercial, y que por tanto plantea problemas de acceso.

\section{Mapas:}

Representaciones abstractas de las características geográficas, físicas y químicas de una porción del territorio, desplegadas gráficamente en una superficie plana. Esta representación puede ser una superficie bidimensional, tridimensional o esférica, independientemente de su formato final o medio de divulgación.

Mendeley:

Gestor de referencias libre soportado por Elsevier que facilita la gestión de las referencias bibliográficas y el cumplimiento de los estándares de citación.

Par:

Evaluador experto en un tema específico, cuya responsabilidad es emitir un concepto sobre un artículo de revista, contenido o libro.

Plantilla:

Tipo de documento en el programa Word que genera un archivo que cumple con indicaciones de formato predefinidas y que tiene a disposición del usuario macros programadas que facilitan tareas diversas. 
Prefacio (o presentación):

Texto escrito por el autor, editor o compilador con el fin de dar una visión del libro como un todo en relación con el mundo de publicaciones y lectores de la disciplina o especialidad (Beltrán, 2017, p. 174).

Prólogo:

Texto escrito por alguien diferente a los autores con una finalidad persuasiva y crítica: invita a leer el libro y a hacer una valoración de su contenido (Beltrán, 2017, p. 175).

Publicación:

Escrito impreso o digital, como libro, revista, mapa o contenido en un sitio web, que ha sido divulgado.

\section{S Sigla:}

Abreviación gráfica formada por el conjunto de letras iniciales de una expresión compleja.

Sistema de Publicaciones del SGC:

Conjunto de políticas, principios, normas, procedimientos, recursos (humano, físico, financiero y tecnológico) y contenidos que estructuran y organizan la producción y difusión del conocimiento geocientífico, nuclear, divulgativo y administrativo del SGC.

\section{Z Zotero:}

Gestor de referencias de acceso libre que trabaja como una extensión del navegador Firefox, que facilita la gestión de las referencias bibliográficas y el cumplimiento de los estándares de citación. 
Ahmad, K. (2005, agosto). Metaphors in the languages of science. [Presentación en conferencia]. 15 $5^{\text {th }}$ European Symposium on LSP, Bérgamo, Italia. https://www.researchgate.net/publication/270448637_ Metaphors_in_the_Languages_of_Science

Almanza, M. F., Gómez, J. y Cuéllar, A. L. (2015). Manual de publicaciones del Servicio Geológico Colombiano. Bogotá: Servicio Geológico Colombiano. http://adminmiig.sgc.gov.co/Lists/RecursosSGC/ DispForm.aspx?ID=17461

Alonso, R. (2017). La metáfora del tiempo fósil. LA.TE. ANDES. http://www.lateandes.com/la-metafora-del-tiempo-fosil

Amaya L., C., Weber S., M., Ibáñez M., M., Cuadros, F. A., Restrepo A., J. J., Botelho, N. F., Maya S., M., Pérez P., O. M. y Ramírez C., C. (2021). San José de Guaviare Syenite, Colombia: Repeated Ediacaran intrusions in the northwestern Amazonian Craton. Boletín Geológico, 48(1), 49-79. https://doi. org/10.32685/0120-1425/bol.geol.48.1.2021.503

APA (American Psychological Association). (2010). Manual de publicaciones. (Miroslava Guerra Frías, trad.). 3a. ed. El Manual Moderno.

APA (American Psychological Association). (2020). Publication manual of the American Psychological Association. 7a. ed. https://doi.org/10.1037/0000165-000

Arrubla-Arango, F. y Silva-Sánchez, S. (2021). Geology of the Frontino-Morrogacho Gold Mining District and metallogeny of the El Cerro Igneous Complex. Boletín Geológico, 48(1), 7-47. https://doi. org/10.32685/0120-1425/bol.geol.48.1.2021.500

Beaugrande, R. y Dressler, U. (1997). Introducción a la lingüística del texto. Ariel.

Beltrán V., J. E. (2017). Manual de edición académica. 1a. ed. Universidad Nacional de Colombia, Universidad de los Andes.

BIPM (Bureau International des Poids et Mesures). (2019). The International System of Units (SI). 9a. ed.

Blanco, D. (2008). El "alfabeto" y la "gramática" de la geología: analogías y metáforas en la estrategia persuasiva de Lyell. Enfoques, XX(1-2), 7-31.

Bolívar, A. y Bolet, F. (2011). La introducción y la conclusión en el artículo de investigación: lectura y escritura para la investigación. Universidad Central de Venezuela.

Brewer, C. A. (2015). Designing better maps: a guide for GIS users. Esri Press.

Calsamiglia Blancafort, H. y Tusón Valls, A. (1999). Las cosas del decir: manual de análisis del discurso. Ariel.

Cargill, M. y O'Connor, P. (2009). Writing Scientific Research Articles: Strategy and Steps. 1a. ed. Blackwell Publishing.

Castro Marín, E., Rangel, M., Ocampo, E. y Medina Ávila, D. (2020). Avenida torrencial del 28 de enero de 2020 en la cuenca del río Frío del municipio de Floridablanca. Departamento de Santander. Versión año 2020. Bogotá: Servicio Geológico Colombiano.

Cerda Silva, A. y Lara Gálvez, C. (2011). Guía legal para editores. ONG Derechos Digitales. https://www. derechosdigitales.org/wp-content/uploads/guias_legales_editores.pdf

Cohen, K. M., Finney, S. C., Gibbard, P. L. y Fan, J. X. (2013, actualizada). The ICS International Chronostratigraphic Chart. Episodes 36, 199-204. https://stratigraphy.org/ICSchart/ChronostratChart2021-05Spanish.pdf 
Comisión Norteamericana de Nomenclatura Estratigráfica. (2010). Código estratigráfico norteamericano. R. Barragán, E. Campos Madrigal, I. Ferrusquía Villafranca, I. López Palomino y G. Tolson (trads.). Boletín 117. Instituto de Geología de la Universidad Nacional Autónoma de México.

Correa, T., Zapata, J. P., Obando, M., Rincón, A., Cetina, L. y Ortiz, F. (2015). Mapa geológico de la plancha 130III Escala 1:50 000. Bogotá: Servicio Geológico Colombiano.

Creative Commons. (s. f.). Sobre las licencias. Recuperado 20/09/2020 de https://creativecommons.org/ licenses/?lang=es

Criales, D. (2019). Cartilla de redacción y ortografía. https://dianacriales.com/

Davis, G. H. y Fischer, D. (2016). Visual metaphors in structural geology: A means for enhancing 3-D visualization. En B. Krantz, C. Ormand y B. Freeman (eds.), 3-D structural interpretation: Earth, mind, and machine: AAPG. Memoir 111, pp. 25-51 AAPG.

Dionicio, V., Mercado, O. y Lizarazo, M. (2020). Semáforo para el monitoreo sísmico durante el desarrollo de los proyectos piloto de investigación integral en yacimientos no convencionales de hidrocarburos en Colombia. Bogotá: Servicio Geológico Colombiano.

Fettes, D. y Desmons, J. (Eds). (2011). Metamorphic Rocks: A Classification and Glossary of Terms: Recommendations of the International Union of Geological Sciences Subcommission on the Systematics of Metamorphic Rocks. Cambridge University Press.

Frías Navarro, D. (2020). Herramientas para la redacción del informe de investigación. 7ạ edición del Manual de Publicación APA (American Psychological Association). https://www.uv.es/friasnav/EscribirnumerosFormatoAPA.pdf

Fundéu BBVA. (2016). Novedades de la ortografía de la lengua española (2010). Versión 1.7. 8 de febrero de 2016. https://www.fundeu.es/wp-content/uploads/2013/01/FundeuNovedadesOrtografia.pdf

Fundéu BBVA. (2017). Cursiva y redonda. Guía de estilo versión 1.3. 22-3-2017. http://www.fundeu.es/ wp-content/uploads/2013/05/CursivasGuiaFundeu.pdf

Fundéu RAE. (2020). Buscador urgente de dudas. https://www.fundeu.es/

Gómez, J., Mateus-Zabala, D., Pinilla-Pachón, A. O., Núñez-Tello, A., Lasso-Muñoz, R. M., Alcárcel-Gutiérrez, F. A., Marín-Rincón, E., Marroquín-Gómez, M. P., Fog-Corradine, L., Cardona, A. y Ramírez, M. G. (2020). Presentation of The Geology of Colombia. En J. Gómez y D. Mateus-Zabala (eds.), The Geology of Colombia, Volume 1 Proterozoic - Paleozoic (pp. xxix-xxii). Publicaciones Geológicas Especiales 35. Servicio Geológico Colombiano. https://doi.org/10.32685/pub.esp.35.2019.Presentation

Gómez, J., Núñez-Tello, A., Mateus-Zabala, D., Alcárcel-Gutiérrez, F. A., Lasso-Muñoz, R. M., Marín-Rincón, E. y Marroquín-Gómez, M. P. (2020). Physiographic and geological setting of the Colombian territory. En Gómez, J, Gómez y D. Mateus-Zabala (eds), The Geology of Colombia, Volume 1 Proterozoic - Paleozoic (pp. 1-16). Publicaciones Geológicas Especiales 35. Servicio Geológico Colombiano. https://doi.org/10.32685/pub.esp.35.2019.01

González Oviedo, L. (2019). Geología, ciencia y cultura. Servicio Geológico Colombiano. https://doi. org/10.32685/9789585978263

Guerrero Salazar, S. (2000). Las redundancias en español: un medio para pulir la lengua en los niveles de perfeccionamiento. Centro Virtual Cervantes. Recuperado 8/10/2020, a partir de https://cvc. cervantes.es/ensenanza/biblioteca_ele/asele/pdf/11/11_0423.pdf 
Hoffmann, A. (2021). Microstructural analyses of deformation phases in faulted, competent limestone alternating with thin marl layers (tesis de maestría). RWTH Aachen University, Aachen, Alemania.

Kleinert, S. y Wager, E. (2011, julio 22-24).) Responsible research publication: international standards for editors. [Posición del evento]. 2nd World Conference on Research Integrity, Singapore. https:// publicationethics.org/files/International\%20standard_editors_for\%20website_11_Nov_2011\%20 \%281\%29.pdf

Laiton C., A. (2021). Guía para uso de Mendeley. Servicio Geológico Colombiano.

Mari Mut, J. A. (2013). Manual de redacción científica. Ediciones Digitales. http://edicionesdigitales.info/

Marinkovich, J. y Benítez, R. (2000). Aproximaciones al análisis intertextual del discurso científico. Revista Signos, 33(48), 117-128.

Maya, M., Gómez, J. P., Rueda, J., Grimaldo, J., Cifuentes, P. y Barajas, A. (2018). Memoria explicativa de la Plancha 329 - Caño Ovejas. Bogotá: Servicio Geológico Colombiano.

McGuire, S. (2020, julio 29). Línea de tiempo: +40 ejemplos y consejos de diseño (venngage.com). https://es.venngage.com/blog/linea-de-tiempo-diseno-ejemplos/

Microsoft. (2021). Métodos abreviados de teclado de Word para Microsoft 365. Consultado el 2/10/2021. https://support.microsoft.com/es-es/topic/m\%C3\%A9todos-abreviados-de-teclado-de-word-95ef89dd-7142-4b50-afb2-f762f663ceb2?wt.mc_id=otc_word\#

Mills, I. M. y Metanomski, W. V. (1999). On the use of italic and roman fonts for symbols in scientific text. Interdivisional Committee on Nomenclature and Symbols, IUPAC.

NACSN (North American Commission on Stratigraphic Nomenclature). (2005). North American Stratigraphic Code. AAPG Bulletin, 89(11), 1547-1591. https://doi.org/10.1306/07050504129

Narváez M., L., Torres C., R., Gómez M., D., Cortés J., G., Cepeda V., H. y Stix, J. (1997). 'Tornillo'-type seismic signals at Galeras volcano, Colombia, 1992-1993. Journal of Volcanology and Geothermal Research, 77(1-4), 159-171. https://doi.org/10.1016/S0377-0273(96)00092-3

National Institute of Standards and Technology (NIST). (2019). The International System of Units (SI). NIST Special Publication 330. D. B. Newell y E. Tiesinga (eds.). https://doi.org/10.6028/NIST.SP.330-2019

Nediger, M. (2020, julio 21). ¿Qué es una infografía? 20 Ejemplos, plantillas y consejos para diseñar infografías. https://es.venngage.com/blog/que-es-una-infografia/

RAE (Real Academia Española) y Asociación de Academias de la Lengua Española. (2009). Nueva gramática de la lengua española. Edición en línea. Consultado el 10/03/2021 de https://www.rae.es

RAE (Real Academia Española). (2010). Ortografía de la lengua española. Espasa Calpe.

RAE (Real Academia Española). (2020a). Diccionario de la lengua española. https://dle.rae.es/

RAE (Real Academia Española). (2020b). Abreviaturas y signos empleados. https://dle.rae.es/contenido/ abreviaturas-y-signos-empleados

RAE (Real Academia Española). (2020c). Diccionario panhispánico de dudas. https://www.rae.es/dpd/

Reina, C. R., Ramírez, C. S., Parra, L. J., Camargo, D., Hernández, J. N., Quiñónez, L., Orjuela, A. M. y Espinel, O. F. (2018). Caracterización física de las muestras extraídas mediante exploración ejecutada en el subsuelo de la estación sismológica "BOG". Servicio Geológico Colombiano - Universidad Nacional de Colombia. https://doi.org/10.32685/4.3.2018.939

Rodríguez, G., Correa Martínez, A. M., Arango, M. I., Zapata, G. y Bermúdez, J. G. (2020). Catálogos de las unidades litoestratigráficas de Colombia: Macizo de Santander. Vol. 1. Servicio Geológico Colombiano. https://doi.org/10.32685/9789585279445 
Rodríguez-García, G., Correa-Martínez, A. M., Zapata-García, G., Arango-Mejía, M. I., Obando-Erazo, G., Zapata-Villada, J. P. y Bermúdez, J. G. (2020). Diverse Jurassic magmatic arcs of the Colombian Andes: Constraints from petrography, geochronology, and geochemistry. En J. Gómez y A. O. PiniIla-Pachón (eds.), The Geology of Colombia, Volume 2 Mesozoic (pp. 117-170). Publicaciones Geológicas Especiales 36. Servicio Geológico Colombiano. https://doi.org/10.32685/pub.esp.36.2019.04

Ruíz, G. L., Reyes, A. A., García, J. R., Murcia, C. A., Castro, J. A., Castro, E., Gamboa, C. A., Pérez, M. A., Méndez, L., Albadán. C. P., Cely, L. C. y Avellaneda, G. (2019). Zonificación de amenaza, vulnerabilidad y riesgo físico por movimientos en masa en 17 zonas del municipio de Popayán escala 1:2000. Bogotá: Servicio Geológico Colombiano.

Sánchez, A. A. (2011). Manual de redacción académica e investigativa: cómo escribir, evaluar y publicar artículos. Católica del Norte Fundación Universitaria.

Sánchez, A. A. (2016). El género artículo científico: escritura y análisis desde la alfabetización académica y la retórica funcional. Católica del Norte Fundación Universitaria.

Sánchez, C. (2019). Cursiva. Normas APA (7. a ed.). https://normas-apa.org/estilo/cursiva/

SGC (Servicio Geológico Colombiano). (1999). Mapa de grandes sismos de Colombia 1566 - 1999. Escala 1:2 000 000. Bogotá: Servicio Geológico Colombiano.

SGC (Servicio Geológico Colombiano). (2017). En Amenaza por movimientos en masa tipo flujo de las cuencas de las quebradas Taruca, Taruquita, San Antonio y El Carmen y los ríos Mulato y Sangoyaco, municipio de Mocoa. Escala 1:10 000. Bogotá: Servicio Geológico.

SGC (Servicio Geológico Colombiano). (2020). Simposio The Geology of Colombia: La historia geológica del territorio colombiano. 24 al 27 de noviembre de 2020.

Solorio, W. (2013). Conoce los conectores lingüísticos y sus funciones. Universidad UTEL. https://www. utel.edu. $\mathrm{mx} / \mathrm{blog} / 10$-consejos-para/conoce-los-conectores-linguisticos-y-sus-funciones

Tait, A. (2018). Visual Hierarchy and Layout. En The Geographic Information Science \& Technology Body of Knowledge (ed.). University Consortium for Geographic Information Science https://doi. org/10.22224/gistbok/2018.2.4

Teberosky, A. (2007). El texto académico. En M. Castelló (coord.), Escribir y comunicarse en contextos científicos y académicos (pp. 17-45). Graó.

University of Chicago. (2010). The Chicago Manual of Style 16 $\underline{a}$ ed. The University of Chicago Press.

Valderrama, J. O. (2005). Principales aspectos sobre la preparación de un artículo para ser publicado en una revista internacional de corriente principal. Información Tecnológica, 16(2), 3-14. http://dx.doi. org/10.4067/S0718-07642005000200002

Whitney, D. L. y Evans, B. W. (2010). Abbreviations for names of rock-forming minerals. American Mineralogist, 95(1), 185-187. https://doi.org/10.2138/am.2010.3371 


\section{Îndice de figuras}

Figura 1 Identificación de los ejemplos del manual 16

Figura 2. Elementos fundamentales de la sección Título 22

Figura 3. Elementos fundamentales de la sección Resumen 23

Figura 4. Elementos fundamentales de la sección Palabras clave 24

Figura 5. Elementos fundamentales de la sección Introducción 25

Figura 6. Elementos fundamentales de la sección Método/metodología 26

Figura 7. Elementos fundamentales de la sección Especificaciones de los datos 27

Figura 8. Elementos fundamentales de la sección Resultados 28

Figura 9. Elementos fundamentales de la sección Discusión 29

Figura 10. Elementos fundamentales de la sección Conclusiones 30

Figura 11. Elementos fundamentales de la sección Referencias 31

Figura 12. Disposición de la estructura de títulos y textos para las publicaciones 53

Figura 13. Disposición de la estructura de títulos y textos en los informes del SGC 55

Figura 14. Ejemplo de cubierta de libro del SGC 69

Figura 15. Ejemplo de una portadilla de un libro del SGC 70

Figura 16. Esquema de organización de portada de informes del SGC (sin convenio o contrato externo)

Figura 17. Esquema de organización de portada de informes del SGC, elaborados en la modalidad de convenio $\quad 72$

Figura 18. Esquema de organización de portadas de visitas de emergencia $\quad 73$

Figura 19. Esquema de organización de portada de memorias de planchas geológicas 74

Figura 20. Esquema de presentación de la primera página de un artículo para el Boletín Geológico

Figura 21. Esquema de presentación de la primera página de un artículo para la Revista Investigaciones y Aplicaciones Nucleares 78

Figura 22. Esquema de organización de página legal para libros 79

Figura 23. Esquema de página legal de informe técnico del SGC e información de autores 80

Figura 24. Esquema de presentación de página legal para informes de trabajos en convenio 81

Figura 25. Esquema de presentación de página legal para informes de trabajos por contrato 82

Figura 26. Esquema de organización de las tablas $\quad 91$

Figura 27. Esquema de organización de las figuras 96

Figura 28. Configuración de formatos de número en Excel 113

Figura 29. Diagrama para la aplicación de las formas de escribir prefijos 115

Figura 30. Esquema para citar libros $\quad 120$

Figura 31. Esquema para citar capítulos de libros $\quad 122$

Figura 32. Esquema para citar reseñas de libros 124

Figura 33. Esquema para citar artículos de revista 126

Figura 34. Esquema para citar informes y literatura gris 128 
Figura 35. Esquema para citar congresos, seminarios y otros 130

Figura 36. Esquema para citar documentos de páginas web 132

Figura 37. Ubicación de textos en elementos lineales 144

Figura 38. Esquema de un mapa en una disposición compartimentalizada: cartografía digital para planchas a escala 1:100 000

Figura 39. Mapa fluido: Geologic Map of the Monte Blanco Borate Deposits, Furnace Creek Wash, Death Valley, California

Figura 40. Imagen de relieve de la esquina noroccidental de Suramérica construida con las recomendaciones

Figura 41. Esquema de un perfil de un mapa geológico

Figura 42. Nomenclatura de las partes de una figura con una sola fila

Figura 43. Nomenclatura de las partes de una figura con más de una fila

Figura 44. Nomenclatura de las partes de una figura que cuenta con poco espacio para las letras de identificación

159

Figura 45. Títulos e información de una figura que ocupa una página completa 160 $\begin{array}{ll}\text { distinta a la figura principal } & 161\end{array}$

Figura 47. Prioridad en la ubicación de los textos descriptivos en un mapa 162

Figura 48. Esquema de mapas que presenta varios temas relacionados $\quad 171$

Figura 49. Esquema de encabezado y pie de página para informes 175

Figura 50. Configuración de los espacios en párrafos en Word 176

Figura 51. Configuración de alineación y sangrías en Word 176

Figura 52. Configuración de los márgenes en Word 177

Figura 53. Administración de los estilos en Word 177

Figura 54. Opción de abrir Mendeley 182

Figura 55. Configuración de estilos de citación 183

Figura 56. Selección de estilo de citación en Mendeley 183

Figura 57. Actualización de la plantilla de citación en Mendeley 183

Figura 58. Instalación de la plantilla de citación en Mendeley 184

Figura 59. Verificación de instalación de plantilla de citación en Mendeley 184

Figura 60. Edición de las preferencias de Zotero 186

Figura 61. Selección de estilos adicionales en Zotero 186

Figura 62. Selección de plantilla APA en Zotero 187

Figura 63. Verificación de plantilla en Zotero 187

Figura 64. Ubicación de las teclas usadas para los comandos de la plantilla 200

Figura 65. Panel de navegación con visualización de la estructura del documento 202 


\section{Índice de tablas}

Tabla 1. Características de los tipos de contenidos del Sistema de Publicaciones del SGC 18

Tabla 2. Elementos utilizados en los tipos de contenido del SGC 20

Tabla 3. Elementos de las publicaciones y su uso, según el tipo de documento 21

Tabla 4. Escogencia de la opción de tablas o figuras para mostrar datos 34

Tabla 5. Expresiones con verbosidad excesiva y sus equivalentes en versión simplificada 34

Tabla 6. Cacofonías comunes y ejemplos de alternativas 35

Tabla 7. Casos de aplicación de uso de los gerundios 36

Tabla 8. Forma de saber si el gerundio se está usando de manera apropiada 37

Tabla 9. Ejemplos en voz pasiva que se expresan mejor en voz activa 40

Tabla 10. Recomendaciones de uso de algunas expresiones comunes 42

Tabla 11. Uso de verbos en forma impersonal 43

Tabla 12. Conectores recomendados para darle cohesión a los textos 46

Tabla 13. Resumen de las normas de presentación de textos 50

Tabla 14. Descripción de los niveles de título para las publicaciones y ejemplo de aplicación 52

Tabla 15. Descripción de los niveles de títulos en informes preparados en el SGC 54

Tabla 16. Uso de mayúsculas y minúsculas

Tabla 17. Consideraciones temáticas para el uso de mayúsculas y minúsculas 60

Tabla 18. Otros casos de uso de mayúsculas y minúsculas 61

Tabla 19. Resumen sobre la forma de escribir y la función de tres tipos de guiones 63

Tabla 20. Información que debe entregarse en los artículos 75

Tabla 21. Abreviaturas más utilizadas en textos 88

Tabla 22. Abreviaturas de las revistas del Servicio Geológico Colombiano (radicadas en el respectivo registro ISSN) 89

Tabla 23. Unidades básicas del Sistema Internacional 107

Tabla 24. Unidades derivadas con los nombres en el Sistema Internacional 107

Tabla 25. Reglas para la escritura de números 108

Tabla 26. Uso de los decimales en los números generados mediante paquetes estadísticos $\quad 109$

Tabla 27. Ejemplo de uso de los decimales para números generados por paquetes estadísticos $\quad 110$

Tabla 28. Ejemplo de aplicación de formatos de números para cantidades 111

Tabla 29. Ejemplos de escritura de números 112

Tabla 30. Ejemplo de aplicación de formato de número en el caso de tener varias cifras 112

Tabla 31. Significado de números con nombres iguales en español y en inglés 114

Tabla 32. Prefijos de las unidades del SI 114

Tabla 33. Criterios básicos de la jerarquía visual $\quad 135$

Tabla 34. Características de los tamaños de figuras para artículos y libros e informes $\quad 145$

Tabla 35. Comparación de las fuentes recomendadas en diferentes tamaños para las figuras 146

Tabla 36. Niveles de elementos de un mapa 151

Tabla 37. Requisitos mínimos de presentación para fotografías de campo (afloramientos o panorámicas) 
Tabla 38. Requisitos mínimos para fotografías macroscópicas de petrografía

Tabla 39. Requisitos mínimos para fotografías microscópicas de petrografía

Tabla 40. Detalles de la licencia de Creative Commons utilizada en el SGC para sus publicaciones e informes

Tabla 41. Comandos de estilos de títulos

Tabla 42. Comandos para el texto normal y estilos de viñetas para listas

Tabla 43. Comandos para obtener algunos signos matemáticos utilizados en documentos del SGC

Tabla 44. Comandos para obtener las letras griegas más usadas en ciencias 204

Tabla 45. Comandos para obtener distintos tipos de espacios 204

Tabla 46. Comandos de formato y diversas acciones en macros 205

Tabla 47. Otros comandos y acciones útiles de la plantilla por defecto de Word 207

Tabla 48. Problemas, causas y soluciones para el funcionamiento de la plantilla 217 


\section{Îndice de ejemplos}

Ejemplo 1. Uso de corchetes aclarando una cita 57

Ejemplo 2. Uso de paréntesis en una aclaración

Ejemplo 3. Uso de cursiva en los textos 58

Ejemplo 4. Tabla sencilla con encabezados en cada columna 93

Ejemplo 5. Tabla con encabezados de diferentes niveles 94

Ejemplo 6. Tabla con información voluminosa entre filas que se separa usando líneas horizontales $\quad 94$

Ejemplo 7. Tabla con divisiones entre grupos de datos y totales parciales 95

Ejemplo 8. Figura de diagrama de barras comparativo con medidas $\begin{array}{ll}\text { de dispersión de mediciones } & 98\end{array}$

Ejemplo 9. Diagrama de puntos para comparar diferentes tendencias 99

Ejemplo 10. Mapa geológico 99

Ejemplo 11. Mapa de accesos a una región $\quad 100$

Ejemplo 12. Mapa temático con leyenda en colores 100

Ejemplo 13. Diagramas, infografías y dibujos 101

Ejemplo 14. Diagrama de concordia e histograma de edades 101

Ejemplo 15. Fotografía de sección delgada 102

Ejemplo 16. Fotografías de campo 102

Ejemplo 17. Fotografía de equipos o montajes para ensayos 103

Ejemplo 18. Presentación consolidada en una sola figura de varios resultados 104

Ejemplo 19. Presentación de figuras con varios componentes 104

Ejemplo 20. Ecuaciones en la misma línea del texto 106

Ejemplo 21. Ecuaciones desplegadas del texto y su referencia 106

Ejemplo 22. Citando varias obras del mismo autor $\quad 116$

Ejemplo 23. Citando un trabajo de dos autores $\quad 117$

Ejemplo 24. Citando un trabajo de tres autores o más $\begin{array}{ll}\text { (para todas las veces que se cite, incluyendo la primera) } & 117\end{array}$

Ejemplo 25. Citando un autor corporativo la primera vez 117

Ejemplo 26. Citando un autor corporativo después de la primera vez 117

Ejemplo 27. Citando varios autores que se ordenan cronológicamente 117

Ejemplo 28. Citando una referencia con página específica o rango de página 117

Ejemplo 29. Citando unas referencias que tengan una forma resumida igual $\begin{array}{ll}\text { (desambiguadas citando más apellidos de autores) } & 117\end{array}$

Ejemplo 30: Citando un párrafo de menos de cuarenta palabras

(en la citación, después del paréntesis debe ir un punto, coma o punto y coma) 118

Ejemplo 31. Citando un párrafo de más de cuarenta palabras

$\begin{array}{ll}\text { (en la citación, después del paréntesis no debe ir punto) } & 118\end{array}$

Ejemplo 32. Referencia de un libro en idioma inglés con DOI 121

Ejemplo 33. Referencia de un libro en español sin DOI 121 
Ejemplo 34. Referencia de un libro con autor corporativo y sigla 121

Ejemplo 35. Referencia a capítulos de libros 123

Ejemplo 36. Referencia a reseñas de libro 125

Ejemplo 37. Referencia a artículos de revista $\quad 127$

Ejemplo 38. Referencia con más de veinte autores 127

Ejemplo 39. Referencia a informes y literatura gris 129

Ejemplo 40. Referencia a tesis 129

Ejemplo 41. Referencia a congresos, seminarios y otros 131

Ejemplo 42. Referencia a contenido de un solo autor en la web 133

Ejemplo 43. Referencia a contenido de autores múltiples en la web 133

Ejemplo 44. Referencia a contenido en la web cuando el autor de la página web y el editor del sitio web son los mismos 133

Ejemplo 45. Referencia a contenido en la web cuando no se puede determinar la fecha 133

Ejemplo 46. Referencia a contenido en la web en que no se requiere la fecha exacta de lectura $\quad 134$

Ejemplo 47. Referencia a contenido en la web en que sí se requiere la fecha exacta de lectura 134

Ejemplo 48. Referencias de mapas 134

Ejemplo 49. Rreferencias de varios mapas de Google Maps 134

Ejemplo 50. Mapa geológico observando las recomendaciones de diseño 163

Ejemplo 51. fotografía panorámica 165

Ejemplo 52. Fotografía de campo de un afloramiento 166

Ejemplo 53. Fotografía de campo de un saprolito con zoom en la imagen 166

Ejemplo 54. Fotografías con descripción macroscópica para petrografía 168

Ejemplo 55. Fotografías con descripción microscópica para petrografía 169

Ejemplo 56. Composición de microfotografías de distintas escalas para mostrar $\begin{array}{ll}\text { detalles de una misma muestra } & 170\end{array}$

Ejemplo 57. infografías en geociencias 172

Ejemplo 58. Ubicación de la información de la licencia de una publicación especial 191

Ejemplo 59. Ubicación de la información de la licencia en un informe 191

Ejemplo 60. Ubicación de la información de la licencia en un artículo de revista en inglés 192 
